Illinois State University

ISU ReD: Research and eData

Theses and Dissertations

9-15-2017

\title{
Measuring The Longitudinal Communication Growth Of Learners Who Are Deafblind
}

Kristi M. Probst

Illinois State University, jandkprobst@gmail.com

Follow this and additional works at: https://ir.library.illinoisstate.edu/etd

Part of the Special Education Administration Commons, and the Special Education and Teaching Commons

\section{Recommended Citation}

Probst, Kristi M., "Measuring The Longitudinal Communication Growth Of Learners Who Are Deafblind" (2017). Theses and Dissertations. 793.

https://ir.library.illinoisstate.edu/etd/793

This Dissertation is brought to you for free and open access by ISU ReD: Research and eData. It has been accepted for inclusion in Theses and Dissertations by an authorized administrator of ISU ReD: Research and eData. For more information, please contact ISUReD@ilstu.edu. 


\title{
MEASURING THE LONGITUDINAL COMMUNICATION GROWTH OF LEARNERS \\ WHO ARE DEAFBLIND
}

\author{
Kristi M. Probst
}

\section{Pages}

The primary concern when planning educational programming for individuals who are deafblind (DB) is their unique communication needs. Additionally, the ability to adequately track student growth is key when education teams are making program and service provision decisions. Therefore, it is important to investigate the longitudinal growth of learners who are DB and the possible effects of service provision (number, type, and intensity) on communication growth. The purpose of this study was to explore the differences in the number, type, and intensity of educational service provision and to track the longitudinal communication growth of students who are DB using the Communication Matrix (CM).

Using the data provided by the $C M$ in addition to other variables obtained from a child's IEP (i.e., educational services received), Growth Curve Modeling (GCM) seemed to be a sensible choice of methodology for this study. However, the limited number of participants and longitudinal data collected prevented the use of GCM. Instead, descriptive statistics were employed to illustrate the communication growth of two participants, examine two groups of learners (6-year-olds and 15-to-18-year-olds), and investigate the number, type, and intensity of the services received. Great variability of service provision was observed in all areas investigated both inter- and intra-individually. Furthermore, though not a research goal, the issue 
of primary and secondary disability labels for education emerged and is discussed in the findings.

KEYWORDS: Deafblind, Education, Service provision, Communication, Growth 


\title{
MEASURING THE LONGITUDINAL COMMUNICATION GROWTH OF LEARNERS \\ WHO ARE DEAFBLIND
}

\author{
KRISTI M. PROBST
}

A Dissertation Submitted in Partial

Fulfillment of the Requirements

for the Degree of

\section{DOCTOR OF EDUCATION}

Department of Special Education

\section{ILLINOIS STATE UNIVERSITY}


(C) 2017 Kristi M. Probst 


\title{
MEASURING THE LONGITUDINAL COMMUNICATION GROWTH OF LEARNERS \\ WHO ARE DEAFBLIND
}

\author{
KRISTI M. PROBST
}

\section{COMMITTEE MEMBERS:}

Christina M. Borders, Chair

Stacey Jones Bock

Olaya Landa-Vialard

Mark Zablocki 


\section{ACKNOWLEDGMENTS}

"Walking with a friend alone in the dark is better than walking alone in the light."

---Helen Keller

It seems surreal that the day I have been working toward for so long is here. Every step of the way, the mountaintops, valleys, days of light as well as those filled with darkness have stretched me, molded me, and pushed me beyond what I thought was possible. Yet, through it all, I had the strength, encouragement, and love of those closest to me. This journey has been one that I have truly enjoyed and I could never have walked through it without my Lord, family, friends, and faculty and staff at Illinois State University by my side. As I have walked this journey, I have found great strength from God. I have clung to so many passages from my Bible, but the one that has sustained me has been Joshua 1:9 "Have I not commanded you? Be strong and courageous. Do not be afraid; do not be discouraged, for the LORD your God will be with you wherever you go.”

After years of encouragement from some people who would become my biggest cheerleaders, mentors, and friends, I embarked upon my doctoral journey with much trepidation. I did not have long to wallow in my fears for my family and friends came alongside me, providing encouragement and support, making me feel invincible and preparing me for the long journey. My husband, Jason, has been my biggest cheerleader, strongest ally, and has filled in the spaces that I had to leave empty for this season of our lives. I have him to thank for the constant words of encouragement, often reminding me that I am "incredible, so smart, and pretty!” You make me a better person, Jason. Thank you. My three children (aka, the Creepies!), Simeon, Elias, and Isaiah, have also provided unparalleled support. This past year alone, they had to learn a new place, attend a new school, and make new friends all while their mom was gone for half the year. Boys, your sacrifices, strength of character, and encouragement 
have taught me and sustained me. My parents, Dick and Toni Helton, taught me the importance of staying true to oneself, honesty, standing up for what you believe in even when it is not easy or popular, and the value of hard work. They taught me to run toward new experiences with fervor, basking in the joy that comes through fearlessness. I would not be the woman I am today without your example, love, and reassurance. Jim, Julie, Kaylee, Kyler, and Kenna Probst, your hospitality, willingness to listen to my doctoral work and missing home woes, and friendship has meant so much, especially over this past year.

I would also like to extend a very heartfelt thank you to my dissertation members, Dr. Christy Borders, Dr. Stacey Jones Bock, Dr. Olaya Landa-Vialard, and Dr. Mark Zablocki for continually providing me with opportunities, encouragement, wisdom, and guidance. Your mentorship and outstanding examples have positively impacted me and provided real life illustrations of the type of professional I yearn to be. Olaya, if not for your urging me to apply to be an NLCSD scholar, serve in AER, or your nominations for a variety of honors, I would not have had such a rich experience over these past few years. I also could not have achieved much of what I have without the friendship and love of my sister-friends, Christy and Stacey. The many hours spent writing in backyards, laughing (and crying) over refreshments, presenting, and talking through a variety of subjects has truly been a pleasure. I count myself blessed to be one of the composite "Khristy Bock" threesome. Finally, to you, Christy, you have been so much more than a faculty member and dissertation chair to me. You walked me through the dark times, leading me gently (and sometimes pushing me!), wiping my tears when they flowed like a waterfall, and also celebrated my accomplishments, growth, and steps along the way. I am so grateful that the Lord placed you in my life and that you followed his lead when you started "bugging me" to begin this doctoral journey. 
These acknowledgements would not be complete without thanking my friends both within and outside of the ISU community. To my ISU cohort, thank you for your enthusiasm, help, feedback that aided in my growth as a researcher and scholar, and for always supporting me. I could never forget my "Westies," the men and women from Normal West High School who encouraged me as I began this journey and was still teaching. Your support has been overwhelming! From coffee dates to lunches, guest speaking to coming to watch me compete in the 3-Minute Thesis competition, you have been there through it all. You are all amazing at what you do every day and I can never tell you how much I appreciate you! To my friends at Eastview Christian Church, I thank you for your prayers, love, and continued support. As I continue to walk along this journey of life, I take all of you with me and treasure you. To my NLCSD friends, you are my people! Thank you to those of you who have become like family for never letting me entertain my self-doubt and for sharing so many laughs and fun times with me in our NLCSD endeavors. Finally, I thank the NLCSD community at large, especially my mentor, Julie Durando and good friend, Kathryn Botsford. Through my participation in NLCSD, I have met and had the opportunity to learn from so many individuals from the field of sensory impairments. Kathryn, your support through texts, Facebook jokes and memes, phone calls, and hugs when I get to see you have cheered me along this journey. Thank you for your friendship! Julie, you have been so helpful as a mentor through this process. Your knowledge and wisdom about deafblindness, support through the research, comps, and dissertation process, and now your help as I'm learning and adjusting to a new job has been wonderful. Thank you!

I am honored to walk in both the light and the dark with all of you and so many more. Thank you for sharing my journey!

K. M. P. 


\section{CONTENTS}

ACKNOWLEDGMENTS

CONTENTS

iv

TABLES

viii

FIGURES

$\mathrm{X}$

CHAPTER I: HISTORY OF DEAFBLIND EDUCATION, RELATED SERVICES, AND

EDUCATIONAL PRACTICES 1

Definition of Deafblind $\quad 5$

$\begin{array}{ll}\text { History } & 6\end{array}$

$\begin{array}{ll}\text { Educational Service Providers } & 17\end{array}$

$\begin{array}{ll}\text { Certified Orientation and Mobility Specialist } & 18\end{array}$

$\begin{array}{ll}\text { Intervener } & 19\end{array}$

$\begin{array}{ll}\text { Deafblind Specialist/Teacher } & 20\end{array}$

$\begin{array}{ll}\text { Accepted Educational Practices } & 25\end{array}$

$\begin{array}{ll}\text { Communication } & 25\end{array}$

$\begin{array}{ll}\text { Child-guided practices. } & 29\end{array}$

$\begin{array}{ll}\text { Systematic instruction. } & 30\end{array}$

$\begin{array}{ll}\text { Assessment } & 33\end{array}$

Assistive Technology 34

$\begin{array}{ll}\text { Low tech AT. } & 34\end{array}$

High tech AT. $\quad 35$

Life Skills (Systematic Instruction) 36

$\begin{array}{ll}\text { Literacy } & 37\end{array}$ 
Science

$\begin{array}{ll}\text { Social-Emotional/Behavior } & 38\end{array}$

$\begin{array}{ll}\text { Transition } & 41\end{array}$

$\begin{array}{ll}\text { Chapter Summary } & 42\end{array}$

CHAPTER II: ASSESSMENT OF STUDENTS WHO ARE DEAFBLIND 43

Assessment and the Individualized Education Plan Process 46

Assessment Difficulties Associated with Learners who are DB 47

$\begin{array}{ll}\text { Evaluators } & 49\end{array}$

General Assessment Guidelines for Learners who are DB 50

Medical Vision Tests $\quad 57$

$\begin{array}{ll}\text { Medical Hearing Tests } & 58\end{array}$

Functional Vision Assessment $\quad 59$

Functional Hearing Tests/Functional Listening Evaluation $\quad 60$

$\begin{array}{ll}\text { Learning Media Assessment } & 61\end{array}$

$\begin{array}{ll}\text { Expanded Core Curriculum (ECC) } & 61\end{array}$

$\begin{array}{ll}\text { Informal Assessments } & 62\end{array}$

$\begin{array}{ll}\text { Formal Assessment Instruments } & 62\end{array}$

Formalized Assessments for Individuals who are DB 63

Alternative Assessments for Learners who are DB 70

The Communication Matrix

$\begin{array}{ll}\text { Chapter Summary } & 78\end{array}$

$\begin{array}{ll}\text { CHAPTER III: METHODOLOGY } & 79\end{array}$

$\begin{array}{ll}\text { Problem Statement } & 79\end{array}$ 
Longitudinal Growth Modeling $\quad 80$

Studies Using Growth Modeling $\quad 83$

$\begin{array}{ll}\text { Purpose Statement } & 88\end{array}$

Research Questions $\quad 89$

$\begin{array}{ll}\text { Hypotheses } & 89\end{array}$

$\begin{array}{ll}\text { Research Design } & 90\end{array}$

Research Participants and Setting 90

$\begin{array}{ll}\text { Target Population } & 91\end{array}$

$\begin{array}{ll}\text { Recruitment } & 93\end{array}$

$\begin{array}{ll}\text { Phase } 1 . & 93\end{array}$

$\begin{array}{ll}\text { Phase } 2 . & 93\end{array}$

$\begin{array}{ll}\text { Phase } 3 . & 93\end{array}$

$\begin{array}{ll}\text { Phase } 4 . & 93\end{array}$

$\begin{array}{ll}\text { Ethical Considerations } & 93\end{array}$

$\begin{array}{ll}\text { Independent Variables } & 95\end{array}$

Dependent Variable $\quad 95$

Data Analysis Procedures 96

$\begin{array}{ll}\text { Interobserver Agreement Procedures } & 97\end{array}$

$\begin{array}{ll}\text { Chapter Summary } & 99\end{array}$

CHAPTER IV: ANALYSIS OF THE DATA 101

Number, Types, and Intensity of Educational Services Provided to Students who are DB 101 $\begin{array}{ll}\text { Six-Year-Old Learners } & 104\end{array}$

Fifteen-to-Eighteen-Year-Old Learners 109 
Case Studies

Research Question 4

Longitudinal Communication Growth

Chapter Summary

Summary of Findings and Discussion

Research Questions One, Two, and Three

Research Question Four

Additional Findings

Implications for Educational Programming

Limitations

Recommendations for Future Research

REFERENCES

APPENDIX A: SPECTRUM OF DEAFBLINDNESS

APPENDIX B: DESCRIPTIONS OF HEARING LOSS 


\section{TABLES}

Table

Page

1. Other Service Professionals

2. Most Frequently Used Educational Practices in the field of Deafblindness

3. Impact of Selected Etiologies

4. Medical Vision Tests

5. Formal Assessment Tools

6. Informal Assessment Tools

7. Studies Using Growth Curve Modeling

8. Demographic Description of Learners

9. Percentage of IOA Agreement Across Variables

10. IOA Disagreement Scores by Category

11. IEP Years and Ages Represented Across Participants

12. Intensity of Direct Service Provision in Minutes for Terry

13. Intensity of Related Service Provision in Minutes for Terry

14. Intensity of Direct Service Provision in Minutes for Ian

15. Intensity of Related Service Provision in Minutes for Ian

16. Intensity of Direct Service Provision in Minutes for Steven

17. Intensity of Related Service Provision in Minutes for Steven

18. Intensity of Direct Service Provision in Minutes for Anna

19. Intensity of Related Service Provision in Minutes for Anna

20. Intensity of Direct Service Provision in Minutes for Lacy

21. Intensity of Related Service Provision in Minutes for Lacy 
22. Intensity of Direct Service Provision in Minutes for Jack

23. Intensity of Related Service Provision in Minutes for Jack

24. Means and Standard Deviations of Scores on the $C M$, Groups

25. Means and Standard Deviations of Scores on the $C M$, Terry 


\section{FIGURES}

Figure

Page

1. Flowchart of Literature Search by Database and Thematic Category

2. Flowchart of Intervention Search

3. Flowchart of Provision of Services Search 4

4. Timeline of Deafblind Education, $17^{\text {th }}-19^{\text {th }}$ Centuries 8

5. Timeline of Deafblind Education, 20 ${ }^{\text {th }}$ Century 12

6. Timeline of Deafblind Education, $21^{\text {st }}$ Century 16

7. Flowchart of Assessment of Learners who are DB 53

8. Example of Communication Matrix Profile 77

9. Flowchart of Assessment Literature Search by Database and Thematic Category 81

10. Flowchart of Growth Model Literature Search by Database and Thematic Category Relative to Growth Modeling $\quad 82$

11. Related Service Provision Across Cases, 6-Year-Olds 105

12. Direct Service Provision Across Cases, 6-Year-Olds 107

13. Intensity of Educational Services Across Cases, 6-Year-Olds 109

14. Related Service Provision Across Cases, Fifteen-to-Eighteen-Year-Olds 110

15. Direct Service Provision Across Cases, Fifteen-to-Eighteen-Year-Olds 112

16. Intensity of Educational Services Across Cases, 15-to-18-Year-Olds 114

17. Longitudinal Direct and Related Service Intensity for Terry 116

18. Longitudinal Direct and Related Service Intensity for Ian 118

19. Longitudinal Direct and Related Service Intensity for Steven 119

20. Longitudinal Direct and Related Service Intensity for Anna 120 
21. Longitudinal Direct and Related Service Intensity for Lacy

22. Longitudinal Direct and Related Service Intensity for Jack

23. Terry Communication Growth Over Time

24. Ian Communication Growth Over Time 


\section{CHAPTER I: HISTORY OF DEAFBLIND EDUCATION, RELATED SERVICES, AND}

\section{EDUCATIONAL PRACTICES}

This chapter includes a presentation of the history of deafblind (DB) education, including timelines of major events, educational services that are unique to learners who are $\mathrm{DB}$, and accepted educational practices. The field of DB education traces its history through individuals, major events, and the evolution of the field since the 1600s. Over the course of nearly 300 years, the approach to educating individuals with deafblindness has changed considerably, particularly since the rubella epidemic in the 1960s (van Dijk \& Nelson, 1997). As educational practices used to meet the needs of these highly heterogeneous learners have evolved, the types of services provided to this group of individuals have changed as well. This chapter examines the history of the field of deafblindness, educational service providers specific to learners who are DB, and current accepted educational practices (including evidence-based practices [EBPs] as well as those not meeting evidence standards for an EBP designation) that are specific to the education of individuals with deafblindness. An emphasis will be placed on three types of service professionals who are unique to this population: orientation and mobility specialists, interveners, and deafblind specialists/teachers.

A search of the professional literature between 1907 and 2016 focused on the history of DB education, accepted educational practices, and related services was conducted using the following databases: National Information Clearinghouse on Children and Youth Who Are DeafBlind (DB-LINK), Google Scholar, PsychINFO, Academic Search Complete, PubMed, and ComDisDome (see Figures 1, 2, and 3). 


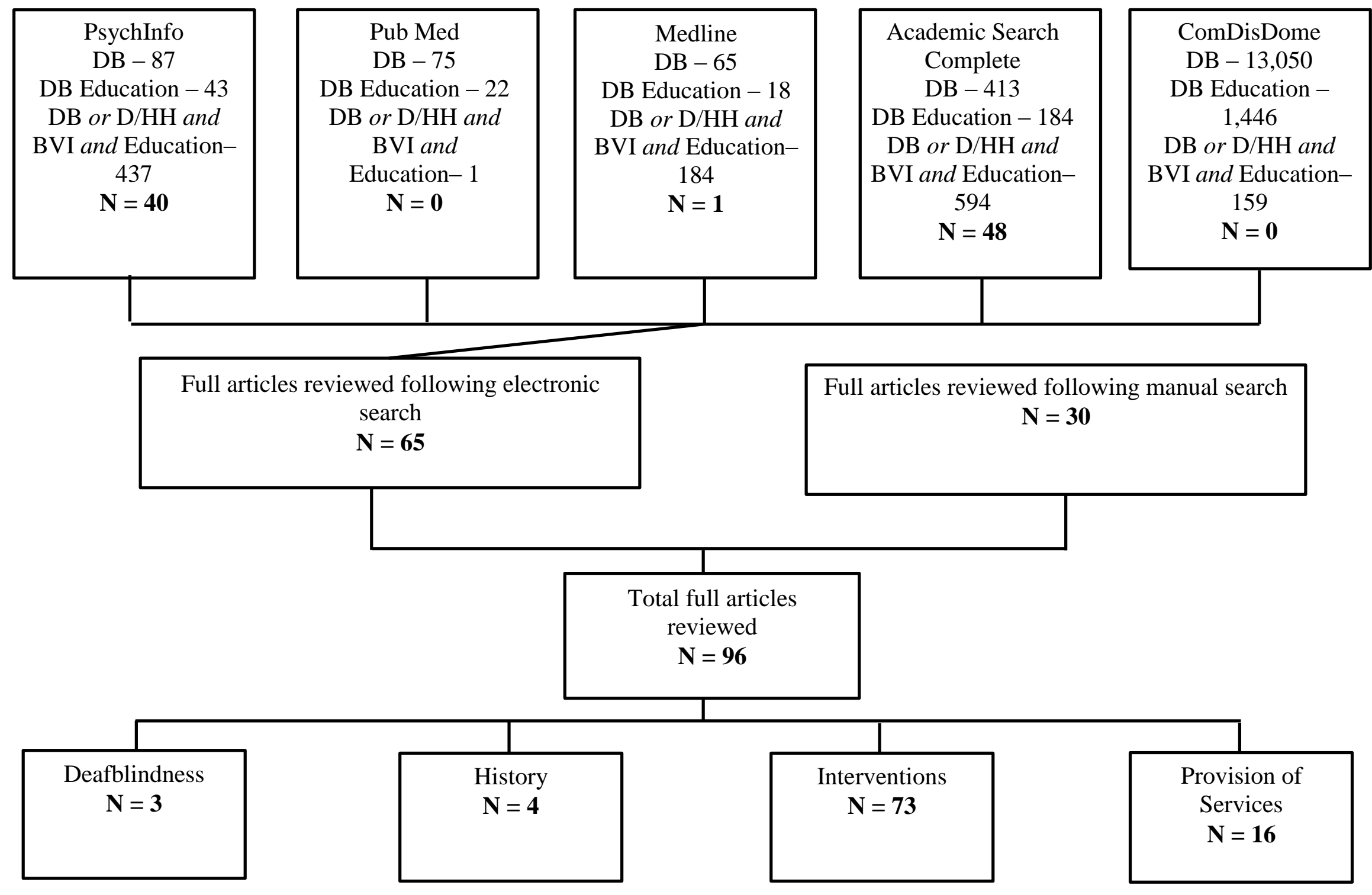

Figure 1. Flow of Literature Search by Database and Thematic Category 


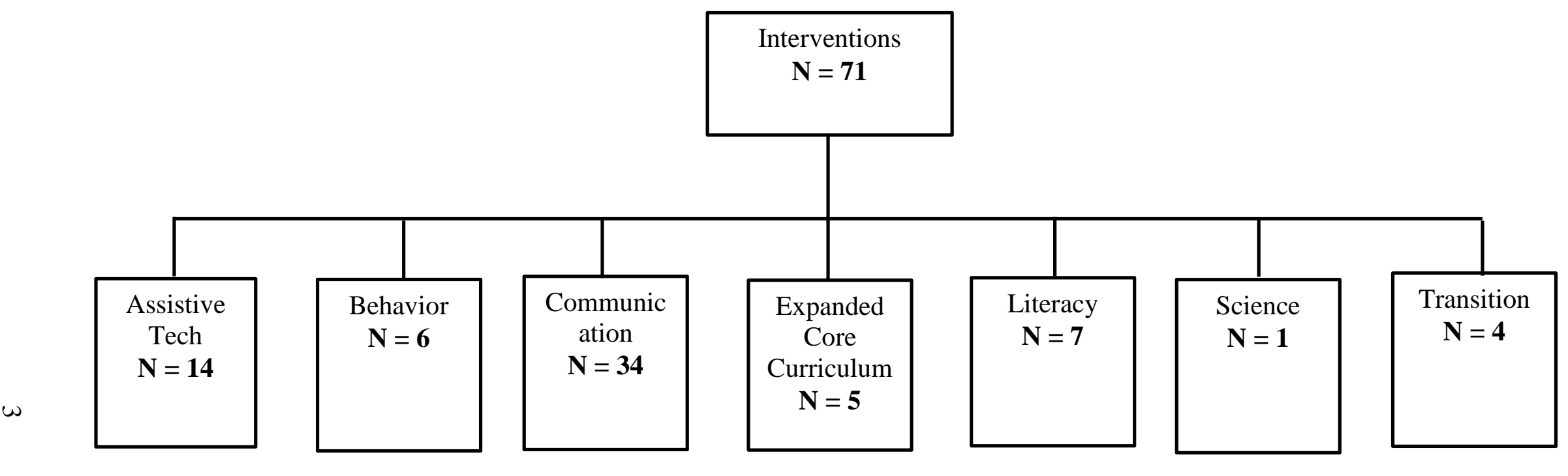

Figure 2. Flowchart of Intervention Search 


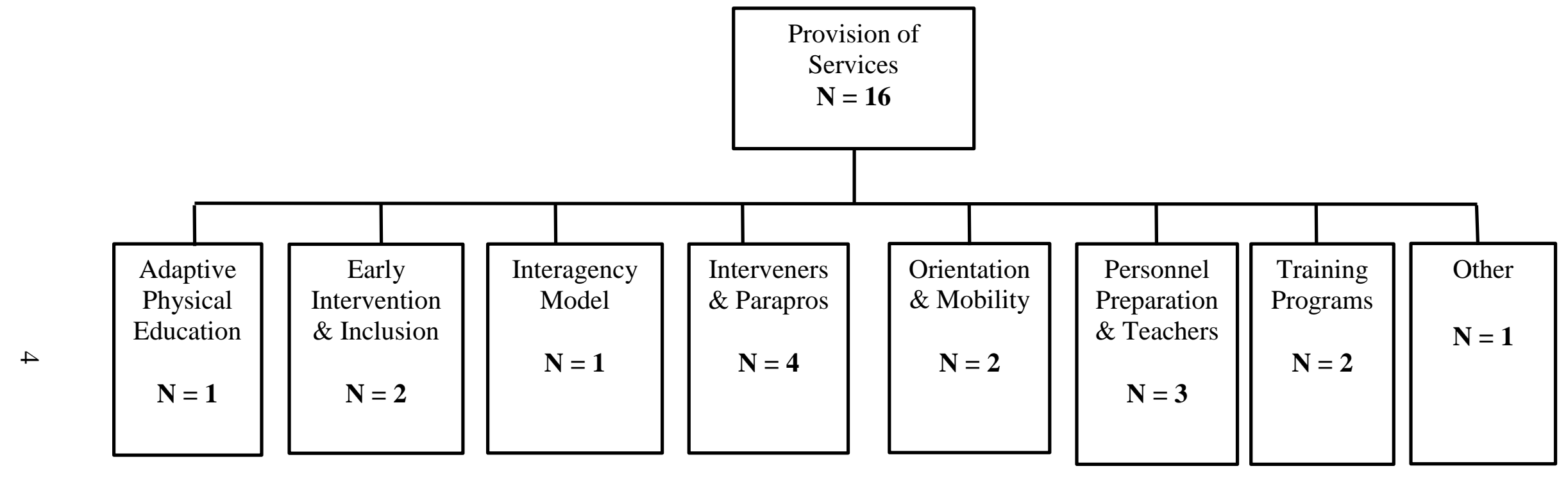

Figure 3. Flowchart of Provision of Services Search 
The combined terms of deafblind* OR deaf AND blind, OR deaf-blind, OR deaf blind, OR dual sensory impairment, AND studies, OR evidence based practices, OR intervention, $\mathrm{OR}$ language, OR literacy, OR reading, OR communication, OR braille, OR interveners, OR orientation and mobility, OR teachers, OR history were used to search for relevant literature. Works that integrated the collective search terms were included and further examined for additional inclusionary conditions: (a) studies published in English, (b) in peer-reviewed journals, (c) were empirical, and, when reviewing interventions, (d) were educational interventions. Articles were excluded if they did not meet inclusionary criteria or were dissertations or included only medical interventions with the exception of cochlear implants (CI). Finally, a snowball search of the reference lists obtained from each article or report was conducted to ensure a comprehensive review.

The field of DB education is rich, knit together by individuals who were DB, their families, and professionals. To effectively discuss educational service providers and accepted educational practices, the history of the field must first be examined. Following the review of the history of DB education, information regarding educational service providers and current accepted educational practices that are specific to the education of individuals with deafblindness will be presented.

\section{Definition of Deafblind}

In the field of deafblindness, professionals define deafblindness as a hearing loss in the better ear greater than 35 decibels and vision loss of 20/200 or less when corrected; however, Evenhuis (1996) suggests using a more conservative hearing loss of greater than 25 decibels for any individuals who have a comorbid intellectual disability. For the purposes of this study, participants chosen had concomitant hearing and visual impairments (as defined in IDEA 
300.8(c)(2) as the combination of which causes such severe communication and other developmental and educational needs that they cannot be accommodated in special education programs solely for children with deafness or children with blindness) that were either congenital or developed prior to language acquisition. Throughout this manuscript, the terms deaf-blind and deafblind are used interchangeably. When appropriate, the acronym "DB" will be used in place of these terms (Lagati, 1995).

\section{History}

Although many people think education for individuals with deafblindness began with Helen Keller, there were three other women who received education prior to her (see Figure 4 for the timeline of the $17^{\text {th }}-19^{\text {th }}$ centuries). According to Collins (1995), these individuals were Victorine Morriseau (1789, Paris, France), Laura Bridgman (1837, United States [U.S.]) and Julia Brace (1842, US). Ms. Morriseau was the first known person with deafblindness to be taught a formal language (French) in Paris. In the US, Ms. Bridgman was the first individual with deafblindness to learn English using the tactile alphabet. Finally, Ms. Brace was the first known person with deafblindness to communicate using tactile sign. In 1887, Anne Sullivan, trained by Laura Bridgman, was sent to Tuscumbia, Alabama, by the Director of Perkins School for the Blind to teach Helen Keller. While she was not the first individual with deafblindness to be educated formally, it was the accomplished Helen Keller's life and education that generated a worldwide awareness regarding the education of children with deafblindness (Collins, 1995).

Two other notable women who were DB were provided education in the 1800s as well: Ragnhild Kaata (1888, Norway) and Marie Heurtin (1895, France). Ragnhild was the first person with deafblindness in Norway to be educated using oral speech methods. The decision to use oral speech methods with Ragnhild followed the historical 1880 Milan Conference ruling 
that oral education was superior to manual for deaf students (Collins, 1995). Her success encouraged other countries to start using the oral method to teach speech to individuals with deafblindness (Collins, 1995). In April 1891, the American people learned of her achievements through oral education when The Mentor printed a story of her accomplishments (de Courson, 1907). While Marie Heurtin was not the first person with deafblindness to be formally educated in France, she was the first documented person to learn both sign language and braille (de Courson, 1907).

With the turn of the century, both education and services for DB students gradually developed and improved (see Figure 5 for a timeline of the $20^{\text {th }}$ century). During the first half of the 1920s, a few schools were established to teach individuals with deafblindness in Europe (Condover Hall, United Kingdom; the Zagorsk School, Moscow; and St. Michielsgestel, Netherlands) as well as in the US (Perkins School for the Blind, New York Institute for the Blind, Overbook School for the Blind, Michigan School for the Blind, California School for the Blind, Texas School for the Blind, and Illinois Braille and Sight Saving School; Collins, 1995). By 1937, the American League for the Deaf-Blind was founded by Frances Bates. Individuals who were DB began to create more organizations (Support Service Providers for People who are Deaf-Blind, 2012). However, students with sensory disabilities were still denied a formal education by public schools and were forced to attend specialized schools. It was not until the late 1950s that public school programs began to provide services to learners with deafblindness. Nevertheless, if a student had additional disabilities (e.g., comorbid visual impairment and intellectual disability), they were not selected to attend the schools that provided specialized services. Once public schools began accepting these students in the late 1950s, the enrollment at 


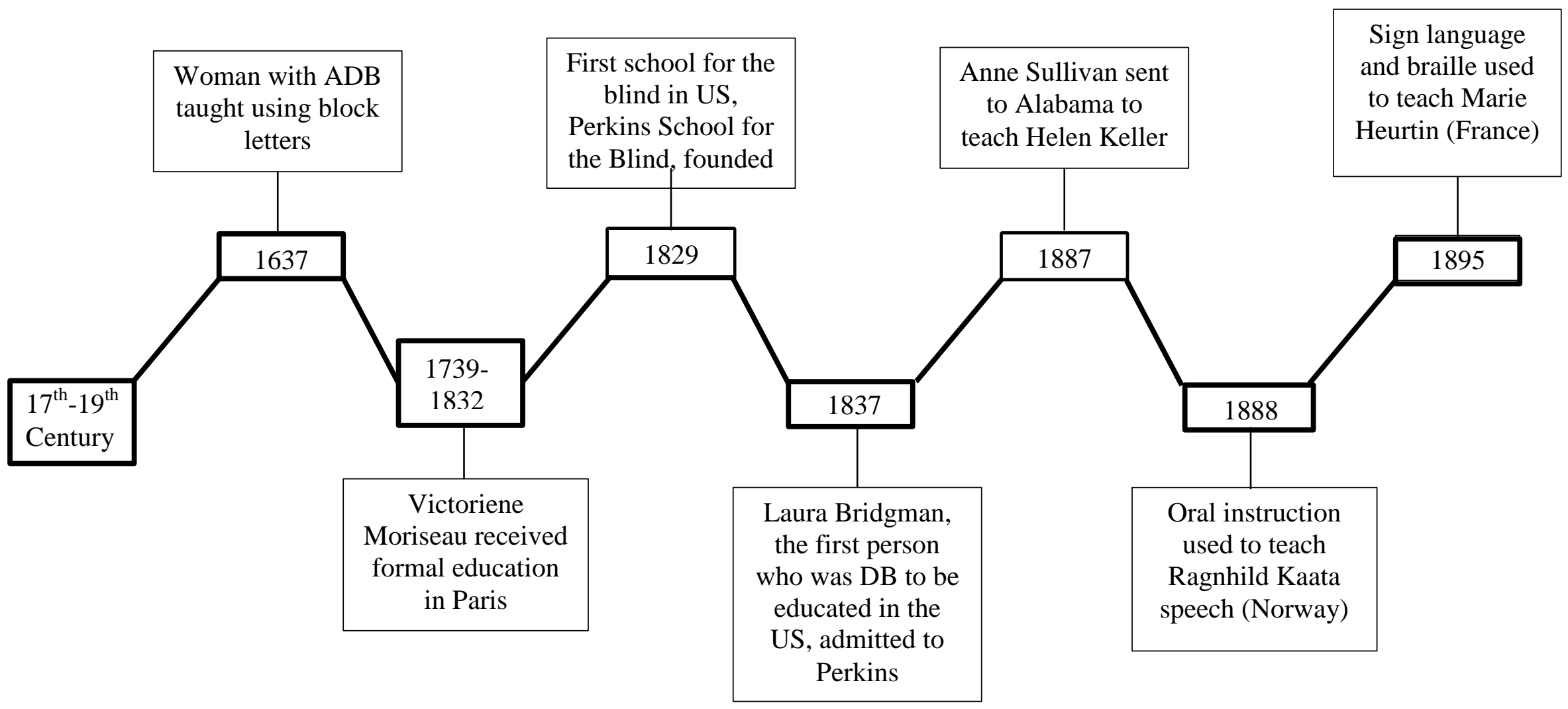

Figure 4. Timeline of Deafblind Education, $17^{\text {th }}-19^{\text {th }}$ Centuries. 
the specialized schools drastically decreased, forcing them to accept students with comorbid diagnoses (Sacks, 1998).

In the early 1960s (1962-1964), there was a worldwide epidemic of rubella, which resulted in the birth of thousands of children with comorbid vision and hearing loss. Many of these children also presented with other disabilities (cognitive and physical; Collins, 1995; Sacks, 1998). This epidemic resulted in the formation of many schools for individuals who were DB throughout Europe, North America, and Oceana. With a newfound awareness of the impact of rubella, more than 5,000 people with deafblindness were identified, creating a need for the educational system to meet the unique and diverse needs of these learners (Enerstvedt, 1996). In 1965, Dr. Jan van Dijk presented a film about his new method, the "moving-acting together" technique. This new idea was vastly different than approaches practiced with persons with cognitive disabilities (substantial delays in both intellectual functioning and adaptive behavior and occurs before the age of 18), which professionals in the field of deafblindness had been employing with learners up until this point. The new approach, dubbed the "co-active movement approach," was adopted because of its process of "joining in" with the child by following his or her attention and interest. The communication partner replicated the child's movements by giving him or her "the lead" to foster independence and avoid dependence on the teacher's actions (van Dijk \& Nelson, 1997).

Due, in part, to the rising numbers of individuals with deafblindness and the changes in teaching methods, federal legislation was passed in 1967 that created centers to serve this population of individuals. This legislation was the origination of the federal government's involvement in establishing educational services and technical assistance (TA) centers to learners who were DB (Sacks, 1998). As a result, the Helen Keller National Center for Deaf-Blind 
Youths and Adults (HKNC) was approved by an act of US Congress (Sacks, 1998). A presentation by one of the founders of this organization, Dr. Robert J. Smithdas (the second person who was DB to receive a college degree), was made to Congress explaining the need for further services (Support Service Providers for People who are Deaf-Blind, 2012) to meet the needs of individuals with deafblindness, their families, and professionals. Congress then passed P.L. 90-230 in 1968 which authorized the creation of Centers and Services for Deaf-Blind Children and Youth (Title VI-C; Collins, 1995).

The 1970s was a time of moderately available funding for individuals with deafblindness and the field. During this decade, a $\$ 16$ million appropriation was used to create a network of multi-state regional centers which promised the development of staff training and direct services to individuals with deafblindness (Collins, 1995). Furthermore, this network provided nationwide communication and sharing of information for professionals working with individuals with deafblindness. Although funding was fairly available and vital information was being shared through the network, education of individuals with deafblindness continued to target learners without additional disabilities and was delivered primarily within segregated settings. Learners who were DB either did not receive an education at all or they were placed in classrooms for children with a variety of disabilities and were therefore not receiving instruction from a teacher educated in deafblindness.

To respond to the growing needs of learners, Congress passed the Education for All Handicapped Children Act, or PL 94-142, in 1975 (EHAC, 1975) which required states to provide a free, appropriate education to all children with special needs (Collins, 1995; Sacks, 1998; Thirty-Five Years, 2010) spurring more local school districts to create programs including all children with multiple impairments, including those with deafblindness. From 1970 to 1975, 
federal funding supported over half of the costs of specialized state programs, providing quality direct services, ongoing training, consultation, publications, and training videos by professionals who had specific knowledge in deafblindness (Blaha, Cooper, Irby, Montgomery, \& Parker, 2009; Collins, 1995). Training programs for aspiring teachers of students with deafblindness were developed at this time as well (McLetchie, 1993). Moreover, instructional methods evolved and expanded to include methods to target learners who were medically fragile and those with multiple disabilities (Collins, 1995).

Educational paradigms shifted following the 1970s from programs in segregated settings toward more inclusive settings at local schools (Montgomery, 2015). This shift was greatly influenced by the passage of PL 94-142 by Congress in 1975 and led to a critical change in educational focus for students who were DB beginning in the late 1980s. The new focus was on "reciprocal social togetherness," which advocated allowing the child to lead followed by the establishment of positive relationships to foster the development of communication and other skills (Brown \& Bates, 2005). PL 94-142 was reauthorized in 1983, shifting priorities to services for children who were DB and providing direct services only to children who were not the responsibility of the State Education Agency because of their ages (Collins, 1995). Additionally, emphasis was placed upon these state agencies to augment the quality of services delivered and allowed for the remaining funds provided to be used for any supplemental services needed.

By 1983, 16 centers with more than 300 programs were established by the Bureau of Education for the Handicapped which provided services to public and private educational organizations serving 5,998 children with deafblindness (Collins, 1995). At the same time, Best (1983) conducted a national survey in the United Kingdom of the children who were DB. 


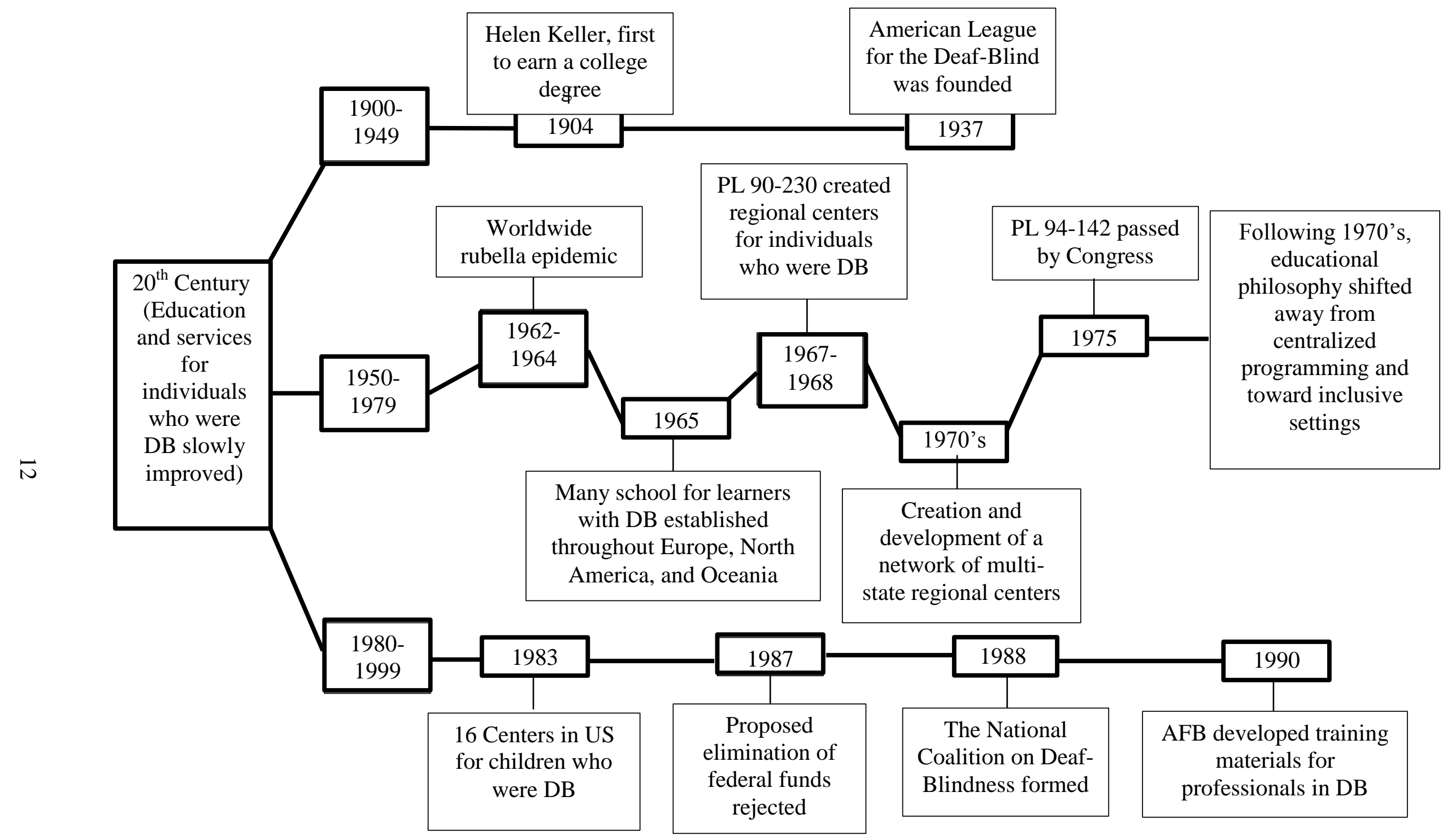

Figure 5. Timeline of Deafblind Education, $20^{\text {th }}$ Century 
The data obtained from the survey suggested that Congenital Rubella Syndrome (CRS) was declining as a leading etiology of deafblindness, other causes of deafblindness were steadily increasing, and the proportion of children with additional severe disabilities was growing (Best, 1983).

In 1986, PL 99-457 (Education of the Handicapped Act, Part H) was established and created a framework for service delivery, which emphasized the need for specific evaluation and education of young children who had visual impairments (VI) with other disabilities (Sacks, 1998). In both 1987 and 1989, proposals to eliminate federal funding for services specific to children with deafblindness were rejected by Congress due to appeals made by professionals and parents of children with deafblindness (Collins, 1995). The formation of The National Coalition on Deaf-Blindness (NCDB) in 1988 (which included many national organizations of parents, professionals, and people with deafblindness) provided input to Congress from individuals which would be affected by changes in the law.

The last decade of the twentieth century was a year of great gains. However, the inclusion of children who were DB in their local schools presented a major challenge because infrastructure to support the local schools was not yet created (Collins, 1995). In 1990, the Education of the Handicapped Act was reauthorized and renamed the "Individuals with Disabilities Education Act (IDEA)." With the reauthorization, funding was allocated explicitly for children who were DB. The reauthorization also defined the population and delineated many new initiatives including a National Information Clearinghouse as well as direct services to children within "pilot" projects (Collins, 1995). Additionally, the Office of Special Education Programs (OSEP) provided funding to the American Foundation for the Blind (AFB) to develop training materials for professionals who worked with students who were DB (Huebner, Kirchner, 
$\&$ Prickett, 1995). Professionals in the field of deafblindness further worked to define the knowledge and skills necessary for competent teachers and paraprofessionals/interveners. Sustained provision from OSEP was crucial to teacher preparation in deafblindness and to the organizations that were providing ongoing professional development opportunities to program graduates (Bruce, 2007).

With the growing challenges related to the education of students with deafblindness, the need for qualified paraprofessionals was addressed in 2002 when the National Intervener Task Force was formed (see Figure 6 for a timeline of the $21^{\text {st }}$ century). The task force's efforts were to develop a reliable interpretation of the topics and services related to how interveners were to be trained and utilized in both educational and early intervention settings. Subsequently, the SKI-HI Institute at Utah State University (a unit of the Research and Evaluation Division of the Center for Persons with Disabilities; SKI-HI Institute, 2016) hosted a meeting where the participants reviewed and recommended practices to be used in the development of intervener training programs. This meeting resulted in an external review conducted by the National Technical Assistance Consortium for Children and Youth who are Deafblind (NTAC) in 2003 (Alsop, Killoran, Robinson, Durkel, \& Prouty, 2004). The issue of support service providers (SSP) continued to be a topic of conversation at the 2003 American Association of the DeafBlind Conference. Delegates spoke of the need for national SSP services to promote independence for individuals with deafblindness. The delegates voiced frustration concerning inadequacy of services offered in particular areas of the US (e.g., rural areas). Consequently, in 2004, to meet the need for these services, the AADB and Deaf Blind Service Center of Seattle, and HKNC began setting up a National SSP Pilot Project for all individuals with deafblindness who needed SSP services (Support Service Providers for People who are Deaf-Blind, 2012). 
Also developed by the SKI-HI Institute and NTAC, was a national Community of Practice Focused on Interveners and Paraprofessionals Working with Children and Youth who are Deafblind (Alsop, et al., 2004). According to Support Service Providers for People who are Deaf-Blind, as of 2006, 31 states did not have support services for individuals who are DB, 14 states had some programming, and only 5 states had statewide programs.

In an effort to train leaders in the field of low vision and blindness, OSEP provided funding for the National Leadership Consortium in Visual Impairments (NLCVI) in 2004. Following the success of the NLCVI program and identifying the need to train highly qualified leaders in all areas of sensory disabilities, the National Leadership Consortium in Sensory Disabilities was developed and supported by OSEP in 2010. The goal of both programs was to increase the number of highly trained leaders in the field of sensory disabilities to meet the needs of learners and improve interventions, services, and learner outcomes. Furthermore, the need for additional educators trained in deafblindness who could support interveners was identified when NCDB conducted a national assessment regarding the needs for improving intervener services in 2012. Following the assessment, NCDB issued a report that reinforced the role of the intervener and the necessity of all-inclusive educational planning for learners who were DB (Schalock, 2012). Modules to train interveners, called Open Hands, Open Access, began to be written in November 2012 and were released in October 2013 (A. Parker, personal communication, June $29,2016)$. Since that time, the field of deafblindness has continued to produce educational and training opportunities to increase the number of service providers as well as improve the services provided to individuals who are DB. 


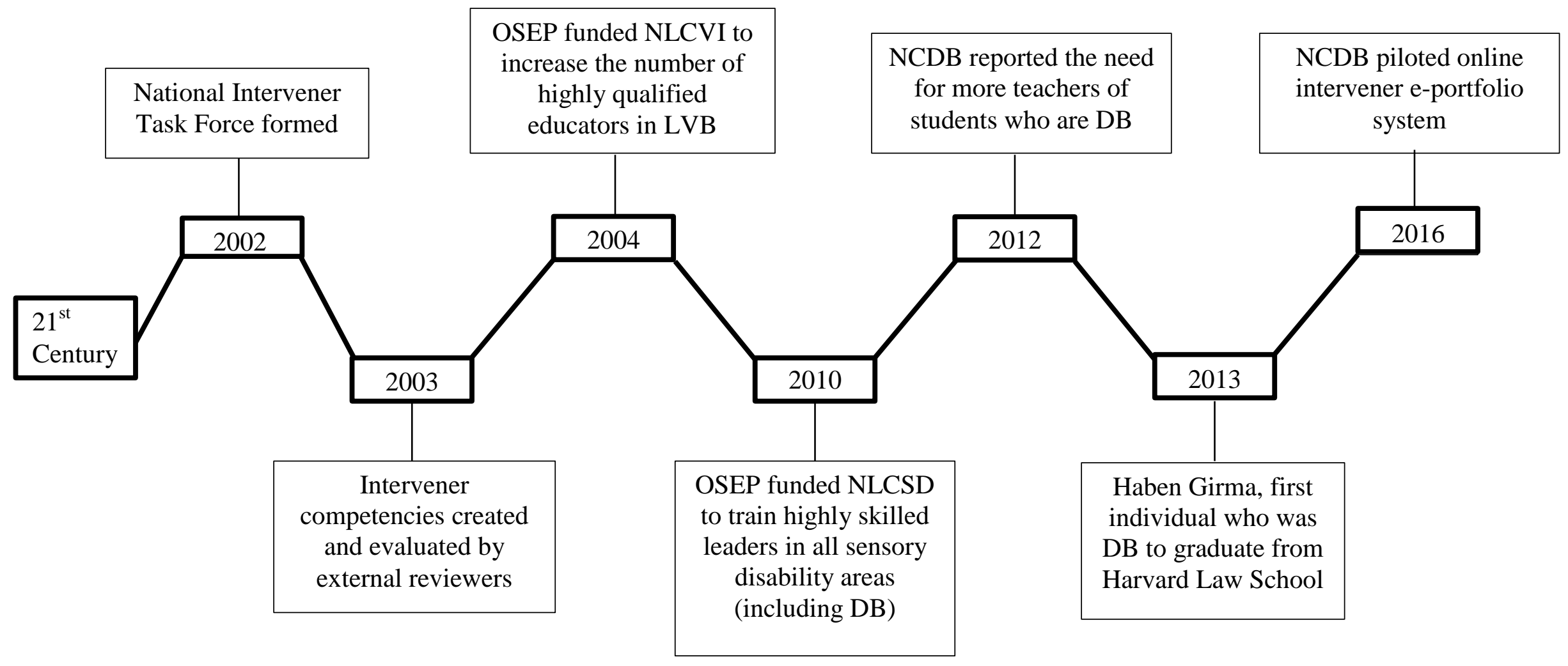

Figure 6. Timeline of Deafblind Education, $21^{\text {st }}$ Century 


\section{Educational Service Providers}

As deafblindness is the most heterogeneous and lowest incidence disability, it is rare for most education personnel to receive much, if any, training related to instructional techniques specific to these learners. For a child who is DB to access their educational world, a team of well-trained individuals must work together with the child and family to determine the most appropriate services and approaches for each individual learner (Luckner, Bruce, \& Ferrell, 2016). Initially, it is important that any professional working with a learner who is DB recognize the impact of deafblindness on learning. These professionals should possess an understanding of methods which can be used to develop communication since this is a primary deficit area for this population of learners (Bruce, 2005). A comprehensive knowledge of various modes and ways to develop these skills is vital since traditional communication methods may not be feasible with this population due to the dual sensory loss. Familiarity with alternative and augmentative communication systems (AAC) and an understanding of several different techniques of teaching learners who are unable to physically access their learning environment is necessary as many learners who are DB also have additional disabilities which impede their abilities to speak and/or independently ambulate. The ability to craft learning opportunities that mimic real-life, incorporate methods from other disciplines, and practice child-directed and family-friendly approaches are also essential skills for professionals working with this population of learners (McGinnity, 2008).

When researching literature that assessed the effectiveness of related services, very little was identified. There was mention of the need for a well-trained team of individuals to provide appropriate educational services to learners who are DB including suggestions for professional disciplines to be included, however no articles were found that extensively outlined the roles and 
responsibilities for each IEP team member (see Table 1 for information regarding other educational personnel).

\section{Certified Orientation and Mobility Specialist}

The role of the certified orientation and mobility specialist (COMS) is to provide service for people who have vision loss so they can gain the skills needed to safely maneuver their dayto-day environment independently and with purpose (COMS, 2016). This is accomplished through a sequential teaching process where the individual with VI uses their residual senses to ascertain their position within the environment and move safely from place to place (COMS, 2016). Regrettably, there is a serious scarcity of COMS with the specialized preparation in deafblindness and/or multiple disabilities (Huebner et al., 1995). Modifications which must be made to orientation and mobility (O\&M) instruction for students who are DB involve consideration of the impact of deafblindness, possible balance problems, and distinctive and multifaceted communication needs (Ferrell, Bruce, \& Luckner, 2014; Huebner \& Prickett, 1996; Joffee, 1995; Joffee \& Rikhye, 1991; Lolli, Sauerburger, \& Bourquin, 2010; Luckner et al., 2016; Sauerburger \& Jones, 1997). Additionally, it is imperative that the child who is DB be trained in "real world" environments (Bourquin \& Sauerburger, 2005; Parker, 2009b).

Customarily, students with VI would depend on their hearing to orient to their environment, but with the addition of a hearing loss, their ability to orient is further complicated and demands the use of unique modifications.

Sauerburger and Jones (1997) contend that COMS need to know three specific things when working with a client who is DB: (a) approaches for communication (e.g., sign language, tactile sign language, AAC devices); (b) methods to teach ways to communicate and interact with others in public (e.g., dual communication books, communication cards); and (c) strategies 
for crossing the street for individuals who are unable to satisfactorily hear traffic noise. She further outlines that the COMS must help individuals with deafblindness to identify ways to gain assistance if they do not feel comfortable crossing alone.

\section{Intervener}

In many districts, designating a paraprofessional to provide support to learners with disabilities has become the principal or sole procedure for delivery of service in inclusive education (Giangreco \& Doyle, 2002). IDEA (2004) acknowledged and strengthened the role of the paraprofessional under the provision of related services in special education. It stated clearly that paraprofessionals who were adequately trained and supervised may aid in the provision of special education services to children with disabilities. Additionally, the No Child Left Behind Act (NCLB) mandated that qualified staff be available for all students. Paraprofessionals who are assigned to students who are DB need both adequate training and specific skills, and also must meet standards set by the state. Presently, there are only three training programs in the US (i.e., Central Michigan University, East Carolina University, and Utah State University) that provide the necessary training for paraprofessionals serving students who are DB (CMU online certificate, 2016; National Center on Deafblindness, 2012a).

Currently in the field of deafblindness there is an emerging model of paraprofessional service delivery via deafblind interveners (Blaha, et. al., 2009; Montgomery, 2015). An intervener is defined as a paraprofessional who has instruction and specific skills relating to deafblindness (Alsop, et al., 2004). Interveners enhance the teaching delivered by educators through the provision of experiences to help the learner understand and participate in their educational program. The intervener provides support for interactions between the learner who is DB, his/her teachers, and other children, as well as, at times, serving as a sign language 
interpreter in many areas such as communication, social relationships, daily living activities,

massage, daily care, positioning and handling, and orientation and mobility (Ferrell et al., 2014). Furthermore, the intervener delivers necessary sensory input and interpretation; becoming, in essence, the eyes and ears of the child (Watkins, Clark, Strong, \& Barringer, 1994). To aid children who are DB in their educational development, it is vitally important for them to have access to a well-trained intervener (Hull \& Hull, 2006).

Only one research article was identified relative to intervener services. According to Watkins, et al. (1994), the use of early intervention (EI) intervener services in the home accelerated the child's development more than what would be expected as a result of typical maturation across various areas of development. Additionally, a noticeable escalation in the rate and complexity of communication was identified while self-stimulatory behaviors decreased. While this study indicated a positive effect of intervener services, there is a need for further investigation into the overall effectiveness of intervener services.

\section{Deafblind Specialist/Teacher}

It is imperative that each IEP team for a DB student include at least one member who is experienced in educating individuals with deafblindness (i.e., specific communication methods and instructional methodologies, development of children who are DB, assessment, and program implementation; Ferrell et al., 2014; Luckner et al., 2016; Parker et al., 2012; Riggio, 2009; Riggio \& McLetchie, 2008). Many researchers support the necessity of collaboration, agreeing that no professional possesses all the expertise required to meet the unique and complex needs of a child who is DB (Bruce, 2007; Cloninger \& Giangreco, 1995; Ferrell et al., 2014). Further, a team would be greatly lacking if it only had members with expertise in VI or in $\mathrm{D} / \mathrm{HH}$ since the impact of deafblindness on a learner is much more significant than simply adding the 
consequences of vision and hearing loss together (Ferrell et al., 2014). A teacher of students with deafblindness (TDB) must be highly trained in a variety of areas in addition to those previously mentioned. NCDB recommends that TDB display proficiency in educating students who are DB as well as coaching, consulting and collaborating with educational teams serving students who are DB (including families and interveners). Unfortunately, there is a critical shortage of TDB to serve on educational teams or as consultants to those teams.

TDB must use appropriate EBPs (when available) and interventions when establishing an education plan. Some of the EBPs recommended by researchers include utilization of small instructional groups to incorporate a 1:1 ratio for students who rely on tactual input for learning, supporting the learner's engagement, and allowing for essential frequent and tactual feedback (Ferrell et al., 2014; Parker et al., 2012; Riggio, 2009; Riggio \& McLetchie, 2008). A low teacher to pupil ratio can increase student engagement through improved access to information and essential feedback, more effective focus on the communication partner, and the reduction of noise and visual clutter (Parker et al., 2012; Riggio, 2009; Riggio \& McLetchie, 2008). 
Table 1

Other Service Professionals

\begin{tabular}{ll}
\hline \multicolumn{1}{c}{ Title } & \multicolumn{1}{c}{ Duties } \\
\hline Adaptive & Physical education was included in IDEA (2004) as a part of special education services. APE teachers must be \\
Physical & able to design achievement-based programs for learners who are DB, collaborate with the IEP team, monitor \\
Education & student progress, implement effective behavior management techniques, modify the environment, equipment, \\
Teachers & and/or activities, and differentiate instruction. APE occurs in a variety of settings: 1:1 settings, self-contained \\
(APE) & classes, small group instruction, inclusive general PE classes, and others, as appropriate (Davis, French, Felix, \\
& Tymeson, Kelly, Lytle, \& Webbert, n.d.). When a student is DB, the APE teacher can work with the team to \\
& establish an environment where the student feels safe to explore, play, and be active.
\end{tabular}

Classroom Responsible for the classroom activities, primary instruction, coordination of classroom staff, and working with Teacher the students who is DB when appropriate. Some additional responsibilities may include: active collaboration with team members, goal setting based on assessment data and team input, adaptation of classroom materials, lesson planning and providing those plans to team members for adaptations, when necessary, learn and promote the child's communication system, encourage social engagement, establish a structured and consistent environment, and coordinate meetings when needed (Rodriguez-Gil, 2009).

Nurse

A nurse may be employed to provide necessary medical support (e.g., administering medication, attending to physical ailments, suctioning, and transference from wheelchair) to the DB student. Additionally, the school nurse can provide training to staff about medical needs, medications and their side effects, and guidance.

Occupational Therapist (OT)

In schools, the OT's goal is to ensure that students are able to participate in all aspects of their education by assessing the entire child and addressing individual tasks to help learners build the skills they need to perform necessary and desirable tasks (Hofmann, 2016). Regarding learners who are DB, an OT may: conduct assessments to determine the student's functioning both with and without assistance in a variety of environments and with various materials/tasks, assess the student's response to different stimuli, promote participation in activities (i.e., feeding, play, classroom activities), and, when appropriate, provide sensory integration therapy (Brody, 2003; Rodriguez-Gil, 2009). 
Table 1 Continued

\begin{tabular}{ll}
\hline \multicolumn{1}{c}{ Title } & \multicolumn{1}{c}{ Duties } \\
\hline Physical & A PT is a professional who provides diagnosis and treatment to individuals who have disorders that limit their \\
Therapist (PT) & $\begin{array}{l}\text { ability to move and accomplish daily activities. PTs use their skills to collaborate with the IEP team to develop } \\
\text { a treatment plan which uses various methods to aid the child who is DB to move about their educational } \\
\text { environment, reduce pain, and, if possible, restore function while preventing further difficulties (American }\end{array}$ \\
& $\begin{array}{l}\text { Physical Therapy Association, 2016). } \\
\text { School }\end{array}$ \\
Psychologist & $\begin{array}{l}\text { The school psychologist's role on the IEP team is to utilize their distinctive expertise in mental health, } \\
\text { leam to establish a supportive educational program and environment. Additionally, school psychologists work }\end{array}$ \\
& with other personnel at the school to provide support, administer assessments, interpret assessment results, and \\
& work with community providers to organize necessary services for the student (NASP, 2015).
\end{tabular}

School Social

Worker (SSW)

SSWs have a unique set of skills that they contribute to the IEP team. They are trained mental health professionals who can provide specialized assistance with mental health and/or behavioral concerns; positive behavioral, academic, and classroom support; consultation with others (e.g., parents, teachers, administrators); and provide individual and group counseling (Kontak, 2012). Individuals who are DB have been found to have high levels of mental health disorders and high levels of anxiety and depression (Armstrong, Surya, Elliott, Brossart, \& Burdine, 2011; Dammeyer, 2011). An SSW could provide the IEP team, including the student who is DB and their family, counseling and/or referrals to mental health services.

Speech-

Language

Pathologist

(SLP)

The goal of the SLP is to avert, evaluate, diagnose, and treat speech, language, social communication, cognitive-communication, and swallowing disorders in children and adults (ASHA, 2016). An SLP would help the team attend to the child's communication needs due to the sensory and any additional disabilities. Since an SLP understands the impact a communication deficit has on educational progress (Swanson, 2011), they can provide services to meet the needs of these learners in language development and speech production. When a child does not use spoken language, the SLP works collaboratively with the team to identify other modes of communication which could be used. Additionally, an SLP could: work with the team to integrate speech strategies into the school day and encourage social communicative interactions with peers, monitor and update the child's communication system, and provide training to staff and parents about the child's communication needs (Rodriguez-Gil, 2009).

(Table Continues) 
Table 1 Continued

\begin{tabular}{ll}
\hline \multicolumn{1}{c}{ Title } & \multicolumn{1}{c}{ Duties } \\
\hline Teacher of the & The TOD provides services (often consultative in nature) as determined by the IEP team. The TOD works with \\
Deaf/Hard of & the team to primarily address communication and language and concept development. This teacher may: \\
Hearing & conduct functional hearing assessments, refer the student for audiological testing, provide information specific \\
(TOD) & to the student's hearing loss, amplification (including use and care), and accommodations, direct instruction \\
& and/or consult with the team regarding teaching strategies, train the team on the learner's chosen communication \\
& system, adapt instructional methods and materials, pre- and post-teach academics to enhance comprehension, \\
& conduct assessments, provide training to staff on instructional strategies and how to embed them within the \\
& school day (Rodriguez-Gil, 2009).
\end{tabular}

Teacher of the

Visually Impaired (TVI)

The TVI often provides services through a consultation model, providing services as detailed in the student's IEP. This teacher's specialty is the adaptation of environmental and learning materials to meet the student's vision needs. Some of the duties of a TVI are: conduct functional vision and learning media assessments, low vision clinic referrals, choose suitable visual materials (based on color, size, and contrast), obtain materials needed to encourage the use of residual vision and/or touch, provide braille instruction (Pugh \& Erin, 1999), collaborate with the team by providing explanations about the child's visual functioning as well as the necessary adaptations and modifications, provide visual and/or tactile experiences to improve the learner's visual/tactile skills, when appropriate, train team members in appropriate techniques and strategies so as to embed these activities into the school day.

Technical The local school district is where most children who are DB receive their education, however, these districts Assistance may lack the expertise to provide appropriate education (McGinnity, 2008). To address the child's needs, state (TA) and national DB projects provide TA to support and train professionals. TA is a method which pairs and applies innovative knowledge and practice to developmental difficulties and is designed to develop or improve programs available (NECTAC, 2016). One goal of the state and national projects is to support and train teachers and staff about the unique needs of learners who are DB, assessment, and teaching strategies (McGinnity, 2008).

Note. $\mathrm{DB}=$ deafblind; IEP = Individualized Education Plan. 


\section{Accepted Educational Practices}

The field of deafblindness has few, if any, educational practices that meet the criteria to be recognized as an EBP due to the low incidence rate, heterogeneity of the population, geographic dispersion, and the limited number of experienced specialists (Ferrell et al., 2014). Nevertheless, in the area of communication, there is a robust research base to support effective practices; however, despite the amount of literature available, those practices do not meet the arduous EBP standards (see Table 2 for the most frequently used educational practices in deafblindness). The most prolific literature in the area of deafblindness focuses on communication strategies and is divided into two categories: child-guided techniques and systematic instruction (a methodical way to teach material by carefully sequencing skill-building activities). Other research has been conducted in the areas of assessment, assistive technology, literacy, systematic instruction in life skills, science, social/emotional behavior, and transition. Unlike research about communication, the amount of literature available relative to these other areas is scant, providing information on field tested practices, but hardly meeting the criteria to be called evidence-based.

\section{Communication}

Whether using a child-guided approach or systematic instruction, the chosen intervention methods must consider the developmental levels of communication and the progression of symbolization to guarantee the selection of appropriate communication intervention (Bashinski, 2011; Bruce, 2005; Hartmann, 2012; MacFarland, 1995; Miller, Swanson, Steele, Thelin, \& Thelin, 2011; Pittroff, 2011; Rowland, 2011; Vervloed, van Dijk, Knoors, \& van Dijk, 2006). In other educational disciplines, the study of communication generally moves quickly from prelinguistic to single words and word combinations; however, the needs of the population of 
Table 2

Most Frequently Used Educational Practices in the field of Deafblindness

\begin{tabular}{ll}
\hline \multicolumn{1}{c}{ Educational Practice } & \multicolumn{1}{c}{ Research Base } \\
\hline Assistive Technology & Both low and high tech AT devices are used to increase the learner's access and \\
& engagement in their learning environment (Emerson \& Bishop, 2012; Ferrell et al., \\
& 2014; Lancioni, Bellini, \& Oliva, 1993a, 1993b; Lancioni, Bellini, Oliva, Guzzini, \& \\
& Pirani, 1989; Lancioni, Mantini, Cognini, \& Pirani, 1988; Mirenda, 1997; Schweigert \\
& \& Rowland, 1992). However, the presence of additional disabilities complicates the \\
& use of AAC interventions (Sigafoos, Didden, Schlosser, Green, O'Reilly, \& Lancioni, \\
& 2008). Computer aided programs increased mobility and independence with daily \\
& living and recreation activities (Lancioni, Oliva, \& Bartolini, 1990; Lancioni, Oliva, \\
& Formica, \& Rossetti, 1988). Dual communication boards increased receptive and \\
& expressive communication in social contexts and appeared to clarify the \\
& communicative intent or function of the communication partner and served as an \\
& indicator of communication exchange completion (Heller, Ware, Allgood, \& Castelle, \\
1994; Wolff Heller, Allgood, Ware, Arnold, \& Castelle, 1996). Cochlear Implants & improved attention, emotional response, and language use (Dammeyer, 2009).
\end{tabular}


Table 2 Continued

\begin{tabular}{|c|c|}
\hline Educational Practice & Research Base \\
\hline Communication & $\begin{array}{l}\text { Support overall communication development by first establishing trust with the child. } \\
\text { When communicating, these approaches use the child's unique forms of expression. } \\
\text { Communication partners respond to the child's interests and communicative attempts, } \\
\text { use of different forms of dialogue, and coactive methods. Any objects chosen for } \\
\text { communication must be meaningful to the child. Some examples: van Dijk Curricular } \\
\text { Approach and the Movement-Based Language Theory (Bruce \& Conlon, 2005; } \\
\text { Goodall \& Everson, 1995; Luckner, Bruce, \& Ferrell, 2016; MacFarland, 1995; } \\
\text { McLetchie, 1995; Reed, Rabinowitz, Durlach, Braida, Conway-Fithian, \& Schultz, } \\
\text { 1985; Wheeler \& Griffin, 1997). }\end{array}$ \\
\hline Child-guided approaches & $\begin{array}{l}\text { Support overall communication development by first establishing trust with the child. } \\
\text { When communicating, use the child's unique forms of expression. Communication } \\
\text { partners respond to the child's interests and communicative attempts, use of different } \\
\text { forms of dialogue, and coactive methods. Any objects chosen for communication must } \\
\text { be meaningful to the child. Some examples: van Dijk Curricular Approach and the } \\
\text { Movement-Based Language Theory (Bruce \& Conlon, 2005; Goodall \& Everson, } \\
\text { 1995; Luckner, Bruce, \& Ferrell, 2016; MacFarland, 1995; McLetchie, 1995; Reed, } \\
\text { Rabinowitz, Durlach, Braida, Conway-Fithian, \& Schultz, 1985; Wheeler \& Griffin, } \\
\text { 1997). Can be effective in improving communication rate as well as variety of } \\
\text { intents/functions (Brady \& Bashinski, 2008; Heller, et al., 1994; Reed, 1996; } \\
\text { Schweigert \& Rowland, 1992; Sigafoos et al., 2008; Wolff Heller, et al., 1996). }\end{array}$ \\
\hline Systematic instructional approaches & $\begin{array}{l}\text { Can be effective in improving communication rate as well as variety of } \\
\text { intents/functions (Brady \& Bashinski, 2008; Heller, et al., 1994; Reed, 1996; } \\
\text { Schweigert \& Rowland, 1992; Sigafoos et al., 2008; Wolff Heller, et al., 1996) } \\
\text { Interventions improve the adult communication partner's communicative behavior } \\
\text { toward the individual with deafblindness. Partners are trained to be more attuned to } \\
\text { the communicative skills using systematic demonstrations and coaching, which } \\
\text { improves responsiveness and turn taking when communicating. Examples include: } \\
\text { the Contact Intervention Program and the Diagnostic Intervention Model (Bruce, 2002; } \\
\text { Bruce, 2007; Chen, Alsop, \& Minor, 2000; Janssen et al, 2003a, 2003b, 2004, 2006; } \\
\text { Janssen, Riksen-Walraven, van Dijk, Huisman, \& Ruijssenaars, 2011; Janssen, Riksen- } \\
\text { Walraven, van Dijk, Ruijssenaars, \& Vlaskamp, 2007; McLetchie \& Riggio, 1997). }\end{array}$ \\
\hline
\end{tabular}

(Table Continues) 


\section{Table 2 Continued}

Educational Practice

Adult communication partner interactions

Tangible representations and tactile approaches/strategies
Research Base

Interventions improve the adult communication partner's communicative behavior toward the individual with deafblindness. Partners are trained to be more attuned to the communicative skills through the use of systematic demonstrations and coaching, which improves responsiveness and turn taking when communicating. Examples include: the Contact Intervention Program and the Diagnostic Intervention Model (Bruce, 2002; Bruce, 2007; Chen, Alsop, \& Minor, 2000; Janssen et al, 2003a, 2003b, 2004, 2006; Janssen, Riksen-Walraven, van Dijk, Huisman, \& Ruijssenaars, 2011; Janssen, Riksen-Walraven, van Dijk, Ruijssenaars, \& Vlaskamp, 2007; McLetchie \& Riggio, 1997).

A form of expressive communication for children who are prelinguistic. When used to support receptive language, they are called tangible cues and can be two-dimensional (pictures) or three-dimensional (objects). Tactile approaches include sign language, object cues (a real object or part of the object that represents an activity, place, or routine), symbols with texture added to them, and touch cues (actions/symbols performed on the body that represent what is about to happen; Bruce, Trief, Cascella, 2011; Cascella, Trief, \& Bruce, 2012; Hartmann, 2012; Prickett \& Welch, 1998; Rowland, 1990; Rowland \& Schweigert, 1989, 2000; Trief, 2007, 2013; Trief, Bruce, \& Cascella, 2010; Trief, Bruce, Cascella, \& Ivy, 2009; Trief, Cascella, \& Bruce, 2013).

Note. $\mathrm{AT}=$ Assistive Technology. 
learners who are DB necessitates the need to break communication down to the most minute steps. Rowland and Schweigert (2000) suggested a sequence of communication development: (1) preintentional behavior (engaging in a behavior without the intent to communicate); (2) intentional behavior (non-communicative in nature such as picking up a favorite object without intending to communicate); (3) pre-symbolic, nonconventional communication (when a child uses nonconventional communication methods like babbling to obtain attention from another); (4) pre-symbolic, conventional communication (communicates to another using conventional communication methods such as pointing); (5) concrete tangible symbols (when a child uses an object to communicate); (6) use of single, abstract symbols; and (7) combinations of two-to-three abstract symbols. Knowing where a child is in the developmental communication sequence allows supports to be provided to best meet the child's communicative needs.

Any interventions or teaching methods chosen for use with learners who are DB should be embedded into each activity, administered in natural environments, and be included in social interactions (Ferrell et al., 2014; Goodall \& Everson, 1995; Luckner et al., 2016; MacFarland, 1995; McLetchie, 1995; Wheeler \& Griffin, 1997). In addition, any chosen approaches should attend to communicative form, function, mode, content, and context (Bashinski, 2011; Bruce, 2002; Crook, Miles, \& Riggio, 1999a, 1999b; Ferrell et al., 2014; McKenzie, 2009; Miller et al., 2011).

Child-guided practices. Child-guided methods (i.e., the van Dijk Curricular Approach) have been utilized to improve communication development (Ferrell et al., 2014; MacFarland, 1995). These strategies include (a) establishment of trust, (b) response to the interests and communicative attempts of the child, (c) use of the child's communicative forms, (d) selection of representations that are relevant to the child, (e) the use of different methods of interchange, and 
(f) the use of coactive practices (Crook et al., 1999b; Ferrell et al., 2014; Hodges, 2002; Janssen, Riksen-Walraven, \& van Dijk, 2002, 2003a, 2003b, 2004; MacFarland, 1995; Nelson, van Dijk, Oster, \& McDonnell, 2009; Olson, Miles, \& Riggio, 1999; Pease, 2002; Pittroff, 2011; Rödbroe \& Souriau, 1999; Silberman, Bruce, \& Nelson, 2004; Wheeler \& Griffin, 1997).

Bruce (2005) identified one child-guided approach as "distancing." Children who are DB exhibit a delay in distancing themselves from others, often viewing themselves as an extension of another person. Therefore, this method seeks to aid the learner in understanding that $\mathrm{s} / \mathrm{he}$ is a separate individual from his/her communicative partners. Strategies such as hand-under-hand exploration (with the child's hand on top of the adult's hand) are used to facilitate distancing. Hand-under-hand examination of objects assists the person with deafblindness to observe the totality of an object, select signals for recollection based on the child's most noteworthy observation to promote recall and understanding of that object, and provide models of play that are just beyond the child's current level of communication.

Systematic instruction. Systematic communication instruction has been shown effective in improving the frequency and variety of communicative intents expressed by children who are DB (Brady \& Bashinski, 2008; Heller, Ware, Allgood, \& Castelle, 1994; Schweigert \& Rowland, 1992; Sigafoos et al., 2008; Wolff Heller, Allgood, Ware, Arnold, \& Castelle, 1996; Wolff Heller, Allgood, Ware, \& Castelle, 1996). A variety of approaches have been utilized (e.g., an adapted version of prelinguistic milieu teaching, A-PMT, Brady \& Bashinski, 2008; and Treatment and Education of Autistic and related Communication-handicapped Children, TEACCH, Taylor \& Preece, 2010), however, most of the research focuses on tactile methods. Tactile methods. Tactile methods used to increase communication in learners who are DB include touch cues, tangible symbols, and even systems using adult communication partners. 
Touch cues are a tactile form of communication that uses minimal prompts to deliver visual, social, and environmental information in real time to individuals who are DB (Engleman, Griffin, \& Wheeler, 1998; Witkow, 2016) during the beginning phases of communicative development (Chen, Downing, \& Rodriguez-Gil, 2001). In the US, there are two primary systems currently employed (e.g., Haptic Communication and Back-Back Channeling), both of which were developed by individuals who were DB.

Haptics consist of a set of signals which are executed in a specified manner and distinct fashion to provide visual and environmental information in addition to social feedback. These signals are drawn onto the back or arm of an individual to provide a detailed visual interpretation of a conversation, giving the individual who is DB the same information someone with sight would receive. Conversely, Back-Back Channeling, while using touch in much the same way as Haptics, is not meant to be standardized, allowing communication partners to choose their own cues (Witkow, 2016). The meaning of each cue is dependent upon the context and situation and should be used for the same communicative purpose by all communication partners. For example, a tap on a child's head could mean "good job," "stand up," "stop," or "go." A child will not be able to ascertain the meaning of a touch cue if it is used for different communicative messages, there is competing tactile input, or if the child finds touch aversive. Furthermore, the use of touch cues should be used judiciously and in moderation to aid in the development of understanding to not confuse or overwhelm the individual (Chen et al., 2001). One way to initiate the use of touch cues is to establish a different cue for each member of a child's family. The cues would be used to alert the child to the presence of the family member when they enter as well as when they leave a room. 
Tangible symbols. Tangible symbols are a practical form of communication for children who are DB and are at the prelinguistic level of communication (Bruce, Trief, Cascella, 2011; Cascella, Trief, \& Bruce, 2012; Prickett \& Welch, 1998; Rowland, 1990; Rowland \& Schweigert, 1989, 2000; Trief, 2007, 2013; Trief, Bruce, \& Cascella, 2010; Trief, Bruce, Cascella, \& Ivy, 2009). These symbols may be three-dimensional (e.g., object symbols) or twodimensional (e.g., photographs). For example, a spoon could be used to represent breakfast, a book for story time, and a ball for play time. Of primary importance when using tangible symbols is that the symbol has meaning for the child. For instance, giving a rubber duck to a child to represent bath time when they do not play with this toy would have no meaning to the child, whereas providing a familiar washcloth to them may be much more meaningful based on their life experiences. When choosing tactile symbols, one must consider ease of recognition, the preferences of the child, ability to reduce the size of the symbols, and the texture of the symbols. The features mentioned in the previous sentence would ease discrimination when more than one symbol is presented. As the child associates the symbol or object with the activity, person, or expectation, it can be reduced in size and/or made more abstract. Finally, some work has focused on the use of an adapted form of Picture Exchange Communication System (PECS) used as tangible symbols with adults who were DB (Bracken \& Rohrer, 2013). However, the study participants did not implement Phase 1 with fidelity, therefore, the results were questionable (Bracken \& Rohrer, 2013).

Adult communication partners. There is a limited, though quickly-developing, research base for adult communication partners using systematic methods and coaching to improve responsiveness, turn taking, attunement, and other communicative skills of children who are DB (Janssen et al., 2003a, 2003b, 2004; Janssen, Riksen-Walraven, van Dijk, Huisman, \& 
Ruijssenaars, 2011; Janssen, Riksen-Walraven, van Dijk, Ruijssenaars, \& Vlaskamp, 2007). In a series of studies, Janssen et al. (2002, 2003a, 2003b, 2004, 2006) trained adult communication partners to respond more appropriately to the communicative behaviors of children who were DB to increase both interactive and independent communication skills. The researchers then added an interaction coach who provided consultation and supervision to the educators with a focus on building pleasant communication interactions between the child who was DB and his/her educator (2003a, 2003b, 2004, 2006). This was done by teaching the educators to recognize and attune to the child's communicative signals to adjust the interactions, when necessary, to encourage all positive communicative behaviors of the child (Janssen et al., 2006). Results from the studies indicated that both the students and the adult participants benefitted from the training and communicative interactions were enhanced.

\section{Assessment}

Research in the area of assessment for individuals who are DB is emerging. The most appropriate assessment approach for learners who are DB seems to be a dynamic approach, conducted by members of the IEP team. This approach is designed to provide authentic information about the learner's learning ability and processes, detailed cognitive features, and any other factors that affect the child's learning ability (e.g., motivational, emotional, physical; Assessment, n.d.). Additional information necessary when conducting assessments of children who are DB consists of medical information, functional vision and hearing evaluations, learning media assessment, and formal and informal assessments, where applicable. With this information, appropriate adaptations and accommodations for the child's visual, hearing, and tactile characteristics can be planned (Ferrell et al., 2014; McLetchie \& Riggio, 1997). Unfortunately, few assessments have been developed for individuals who are DB nor have 
existing assessments included norms for this population of learners (Ferrell et al., 2014).

Therefore, the use of standardized assessments (i.e., the Partnership for Assessment of Reading for College and Careers, Measures of Academic Progress, Wechsler Intelligence Scale for Children, Woodcock Johnson Test of Cognitive Abilities, etc.) often do not produce meaningful information regarding the cognitive functioning and skills of learners who are DB. More

research is necessary to adapt and provide norms for existing assessments as well as to ascertain the usefulness of existing formal assessments for this population.

\section{Assistive Technology}

For learners who are DB, assistive technology (AT) may be necessary to aid them in communication, O\&M, life skills, and participation in their educational environment. However, it is crucial that the selection of AT is informed and led by a thorough assessment and includes the objective of increasing the learner's access and engagement in their learning environment (Ferrell et al., 2014). AT can consist of both low tech (non-electronic devices such as a handheld magnifier) and high tech (cochlear implants, CI, have been identified by Dammeyer in 2009, a researcher in the field of deafblindness, as high tech AT in addition to AAC devices, computer aided programs, microtechnology, robots, videophone, and visual orientation systems) devices.

Low tech AT. Only one low tech device was identified in the literature (communication board; Heller et al., 1994; Wolff Heller, Allgood, Ware, Arnold, \& Castelle, 1996). The use of a communication board increased the system of communication for an individual with deafblindness so that a communication partner could interpret their communicative intent (Heller et al., 1994). In Heller and colleagues' study, two students used identical boards. The identical boards consisted of pictures that had been visually enhanced (one for the individual who was DB 
and one for the partner), vocabulary specific to the environment (i.e., job sites), and social content (i.e., conversation starters for peers). When the learner who was DB approached a communication partner, they handed one of the communication boards to the partner to initiate conversation. The partner then pointed to their board to say something to the individual who was DB and the person who was DB answered by pointing to an icon on their own board. Data indicated that this was a preferred mode of communication and increased turn taking and communication.

One other study (Wolff Heller, Allgood, Ware, \& Castelle, 1996) was conducted using dual communication boards. In this study, students used the communication boards to initiate requests for assistance. The students were given a communication board with the symbol "I need" and a specific referent on it to initiate requests. The data indicated an increase in requesting ability, but overall, the only time the student used the communication board was when s/he was requesting assistance.

High tech AT. The CI is one of the high tech devices that was identified through the literature, however, only one study documented it as such (Dammeyer, 2009). A CI is a small electronic device that is placed surgically and can provide a sense of sound to an individual who is deaf or hard of hearing (D/HH; Cochlear Implants, 2016). Dammeyer (2009) found that children who received a CI between the ages of 2.2 and 4.2 years experienced both heightened attention and emotional response as well as an improved use of objects when interacting with adults. Moreover, when the child who was DB used the CI, there was a significant impact on the child's social engagement. With increased social engagement, the child who is DB can build shared social meanings and communication, and more fully participate in their environment. This initial inquiry into the benefits of CI use with children with congenital deafblindness (CDB) 
indicates a positive effect and should be further investigated to continue to build the evidence base.

Other high tech devices used included AAC devices (Sigafoos et al., 2008), computer aided programs (Lancioni, Oliva, \& Bartolini, 1990; Lancioni, Oliva, Formica, \& Rossetti, 1988), microtechnologies (Schweigert \& Rowland, 1992), robots (Lancioni, Bellini, \& Oliva, 1993a, 1993b; Lancioni, Bellini, Oliva, Guzzini, \& Pirani, 1989), videophones (Emerson \& Bishop, 2012), braille note takers (Belanich, 1995), and visual orientation systems (Lancioni, Mantini, Cognini, \& Pirani, 1988). The AAC devices, microtechnologies, and videophone devices were used to increase communication, requesting, and/or make choices. Data from the studies indicated that these devices were effective in improving communication for individuals who were DB. The other high tech devices (computer aided programs, robots, and visual orientation systems) were used to improve mobility and/or engagement in an activity. Reported data indicated that participants could successfully use these devices to navigate their environment and more effectively participate in activities.

\section{Life Skills (Systematic Instruction)}

Systematic instruction in the area of life skills has a fairly strong evidence base to support its use to increase daily living skills (i.e., choice making, dressing, self-feeding, and toilet training) in learners who are DB (Lancioni et al., 1993a, 1993b; Lancioni et al., 1989; Lancioni et al., 1988; Lancioni et al., 1988). Exploration using systematic instruction with prompting and praise (Luiselli, 1988a; McKelvey, Sisson, Van Hasselt, \& Herson, 1992), reinforcers and interruption (Luiselli, 1988b; Luiselli, 1993), paired reinforcement and punishment (Lancioni, 1980), and chaining with tangible reinforcement resulted in success when teaching life skills to learners with deafblindness (Loumiet \& Levack, 1993; McKelvey, Sisson, Van Hasselt, \& 
Herson, 1992). Because individuals who are DB rarely learn skills through incidental learning, each skill must be broken into individual steps and taught systematically. The data obtained by various researchers indicated that each participant learned the targeted skill when systematic instruction was used with high levels of fidelity. Though these studies revealed positive results, there is a need for replication of the results to build the evidence base.

\section{Literacy}

Literacy has been traditionally defined as the ability to read and write (Literacy, 2016).

The contemporary definition of literacy is one that includes all learners (McKenzie \& Davidson, 2007; Miles, 2005), beginning at birth (Parker \& Pogrund, 2009), and perceives that learner differences influence the materials and media of literacy. Other definitions also include communication as complementary or a portion of literacy (McKenzie \& Davidson, 2007). New literacy is often described as that which uses technology (i.e., speech-generating devices;

Emerson \& Bishop, 2012). To assist in the understanding of the literary content, it is important that children who are DB participate in hands-on experiences (Miles, 2005) because they have few occasions to gain information by listening or observing others incidentally. While five articles were identified, only one included a study which utilized educational interventions to improve literacy (daily schedule, home-school journal, experiential based literacy, and childguided instruction; Bruce, Randall, \& Birge, 2008). Research has also shown that prelinguistic learners who are DB often experience the most literacy success with daily schedules (anticipation shelves or calendar systems; Blaha, 2001, 2002; Bruce et al., 2008), story boxes (assortments of items which relate to an experience or book), experience books (books detailing the learner's personal experiences which are co-constructed with the child; Bruce et al., 2008), authentic choice-making opportunities, and interactive home-school journals which represent 
important activities from the child's school day (Bruce \& Conlon, 2005; Ferrell et al., 2014;

Swanson, 2011).

\section{Science}

Regarding science instruction, only one peer-reviewed article was identified. Penrod, Haley, and Matheson (2005) suggested the use of a multisensory learning experience to instruct students with VI about environmental science. By providing this type of learning experience, the students were able to use the senses of hearing, taste, touch, and smell in an outdoor classroom to make connections between where they lived, their school, and the sites they visited. The use of multiple senses during the learning process was a beneficial opportunity that engaged the students more than the use of Braille, tactile maps, and models. While the authors of this study included information that could be applicable to students with deafblindness, the study focused on training teachers to use multisensory learning experiences in their teaching, not on the learner who was DB. Therefore, there is a drastic need for research in science relating to the education of students who are DB.

\section{Social-Emotional/Behavior}

Two primary lines of research have been conducted relative to social emotional skills and behavior in the field of deafblindness: function of the behavior (Durand \& Kishi, 1987;

Hartshorne, Hefner, \& Davenport, 2000; Janssen et al., 2004; Mirenda, 1997; Prickett \& Welch, 1998; Silberman et al., 2004) and the impact of deafblindness and the effects of etiology (the cause, or set of causes, of deafblindness) on behavior (Dammeyer, 2012; Hartshorne, 2011; Hartshorne et al., 2000; Hartshorne \& Cypher, 2004; Hartshorne, Nicholas, Grialou, \& Russ, 2007). Neither line of research has enough literature to meet the rigorous criteria for an EBP, but provides vital information for the field of deafblindness. 
Prior to selection of an intervention, it is imperative that both the impact of deafblindness and effects of etiology are considered. The research conducted along these lines provides a foundation from which educators can draw when seeking to identify appropriate interventions for learners who are DB. In fact, three articles (Hartshorne \& Cypher, 2004; Hartshorne et al., 2000; Hartshorne et al., 2007) identified behaviors associated with a specific genetic etiology of deafblindness, CHARGE Syndrome. Results from these studies indicated that individuals with CHARGE Syndrome typically presented with the following disorders most frequently: autism, attention deficit/hyperactivity disorder, obsessive-compulsive disorder, Tourette syndrome, and deafblindness (Hartshorne \& Cypher, 2004). Regarding aberrant behaviors, Hartshorne and Cypher (2004) reported that children who were DB displayed higher ratings on all challenging behaviors and the three most reported behaviors in children with CHARGE Syndrome were restricted range of interest, extreme preferences, and significant difficulty in establishing peer friendships. According to Hartshorne and colleagues (2000), behaviors exhibited by individuals with CHARGE syndrome were different than behaviors exhibited by individuals with other syndromes or etiologies of deafblindness. Furthermore, their behavior was dependent upon their environment, individual disabilities, and biobehavioral state. Finally, Hartshorne and colleagues (2007) used the Behavior Rating Inventory of Executive Function (BRIEF) to identify the presence of executive dysfunction in 98 children who were diagnosed with CHARGE and deafblindness. They reported that children with CHARGE Syndrome presented with substantial executive dysfunction. Specific problems displayed by the participants were inability to flexibly respond to situational demands, track self-behavior regarding tasks, and lack of impulse control and required termination of behaviors. Like the field of autism spectrum disorder (ASD), data obtained specifies the importance of identification of the function of a learner's behavior 
preceding the development of an intervention plan. Data obtained from a functional behavior assessment (FBA) identifies the importance and function of a learner's behavior preceding the development of an intervention plan. While this is an EBP in the field of ASD, the use of FBAs in deafblindness is still emerging.

Studies have also been conducted regarding the effectiveness of using behavioral principles (i.e., praise, token economies, overcorrection, differential reinforcement, and response blocking, Sisson et al., 1993; physical structure, schedules, work systems, and choice systems, Taylor \& Preece, 2010; reinforcement systems and contingency awareness, Yarnall \& DodgionEnsor, 1980). These behavioral methods have been used to decrease or eradicate stereotypies, self-injurious behavior, and aggression toward others. Three articles were identified (Sisson et al., 1993; Taylor \& Preece, 2010; Yarnall \& Dodgion-Ensor, 1980) which utilized behavior interventions with participants who were DB and had additional disabilities (i.e., intellectual disabilities, echolalia, and multiple disabilities). All researchers reported using multiple interventions simultaneously to address aberrant behavior, similar to the behavioral package from the field of autism. While the interventions used by each of the researchers were different, it is important to note that all participants benefitted from the use of combined interventions. Sisson and colleagues (1993) were the only researchers to document the use of one intervention with their participants prior to the addition of others. They reported that the sole use of differential reinforcement of behavior was ineffective, however, when other interventions were used collaboratively, aberrant behaviors were reduced and the participants could complete their work. 


\section{Transition}

There is a dearth of research in the area of transition for individuals who are DB resulting in a tenuous evidence base. The HKNC led a national transition project in the 1990 s which created comprehensive documentation of personal-futures planning (PFP), a type of personcentered planning (Marks \& Feeley, 1995; Taylor, 2007). PFP seeks to identify the strengths and needs of each individual who is DB to adequately and appropriately plan for supports necessary as the individual transitions from the education system into adult living (Everson, 1995; Malloy, McGinnity, Kenley, Vellia, \& Voelker, 2009; Nelson, 2005; Rachal, 1995; Rachal, Steveley, Goehl, \& Robertson, 2002). This is done through the creation of maps by a team working with the young adult who is DB (Ferrell et al., 2014). Generally, there are five different maps (i.e., background, people, places, preference, and images of the future) to create each individual profile. As the maps are completed, they are compiled and a "total picture" of the individual can be generated. The team is then able to observe the many aspects of the learner as they join to form a mutual understanding of that person and a shared vision for the learner's future.

Luft, Rumrill, Snyder, and Hennessey (2001) investigated the critical characteristics of individuals with deafblindness as they relate to education and vocation to provide support and assistance for more effective transitions for this population. They found that the most important considerations to consider for these young adults were distinctive learning challenges, assessment concerns, AT, and accommodations. Additionally, Hersh (2013) reported that barriers to communication and inadequate transition support negatively impacted the ability for individuals with deafblindness to successfully transition, resulting in struggles with isolation and depression. Overall, there is a vast shortage of research relating to transition for young adults who are DB. 


\section{Chapter Summary}

With the ever-changing population of individuals with deafblindness, service provision and educational practices have been compelled to evolve to meet the unique needs of these learners. Due to the wide dispersion and heterogeneity of the population coupled with the scarcity of highly trained professionals, there is a dearth of research to support administrative practices (including service provision) and the development of EBPs. This comprehensive review included a history of the field of DB education, services specific to DB education, and accepted educational practices (including communication, assessment, AT, systematic instruction in life skills, literacy, science, social/emotional behavior, and transition). The evidence base relative to DB education is limited. Very little literature focuses on the effectiveness or ineffectiveness of related services providers while the available literature regarding educational practices is variable, ranging from relatively strong (communication) to very limited (science). However, without the critical features necessary to meet the rigorous standards established for EBPs (operational definition of the practice and the context, fidelity of implementation, documentation of a functional relationship, and replication the effect over several studies; Horner, Carr, Halle, McGee, Odom, \& Wolery, 2005), there is a dire need for extended research in all areas related to deafblindness. With so little empirical research to guide practices and service provision, it would seem that the longitudinal educational trajectory of this population of students would vary greatly, depending upon the services provided and practices employed. As the field moves forward, researchers must focus their attention on building the evidence base to provide direction to professionals, thus improving education for all individuals with deafblindness. 


\section{CHAPTER II: ASSESSMENT OF STUDENTS WHO ARE DEAFBLIND}

This chapter presents information about assessment of students who are DB. Included in this chapter are descriptions of the definitions of deafblindness and difficulties associated with assessment of learners who are DB as well as general assessment guidelines to be used when completing assessments of learners who are DB. Both formal and informal assessment measures are discussed with an emphasis on the description of the Communication Matrix $(C M)$.

The quest to identify a comprehensive battery of appropriate assessment instruments for individuals who are DB is one that professionals who work with these learners must undertake. However, it is the lack of a unified definition of deafblindness that is the greatest impediment when developing suitable tests for this population (Aitken, 1995). Although the term "deafblind" implies a complete absence of both vision and hearing, this is not true for most individuals who are DB as most have some degree of useable hearing and/or vision. One way to view deafblindness is as if it were a spectrum (see Appendix A). Furthermore, there is a legal (29 U.S. Code $§ 1905)$ definition of deafblindness:

the term "individual who is deaf-blind" means any individual - (A) (i) who has a central visual acuity of 20/200 or less in the better eye with corrective lenses, or a field defect such that the peripheral diameter of visual field subtends an angular distance no greater than 20 degrees, or a progressive visual loss having a prognosis leading to one or both these conditions; (ii) who has a chronic hearing impairment so severe that most speech cannot be understood with optimum amplification, or a progressive hearing loss having a prognosis leading to this condition; and (iii) for whom the combination of impairments described in clauses (i) and (ii) cause extreme difficulty in attaining independence in daily life activities, achieving psychosocial adjustment, or obtaining a vocation; (B) who 
despite the inability to be measured accurately for hearing and vision loss due to cognitive or behavioral constraints, or both, can be determined through functional and performance assessment to have severe hearing and visual disabilities that cause extreme difficulty in attaining independence in daily life activities, achieving psychosocial adjustment, or obtaining vocational objectives; (C) meets such other requirements as the Secretary may prescribe by regulation (29 U.S. Code $\S 1905$ )

Alternatively, there is also an educational (IDEA 300.8(c)(2)) definition of deafblindness which is used:

Deaf-blindness means concomitant hearing and visual impairments, the combination of which causes such severe communication and other developmental and educational needs that they cannot be accommodated in special education programs solely for children with deafness or children with blindness (IDEA 300.8(c)(2))

This issue is further complicated by additional variables of etiology, symptomology, and time of onset. Deafblindness may be associated with several different genetic etiologies and encompass a wide range of severity of symptoms of the dual sensory loss. Further, individuals who are congenitally DB (CDB; born with both vision and hearing loss or, before the development of language, become deaf and blind; Dammeyer, 2014; Miles, 2008) and those who have acquired deafblindness (ADB; becoming deaf and blind after language has developed; Dammeyer, 2014; Miles, 2008) also may impact one's definition of DB and how to analyze assessment results. Therefore, the field remains divided and no consensus has been reached regarding one standard definition (Larsen \& Damen, 2014). In fact, much research in the field of deafblindness does not encompass individuals who have ADB together with those who have $\mathrm{CDB}$, but rather separates them due to the differences in the development of language and 
communication. Those with $\mathrm{CDB}$ are required to achieve developmental milestones without both senses, whereas those with ADB must work to maintain their language and communication skills (Dammeyer, 2014). When attempting to identify appropriate assessments, professionals must accurately determine the learners hearing and vision through functional and performance assessments (Probst \& Borders, 2016).

The process of assessment is used to make informed educational decisions. In special education, there are four main reasons for assessment: screening, determining eligibility, planning and placement, and evaluating student progress (Diebold, Curtis, \& DuBose, 1978; Lewis \& Russo, 1998). Unfortunately, the wide-scale assessments used in schools (e.g., the Partnership for Assessment of Reading for College and Careers, Measures of Academic Progress, Wechsler Intelligence Scale for Children, Woodcock Johnson Test of Cognitive Abilities, etc.) are often inappropriate for learners who are DB (Engleman, Griffin, Griffin, \& Maddox, 1999; Rönnberg \& Borg, 2001). With the highly heterogeneous nature of learners who are DB (relative to life experiences, differences in cognition due to degree of sensory impairment, and impact on development), comparable norms are difficult to obtain (Horvath, Kampfer-Bohach, \& Kearns, 2005; Sisson, Van Hasselt, \& Hersen, 1987). Some assessments created for children with either a vision or hearing impairment (HI) or for individuals with developmental disabilities may be marginally appropriate for use with students who are DB, and will likely require adaptations. Few assessments have been developed explicitly for learners who are $\mathrm{DB}$, nonetheless, the ones that exist are unlikely to have undergone comprehensive reliability or validity studies and usually do not include normative data for this population (Chen, Stillman, Mar, \& Rowland, 2009; Stillman \& Mar, 2009). However, there are some criterion-referenced assessments which can be used with this population of students (i.e., Callier-Azusa Scale, 
Communication Matrix, etc.). Assessment of children who are DB may be challenging, but there are ways to overcome these difficulties (Wolf-Schein \& Schein, 1998), primarily by using a team approach.

Because norm-referenced tests typically do not provide useful information for students who are DB (Engleman et al., 1999; Ferrell, Bruce, \& Luckner, 2014; Rönnberg \& Borg, 2001), evaluations must not be approached in the same way as for students with other disabilities (Crook, Miles, \& Riggio, 1999). Overall, the best assessment of an individual who is DB is one that should be approached cautiously, be multidimensional and ongoing, and be conducted by a team of individuals who are experienced in assessing learners who are DB (Crook et al., 1999; Engleman et al., 1999; Ferrell et al., 2014). Assessments should be conducted in a transdisciplinary manner (conducted by each member of the IEP team), in multiple environments (both at home and school), use a variety of different assessments (e.g., communication sampling, formal and informal assessments as appropriate, informal observations, criterion referenced checklists, and developmental scales; Engleman et al., 1999), and include the input from multiple adults familiar with and to the child (Chen et al., 2009; Ferrell et al., 2014; Holte et al., 2006;

McLetchie, 1993). Crook and colleagues (1999) report that there are many means of assessment, including direct (e.g., observations, testing the learner who is DB during interactions, play, conversations, or exploring) and indirect assessments (e.g., interviewing those who know the child well and reading reports).

\section{Assessment and the Individualized Education Plan Process}

A crucial part of the IEP process for learners with disabilities is the use of current assessment data. These data drive the creation of student-centered goals and objectives and provide the information necessary for the team to write precise present level of performance 
statements (McKenzie, 2009) and transition plans. Moreover, decisions regarding eligibility for service provision require current comprehensive assessment information (Lewis \& Russo, 1998). To identify appropriate eligibility, the assessment process is quite complex and must identify the primary areas for instruction and teaching strategies to be used, specific goals and objectives, professionals responsible for the implementation of the developed program, and methods of measuring educational success (Crook et al., 1999). It is the responsibility of the IEP team to determine and adequately justify any necessary accommodations to be used both in assessment as well as instruction, to allow the learner equitable access to the educational environment (Horvath et al., 2005).

\section{Assessment Difficulties Associated with Learners who are DB}

The assessment measures developed for learners who are DB rarely consider the limitations of this population of learners. Most tests involve the skills of comprehending spoken language, visual ability, the capability to respond either verbally or physically, or all three (Fewell, 1991; Finn \& Fewell, 1994). Professionals are forced to identify tests and techniques that can be used effectively with these children as they are the most difficult to test due to insufficiencies in both sensory channels as well as, in some instances, physical abilities (Finn \& Fewell, 1994).

During the assessment process, accommodations may need to be made for vision (e.g., Braille, large print, specific lighting), hearing (e.g., use of an interpreter, intervener, and amplification devices), and/or motor response (e.g., additional time, in-booklet responding, physical positioning). Making these accommodations could be a plausible solution for some students who are DB, however, for many of these students, traditional assessments remain inappropriate due to a lack of norms and sensitivity to cognitive and communication needs. 
Finally, some students may experience degenerative disorders related to vision and hearing that will require accommodations (Horvath et al., 2005). The heterogeneity within the population of learners who are DB provides an opportunity for professionals to contemplate the range of complexities and considerations that are essential to achieving valid learner participation, possibly requiring changes in the educational program (Horvath et al., 2005).

Often, assessments that have been developed for children without disabilities are utilized with learners who are DB to obtain data from standardized tests, however, these are unlikely appropriate because they have not been normed for this population. Consequently, the implication is that these learners are difficult to test, placing the blame on the learner or the professionals making the accommodations and not on the chosen assessment (Rowland, 2009). Other times, assessments employed are those that have been developed for individuals who are blind or deaf (i.e., Oregon Project for Visually Impaired and Blind Preschoolers or MeadowKendall Social/Emotional Assessment Inventory for Deaf Students), however, the information obtained is not directly compatible with the child's skills (Rönnberg \& Borg, 2001).

Although tools and measures have greatly improved over the past 25 years, the assessment of children who are DB has long been a concern for professionals in the field of deafblindness (Jones, 2002). The primary reason for the concern is because many learners who are $\mathrm{DB}$, despite their age, communicate at the sensorimotor stage (the first of the four stages of development in Piaget's (1964) theory of cognitive development when foundational communication skills are developed before oral expression is achieved). Many researchers suggest using a multidisciplinary evaluation team who can conduct various assessments including those which are norm and criterion-referenced, informal, observational, and nonintrusive (Crook et al., 1999; Jones, 2002; Wolf-Schein \& Schein, 1998). However, when using 
this type of process, it is important that the team conducting the assessment is familiar to the child who is DB and the assessment is being conducted in a familiar environment. These considerations can help ensure that the assessment will deliver an accurate picture of the child's skills. Furthermore, assessment results are dependent upon the child's mood or biobehavioral state and the child's relationship with the evaluator (Crook et al., 1999).

Behavior checklists are another data collection device used to measure the skills of the learner with deafblindness (Rönnberg \& Borg, 2001). There are various complications with using these checklists, the primary one being lack of quantification of the assessment. The American Association on Mental Deficiency Adaptive Behavior Scale (AAMD-ABS) has been used to control some of the problems with these checklists, however, often the data obtained from the use of checklists are not evaluated for reliability. Another way professionals have worked to overcome some of the problems is to use direct observation of learner behavior coupled with rating videotaped data (Wolf-Schein, 1993). The recommendation from researchers is to use combinations of these checklists, observations, standardized tests, and developmental scales to obtain the most comprehensive assessment of the skills of the learner who is DB (Rönnberg \& Borg, 2001).

\section{Evaluators}

It is imperative that individuals conducting assessments of learners who are DB have experience working with conducting evaluations with this population. They should be able to fluently use the communication mode understood and used by the learner (Crook et al., 1998). Children who are CDB experience serious delays in communication development, resulting in the inability to transition from intentional pre-symbolic communication to the higher forms of language development (Bruce, 2005). The development of higher forms of language (i.e., 
symbolic reference) is vital to both communication and cognitive development as they complement one another. It is important to understand the developmental sequence of communication so that instruction and assessment are aligned with the child's communicative readiness (Bruce, 2005). Without this knowledge and adequate experience with individuals who are DB, it is likely that the skills of the learner who uses non-traditional receptive and expressive communication (i.e., speech) will be underestimated. Finally, it is possible to overvalue a child's ability to understand manual language (i.e., sign language). The individual may be capable of discerning signed language, but unable to distinguish distinct pieces of the sign or signs (Blaha \& Carlson, 2007). Unfortunately, without knowledgeable evaluators conducting high quality assessments, decisions concerning educational programming choices will likely result in destructive impacts (i.e., lack of growth, regression, or slower growth) on the learning trajectory of the child (Crook et al., 1999).

As mentioned previously, any professional seeking to obtain the most comprehensive and meaningful information about the skills of learners who are DB should look to assessments conducted by a team of individuals. Further, at least one person on the team should be very familiar with the specific child who is being assessed (Nelson, van Dijk, McDonnell, \& Thompson, 2002) and should administer the assessment in the child's natural setting (i.e., home, familiar school environments, etc.; Trief, Cascella, \& Bruce, 2013).

\section{General Assessment Guidelines for Learners who are DB}

Before commencing an assessment of a learner who is DB, it is advantageous to collect all available information, including past educational records, medical reports, and reports of other diagnostic tests (see Figure 7; Crook et al., 1999). Medical records provide valuable information regarding the etiology of the child's sensory loss (Blaha \& Carlson, 2007). 
Knowing the etiology of the loss provides a critical foundation for assessment, accommodations and modifications, and program planning as etiology greatly impacts learner behavior and abilities as well as effective means of interaction (see Table 3 for an example of the impact of selected etiologies). Finally, knowing about any medical procedures and when they were delivered affords some understanding of possible obstacles to learning opportunities as well as access to learning environments, opportunities delivered, and the rate of development within the circumstances (Crook et al., 1999a, 1999b). Obtaining the age of onset of the learner's sensory disabilities (i.e., vision and hearing loss) informs the assessment team about the learner's access to visual and auditory information.

To ensure a comprehensive evaluation of the child's skills is completed, the following assessments should be conducted in addition to the information described previously (i.e., medical information, prior educational records, reports of other diagnostic tests)

- medical reports (i.e., vision and hearing tests; Dammeyer, 2010),

- functional vision assessment (FVA) including an appraisal of the student in all the skill areas at risk due to the presence of the VI (i.e., concept development and academic skills, communication skills, social-emotional skills, sensory-motor skills, and orientation and mobility skills (Dammeyer, 2010; Lewis \& Russo, 1998; McKenzie, 2009),

- functional hearing assessment/functional listening evaluation (FLE; Dammeyer, 2010; IDEA, 2004; Koenig \& Holbrook, 1995; McKenzie, 2007, 2009; McLetchie, 1993; Michael \& Paul, 1991),

- learning media assessment (LMA; Ferrell et al., 2014; McKenzie, 2007, 2009),

- expanded core curriculum assessment (ECC; McKenzie, 2009), 
- informal evaluative instruments and processes, including dynamic assessments and interviews of team members (e.g., family, interpreter, intervener, teacher, etc.) who are most familiar with the learner (Blaha \& Carlson, 2007; Chen et al., 2009; Eyre, 2002;

Holte et al., 2006; Nelson, Janssen, Oster, \& Jayaraman, 2010), and

- formal assessment instruments (e.g., state assessments). 


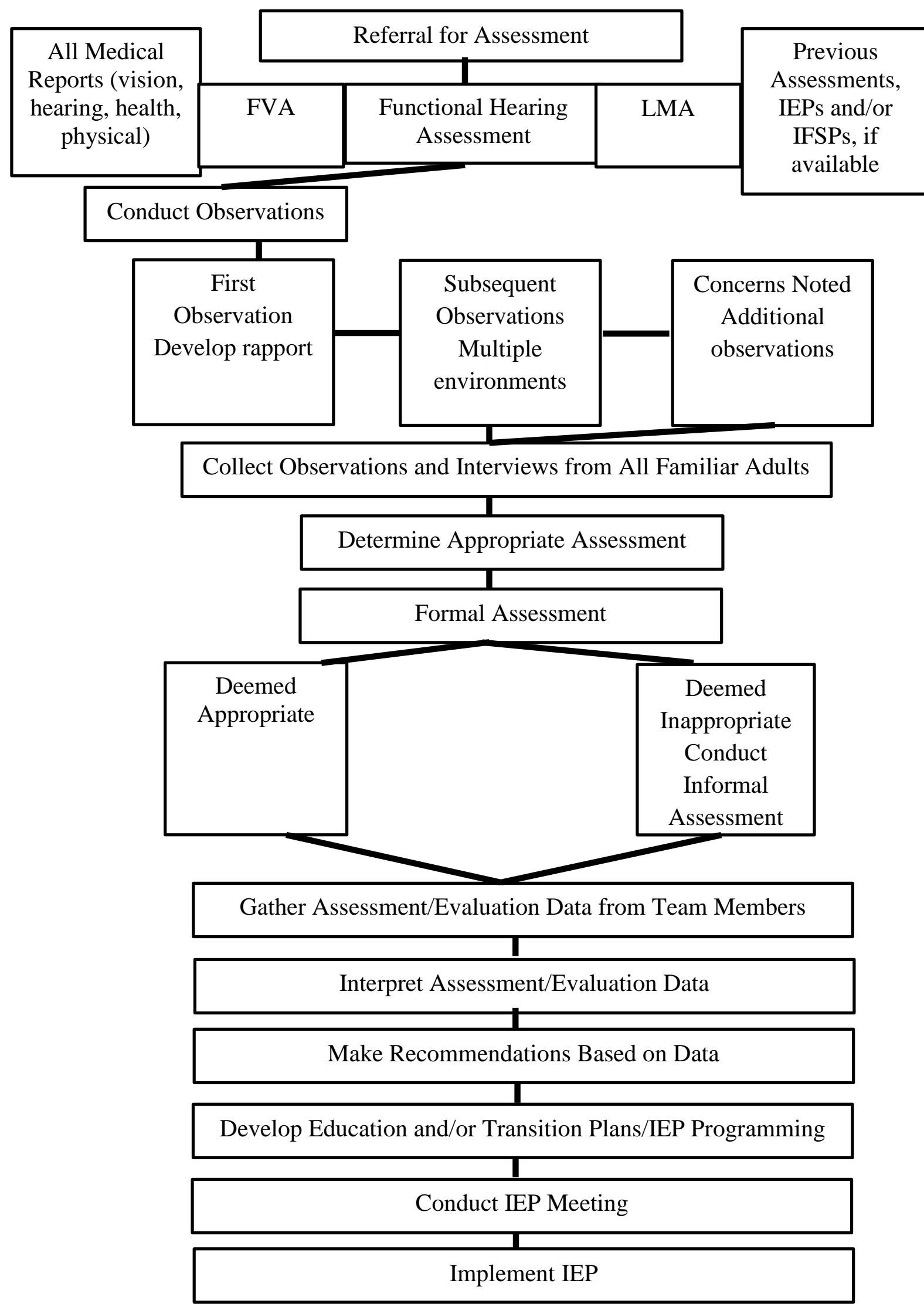

Figure 7. Flowchart of Assessment of Learners who are DB 
Table 3

Impact of Selected Etiologies

\begin{tabular}{|c|c|c|}
\hline Syndrome & Visual \& Auditory Impairments Possibly Present & Impact \\
\hline CHARGE Syndrome & $\begin{array}{l}\text { Coloboma (a hole in one of the eye structures, } \\
\text { i.e., iris, retina, choroid or optic disc) in one or } \\
\text { both eyes and microphthalmia (abnormally small } \\
\text { eyeballs). Other abnormalities that can be seen: } \\
\text { optic nerve hypoplasia (underdeveloped optic } \\
\text { nerve), cataracts, retinal detachment, nystagmus, } \\
\text { and disorders of refraction and ocular } \\
\text { movement. Typically, individuals have middle } \\
\text { and inner ear abnormalities and abnormally } \\
\text { shaped ears with mild to profound hearing loss } \\
\text { (CHARGE Syndrome, 2016). }\end{array}$ & $\begin{array}{l}\text { Vision and hearing loss remain throughout life. } \\
\text { Additionally, growth, development, cognitive } \\
\text { abilities, and psychomotor abilities are delayed. }\end{array}$ \\
\hline $\begin{array}{l}\text { Congenital Rubella } \\
\text { Syndrome }\end{array}$ & $\begin{array}{l}\text { Cataracts as well as sensorineural hearing loss in } \\
\text { one or both ears (Congenital rubella, 2015). }\end{array}$ & $\begin{array}{l}\text { Further conditions may develop such as: } \\
\text { glaucoma, retinal detachment, or cataracts. } \\
\text { Often, delays in all areas of functioning are } \\
\text { exhibited. }\end{array}$ \\
\hline Down Syndrome & $\begin{array}{l}\text { Eye abnormalities (Brushfield spots, eye shape } \\
\text { slanted, extra skin folds at inner corners of eye, } \\
\text { inflammation of eyelids), visual acuity } \\
\text { (nearsightedness or far-sightedness), strabismus } \\
\text { (eyes crossing), Keratoconus (cone-shaped } \\
\text { cornea), and cataracts. Hearing loss may be } \\
\text { present (Down Syndrome, 2016). }\end{array}$ & $\begin{array}{l}\text { Vision and hearing impairments may remain } \\
\text { present throughout life. Global developmental } \\
\text { delays may be present as well as behavioral } \\
\text { problems including attention, } \\
\text { obsessive/compulsive behavior, and } \\
\text { stubbornness (Down Syndrome, 2016). }\end{array}$ \\
\hline Goldenhar Syndrome & $\begin{array}{l}\text { Defects in the eyes and ears such as cysts on the } \\
\text { eyes, crossed eyes, missing eyelids, small ears, } \\
\text { missing ears, ear tags, or even hearing loss } \\
\text { (Ellis, 2013). }\end{array}$ & $\begin{array}{l}\text { Vision and hearing loss remain throughout life. } \\
\text { Other impacts include: feeding issues, breathing } \\
\text { problems, tumors of the eyes, and speech } \\
\text { development. }\end{array}$ \\
\hline
\end{tabular}

(Table Continues) 
Table 3 Continued

\begin{tabular}{|c|c|c|}
\hline Syndrome & Visual \& Auditory Impairments Possibly Present & Impact \\
\hline $\begin{array}{l}\text { Moebius } \\
\text { Syndrome }\end{array}$ & $\begin{array}{l}\text { Eyes may not look in the same direction, eyelids } \\
\text { may not close completely when blinking or } \\
\text { sleeping. Hearing loss is possible (Moebius } \\
\text { Syndrome, 2016). }\end{array}$ & $\begin{array}{l}\text { Some studies have proposed that individuals with } \\
\text { Moebius Syndrome also display characteristics of } \\
\text { ASD, however, recent studies have challenged this } \\
\text { association. }\end{array}$ \\
\hline $\begin{array}{l}\text { Oculo-auriculo- } \\
\text { vertebral Spectrum } \\
\text { (OAV) }\end{array}$ & $\begin{array}{l}\text { Abnormalities of the face, including the ears and } \\
\text { eyes. External ear may be smaller/absent, hearing } \\
\text { loss may be present, cysts of the eye, or colobomas } \\
\text { (Oculo-Auriculo-Vertebral Spectrum, 2016). }\end{array}$ & $\begin{array}{l}\text { Vision and hearing loss remain throughout life. } \\
\text { Cognitive abilities are often not affected. }\end{array}$ \\
\hline Stickler Syndrome & $\begin{array}{l}\text { Severe nearsightedness, increased pressure within } \\
\text { the eye (glaucoma), clouding of the lens of the } \\
\text { eyes (cataracts), tearing of the lining of the eye } \\
\text { (retinal detachment) and, in some, the clear gel that } \\
\text { fills the eyeball (the vitreous) has an abnormal } \\
\text { appearance. These eye abnormalities can cause } \\
\text { impaired vision or blindness in some cases. } \\
\text { Degree of hearing loss varies and could become } \\
\text { progressively worse over time (Stickler Syndrome, } \\
\text { 2016). }\end{array}$ & $\begin{array}{l}\text { Vision and hearing impairments remain present } \\
\text { throughout life, possibly becoming progressively } \\
\text { worse. Typically, intelligence is not affected by } \\
\text { this syndrome, however, due to comorbid vision } \\
\text { and hearing loss, individuals may develop learning } \\
\text { disabilities (National Organization for Rare } \\
\text { Disorders, 2015). }\end{array}$ \\
\hline Usher Syndrome & $\begin{array}{l}\text { Retinitis Pigmentosa abnormality of the cones and } \\
\text { rods in the eyes). Type 1: profound bilateral } \\
\text { deafness from birth and decreased night vision } \\
\text { before age } 10 \text {. Type } 2 \text { : Moderate to severe hearing } \\
\text { loss from birth, decreased night vision, beginning } \\
\text { in late childhood or teens. Tvpe } 3 \text {. Progressive }\end{array}$ & $\begin{array}{l}\text { Vision loss typically begins during adolescence or } \\
\text { early adulthood, beginning with night blindness } \\
\text { which progresses to tunnel vision. Blindness may } \\
\text { not occur until late adulthood. Many individuals } \\
\text { also have difficulty with balance. }\end{array}$ \\
\hline
\end{tabular}

(Table Continues) 
Table 3 Continued

\begin{tabular}{|c|c|c|}
\hline Syndrome & Visual \& Auditory Impairments Possibly Present & Impact \\
\hline $\begin{array}{l}\text { Waardenburg } \\
\text { Syndrome }\end{array}$ & $\begin{array}{l}\text { Primary sign of Type } 1 \text { is increased distance } \\
\text { between eyes, but normal visual acuity. Abnormal } \\
\text { iris coloration, drooping eyelids and cataracts may } \\
\text { be present and negatively impact vision. Often, } \\
\text { sensorineural deafness ranging in severity is present } \\
\text { and hearing loss may be progressive (Waardenburg } \\
\text { Syndrome, 2016). }\end{array}$ & Vision and hearing loss remain throughout life. \\
\hline
\end{tabular}




\section{Medical Vision Tests}

Medical vision tests provide educators information regarding the physical functioning of the eyes, an important first step when beginning the assessment process. According to Michael and Paul (1991), there are several medical tests which are non-conventional that may be used to assess a child's visual acuity if the individual is unable to respond to standard vision tests. Important to note is that these tests do not require a rigorous (or any) behavioral task. Some of these tests include the Visually Evoked Response (VER), also known as Visually Evoked Potential (VEP), Electroretinogram (ERG), Opkinetic Nystaqmx (OKN), Forced Preferential Looking Test (FPL), Operant Preferential Looking Test (OPL), and the Teller Acuity Card Technique (Teller, 1979; Teller, McDonald, Preston, Sebris, \& Dobson, 1986; See Table 4 for a description of medical vision tests).

\section{Table 4}

Medical Vision Tests

\begin{tabular}{|c|c|c|c|}
\hline Test & Age & Disabilities & Assesses \\
\hline VER/VEP & $\begin{array}{l}\text { Infants \& } \\
\text { Children }\end{array}$ & Intellectual Disabilities & Visual Acuity \\
\hline Electroretinogram (ERG) & All ages & N/A & $\begin{array}{l}\text { Retinal } \\
\text { Functioning }\end{array}$ \\
\hline Opkinetic Nystaqmx (OKN) & Infants & $\mathrm{N} / \mathrm{A}$ & $\begin{array}{l}\text { Acuity } \\
\text { Threshold, } \\
\text { Visual } \\
\text { Fixation }\end{array}$ \\
\hline $\begin{array}{l}\text { Forced Preferential Looking Test } \\
\text { (FPL) }\end{array}$ & $0-6$ months & "Difficult to Test" Infants & $\begin{array}{l}\text { Preferential } \\
\text { Looking }\end{array}$ \\
\hline $\begin{array}{l}\text { Operant Preferential Looking Test } \\
\text { (OPL) }\end{array}$ & $\begin{array}{l}\text { Infants } \\
\text { older than } \\
6 \text { months }\end{array}$ & $\begin{array}{l}\text { N/A, but has produced } \\
\text { positive results with those } \\
\text { with multiple disabilities }\end{array}$ & Fixation \\
\hline Teller Acuity Card Technique & $0-3$ & $\begin{array}{l}\text { Normed on children without } \\
\text { disabilities, but used } \\
\text { effectively with those with } \\
\text { developmental delays }\end{array}$ & Visual Acuity \\
\hline
\end{tabular}




\section{Medical Hearing Tests}

Durkel (2010) explains that there are two main types of audiological tests: physiological and behavioral tests. Physiological tests describe how the auditory structure is functioning and do not require active participation from the individual being tested (McKenzie, 2009).

Physiological tests are comprised of the auditory brainstem response testing (ABR), otoacoustic emission audiometry (OAE), and tympanometry. While medical personnel use the results to make inferences about the way one uses auditory cues, there is no way for them to know conclusively.

Behavioral tests use pure tones, controlled for pitch and volume, produced by a machine and require the participation of the individual being tested (Durkel, 2010; Michael \& Paul, 1991). Pure tone tests produce results that are a good foundation for professionals to use to predict hearing functioning. The tones can be delivered either through the air (headphones or speakers) or through bone conduction (a vibrator is positioned on the head). By using the different methods, medical professionals can evaluate which part of the auditory system is impacted. However, speech may also be used to determine how loud speech sounds should be for the individual to perceive, identify (using 2-syllable words), and discriminate (Durkel, 2010) sound. This last type of behavioral test is not usually used with leaners who are DB because it is the most difficult, requiring the individual being tested to repeat, write, or point to pictures of words. Michael and Paul (1991) posit that many children who are DB do not have the requisite cooperative and receptive language skills to participate in behavioral testing and that effective assessments pair visual/tactile with auditory stimuli, and then fade them to ascertain the level of auditory response. 
Michael and Paul (1991) outline some hearing tests which can be adapted for individuals who have VI. Visual Reinforcement Audiometry (VRA) can be adapted by the inclusion of vibrotactile reinforcement (Michael \& Paul, 1991; Spradlin, 1985). The Tangible Reinforcement Operant Conditioning Audiometry (TROCA) can be used to teach children to respond to stimuli before formal audiological assessments are conducted. Further, children under one year of age are considered difficult to test, therefore, standard immittance audiometry (i.e., tympanometry, or when air pressure is used to identify middle ear disorders and acoustic reflex threshold measurement) is not feasible; however, a practice identified as acoustic otoscopy or acoustic reflectometry (a device used to detect middle ear fluid which results in decreased hearing ability; Teele \& Teele, 1984) can be used. Finally, ABR and OAE assessments are used in place of behavioral tests for these children.

\section{Functional Vision Assessment}

To identify appropriate adaptations and accommodations for learners who are DB, the visual, hearing, and tactile features of present and prospective environments should be evaluated (McLetchie \& Riggio, 1997; Olson, Miles, \& Riggio, 1999). The FVA was created to assess the visual behavior of the learner rather than simply the physical condition of the eyes. This type of test, often administered by the teacher of the visually impaired (TVI), assesses the ability to visually track objects, use visual fields, eye-hand coordination, and other visual development functions (Michael \& Paul, 1991). Because a VI has such influence on the development of other skills, the assessment process must include an FVA for students who have any useable vision. It is essential that a learner with low visual functioning be defined as precisely as possible before other assessments are administered (Lewis \& Russo, 1998). 
There are times when learners with some vision utilize clinic-based low vision services. One of the amenities at these clinics is vision assessment. Unfortunately, the assessments conducted by low vision clinics often do not consider the cognitive level, mode of communication, motor delays, behavioral issues, and/or other conditions associated with the dual diagnoses (low vision and hearing loss). The outcome of such examinations may be insufficient or produce erroneous information about the learner's visual abilities (Miller \& Peck, 1995). When at a clinic, the learner is not in his/her natural setting which could also negatively impact the vision evaluation. An FVA, conducted in various natural settings, will provide critical information for the assessment process, therefore, the report obtained from a low vision clinic can be used as supplemental, but should not be relied upon as a true test of the learner's functional vision skills (McKenzie, 2009).

\section{Functional Hearing Tests/Functional Listening Evaluation}

Functional hearing tests, also called functional listening evaluations (FLEs) are designed to obtain information regarding how an individual uses hearing across environments. They are used to identify the best supports for the individual to both aid in and improve the use of auditory information (Durkel, 2010). These evaluations are completed via observation and are supported by the information gained from formal auditory tests. FLEs include presenting a variety of auditory stimuli to learners while keeping a record of changes in their behavior, thus providing critical information about how well the learners use their residual hearing (Erber, 1982; Michael $\&$ Paul, 1991). Teachers assess the general functioning of the learner, responses to auditory information, patterns of responses to stimuli, and how the child uses the auditory information (Durkel, 2010). Using the information obtained from the FLE, the team can determine next steps both in assessment as well as educational placement/programming, interventions, and teaching 
strategies. Furthermore, TODs use FLEs to assess student response to hearing assistive technology (conducted with a sound field versus personal frequency modulation systems, cochlear implants, or hearing aids alone) and to ascertain necessary ear-specific information.

\section{Learning Media Assessment}

The LMA is "an objective process of systematically selecting learning media and literacy media; this assessment process guides the educational team in making deliberate and informed decisions on the total range of instructional media needed to facilitate learning" (Koenig \& Holbrook, 1995, p. 2). Moreover, it is ongoing and completed annually (informally) and formally every three years (McKenzie, 2009). The central objective of an LMA is to determine a student's preferred use of sensory channels, general learning media (visual, tactile, or auditory), and literacy media (print, braille, or print and braille). IDEA 2004 specifies in Section 614

(3)(B)(iii) that braille instruction must be provided for all children who are blind or VI unless the IEP team concludes, after an evaluation of the needs of the child, that the braille instruction and use is not suitable. In fact, the LMA is the only evaluative tool that reports the unique literacy media requirements of learners who are DB (McKenzie, 2009).

\section{Expanded Core Curriculum (ECC)}

To improve a learner's independence and preparedness for life after school, it is important to evaluate all areas of functioning. As such, professionals in the field of low vision and blindness as well as deafblindness recommend assessing a student's ECC skills. The ECC encompasses skills beyond literacy and mathematics. There are nine skill areas included in ECC for learners who are DB: compensatory/functional skills, sensory efficiency, orientation and mobility, social interaction skills, assistive technology, independent living skills, recreation and leisure skills, career education, and self-determination. There are few evaluative tools available 
for learners who are DB. One resource, Evals: Evaluating Visually Impaired Students, developed by Texas School for the Blind and Visually Impaired, may be useful for this population (Dignan, n.d.), however, no data exists to verify its use. Evals targets the ECC by evaluating a student's compensatory/access skills, abacus/counting methods, beginning concepts, braille skills, handwriting, Nemeth Code knowledge, organizational skills, slate and stylus knowledge, study skills, and tactile graphic skills for math.

\section{Informal Assessments}

Five informal assessments were identified for use with DB students: Assessment of Deafblind Access to Manual Language Systems (ADAMLS), Dimensions of Communication, HomeTalk: A Family Assessment of Children Who Are Deafblind, Basic Skills and Infused Skills Assessment, and School Inventory of Problem Solving Skills (SIPSS) and Home Inventory of Problem Solving Skills (HIPSS). Of these informal assessments, four are checklists (i.e., ADAMLS, Holistic Communication Profile, HomeTalk, and Basic Skills) which are completed with input from the learner, individuals who are familiar with the learner, observations, and information gleaned from medical reports, FVA, FHA, and LMA. The SIPSS and HIPSS include direct observation using objects to evaluate the child's achievement of sensory motor skills to describe development relative to problem solving.

\section{Formal Assessment Instruments}

There are several formal assessment instruments which have been used by professionals when attempting to ascertain functioning levels of learners who are DB. While these assessments are used, only a few of them were developed for use with individuals who are DB (i.e., Callier-Azusa Scales G and H). Some formal assessment instruments may be appropriate for a portion of the population of learners who are $\mathrm{DB}$, however, with the high percentage of 
learners who have multiple disabilities including cognitive impairment, these formal assessments often do not include norms for this population and may not be sensitive enough to adequately measure these learners' skills.

\section{Formalized Assessments for Individuals who are DB}

To fully employ the kinds of educational interventions and instructional practices that will produce the best results for learners with multiple disabilities, a variety of assessments should be conducted to evaluate the students' strengths and educational needs (Lewis \& Russo, 1998), however, the assessments currently available seldom target a specific age group, and many are used for individuals of all ages. To qualify for special education services, students are provided a primary label and are eligible for all special education and related services that may be required. It is important to consider this when working with students who have multiple disabilities as all areas of disability should be comprehensively assessed, including any possible unique needs associated with the specific etiologies and disabilities. It is the role of the team to determine the range of assessments based on all information obtained from both formal (assessments that have data supporting the conclusions of the test, referred to as standardized measures) and informal assessments (measures that are content and performance driven; Lewis \& Russo, 1998) as well as any adaptations and modifications that should be applied since the tests typically do not include norming samples for learners who are DB (See Table 5 for formal assessments). Any assessment chosen must match the purpose of the evaluation. When examining overall achievement, most professionals use formal or standardized assessments to compare the learner's performance or identify analogous strengths and weaknesses with their peers. While this is useful for many students, not all assessments have been standardized, as is the case for learners who are DB. However, an attempt to administer standardized assessments 
must still be made to officially rule out the appropriateness of their use for each individual student. Finally, if standardized assessments are found to be inappropriate for a student, a statement indicating why this data was excluded must be present in the final assessment report.

According to the 2014 Deaf-Blind Child Count, when considering learners who were at the age or grade level for which state assessments are administered, $42 \%$ of the DB learners were participating in statewide assessments (Schalock, 2015). No description of the adaptations needed for the statewide assessments was provided, but typical accommodations would include, at minimum, those recommended for individuals with VI and those with HI (i.e., interpreter, extended time, breaks, small group administration, audio amplification, visual aids, large print or braille, text-to-speech programs, scribe, etc.). Although these learners participated in statewide assessments, it is imperative that educators employed a variety of assessment tools to obtain comprehensive information about the student's abilities since standardized assessments do not target daily living skills, transition, social skills, and other compensatory skills necessary for learners with a dual sensory loss. 
Table 5

Formal Assessment Tools

\begin{tabular}{|c|c|c|c|}
\hline Assessment & Age & Skills Assessed & Adaptations \\
\hline $\begin{array}{l}\text { Battelle } \\
\text { Developmental } \\
\text { Inventory }\end{array}$ & Birth-7.11 & $\begin{array}{l}\text { Early childhood developmental milestones } \\
\text { (Cognitive, Communication, Motor, } \\
\text { Adaptive, and Personal-Social) }\end{array}$ & $\begin{array}{l}3 \text { items require vision, therefore, tactile } \\
\text { supports (e.g., enlargements, high } \\
\text { contrast, lights, raised line drawings, } \\
\text { magnifiers), may need an interpreter, } \\
\text { considerations for hearing loss (e.g., } \\
\text { louder, different frequencies), adapted } \\
\text { writing instruments, use of familiar } \\
\text { objects, however, some items cannot be } \\
\text { adapted for vision }\end{array}$ \\
\hline
\end{tabular}

\section{Brigance IED III Birth-7}

School readiness, learner's strengths and needs, plan individualized instruction, and monitor child progress in the following areas: physical development, language development (receptive and expressive), literacy, mathematics and science, daily living, and social/emotional development (Curriculum Associates, 2016)
Tactile supplements included, may need an interpreter, enlargements 
Table 5 Continued

\begin{tabular}{|c|c|c|c|}
\hline Assessment & Age & Skills Assessed & Adaptations \\
\hline $\begin{array}{l}\text { The Carolina } \\
\text { Curriculum }\end{array}$ & Birth-5 & $\begin{array}{l}26 \text { targeted developmental areas: visual } \\
\text { pursuit and object permanence; motor } \\
\text { and visual object permanence; auditory } \\
\text { localization and object permanence; } \\
\text { attention and memory; concept } \\
\text { development; understanding space; } \\
\text { functional use of objects and symbolic } \\
\text { play; problem solving; visual perception; } \\
\text { prevocabulary/vocabulary; imitation: } \\
\text { sound and gestures; responses to } \\
\text { communication; conversation skills; self- } \\
\text { direction; social skills; self-help skills; } \\
\text { fine motor skills; visual-motor skills: } \\
\text { pencil control and copying; gross motor } \\
\text { skills (Johnson-Martin, 1991) }\end{array}$ & $\begin{array}{l}\text { Tactile supplements appropriate for the } \\
\text { individual's vision loss (e.g., } \\
\text { enlargements, high contrast, lights, } \\
\text { raised line drawings, magnifiers), may } \\
\text { need an interpreter, considerations for } \\
\text { hearing loss (e.g., louder, different } \\
\text { frequencies), adapted writing } \\
\text { instruments, use of familiar objects }\end{array}$ \\
\hline $\begin{array}{l}\text { Hawaii Early Learning } \\
\text { Profile }\end{array}$ & $0-3$ & $\begin{array}{l}\text { Cognition and general knowledge, } \\
\text { approaches to learning, language and } \\
\text { literacy, social and emotional } \\
\text { development, and physical development } \\
\text { and health as well as an additional } 685 \\
\text { developmental skills and behaviors }\end{array}$ & $\begin{array}{l}\text { Tactile supplements appropriate for the } \\
\text { individual's vision loss (e.g., } \\
\text { enlargements, high contrast, lights, } \\
\text { raised line drawings, magnifiers), may } \\
\text { need an interpreter, considerations for } \\
\text { hearing loss (e.g., louder, different } \\
\text { frequencies), use of AAC devices to } \\
\text { assess conversation skills, adapted } \\
\text { writing instruments, use of familiar } \\
\text { objects }\end{array}$ \\
\hline
\end{tabular}

(Table Continues) 
Table 5 Continued

\begin{tabular}{|c|c|c|c|}
\hline Assessment & Age & Skills Assessed & Adaptations \\
\hline INSITE Developmental Checklist & $0-6$ & $\begin{array}{l}\text { A developmental checklist that assesses } \\
\text { gross motor, fine motor, self-help, } \\
\text { cognition, social, emotional, } \\
\text { communication, vision, auditory, and } \\
\text { tactile development (Morgan, 1989) }\end{array}$ & $\begin{array}{l}\text { N/A - checklist completed by } \\
\text { professionals and caregiver(s) }\end{array}$ \\
\hline The Oregon Project & $0-6$ & $\begin{array}{l}\text { Cognitive, language, compensatory, vision, } \\
\text { self-help, social, fine motor and gross } \\
\text { motor }\end{array}$ & $\begin{array}{l}\text { May need an interpreter, } \\
\text { considerations for hearing loss } \\
\text { (e.g., louder, different } \\
\text { frequencies), use of AAC devices } \\
\text { to assess conversation skills, use of } \\
\text { familiar objects }\end{array}$ \\
\hline $\begin{array}{l}\text { Test of Visual-Motor Perceptual } \\
\text { Skills (Non-Motor), Third Edition }\end{array}$ & $\begin{array}{l}4-12 \\
\text { years, } 11 \\
\text { months }\end{array}$ & $\begin{array}{l}\text { Visual-perceptual skills (visual acuity and } \\
\text { visual functioning) }\end{array}$ & $\begin{array}{l}\text { Appropriate for learners with } \\
\text { useable vision }\end{array}$ \\
\hline Communication Matrix & All ages & $\begin{array}{l}\text { Expressive functional communication } \\
\text { skills in social contexts }\end{array}$ & $\begin{array}{l}\text { N/A (developed for learners who } \\
\text { are DB) }\end{array}$ \\
\hline Callier-Azusa Scale G & All ages & $\begin{array}{l}\text { A comprehensive developmental behavior } \\
\text { checklist that assesses behavior by } \\
\text { observation of the child who is DB in the } \\
\text { classroom completed by professionals who } \\
\text { have extensive experience with the child }\end{array}$ & $\begin{array}{l}\text { N/A (developed for learners who } \\
\text { are DB) }\end{array}$ \\
\hline
\end{tabular}




\section{Table 5 Continued}

\begin{tabular}{|c|c|c|c|}
\hline Assessment & Age & Skills Assessed & Adaptations \\
\hline Callier-Azusa Scale H & All ages & $\begin{array}{l}\text { The scale compares the child to the } \\
\text { developmental sequence which would be } \\
\text { anticipated in children who are DB and } \\
\text { receiving appropriate interventions, not } \\
\text { to typically developing children } \\
\text { (Bennett, Hughes, \& Hughes, 1979). } \\
\text { This scale was intended to assess the } \\
\text { developmental level of an individual, } \\
\text { their progress over time, and also to } \\
\text { provide the teacher a template for } \\
\text { educational program planning (Bennett, } \\
\text { Hughes, \& Hughes, 1979; Stillman, } \\
\text { 1973, 1975) }\end{array}$ & $\begin{array}{l}\text { The test may be difficult to use with } \\
\text { children who have physical } \\
\text { impairments as there is an emphasis } \\
\text { on movement, and it is difficult to } \\
\text { use obtained results in educational } \\
\text { environments that do not use one-to- } \\
\text { one social-communicative } \\
\text { approaches (i.e., van Dijk; Rowland, } \\
\text { 2009), therefore, adaptations would } \\
\text { need to be made to address these } \\
\text { things }\end{array}$ \\
\hline $\begin{array}{l}\text { The Vineland Adaptive Behavior } \\
\text { Scales, Second Edition }\end{array}$ & All ages & Personal and social skills & $\begin{array}{l}\text { Tactile supplements appropriate for } \\
\text { the individual's vision loss (e.g., } \\
\text { enlargements, high contrast, lights, } \\
\text { raised line drawings, magnifiers), } \\
\text { may need an interpreter, } \\
\text { considerations for hearing loss (e.g., } \\
\text { louder, different frequencies), use of } \\
\text { AAC devices to assess conversation } \\
\text { skills, adapted writing instruments, } \\
\text { use of familiar objects (Sparrow, } \\
\text { Cicchetti, \& Balla, 2005; What is the } \\
\text { vineland test?, n.d.) }\end{array}$ \\
\hline
\end{tabular}

(Table Continues) 
Table 5 Continued

\begin{tabular}{|c|c|c|c|}
\hline Assessment & Age & Skills Assessed & Adaptations \\
\hline Woodcock-Johnson III & All ages & $\begin{array}{l}\text { Subtests include Letter Word } \\
\text { Recognition (Reading Recognition), } \\
\text { Passage Comprehension (Reading } \\
\text { Comprehension), Applied Math } \\
\text { (Math), Spelling and Academic } \\
\text { Knowledge (Science, Social Studies, } \\
\text { Humanities) }\end{array}$ & $\begin{array}{l}\text { Available in large print \& braille. } \\
\text { May need an interpreter, } \\
\text { considerations for hearing loss (e.g., } \\
\text { louder, different frequencies), use of } \\
\text { AAC devices to assess conversation } \\
\text { skills, adapted writing instruments, } \\
\text { use of familiar objects }\end{array}$ \\
\hline $\begin{array}{l}\text { Woodcock-Johnson III } \\
\text { Continued }\end{array}$ & & & $\begin{array}{l}\text { Use caution when using with younger } \\
\text { children and those with intellectual } \\
\text { disabilities as there are a limited } \\
\text { number of low-level items on some of } \\
\text { the subtests }\end{array}$ \\
\hline $\begin{array}{l}\text { Informal Assessment of } \\
\text { Development Skills }\end{array}$ & All ages & $\begin{array}{l}\text { Visual Functioning, Unique } \\
\text { Academic Needs, Orientation and } \\
\text { Mobility, Vocational Skills, and } \\
\text { Behavior }\end{array}$ & $\begin{array}{l}\text { Designed for children with VI, some } \\
\text { checklists require Braille reading. } \\
\text { May need an interpreter, } \\
\text { considerations for hearing loss (e.g., } \\
\text { louder, different frequencies), use of } \\
\text { AAC devices to assess conversation } \\
\text { skills, adapted writing instruments, } \\
\text { use of familiar objects }\end{array}$ \\
\hline
\end{tabular}


Additionally, the 2014 Child Count report noted that $90 \%$ of those counted had one or more additional disabilities and over $40 \%$ had four or more additional disabilities, indicating that the level of complexity in this population continues to grow as does the need for additional adaptations to existing assessments (Schalock, 2015). Due to the lack of norms or standardized tests for this population, it may be prudent to use alternative assessments in addition to a wide assortment of informal tools to adequately gauge student level of functioning. The more judicious approach may be a dynamic approach (set criterion, teach the skill and take data, compare data against the criterion).

\section{Alternative Assessments for Learners who are DB}

Alternative forms of assessments are used to evaluate the performance of learners who cannot successfully participate in standardized assessments even when provided accommodations (NCEO, 2016). They can be vital to procuring a comprehensive portfolio of the child who is DB (see Table 6 for informal assessment tools). The use of alternative assessments provides a procedure for educators of students with the most significant disabilities (including deafblindness) to obtain educational achievement and overall functioning levels for these students. There are alternative assessments for use within the educational accountability system (i.e., Alternate Assessments Based on Alternate Achievement Standards, AA-AAS; Alternate Assessment Based on Modified Academic Achievement Standards, AA-MAS; Alternate Assessments Based on Grade-Level Achievement Standards, AA-GLAS; Dynamic Learning Maps, DLM). The students who are eligible to participate in alternate state assessments are those who have the significant cognitive disabilities (i.e., below an IQ score of 55) and may be identified from an assortment of educational categories (i.e., cognitive impairment, multiple disabilities; ISBE, 2014). 
In addition to the educational alternate assessments, there are a variety of different behavior checklists as well as curriculum-based assessments (CBA), performance assessments, and authentic assessments. Performance assessments require a learner to do a task (including producing, demonstrating, performing, creating, showing, etc.; Taylor, 1997) whereas CBAs match the assessment items with the requirements of the classroom (i.e., tasks and skills; Silberman \& Brown, 1998). Authentic assessments are conducted by a multidimensional team and strive to describe the entirety of a child's cognition and behavior, understand the learner in the context of his/her natural environment (both social and physical), incorporate the family's and professionals' perceptions, and relate the evidence obtained to the child's development and acquisition of skills to encourage growth (Chen et al., 2009). While it is important for educational teams to use these types of alternative assessments to obtain data relative to the growth of a learner who is DB, there may be drawbacks with this type of information. Since the data is qualitative and subjective in nature and is often conducted by individuals not adequately trained in the implications of deafblindness, the reports from one year to the next may not accurately illustrate the learner's growth. Furthermore, team members often struggle to operationalize the skills they are seeking to measure and, without normative data, minute gains may be overlooked. 
Table 6

Informal Assessment Tools

\begin{tabular}{|c|c|c|c|}
\hline Instrument & Population & Format & Process \\
\hline $\begin{array}{l}\text { Assessment of } \\
\text { Deafblind } \\
\text { Access to } \\
\text { Manual } \\
\text { Language } \\
\text { Systems } \\
\text { (ADAMLS) }\end{array}$ & Deafblind & Checklist & $\begin{array}{l}\text { Educational teams compile medical reports (vision, hearing, health), } \\
\text { FVA, functional hearing assessments, LMA, and interviews of } \\
\text { individuals who have extensive knowledge of the abilities of the } \\
\text { learner and, if possible, the learner himself (for those learners who are } \\
\text { able to participate in an interview). Once this information is compiled, } \\
\text { the team can complete the ADAMLS forms which also contain } \\
\text { suggested adaptations and possible strategies (Blaha \& Carlson, 2007). }\end{array}$ \\
\hline
\end{tabular}

Dimensions of Learners with multiple

Communication disabilities, including deafblindness

Holistic Deafblind

Communication

Profile
Qualitative

When customary language tests are not appropriate (due to inability to measure alternative communication forms like gestures, vocalizations, or signs), this assessment may be useful as it provides a qualitative approach regarding an individual's communication behaviors when speech may or may not be present and links the results to interventions. This instrument is useful for children of all ages who have limited communication skills and directly links results with intervention (Mar \& Sall, 1999).

Checklist/

Profile
The four characteristics of communication (form, function, content, and context) are covered. Can be completed using knowledge of a child's daily communication, observations, and/or interviews of individuals who know the child well and gives the educational team a way to assess and record the learner's current communication skills as well as indicators of development in other areas which influence their communicative accomplishments. 
Table 6 Continued

\begin{tabular}{|c|c|c|c|}
\hline Instrument & Population & Format & Process \\
\hline $\begin{array}{l}\text { HomeTalk: A } \\
\text { Family } \\
\text { Assessment of } \\
\text { Children Who } \\
\text { Are Deafblind }\end{array}$ & Deafblind & Checklist & $\begin{array}{l}\text { Assessment involves families in the educational planning of their child } \\
\text { and provides a comprehensive depiction of the learner's skills, special } \\
\text { interests, and personality. There are four portions: Part } 1 \text { (basic } \\
\text { information); Part } 2 \text { (interests, talents, habits, routines, special needs, } \\
\text { and behaviors); Part } 3 \text { (social interaction, everyday problem solving, } \\
\text { exploring the environment, and discovery and learning); and Part } 4 \\
\text { (scores from the previous } 3 \text { portions are used as the parents and } \\
\text { professionals work together to plan educational goals and } \\
\text { programming; Harris, et al., 2003). }\end{array}$ \\
\hline $\begin{array}{l}\text { Basic Skills } \\
\text { Infused Skills } \\
\text { Assessment }\end{array}$ & $\begin{array}{l}\text { Learners with visual } \\
\text { impairments who may } \\
\text { also have additional } \\
\text { disabilities (cognitive } \\
\text { and/or behavioral) }\end{array}$ & Checklist & $\begin{array}{l}\text { Evaluation tool to explore the strengths and weaknesses of students, } \\
\text { beginning at a non-verbal skill level, progressing up to higher } \\
\text { cognitive functions. Divided into areas: social communicative } \\
\text { interactions, emotional development, senses/motor skills, basic } \\
\text { concepts, and representation and cognition. Each category contains a } \\
\text { skills list, organized in a developmental hierarchy, from lowest to } \\
\text { highest. Scoring consists of rating the student on three levels of } \\
\text { competency in the skill or that the learner has generalized the skill } \\
\text { (Hagood, 2006). }\end{array}$ \\
\hline $\begin{array}{l}\text { School } \\
\text { Inventory of } \\
\text { Problem } \\
\text { Solving Skills } \\
\text { (SIPSS) and } \\
\text { Home } \\
\text { Inventory of } \\
\text { Problem } \\
\text { Solving Skills }\end{array}$ & $\begin{array}{l}\text { Learners who are DB or } \\
\text { have severe disabilities }\end{array}$ & $\begin{array}{l}\text { Object based } \\
\text { assessment }\end{array}$ & $\begin{array}{l}\text { Assessment of cognitive skills related to object use in these children, } \\
\text { but not a measure of overall progress. Because the instrument uses } \\
\text { objects to evaluate the child's achievement of sensory motor skills, it } \\
\text { describes development relative to problem solving situations in a } \\
\text { classroom that a child would encounter be expected to become } \\
\text { proficient. Three sections permit credit to be given to a child whose } \\
\text { ability to perform skills has been hindered due to physical } \\
\text { impairments. Although the tests were developed for use with children } \\
\text { who are DB, some of the test items require cognitive skills of diverse } \\
\text { degrees or types (Rowland, 2009). }\end{array}$ \\
\hline
\end{tabular}




\section{The Communication Matrix}

The Communication Matrix $(C M)$ is one measure that has been developed to document communication development while emphasizing the functional use of communication (Rowland, 2012). The strong research basis of the $C M$ includes diverse methods of empirical study that are part of the rigorous research standards used to evaluate educational studies. The National Research Council (NRC) developed a set of guidelines addressing the rigor and trustworthiness of scientific evidence. The guidelines developed by the NRC to evaluate studies include internal validity, external validity, and generalization (Gast \& Ledford, 2014). To evaluate the $C M$, Rowland (2012) included evaluation of validity, reliability (including interrater and test-retest reliability), and sensitivity to change (due to child development over time). A construct validity study was conducted in 2011 which asked participants (ten national experts in the field of communication disorders in severe/multiple disabilities), via an anonymous online survey, to rate the intelligibility and applicability of each of the 24 items/questions on a 3 -point scale $(0=$ not at all clear/relevant to $3=$ very relevant/clear). The results of the survey (mean relevance score across items was 2.8 and the mean clarity score across items was 2.7) indicated a high level of both clarity and relevance of all items on the $C M$ (Rowland, 2012).

Rowland (2012) described the $C M$ as a tool used in direct observation situations as a behavioral inventory. Because of this, customary approximations of inter-rater reliability are problematic. However, a parent version of the $C M$ was created and, using the data from the parent version in conjunction with data from educators, reliability measures could be obtained. Reliability measures were conducted between parents and professionals and were analyzed using the Pearson's product-moment correlation between parent and professional scores for a sample of 19 children with diverse severe and multiple disabilities. The result was a correlation of .93 
( $p<.01,2$-tailed), which demonstrated an exceptionally high rate of agreement between two autonomous assessments of the same individual (Rowland, 2012).

Parker (2009a) conducted an additional statistical test of inter-rater reliability between professionals by evaluating inter-observer reliability on $C M$ scores across three children with VI and developmental disabilities using data gathered from videotapes and written data. Interobserver reliability between professionals was evaluated based on $C M$ scores obtained by viewing videotapes and written data. The results of this evaluation of inter-observer reliability was a mean agreement of $90 \%$. The test-retest reliability was evaluated between two and five weeks after the inter-observer reliability sessions and yielded an agreement of $89 \%$ on mastered skills within participants. Furthermore, an agreement of $83 \%$ on skills mastered between pairs of participants, based on scores across all 80 cells of the $C M$ profile, was obtained from a study of inter-rater reliability. In this study, a convenience sample of ten pairs of professionals (special educators or speech language pathologists) was recruited from local school districts and clinics (Rowland, 2012). The results generated an $89 \%$ agreement on mastered skills within participants, constructed by the scores for each of the cells on the $C M$ profile (Rowland, 2012). For this study, skills rated "mastered" and "surpassed" were grouped together and compared to the "not used" skills because, ultimately, it is the mastery of skills that is most desired.

The construct validity of the $C M$ has proven sensitive to development over time in children with severe communication disorders. Many studies have documented the usefulness of the $C M$ in identifying longitudinal gains in the communication skills of children with severe and multiple disabilities. The $C M$ is considered one of the best assessment tools to use with this population of learners due to the profound effects of deafblindness on communication and because of the lack of consideration of the vital incremental steps in pre-symbolic and symbolic 
communicative development. It is essential that assessments consider the steps of communicative development to accurately detail the gains of children who are DB since many of these learners function at the earliest stages of communication. It is imperative that the instrument(s) used correctly measure gains as learners who are DB follow an extremely slow pace (Rowland, 2012). Using an instrument as sensitive as the $C M$ can provide the detection of minute communicative gains that are necessary to professionals who are endeavoring to develop programs linking the use of appropriate assessment tools to improved outcomes for children who are DB (see Figure 8 for a $C M$ profile example). Due to the lack of communication skills assessments that cover the range of behaviors that are in the $C M$, significant comparisons to other instruments were not possible (Rowland, 2012). Other instruments that focus on assessing communication skills do not include alternatives to speech but rather emphasize speech; therefore, any comparison would be inappropriate and results from the other assessments would not be expected to be similar to $C M$ scores (Rowland, 2012). 


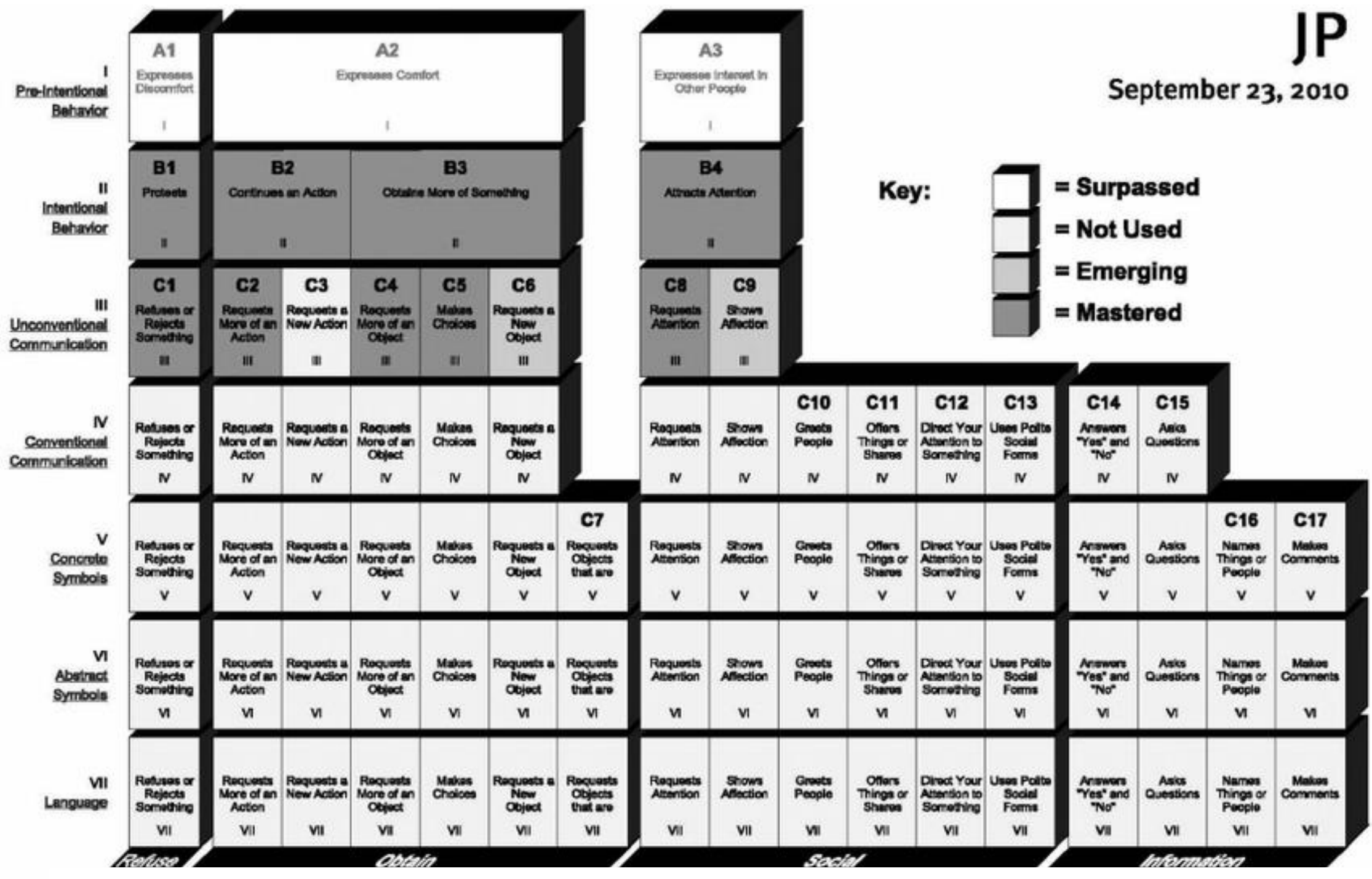

Figure 8. Example of Communication Matrix Profile 


\section{Chapter Summary}

Assessment of learners who are DB is a vast undertaking and involves many different data sources as well as team members. To obtain the most comprehensive information about a learner who is $\mathrm{DB}$, the team should use medical reports, ongoing functional data, functional assessments, interviews, formal assessment tools, and any informal assessment tools which may be applicable. In some cases, accommodations for vision and hearing (e.g., large print, magnifiers, Braille, sign language interpreters, interveners, etc.) will also be necessary. It is imperative that all assessments be chosen and administered in a child-directed and individualized manner so that the data acquired is valid and useful. It is only through the use of a variety of information sources that a comprehensive picture of the learner who is DB can be created and effectively used to plan educational programming. 


\section{CHAPTER III: METHODOLOGY}

This chapter includes the methods for this research study. To begin this chapter, the statement of the problem, a description of longitudinal growth modeling, and four studies that used growth modeling with participants who were hearing impaired are discussed. Next, the purpose of the study, research design, research participants and setting, and ethical considerations are detailed. Finally, independent and dependent variables, data collection and analysis procedures, and interobserver agreement procedures are presented.

\section{Problem Statement}

The field of DB education has a long and rich history which includes a lack of qualified personnel to meet the needs of the population of learners. In addition, the literature base is small, with limited evidence for effective practices or methods of assessing and tracking growth with these learners. The ability to adequately track student growth is key when IEP teams are making educational decisions. Therefore, it is important to investigate the longitudinal growth of learners who are DB and the possible effects of service provision (number, type, and intensity of services) on communication growth.

Since growth is a process, it is imperative that information gathered be more than a measure of the amount of change between indiscriminate points of time. Often, professionals seeking to measure growth examine data obtained from annual formal assessments.

Unfortunately, as discussed previously, many of the available formal assessments are unusable for this population of learners as they do not include underlying constructs or norms which apply to individuals with dual sensory loss. Without these, any data obtained has little meaning. Many previous studies regarding measurement of student growth describe the use of an 
assessment at one point in time with learners who are DB rather than measuring growth over time.

\section{Longitudinal Growth Modeling}

To account for developmental changes, growth modeling (GCM; also called Growth Curve Analysis, GCA) is an appropriate method to use as it uses repeated measures of data to capture complex inter- and intra-individual growth over time (Baer \& Schmitz, 2000; Curran, Obediat, \& Lossaro, 2010; Grilli \& Varriale, 2014; Ke \& Wang, 2015). To measure the change in the underlying variable across time, the analysis is designed to elucidate the correlation of the variables both within and across occurrences (Grilli \& Varriale, 2014). The goal of growth modeling is to both comprehend and envisage specific difference (or variability) in considerations which reflect change in outcomes over time and to "probabilistically assign individuals into subpopulations by inferring each individual's membership to latent classes from the growth model data" (Berlin, Parra, \& Williams, 2014; p. 191). Also included are random effects of change to grasp the longitudinal data, allowing for direct modeling of the changes in both intra-individual and inter-individual data (Ke \& Wang, 2015). By including the random effects of change, measures of individual differences are evaluated by assessing the variation to deduce whether the variance is significantly different (Ke \& Wang, 2015). Growth modeling measures also endeavor to estimate differences in change both between-person and withinperson. Frequently, the within-person patterns are considered time trends, time paths, growth curves, or latent trajectories (Curran et al., 2010). For a student who is DB, the variables examined could include estimated overall communication growth and the effect of the educational and related services received on communication growth. 


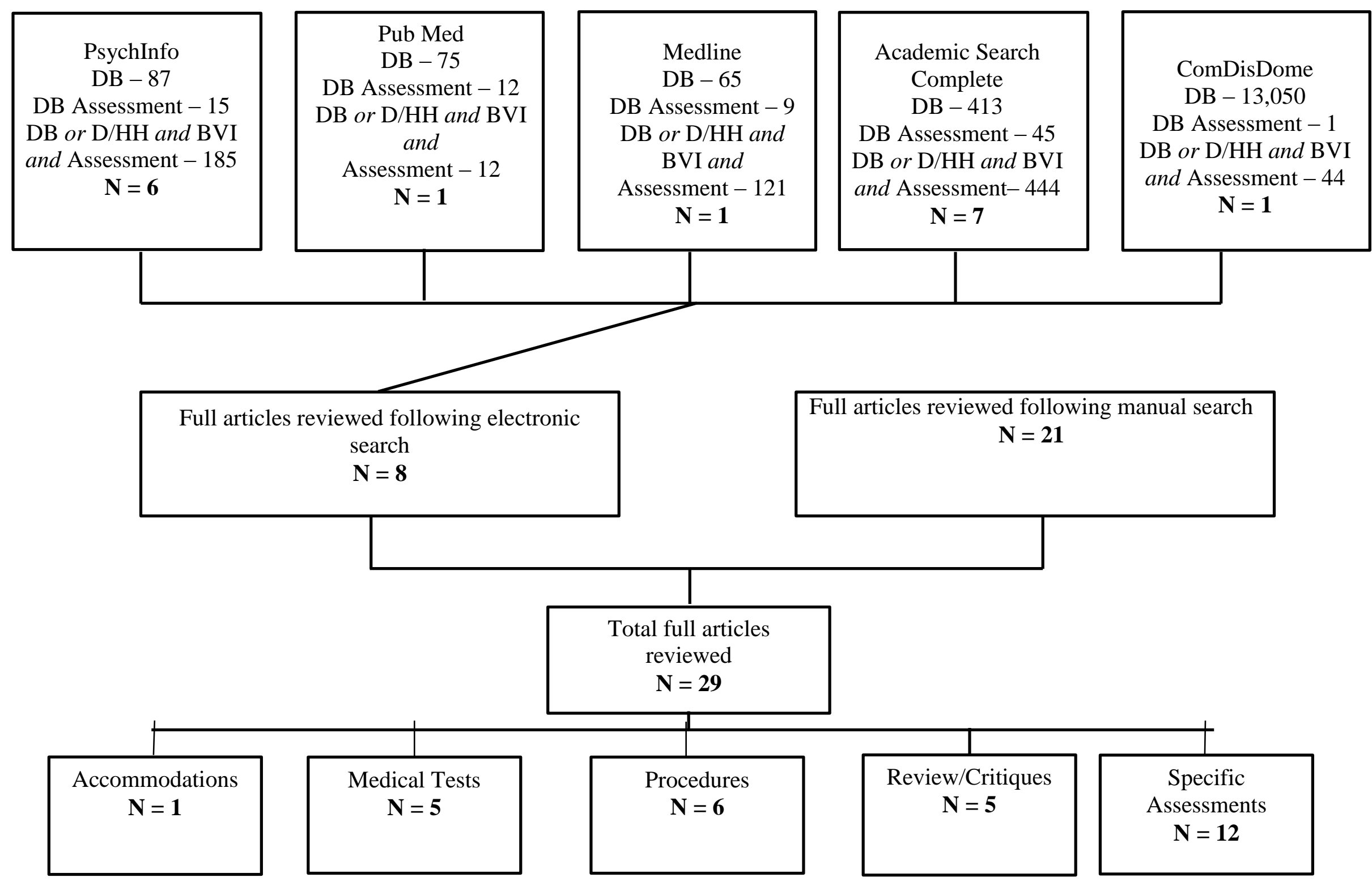

Figure 9. Flowchart of Assessment Literature Search by Database and Thematic Category. 


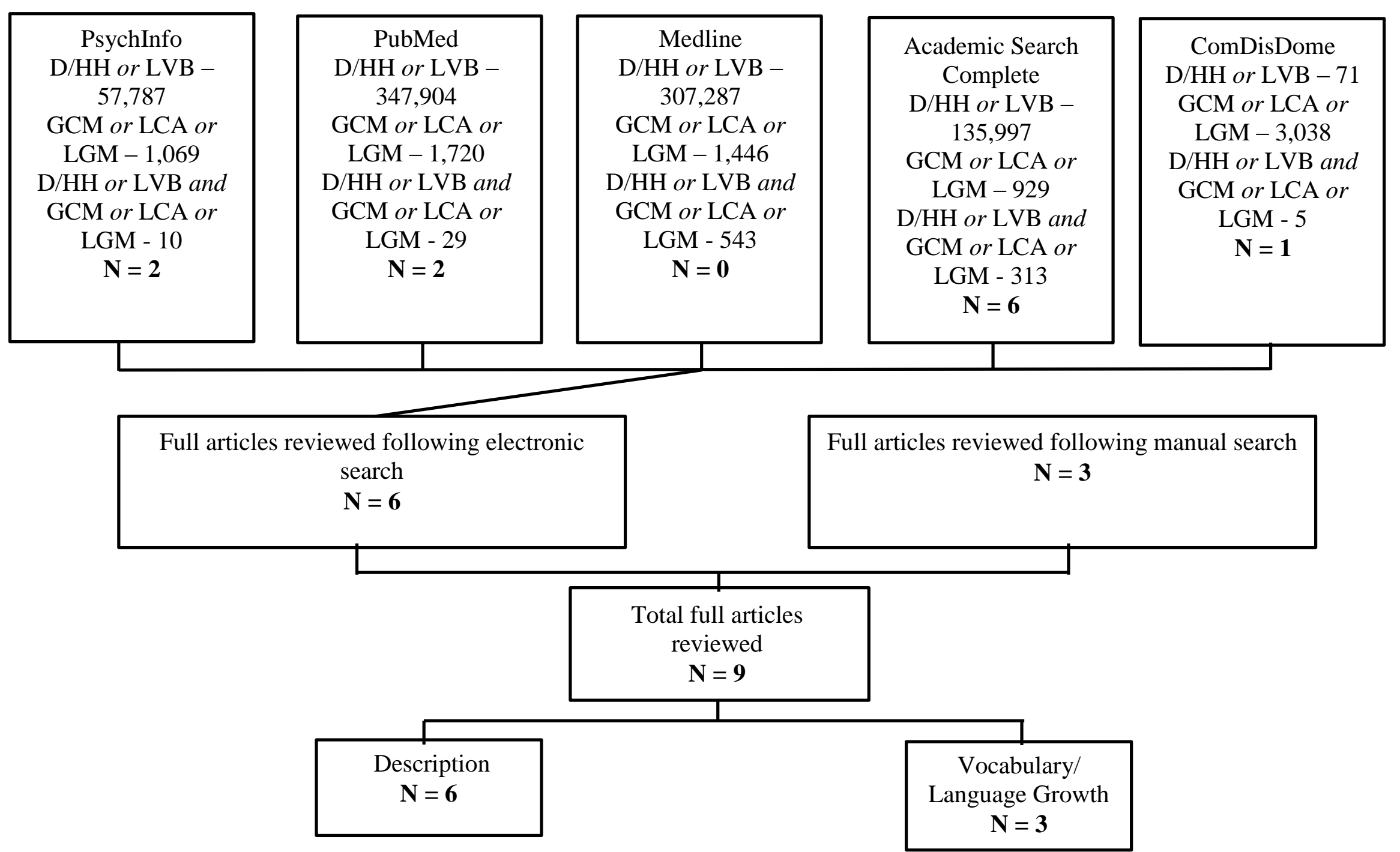

Figure 10. Flowchart of Growth Model Literature Search by Database and Thematic Category Relative to Growth Modeling.

GCM = Growth Curve Modeling; LCA = Latent Class Growth Analysis; LGM = Latent Growth Modeling; D/HH = deaf $/$ hard of hearing; LVB = low vision and blindness. 


\section{Studies Using Growth Modeling}

Studies were gleaned from the following databases: Google Scholar, PsychINFO, ERIC, and Academic Search Complete. Search terms included deaf-blind, deafblind*, dual-sensory impairment, growth curve model*, growth curve analysis, latent growth mixture model*, latent class growth analysis, deaf*, disabilities, and blind (see Figure 9 and Figure 10). To be considered for evaluation, the inclusion criteria for the studies were that they (1) were published in peer-reviewed journals, (2) were not dissertations, (3) included at least one or more persons with any disability as participants, (4) used growth curve statistical design to evaluate the data, and (5) were published in English.

Three studies were identified which used growth modeling to understand the growth trajectories (speech, Connor, Craig, Raudenbush, Heavner, \& Zwoland, 2006; vocabulary, Hayes, Geers, Trieman, \& Moog, 2007; and language, Jackson \& Schatschneider, 2014) of participants with low incidence disabilities (see Table 7). Since traditional statistical methods for exploring growth of individuals with low incidence disabilities have proven to be challenging, these studies opted for GCM to avoid the problem of violating the assumptions of traditional analysis of variance (i.e., that all participants were tested equally, at equal time intervals, and that each result is independent of prior test results). Because of this, these studies provided empirical evidence to support the use of GCM to measure the growth of individuals with low incidence disabilities and illustrated the importance of examining both the group and individual growth trajectories. Growth modeling was chosen for the analyses because it could (1) account for unequal group size, (2) make adjustments for missing data, (3) represent longitudinal data gathered across irregular interims, (4) allow representations of latent-growth curves and assist in analysis of the shapes of the growth curves, (5) support inspection of the learner characteristics 
that lead to both outcomes and latent-growth curves, and (6) enable association of the growth curves across the participants (Connor, Craig, Raudenbush, Heavner, \& Zwolan, 2006; Hayes,

Geers, Treiman, \& Moog, 2007; Jackson \& Schatschneider, 2014).

Table 7

Studies Using Growth Curve Modeling

\begin{tabular}{|c|c|c|c|c|}
\hline Author(s) & Participants & IV & $\mathrm{DV}$ & Findings \\
\hline $\begin{array}{l}\text { Connor, Craig, } \\
\text { Raudenbush, } \\
\text { Heavner, \& } \\
\text { Zwolan (2006) }\end{array}$ & $\begin{array}{l}100 \text { deaf children } \\
\text { with cochlear } \\
\text { implants }\end{array}$ & $\begin{array}{l}\text { Peabody } \\
\text { Picture } \\
\text { Vocabulary } \\
\text { Test-3 }\end{array}$ & $\begin{array}{l}\text { Speech and } \\
\text { language } \\
\text { outcomes } \\
\text { relative to age } \\
\text { at } \\
\text { implantation }\end{array}$ & $\begin{array}{l}\text { Children who received a CI } \\
\text { before the age of } 2.5 \text { years } \\
\text { displayed stronger outcomes, } \\
\text { exhibited early consonant } \\
\text { production accuracy and } \\
\text { vocabulary growth than those } \\
\text { who received their CI's at a } \\
\text { later age, indicating a } \\
\text { significant benefit to early } \\
\text { implantation. }\end{array}$ \\
\hline $\begin{array}{l}\text { Hayes, Geers, } \\
\text { Treiman, \& } \\
\text { Moog (2007) }\end{array}$ & $\begin{array}{l}65 \text { deaf children } \\
\text { with cochlear } \\
\text { implants }\end{array}$ & $\begin{array}{l}\text { Peabody } \\
\text { Picture } \\
\text { Vocabulary } \\
\text { Test } \\
\text { (repeated } \\
\text { measures) }\end{array}$ & $\begin{array}{l}\text { Children's } \\
\text { overall } \\
\text { abilities and } \\
\text { rates of } \\
\text { vocabulary } \\
\text { growth over } \\
\text { time }\end{array}$ & $\begin{array}{l}\text { Results indicated lower } \\
\text { vocabulary scores for deaf } \\
\text { children with CI's compared } \\
\text { with typically developing } \\
\text { peers, however, significant } \\
\text { vocabulary growth (more than } \\
\text { one year's worth of growth in } \\
\text { one year) was demonstrated. }\end{array}$ \\
\hline $\begin{array}{l}\text { Jackson \& } \\
\text { Schatschneider, } \\
2014\end{array}$ & $\begin{array}{l}24 \text { children with } \\
\text { hearing loss }\end{array}$ & $\begin{array}{l}\text { Auditory- } \\
\text { verbal } \\
\text { therapy } \\
\text { (AVT) }\end{array}$ & $\begin{array}{l}\text { Rate of } \\
\text { language } \\
\text { growth over } \\
\text { time }\end{array}$ & $\begin{array}{l}\text { Degree of hearing loss seemed } \\
\text { to contribute to the outcomes } \\
\text { of the AVT between children } \\
\text { with CI's and those with } \\
\text { hearing aides. Significant } \\
\text { variation of language outcomes } \\
\text { was observed for children } \\
\text { based on amount of time spent } \\
\text { receiving AVT, suggesting a } \\
\text { positive relationship between } \\
\text { the intervention and rate of } \\
\text { growth, however, the } \\
\text { individual data was variable. }\end{array}$ \\
\hline
\end{tabular}

Connor and colleagues (2006) conducted a study to examine the use and effects of a CI and the age at which the children received a CI on speech, language, and literacy of 100 deaf children. They used latent growth modeling to separate and determine the effects of 
developmental growth, length of CI use, and age at implantation on children's speech and vocabulary growth. They also explored additional significance (e.g., progress in speech and language skills gained over what could be explicated solely by length of device use) early implantation may afford.

Propensity scores (a balancing score: depending on the propensity score, the dispersal of observed baseline covariates will be comparable between treated and untreated subjects) were used to control for potential selection bias regarding age at implementation. Regression with age at implementation was computed (propensity) with the dependent/outcome variable as age at implantation. Additionally, the researchers used systematic variables that might influence age at implantation as the independent or predictor variables to make all comparison groups equal. In the regression model created, the following independent variables were included: year of birth, low versus middle socioeconomic status ( $\mathrm{LSES}=1 ; \mathrm{MSES}=0$ ), pre-implant hearing sensitivity measures (unaided binaural pure-tone thresholds, $\mathrm{dB}$ of hearing loss, HL), cause of deafness (unknown $=0$, familial $=1$ ), type of CI device (a series of counterfeit coded variables), and gender (girl $=1$, boy $=2$ ) (Connor et al., 2006). Further, all analyses included propensity scores to control for age-related variables.

Growth curves of children who used hearing aids pre-implant were estimated to envisage how they may have functioned over time without a CI. Data collected indicated that participants who received their CIs younger than 7 years of age displayed assessment scores (speech, language, and literacy) that grew more rapidly than those who received their CIs after 7 years of age. Moreover, the participants who were implanted younger than 7 years of age showed growth rates that were significantly greater than those older than 7 even after four years of using the CI, 
thus indicating that the change in growth rate for those in the younger than 7 group was maintained over time.

Similarly, Hayes and colleagues (2009) used growth modeling to examine the overall abilities and growth of receptive vocabulary in 65 children with CI's at a private, auditory-oral school. All children were implanted before the age of 5 years and received intensive auditoryoral instruction. Using repeated, annual measures of the Peabody Picture Vocabulary Test (PPVT) along with nonverbal intelligence scores (using a variety of assessments such as the Wechsler Intelligence Scale for Children-III; Weschler Preschool and Primary Scale of Intelligence-Revised III; and Central Institute for the Deaf Preschool Performance Scale), parental education, gender, year of implantation, and repeated observations, the researchers examined if the children's vocabulary changed over and which factors contributed to differences. The results indicated that the children's progress each year improved more than one standard deviation, which is a faster gain than what would be expected of hearing children with similar vocabulary levels. Additionally, the researchers found that learners who had received implants more recently obtained higher scores on their initial assessments than those who had been using their implants longer. The authors postulated that this difference was due to changes in the requirements for implantation which allowed children with more residual hearing to receive implants, an aspect which has been shown to affect language development. Finally, the variables of gender, nonverbal intelligence, and parental education did not prove to be significant predictors of vocabulary growth, but age at which the child received his/her CI did have a significant impact on both vocabulary growth and rate of skill acceleration.

Jackson and Schatschneider (2014) conducted a study with 24 child participants who had hearing loss (HL). While language outcomes are often examined, it has been difficult to predict 
children who are $\mathrm{D} / \mathrm{HH}$ 's rate of language progress, so the researchers utilized a linear growth model to approximate a mean growth curve and the degree of individual dissimilarity in language performance when using the Preschool Language Scale, 4th edition (PLS-4). The objective of their study was to chronicle children's receptivity to an auditory-verbal intervention approach in a private clinical program where the children received weekly auditory-verbal therapy (AVT).

The data for this study were amassed through a longitudinal review of records from a university clinic and was used to exemplify the expressive and receptive language growth trajectories of the children who participated in the program. Using a linear individual growth model, the study sought to estimate, at six-month intervals, the mean growth in spoken language and receptive aural comprehension and to inspect possible covariates contributing to individual differences in the degree of progress, including device use and duration of AVT. The growth model was employed as a way to approximate the amount of time in therapy with rate of change and individual participant predictors (i.e., sensory device usage). Furthermore, individual growth curve analyses using a mixed-modeling procedure (hierarchical linear modeling; HLM) were conducted to allow for variability within individuals and testing points. Random intercepts and slopes were used to predict mean growth curve, investigate individual growth differences, and overall level and growth. These predictors encompassed sensory device used and duration of treatment.

Although the goal of this study was to detail the findings of the program used rather than the effectiveness of the program, this article provided further support for the use of progress monitoring through GCM for both the individual child and groups of children. Results showed that, with time as a static effect, compelling differences in expressive language raw scores were 
observed for the group as a whole, indicating predictable growth in expressive language on the PLS-4.

The use of growth modeling to ascertain the evolution of children with disabilities has been shown to be a promising method. The use of GCM to measure individual differences and to estimate differences in change between participants has been successfully used with the aforementioned studies. Each study discussed used this type of statistical technique to map projected growth for the participants. Although none of the studies targeted participants who were DB, they were chosen as examples to provide clarification about potential use of GCM with participants who have dual diagnoses. Across the selected studies, participants were individuals with a low incidence disability, the population was heterogeneous, and each study needed a flexible analysis tool to account for variances (i.e., unequal numbers of observations and numbers of test data, differences in spacing of observations, etc.) which could be beneficial.

GCM has been chosen as the statistical method to be used in conjunction with assessment data obtained through the aforementioned guidelines to investigate the growth trajectory of this population of learners because it provides flexibility that other methodologies lack (allows for heterogeneity, variable numbers of data points, and the ability to capture the complex growth processes both intra- and inter-individually). Using the data provided by the $C M$ in addition to other variables obtained from a child's IEP (i.e., related services, number of minutes of service per week, placement setting), GCM seems to be a sensible choice of methodology for this study.

\section{Purpose Statement}

The purpose of this study was to explore differences in the number, type, and intensity of educational service provision and to track the longitudinal communication growth of students who were DB using the $C M$. 


\section{Research Questions}

Through this study, the following research questions were addressed:

1. Are there differences in the number of services provided to students who are DB?

2. Are there differences in the type of services provided to students who are DB?

3. Are there differences in the intensity of services provided to students who are DB?

4. What is the trajectory of communication growth over time as measured by the $C M$ for students with both deafness and visual impairment?

This study was significant because it provided educational personnel, researchers, and those working in teacher preparation programs guidance for monitoring the longitudinal communication growth of learners who are $\mathrm{DB}$ and for decision making regarding educational service provision. Moreover, findings may have implications for educational personnel (i.e., teachers, interveners, related service providers) training, professional development, and future research avenues. This study offered one promising assessment that could be used for tracking longitudinal communication growth for learners who are DB while beginning to elucidate the effect that service provision had on that growth. Results of this study provided insight to educational teams and researchers regarding the usefulness of the $C M$ and the statistical method of growth modeling with this population so that future research can further investigate their usefulness with a larger population of students who are DB.

\section{Hypotheses}

It was hypothesized that educational service provision would vary both inter-individually (i.e., from year to year) and intra-individually (across participants). Furthermore, it was hypothesized that the longitudinal communication growth of students who were DB would either decrease or remain stagnant when service provision (i.e., number, type, and intensity) was 
variable. Regarding growth modeling, there are some assumptions as well. One assumption is that the control variables do not display a systematic growth process. Another assumption that is made is that the guidelines that define growth across all participants are equivalent (Curran et al., 2010).

\section{Research Design}

The current study was exploratory in nature and utilized data collected from student individualized family service plans (IFSPs), IEPs, medical reports, and multi-factored evaluations (MFEs) in conjunction with scores from profiles created by the $C M$.

\section{Research Participants and Setting}

Data were collected through snowball sampling from individuals who responded to recruitment efforts through flyers, email blasts to professional organization listservs (i.e., American College Educators - Deaf/Hard of Hearing, ACE-DHH, the Division of Communication Disabilities and Deafness of the Council for Exceptional Children, DCDD-CEC, and Illinois Service Resource Center) and social media groups (Facebook), and email to administrators in programs known to educate students who are DB across the United States. Participation in the study was voluntary, and while information regarding disability label(s), educational services, and level of performance was collected, it was done only with the intent of using the information to investigate group differences. Research occurred in a self-selected location for the parent/guardians and/or teachers as they uploaded student data to REDCap (a national data repository with security features designed for clinical trial data and only individuals with the link could upload data) from either their classroom, office, or personal computer. All special education teachers were previously trained on ethics of data and confidentiality as part of their teacher training programs. 


\section{Target Population}

The target population of students for this study included individuals who met the diagnostic criteria for deafblindness or who met the diagnostic criteria for both D/HH and VI (VI is defined as having a vision loss of 20/200 or worse in the better eye; D/HH is determined by a documented hearing loss resulting in ongoing hearing services and continued hearing services as stated in the IEP; diagnosed or suspected ASD). Only parents or teachers of individuals who had CDB or prelinguistic vision and/or hearing loss were included as participants. Longitudinal data were collected from a total of 7 individuals from 5 different states (see Table 8 for a demographic description of the learners). 
Table 8

Demographic Description of Learners

\begin{tabular}{|c|c|c|c|c|c|c|c|c|}
\hline $\begin{array}{l}\text { Learner } \\
\text { ID }\end{array}$ & Gender & $\begin{array}{l}\text { Vision } \\
\text { Loss }\end{array}$ & $\begin{array}{l}\text { Hearing } \\
\text { Loss }\end{array}$ & Etiology & $\begin{array}{l}\text { Hearing } \\
\text { Device }\end{array}$ & $\begin{array}{l}\text { Visual } \\
\text { Aides }\end{array}$ & $\begin{array}{l}\text { Primary } \\
\text { Disability } \\
\text { Label }\end{array}$ & $\begin{array}{c}\text { Secondary } \\
\text { Disability Label }\end{array}$ \\
\hline Terry & Male & Unknown & $\begin{array}{l}\text { Moderate } \\
\text { to Profound }\end{array}$ & $\begin{array}{l}\text { DiGeorge } \\
\text { Syndrome, } \\
\text { CHARGE } \\
\text { Syndrome }\end{array}$ & $\begin{array}{l}\text { Hearing } \\
\text { Aides }\end{array}$ & Glasses & $\begin{array}{l}\text { Other Health } \\
\text { Impairment } \\
(\mathrm{OHI})\end{array}$ & $\begin{array}{l}\text { Multiple } \\
\text { Disabilities (MD) }\end{array}$ \\
\hline Steven & Male & $\begin{array}{l}\text { Cerebral } \\
\text { Visual } \\
\text { Impairment } \\
\text { (CVI) }\end{array}$ & $\begin{array}{l}\text { Cortical } \\
\text { Loss }\end{array}$ & $\begin{array}{l}\text { Encephalopathy, } \\
\text { Meningitis }\end{array}$ & None & None & MD & None \\
\hline Anna & Female & $\begin{array}{l}\text { "Legally } \\
\text { Blind" }\end{array}$ & $\begin{array}{l}\text { Moderate } \\
\text { to Severe }\end{array}$ & $\begin{array}{l}\text { Chromosome } 18 \\
\text { ring genetic } \\
\text { disorder }\end{array}$ & $\begin{array}{l}\text { Hearing } \\
\text { Aides }\end{array}$ & Glasses & MD & $\begin{array}{l}\text { Hearing } \\
\text { Impairment }(\mathrm{HI})\end{array}$ \\
\hline Ian & Male & CVI & $\begin{array}{l}\text { Mild to } \\
\text { Moderate- } \\
\text { Severe }\end{array}$ & Hydrocephalus & $\begin{array}{l}\text { Hearing } \\
\text { Aides }\end{array}$ & Glasses & Unknown & Unknown \\
\hline Lacy & Female & $\begin{array}{l}\text { "Legally } \\
\text { Blind" }\end{array}$ & $\begin{array}{l}\text { Severe or } \\
\text { Profound* }\end{array}$ & $\begin{array}{l}\text { Sclerocornea, } \\
\text { Corneal Opacity }\end{array}$ & $\begin{array}{l}\text { Cochlear } \\
\text { Implant }\end{array}$ & None & Deafblind & None \\
\hline Jack & Male & CVI & Profound & Meningitis, Stroke & $\begin{array}{l}\text { Cochlear } \\
\text { Implant }\end{array}$ & Glasses & $\mathrm{HI}$ & $\begin{array}{l}\text { Visual } \\
\text { Impairment (VI), } \\
\text { Speech Language } \\
\text { Disorder (SLD) }\end{array}$ \\
\hline Fiona & Female & $\begin{array}{l}\text { "Legally } \\
\text { Blind" }\end{array}$ & Profound & Albinism & $\begin{array}{l}\text { Cochlear } \\
\text { Implant }\end{array}$ & Glasses & $\mathrm{DD}$ & SLD \\
\hline
\end{tabular}

Note. Assumed hearing loss based on CI candidacy requirements. 


\section{Recruitment}

Phase 1. Recruitment began in January 2017 via a recruitment blast through professional organization listservs, social media groups, and emails to administrators. The recruitment email to administrators asked them to forward the email to TODs, TVIs, and any other teachers known to work with students who were DB and included contact information for interested teachers. Recruitment through Facebook posts and email blasts to parent organizations detailed the study and asked that interested parties contact the primary investigator.

Phase 2. Once contacted by interested teachers via email or phone, basic information about the study was conveyed to the participants and any questions the teachers had were answered. Teachers and parents were informed that they would receive in the mail two copies of an informed consent form (one for the teacher and one for the parent/guardian) and an addressed, stamped envelope for return of the signed forms.

Phase 3. Once the informed consent forms were returned, each parent/guardian and/or teacher was sent an email which included a link to allow upload of student files onto REDCap. Parents/teachers were further encouraged to send information to known individuals or schools that had programming for students who were DB for additional snowball sampling.

Phase 4. Teachers and parents/guardians were asked to work together to gather as many IEPs and evaluation reports as possible, scan the files, and upload them to REDCap. The files were examined and analyzed for demographic information; trends in the numbers, types, and intensities of educational services; and documentation of communication progress over time.

\section{Ethical Considerations}

The study adhered with federal ethics policy (Public Welfare Department of Human Health and Human Services, 2009). Informed consent was obtained for all adult participants and 
parents/guardians gave permission use minors extant data. Minors were not required to participate beyond the normal educational services they received per their existing IEPs. No modifications would be made to the child's program or IEP and therefore, the children were not consulted or considered direct participants. Administrators gave permission for teachers/parents to be contacted for research purposes prior to contact. Furthermore, all data from the IEPs, MFEs, and accompanying assessment reports were stored in REDCap, a web-based interface for data collection and storage that was password-protected, and backed up on a secure server nightly. When uploaded, the interface de-identified the data to maintain anonymity. Electronic data will be deleted from REDCap 5 years after dissemination.

Additionally, to address the risk of breach of confidentiality, all data from uploaded files were de-identified by REDCap and placed in a database for analyses. Files that were linked for analysis by any linking codes were kept in a separate, locked location from the data. Records of participation (i.e., consent forms and student records) will be maintained for at least five years after completion of this study. At which time, all documents will be shredded and/or deleted from computers. To address the risk of loss of time, participants were informed of the potential time it would take to gather requested information. The informed consent forms apprised participants of possible time lost and reminded participants that their participation was voluntary with the option to withdraw at any point during the study.

Although there was no direct benefit to the participants, this study focused on a highly under-researched group, learners who were DB. Because individuals who are DB comprise a small and highly heterogeneous population of learners, there are few studies available which provide guidance to educational teams regarding decision making for educational services or ways to accurately document communication growth. The potential for knowledge 
dissemination was considered abundant while the risks associated with this study were low. No direct benefit was gained by the participants and no tangible benefits were provided based on their participation in this study.

\section{Independent Variables}

For this study, there were three independent variables (IV): types of services, number of services, and intensity of services. Since service provision is dependent upon the IEP team and available services, each IV was variable both inter- and intra-individually. The only educational service that was consistently present across participants was special education teacher (SET). Other educational services provided to participants included: adaptive physical education (APE), audiology (Aud), nursing, occupational therapy (OT), physical therapy (PT), school health services (SHS), speech language pathology (SLP), teacher of the deaf (TOD), and teacher of the visually impaired (TVI).

\section{Dependent Variable}

Scores on $C M$ were the dependent variable for the study. Profiles were created from information obtained from the student's IEP and subsequently analyzed to obtain communication scores for the following categories: not used, emerging, mastered, and surpassed. To acquire a numerical score, the number of boxes in each color (white, not used; yellow, emerging; orange, mastered; and grey, surpassed) was divided by total number of boxes (e.g., emerging $=\frac{27}{80}=$ 34\%). Skills that were scored as "mastered" or "surpassed" were grouped together and compared to those that were "not used." As stated previously, this was done because once an individual has mastered the skill, the goal of acquiring that communication ability has been met. $C M$ profiles were further analyzed by level (pre-intentional behavior, intentional behavior, unconventional communication, conventional communication, concrete symbols, abstract 
symbols, and language). To obtain a numerical score for each level, the same formula was used for each category (dividing the number of boxes in each color by the total number of boxes in the level; e.g., mastered $=\frac{1}{14}=7 \%$ ).

\section{Data Analysis Procedures}

All data were placed in a database on REDCap and prepared for analysis. The database assigned a numeric value to each variable (primary disability label, educational services, and scores on the $C M$ ), including the amount of time (i.e., intensity and length) each educational service was received. A codebook was developed (see Appendix B) for the data as well. The codebook included coding rules and definitions for all dependent and independent variables as well as an in-depth explanation of how to score each item on the $C M$. A serial identifier was assigned to each participant and was used to track data. The database was exported to SPSS (IBM Corp., 2012) for analysis. Inferential statistics were used to test the hypothesis that service provision (length and intensity) would influence the longitudinal communication growth of individuals who were DB. Finally, descriptive statistics were used to examine the relationship between the IVs and DV.

The use of longitudinal growth modeling (LGM) to examine the communication growth of participants over time was the intended statistical measure for this study. LGM would describe trends and estimate differences in communication growth (both between-person and within-person) by examining the estimated overall communication growth as measured over time on the $C M$, and the effect of the number, type, and intensity of services received.

However, due to a limited number of participants and widely available data, LGM could not be used. Since it is unethical to change the planned methodology of the study to match the data obtained, LGM remained the chosen statistical methodology, nevertheless, in the end, the 
data required the use of descriptive statistics. Two groups of learners' (6-year-olds and 15-to-18year-olds) data were examined to determine the educational services provided (type, intensity, and duration) and their scores on the $C M$ were scrutinized to define means and standard deviations for each category. Case studies of two learners, Terry and Ian, whose data were truly longitudinal (spanning more than 15 years), providing the opportunity to examine $C M$ scores over time and educational service provision.

\section{Interobserver Agreement Procedures}

To assess agreement and ensure that the profile scores on the $C M$ were reliable, two reviewers used data from student longitudinal education files to construct profiles of $20 \%$ of randomly-selected files. Training was developed by the researcher and provided to the second observer to ensure consistency. Prior to an interobserver training meeting, both the researcher and the second observer thoroughly read the codebook created by the researcher and viewed training videos developed by the creators of the $C M$ (i.e., "The Basics," "Demographics and Screening Questions," and “Answer the Questions,” Rowland, 2017). Preceding the creation of any profiles on the $C M$, the researcher held a training meeting with the secondary observer to review the codes and administered a practice coding test which required a score of $80 \%$ or better. To participate in the training meeting, researchers were provided with binders which included the following information: a) information about REDCap; b) descriptions of hearing loss (degree, type, see Appendix B); c) Communication Matrix Manual and coding explanations (see Appendix C); d) sample IEPs for use during training; and e) practice test (see Appendix D) with sample IEP. The training meeting lasted two hours and included a review of binder content, hands-on training for both REDCap and $C M$, a PowerPoint presentation to review codes, and concluded with a practice coding test. Once the second observer passed the test and all data were 
uploaded, $20 \%$ of obtained files were randomly selected for interobserver agreement (IOA) procedures for baseline $C M$ profiles only. Because profiles created by the $C M$ are progressive and built upon one another, it is vital that the baseline profile is valid. For this reason, only baseline profiles were used for IOA measures. The IOA was computed by taking the number of agreements and dividing them by the total number of agreements plus disagreements then multiplied by 100 , allowing for a determination of the mean IOA percentage. If agreement fell below $80 \%$, the researchers met to carefully evaluate and discuss the discrepancy to resolve the incongruity. Overall IOA was $90.02 \%$ (see Table 9).

\section{Table 9}

Percentage of IOA Agreement Across Variables

\begin{tabular}{lccccc}
\hline \multicolumn{1}{c}{ Levels } & Not Used & Emerging & Mastered & Surpassed & Total \\
\hline Level 1 & 100 & 100 & 100 & 100 & 100 \\
Level 2 & 33 & 0 & 0 & 100 & 33.25 \\
Level 3 & 87.5 & 100 & 100 & 100 & 96.88 \\
Level 4 & 100 & 100 & 100 & 100 & 100 \\
Level 5 & 100 & 100 & 100 & 100 & 100 \\
Level 6 & 100 & 100 & 100 & 100 & 100 \\
Level 7 & 100 & 100 & 100 & 100 & 100 \\
TOTAL & 88.64 & 85.7 & 85.7 & 100 & 90.02 \\
\hline
\end{tabular}

As noted in the table, there was low IOA agreement for all Level Two scores. The disagreements were few and overall minor (see Table 10). 


\section{Table 10}

IOA Disagreement Scores by Category

\begin{tabular}{lcc}
\hline \multicolumn{1}{c}{ Skill } & $\begin{array}{c}\text { Researcher } \\
\text { Score }\end{array}$ & $\begin{array}{c}\text { Second } \\
\text { Observer } \\
\text { Score }\end{array}$ \\
\hline $\begin{array}{l}\text { Expresses Comfort } \\
\text { Expresses Interest in Other }\end{array}$ & Mastered & Emerging \\
$\begin{array}{l}\text { People } \\
\text { Continues Action }\end{array}$ & Emerging & Mastered \\
Obtains More of Something & Emerging & Not Used \\
Attracts Attention & Not Used & Mastered \\
Requests More Objects & Emerging & Not Used \\
\hline
\end{tabular}

When answering the questions on the $C M$, there is an additive effect; when a question is answered "no" instead of "yes" on each of the overall categories (A, B, and C), the program does not allow for recovery. Instead, that category is "closed," opening the next category, but not allowing for return to the prior category. To resolve the incongruity, the researcher and second observer met and discussed the scoring, coming to $100 \%$ agreement.

\section{Chapter Summary}

The purpose of this study was to investigate the type, duration, and intensity of educational services provided to learners who were DB as well to measure the longitudinal communication growth on the $C M$. To achieve this, data was collected from IFSPs, IEPs, medical reports, and MFEs in conjunction with scores from profiles created by the $C M$ to answer the four research questions. Data were collected from seven individuals during the spring and summer of 2017 using a survey format using the REDCap system. Because LGM could not be used, descriptive statistics were used to examine the data.

The learners in this study were divided into two groups (6-year-olds and 15-to-18-yearolds) and case studies were conducted on the two students whose data spanned more than 15 years. There was only one educational service that remained constantly present across all 
participants: SET. Eight other educational services were assigned to the participants' educational programs. These included: APE, Aud, nursing, OT, PT, SHS, SLP, TOD, and TVI. Results and analysis of the data is provided in the next chapter. 


\section{CHAPTER IV: ANALYSIS OF THE DATA}

This chapter contains a presentation of the results of this research study. The study examined the educational services (type, intensity, and duration) as well as the longitudinal communication growth of students who were deafblind (DB) to answer the following research questions:

1. Are there differences in the number of services provided to students who are DB?

2. Are there differences in the type of services provided to students who are DB?

3. Are there differences in the intensity of services provided to students who are DB?

4. What is the trajectory of communication growth over time as measured by the Communication Matrix $(C M)$ for students with both deafness and visual impairment?

\section{Number, Types, and Intensity of Educational Services Provided to Students who are DB}

Questions one, two, and three examined the number, type, and intensity of educational services provided to students who are DB. I was unable to answer these questions using the originally-planned quantitative method due to the limited and variable data obtained. To address these questions, I used descriptive statistics to examine the differences in the type, number, and intensity of educational services provided to students who were DB. Intensity of educational services provided to students who were DB was defined as the number of minutes per week the participant received the service. If an IEP did not delineate minutes per week of service provision, the number of minutes were divided by the number of school days (e.g., Example: North Carolina "Hearing Impaired Services” assigned as: 160 sessions/year calculated as

$\frac{160 \text { minutes }}{36 \text { weeks of school }}=4.44$ ). Because the data obtained was inconsistent across participants, no conclusive determinations could be made regarding differences in the type, number, and intensity of educational services provided to learners who were DB. The data obtained included IEPs that 
covered many different time spans and ages (see Table 11). Each document was examined for pertinent data (service provision and communication information) and included in the data representations. Therefore, service provision information was analyzed and compared relative to two different age groups: 6-year-olds and 15-18-year olds.

\section{Table 11}

IEP Years and Ages Represented Across Participants

\begin{tabular}{|c|c|c|c|}
\hline Participant & $\begin{array}{c}\text { IEP } \\
\text { Number }\end{array}$ & Year & Age \\
\hline \multirow[t]{17}{*}{ Terry } & 1 & 2000 & 2 \\
\hline & 2 & 2001 & 3 \\
\hline & 3 & 2002 & 4 \\
\hline & 4 & 2002 & 4 \\
\hline & 5 & 2002 & 4 \\
\hline & 6 & 2003 & 5 \\
\hline & 7 & 2003 & 5 \\
\hline & 8 & 2004 & 6 \\
\hline & 9 & 2004 & 6 \\
\hline & 10 & 2005 & 7 \\
\hline & 11 & 2009 & 11 \\
\hline & 12 & 2010 & 12 \\
\hline & 13 & 2011 & 13 \\
\hline & 14 & 2012 & 14 \\
\hline & 15 & 2014 & 16 \\
\hline & 16 & 2015 & 17 \\
\hline & 17 & 2016 & 18 \\
\hline \multirow[t]{3}{*}{ Steven } & 1 & 1996 & 5 \\
\hline & 2 & 1996 & 5.5 \\
\hline & 3 & 1997 & 6 \\
\hline \multirow[t]{4}{*}{ Anna } & 1 & 2014 & 14.5 \\
\hline & 2 & 2016 & 17 \\
\hline & 3 & 2017 & 17.5 \\
\hline & 4 & 2017 & 18 \\
\hline
\end{tabular}

(Table Continues) 


\section{Table 11 Continued}

\begin{tabular}{|c|c|c|c|}
\hline \multicolumn{4}{|c|}{ IEP } \\
\hline Participant & Number & Year & Age \\
\hline \multirow[t]{20}{*}{ Ian } & 1 & 1993 & 0.25 \\
\hline & 2 & 1994 & 1 \\
\hline & 3 & 1995 & 2 \\
\hline & 4 & 1996 & 3 \\
\hline & 5 & 1997 & 4 \\
\hline & 6 & 1998 & 5 \\
\hline & 7 & 1998 & 5.5 \\
\hline & 8 & 1999 & 6 \\
\hline & 9 & 2000 & 7 \\
\hline & 10 & 2002 & 9 \\
\hline & 11 & 2003 & 10 \\
\hline & 12 & 2004 & 11 \\
\hline & 13 & 2006 & 13 \\
\hline & 14 & 2007 & 14 \\
\hline & 15 & 2008 & 15 \\
\hline & 16 & 2011 & 18 \\
\hline & 17 & 2012 & 19 \\
\hline & 18 & 2012 & 19.5 \\
\hline & 19 & 2014 & 21 \\
\hline & 20 & 2015 & 21.75 \\
\hline \multirow[t]{6}{*}{ Lacy } & 1 & 2013 & 15 \\
\hline & 2 & 2014 & 15 \\
\hline & 3 & 2014 & 15.5 \\
\hline & 4 & 2014 & 15.75 \\
\hline & 5 & 2015 & 16 \\
\hline & 6 & 2016 & 17 \\
\hline \multirow[t]{7}{*}{ Jack } & 1 & 2009 & 2.75 \\
\hline & 2 & 2010 & 3 \\
\hline & 3 & 2011 & 5 \\
\hline & 4 & 2012 & 5.5 \\
\hline & 5 & 2012 & 6 \\
\hline & 6 & 2016 & 9.5 \\
\hline & 7 & 2017 & 11 \\
\hline
\end{tabular}




\section{Six-Year-Old Learners}

When examining IEP data for six-year-old learners $(n=4)$, a total of six different related services were provided (adaptive physical education, APE; occupational therapy, OT; physical therapy, PT; speech language pathology, SLP; Orientation and Mobility, O\&M; and Nursing, Nurs). This group of learners also received direct services which included Teacher of the Deaf (TOD), Teacher of the Visually Impaired (TVI), Special Education Teacher (SET), and Interpreter (Interp). While every learner received direct services from an SET, the intensity of this service varied across participants from 936 minutes per week to 2030 minutes per week. Overall, the educational service that was assigned the highest intensity was SET (see Figures 11, 12, and 13).

Regarding related services, the expectation is that this set of educational services would have less minutes assigned. All learners received SLP (with minutes per week ranging from 30 to 60), OT (minutes per week ranging from consultant to 40) and PT (minutes per week ranging from consultant to 30). Other services received by the 6-year-old group were: nursing, PT, and TOD. Services received by the 15-to-18-year-old group that were not consistent with those in the previous group were assistive technology (AT), individual aide (IA), career, and social work (SW). 
Figure 11. Related Service Provision Across Cases, 6-Year-Olds

\section{Ian}

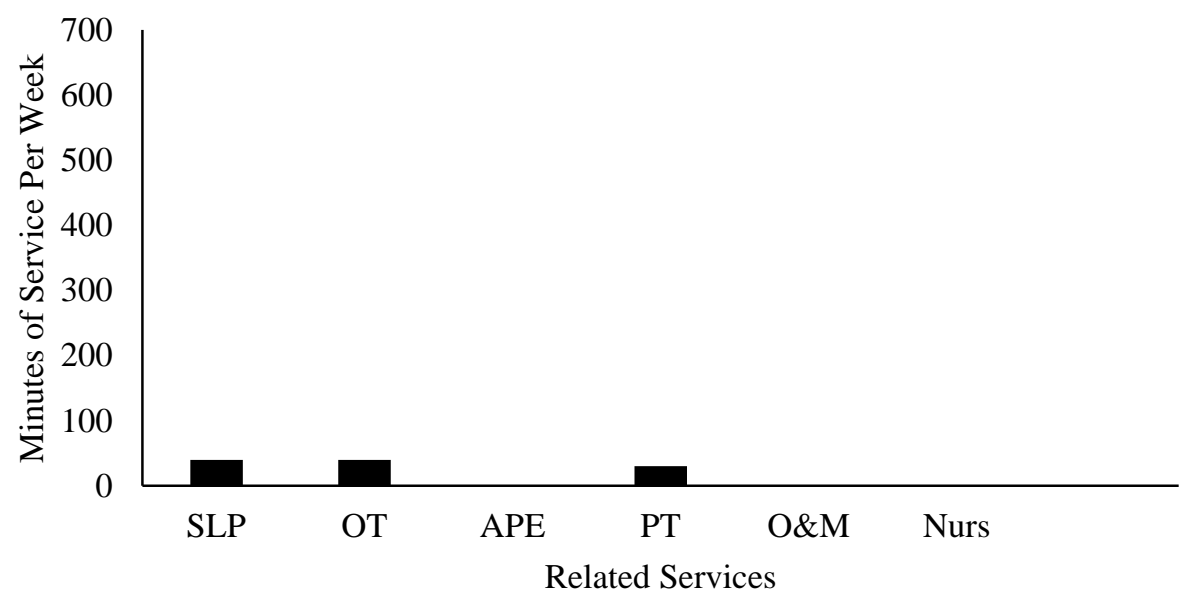

\section{Steven}

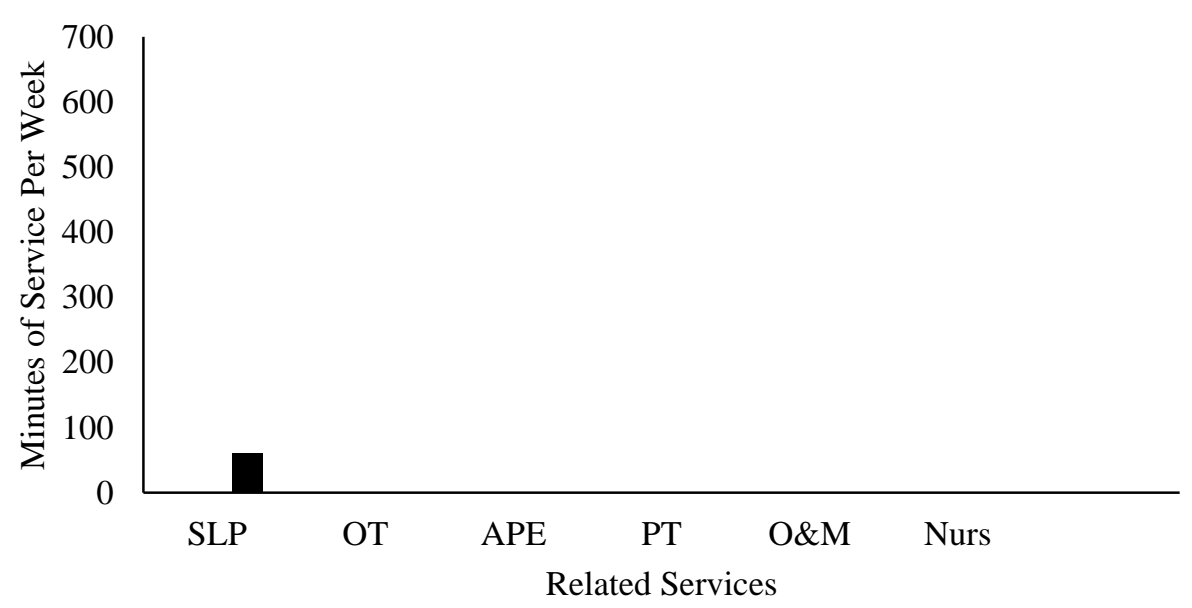


Figure 11 Continued.

\section{Jack}

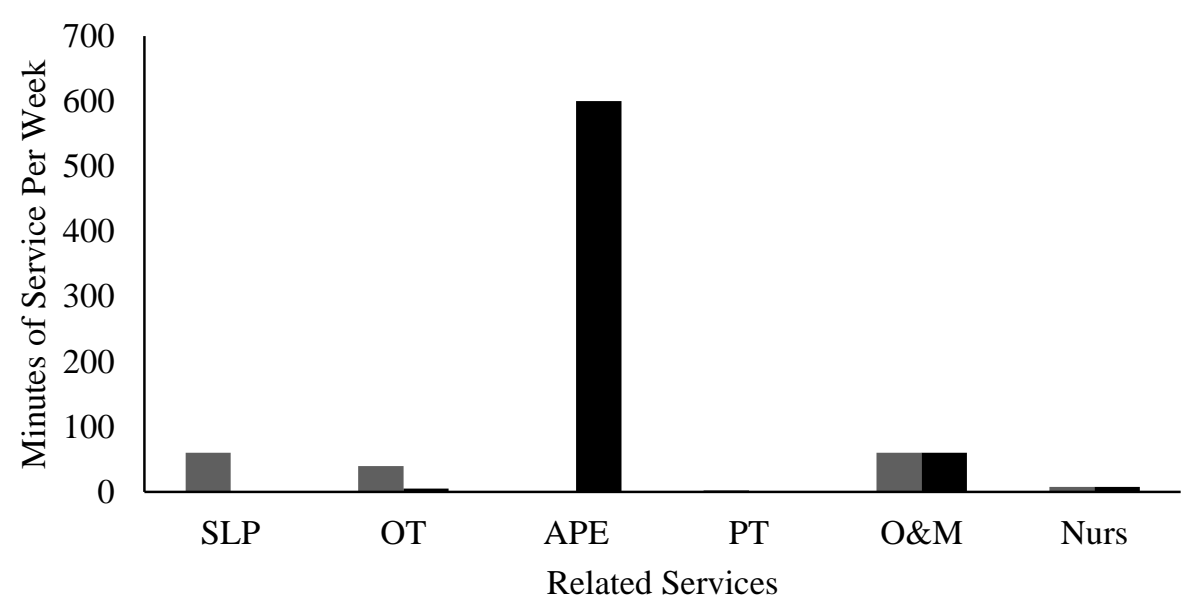

\section{Terry}

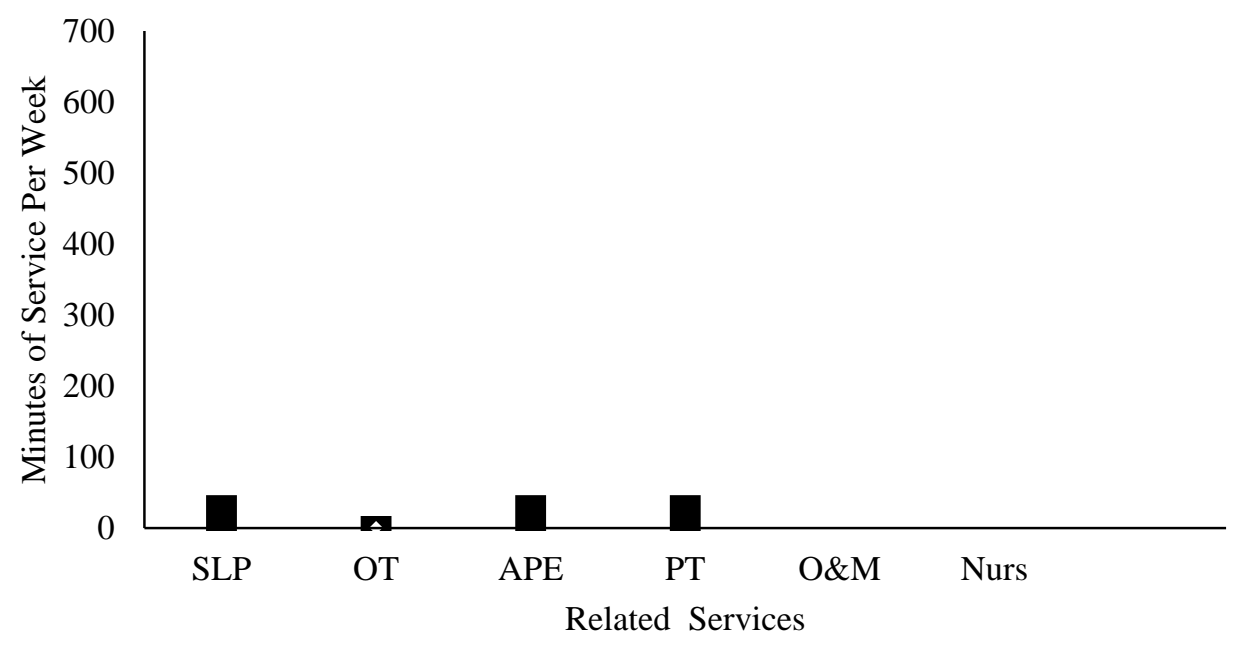


Figure 12. Direct Service Provision Across Cases, 6-Year-Olds

\section{Ian}

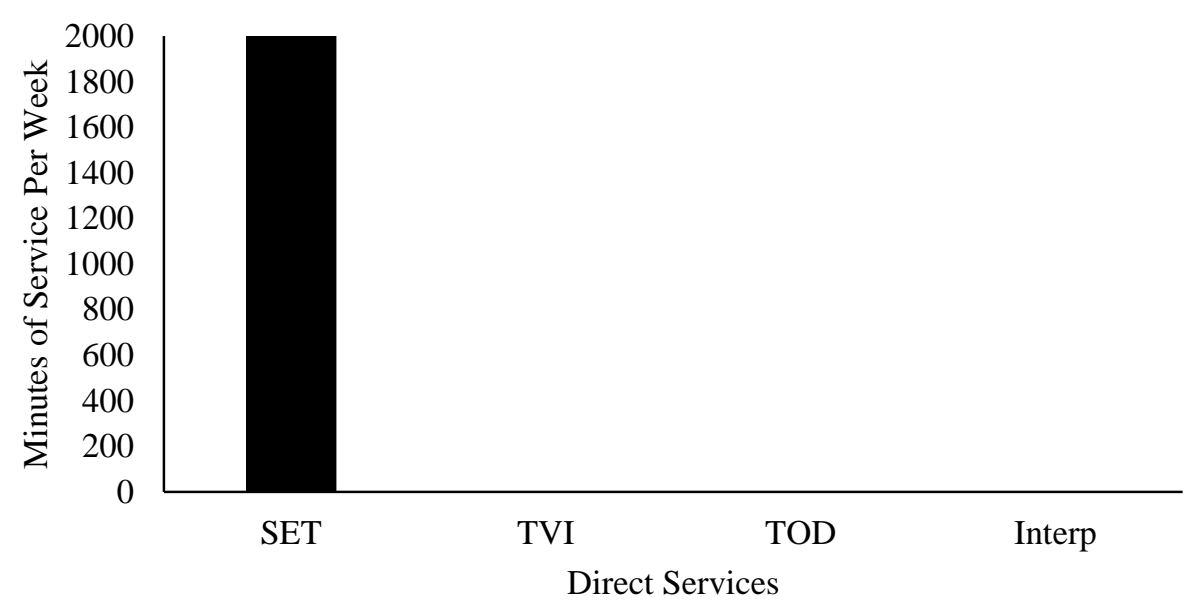

Steven

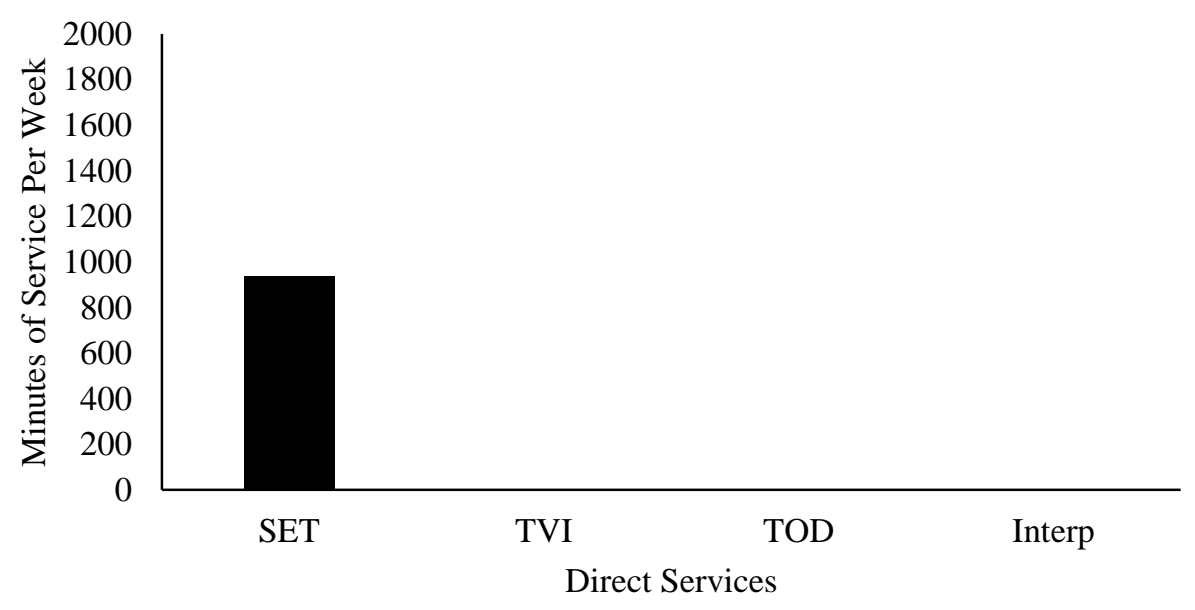


Figure 12 Continued.

\section{Jack}

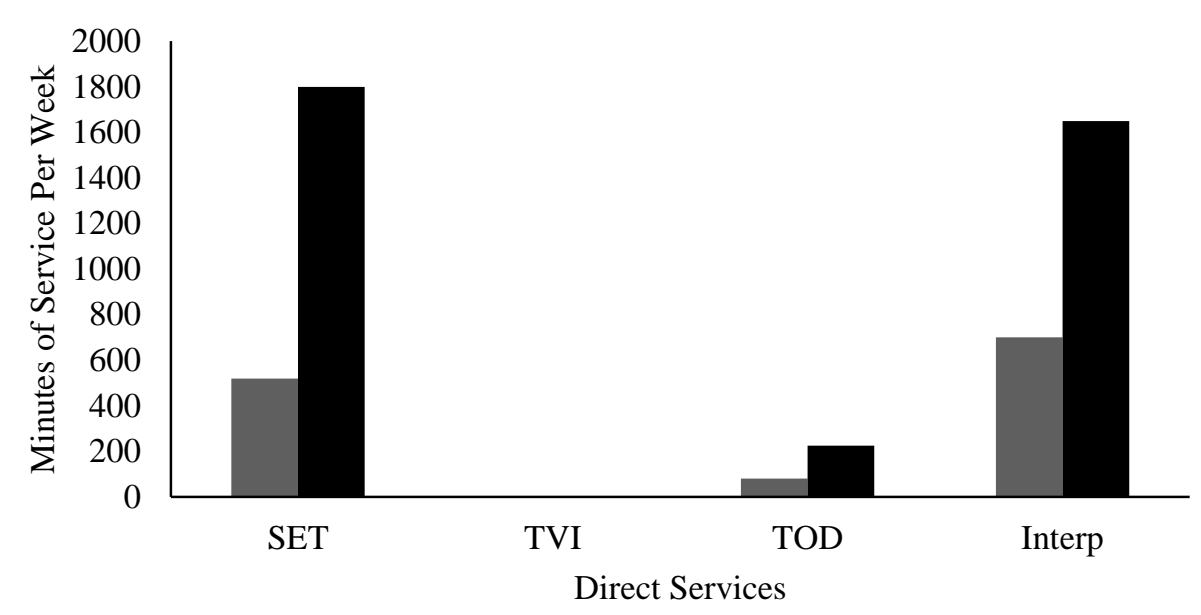

\section{Terry}

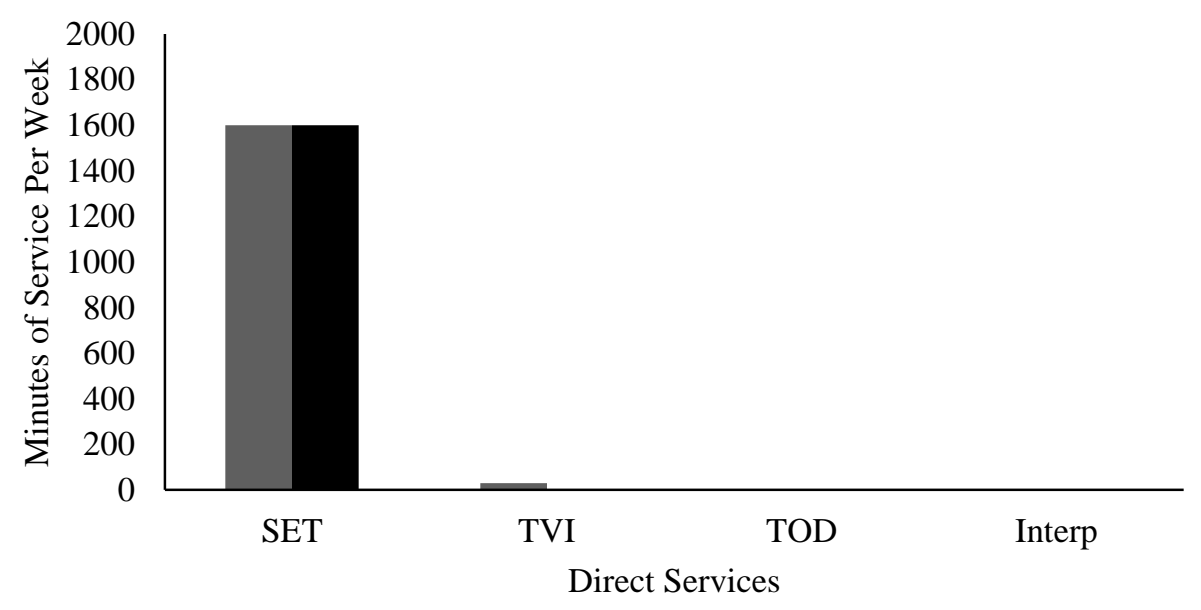


Figure 13. Intensity of Educational Services Across Cases, 6-Year-Olds

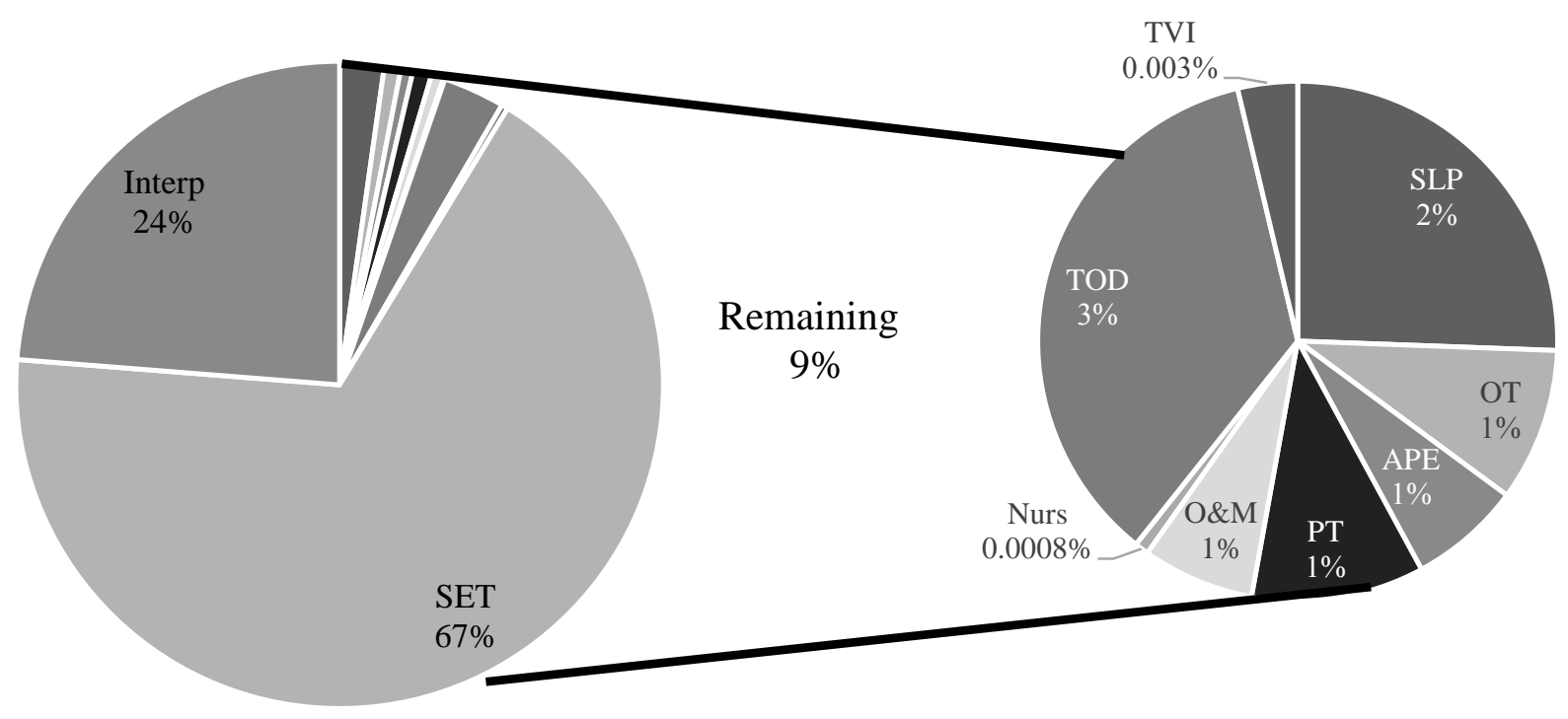

\section{Fifteen-to-Eighteen-Year-Old Learners}

The data procured included IEPs for three learners spanning the ages of fifteen to eighteen ( $n=13$ IEPs). As with the services provided to the six-year-old learners, the direct educational service provider that indicated the most intensity was the SET. Only one participant received services from a TVI and those services were limited (15 minutes per week). Interestingly, the learner whose IEP included minutes of service from a TOD only received consult services and no minutes of direct service. When all service minutes were compiled across all participants, the three services that comprised the most intensity were SET (62\%), Interp (16\%), and Career (13\%).

Regarding the related services, there was variability in the services provided across participants. The educational services provided to these learners included most of the same 
services as those provided to the group of learners who were six-years-old (minus nursing). Six other related services were added to the 15-to-18-year-old group: art therapy, AT; audiology, Aud; career; individual aide, IA; school health services, SHS; and social work, SW (see Figures 13, 14, and 15). A TOD, AT, audiology, career, interpreter, IA, SW, and SHS were only documented for one participant.

Figure 14. Related Service Provision Across Cases, Fifteen-to-Eighteen-Year-Olds
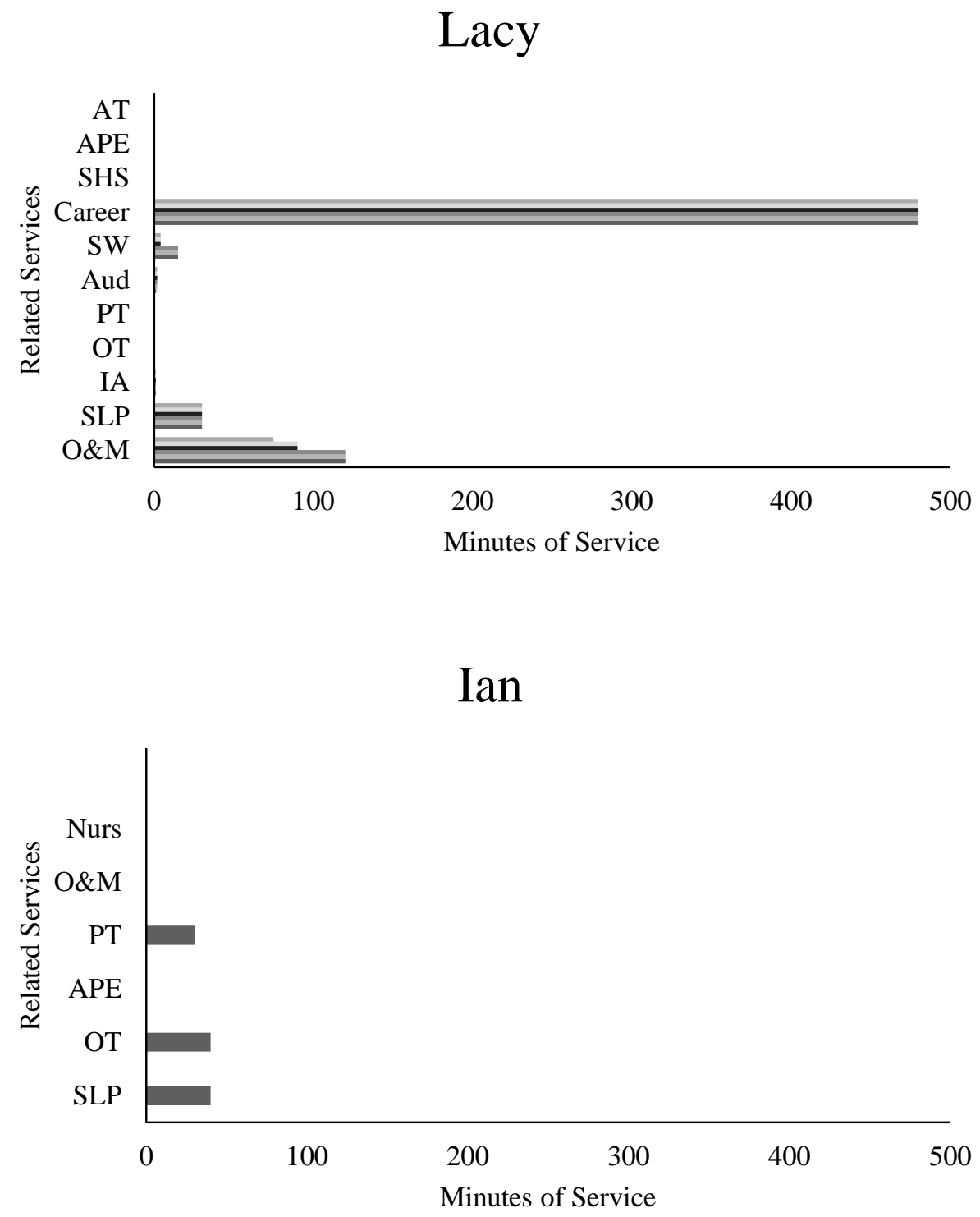
Figure 14 Continued.

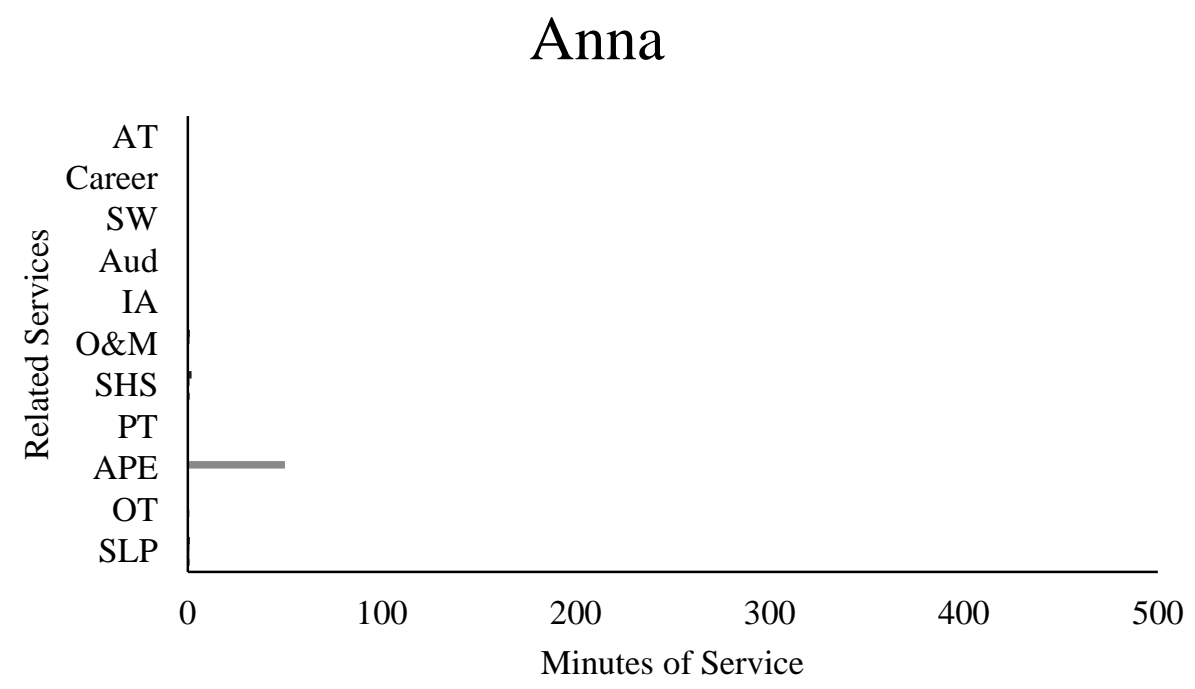

Terry

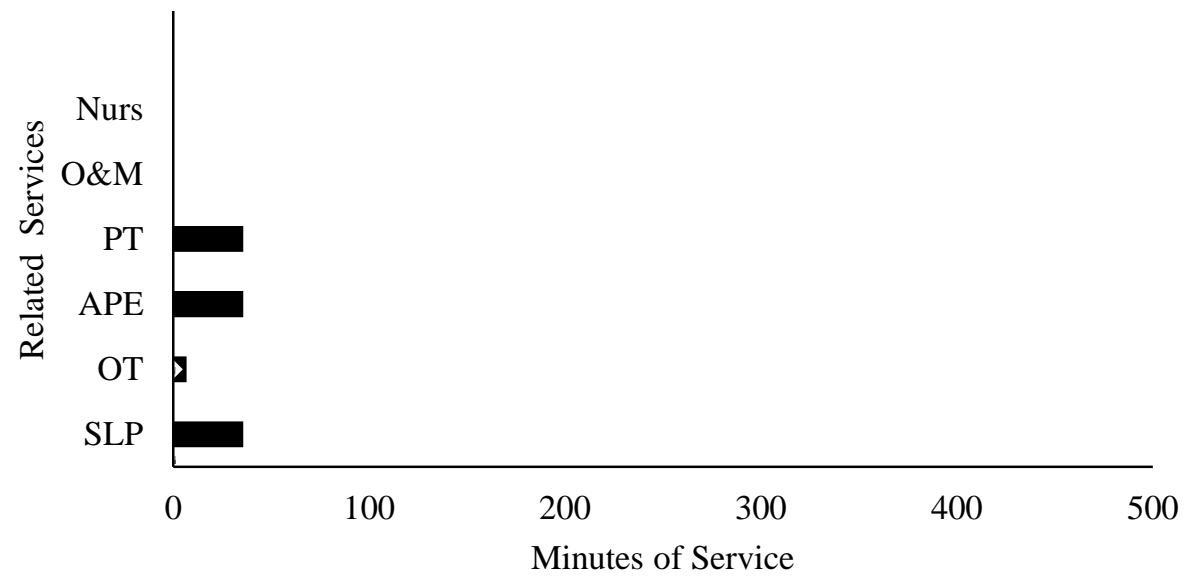


Figure 15. Direct Service Provision Across Cases, Fifteen-to-Eighteen-Year-Olds.
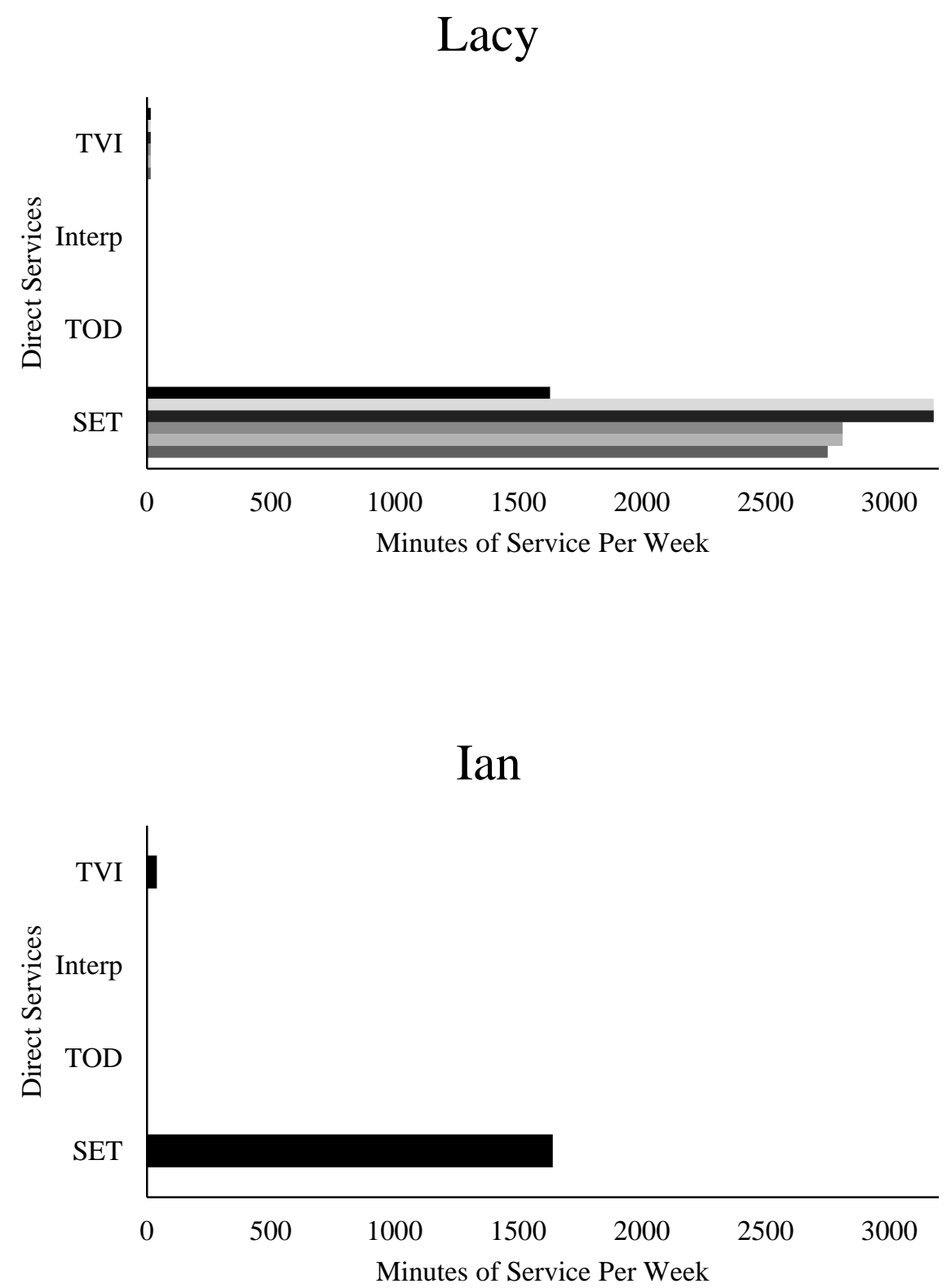
Figure 15 Continued.
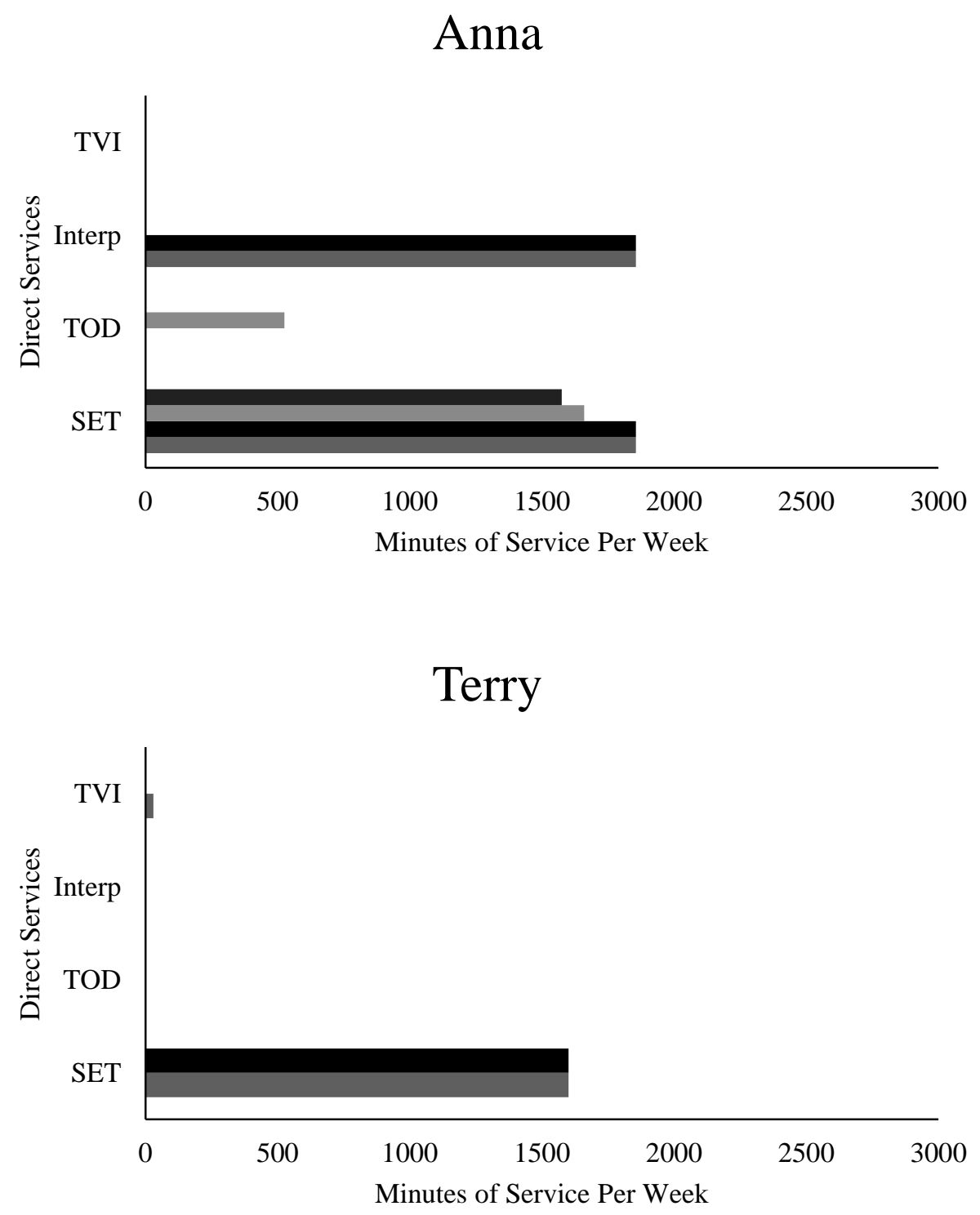
Figure 16. Intensity of Educational Services Across Cases, 15-to-18-Year-Olds

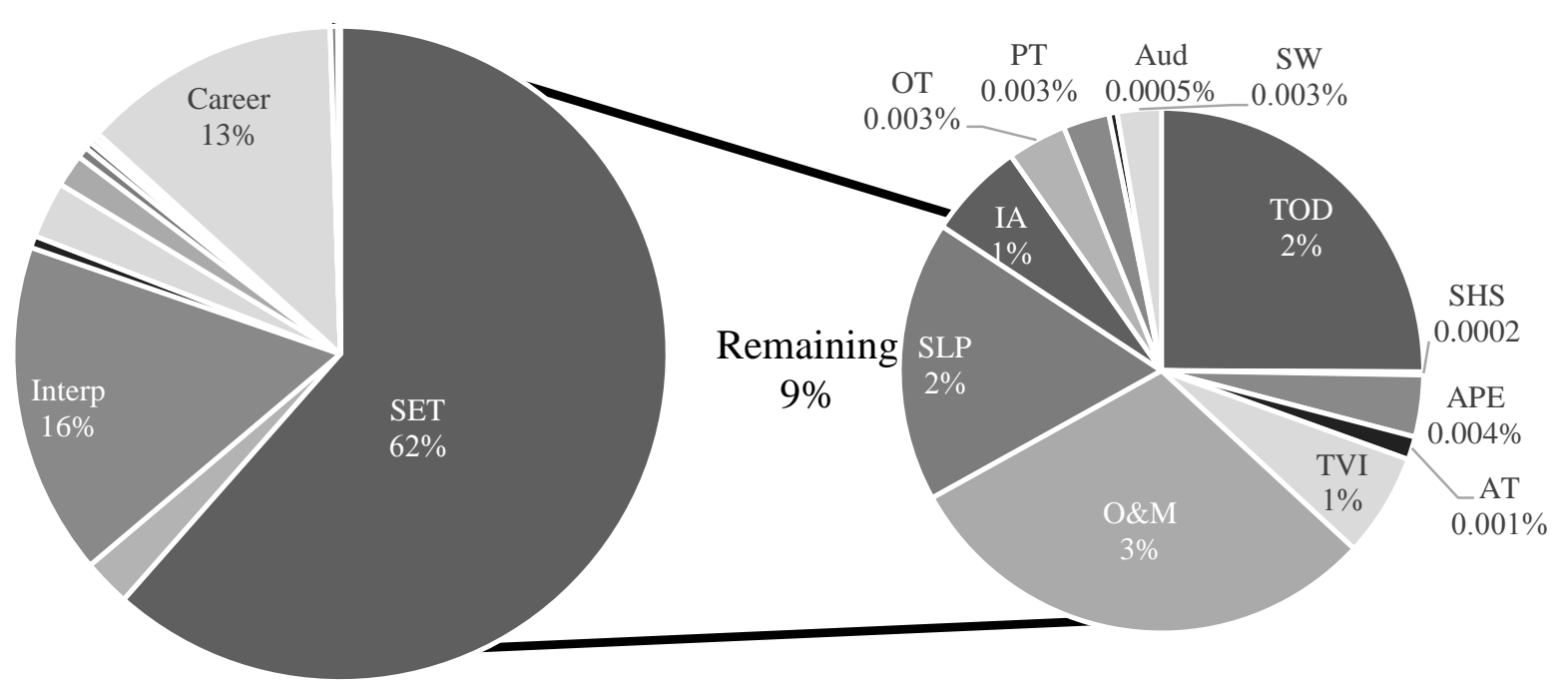

\section{Case Studies}

Although seven individuals provided data for this study, only two provided true longitudinal data, spanning from early intervention (EI) through age 18 and 22. For this reason, their data was examined more deeply and highlighted, providing detail about their service provision (type, intensity, and duration).

Terry. The data provided for Terry included seventeen individualized family service plans (IFSPs) and IEPs covering ages two through 18. Over the sixteen years of this learner's education, 15 different educational services were provided. Of those services, five were specific to EI (coordinator of developmental services, CDS; developmental therapy, DT; developmental therapy deafblind, DTDB; and family support and training, FS). Consistent with the previous findings, the educational service with the highest intensity was SET (see Table 11 and Figure 17). 
Figure 17 and Tables 12 and 13 show the variability of educational services and intensity of those services from IEP to IEP intraindividually. Furthermore, while this learner received DTDB services, no other service providers specific to deafblindness (i.e., teacher of the DB and intervener) were provided to this learner. While SLP services were assigned across nearly every year, this learner only received consult services from a TOD and 30 minutes per week of direct service from a TVI for three years (ages four to six).

\section{Table 12}

\begin{tabular}{lcccc}
\multicolumn{5}{c}{ Intensity of Direct } \\
\hline IEP \# & Age & SET & TOD & TVI \\
\hline 1 & 2 & & 1 & 1 \\
2 & 3 & & \\
3 & 4 & 900 & & \\
4 & 4 & 1500 & & 30 \\
5 & 4 & 1400 & & 30 \\
6 & 5 & 1700 & & 30 \\
7 & 5 & 1600 & & 30 \\
8 & 6 & 1600 & & 1 \\
9 & 6 & 1600 & 1 & 1 \\
10 & 7 & 1590 & 1 & 1 \\
11 & 11 & 1535 & 1 & 1 \\
12 & 12 & 1775 & 1 & \\
13 & 13 & 1500 & & \\
14 & 14 & 1230 & & \\
15 & 16 & 1500 & & \\
16 & 17 & 1785 & & \\
17 & 18 & 2020 & & \\
\hline
\end{tabular}


Figure 17. Longitudinal Direct and Related Service Intensity for Terry

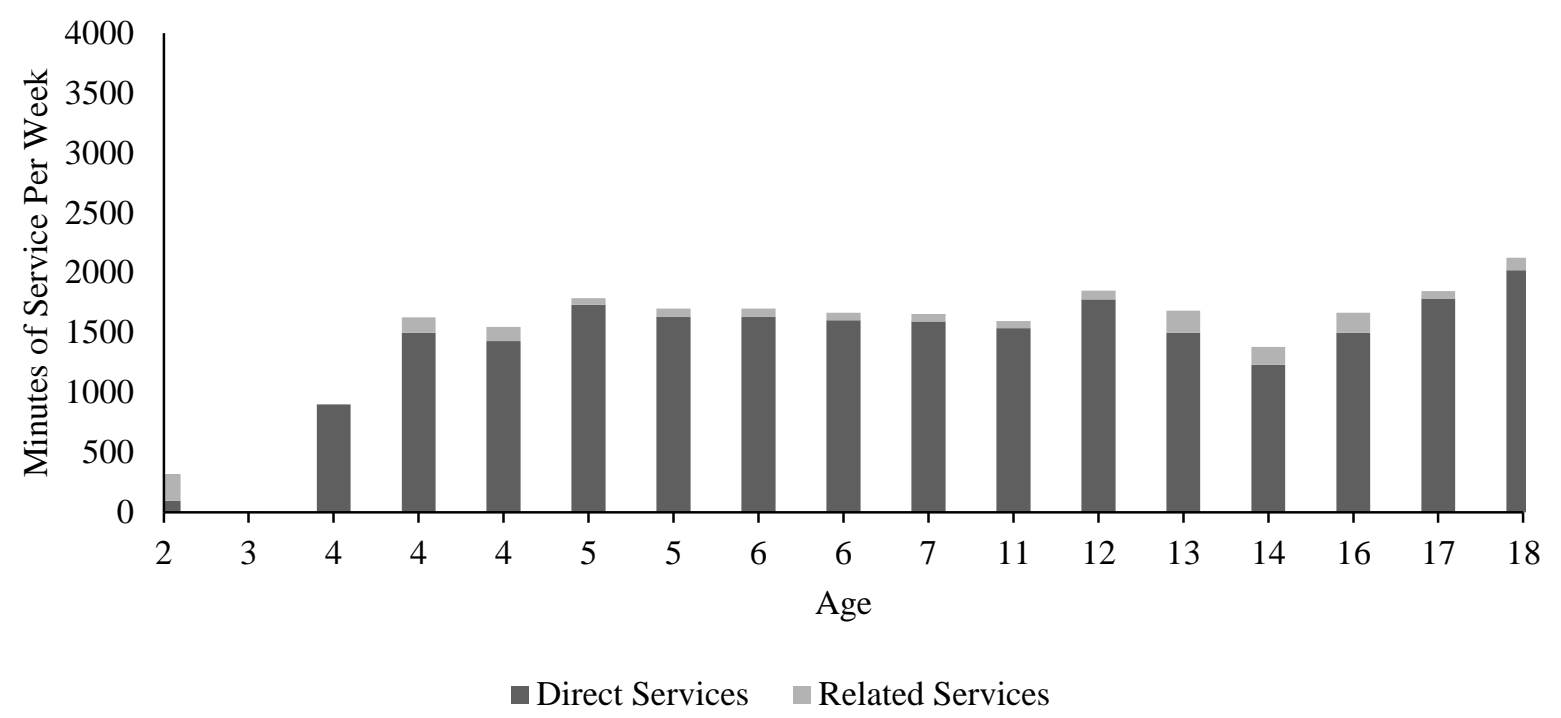

Table 13

Intensity of Related Service Provision in Minutes for Terry

\begin{tabular}{|c|c|c|c|c|c|c|c|c|c|c|c|c|c|}
\hline IEP \# & Age & APE & $\mathrm{AT}$ & Aud & CDS & DT & DTDB & FS & Nurs & O\&M & OT & $\mathrm{PT}$ & SLP \\
\hline 1 & 2 & & & & 12 & 60 & 37.5 & 30 & 15 & & 60 & 45 & 60 \\
\hline 2 & 3 & & & & & & & & & & 1 & 1 & 1 \\
\hline 3 & 4 & & & & & & & & & & & & \\
\hline 4 & 4 & 22.5 & & & & & & & & & & 7.5 & \\
\hline 5 & 4 & 90 & & & & & & & & & & 7.5 & 20 \\
\hline 6 & 5 & 30 & & & & & & & & & 1 & 7.5 & 20 \\
\hline 7 & 5 & 30 & & & & & & & & & 1 & 7.5 & 30 \\
\hline 8 & 6 & 30 & & & & & & & & & 1 & 7.5 & 30 \\
\hline 9 & 6 & 30 & & 1 & & & & & & & 1 & 1 & 30 \\
\hline 10 & 7 & 30 & & 1 & & & & & & & 1 & & 30 \\
\hline 11 & 11 & 30 & & & & & & & & & & & 30 \\
\hline 12 & 12 & 43 & & & & & & & & & & & 30 \\
\hline 13 & 13 & 45 & 30 & & & & & & & 15 & 30 & 1 & 60 \\
\hline 14 & 14 & 45 & & & & & & & & 15 & 30 & & 60 \\
\hline 15 & 16 & 30 & 30 & & & & & & & 15 & 30 & & 60 \\
\hline 16 & 17 & & & & & & & & & & & & 60 \\
\hline 17 & 18 & & & & & & & & & & 45 & & 60 \\
\hline
\end{tabular}

Ian. The longitudinal data for Ian included 20 different IFSPs $(n=3)$ and IEPs $(n=17)$ spanning ages three months to 22 years. Over the 18 years of EI and school-aged education, this 
learner received 13 different educational services with three services being provided only during EI (Aud; DT; and social work, SW) and transition services offered the last two years of the learner's education. As with prior findings, the educational service that provided the most intensity per week was SET (see Figure 18 and Tables 14 and 15). Two of the educational services provided were assigned for one or two years: school psychologist (SP; 1 year for assessment only at age nine) and assistive device (AD; two years, ages 11 and 12). As with Terry, this learner's data indicated much variability in number (2 to 8 services provided), intensity (0 to 319.5 minutes of services), and duration of educational services (SLP, 15 IEPs; APE, 12 IEPs; OT, 11 IEPs; PT, 9 IEPs).

\section{Table 14}

Intensity of Direct Service Provision in Minutes for Ian

\begin{tabular}{ccccc}
\hline IEP \# & Age & TVI & SET & Transition \\
\hline 1 & .25 & & & \\
2 & 1 & & & \\
3 & 2 & & 60 & \\
4 & 3 & & 902 & \\
5 & 4 & & 900 & \\
6 & 5 & 1 & 1000 & \\
7 & 5 & & 2025 & \\
8 & 6 & 1 & 2030 & \\
9 & 7 & & 2025 & \\
10 & 9 & 1 & 1 & \\
11 & 10 & 40 & 1640 & \\
12 & 11 & 40 & 1640 & \\
13 & 13 & 0 & 40 & \\
14 & 14 & 40 & 1640 & \\
15 & 15 & & & \\
16 & 18 & 1 & 1 & \\
17 & 19 & 1 & 2205 & \\
18 & 19 & 10 & 2230 & \\
19 & 22 & 1 & 1350 & 900 \\
20 & 21 & 1 & 1350 & 360 \\
\hline
\end{tabular}


Figure 18. Longitudinal Direct and Related Service Intensity for Ian

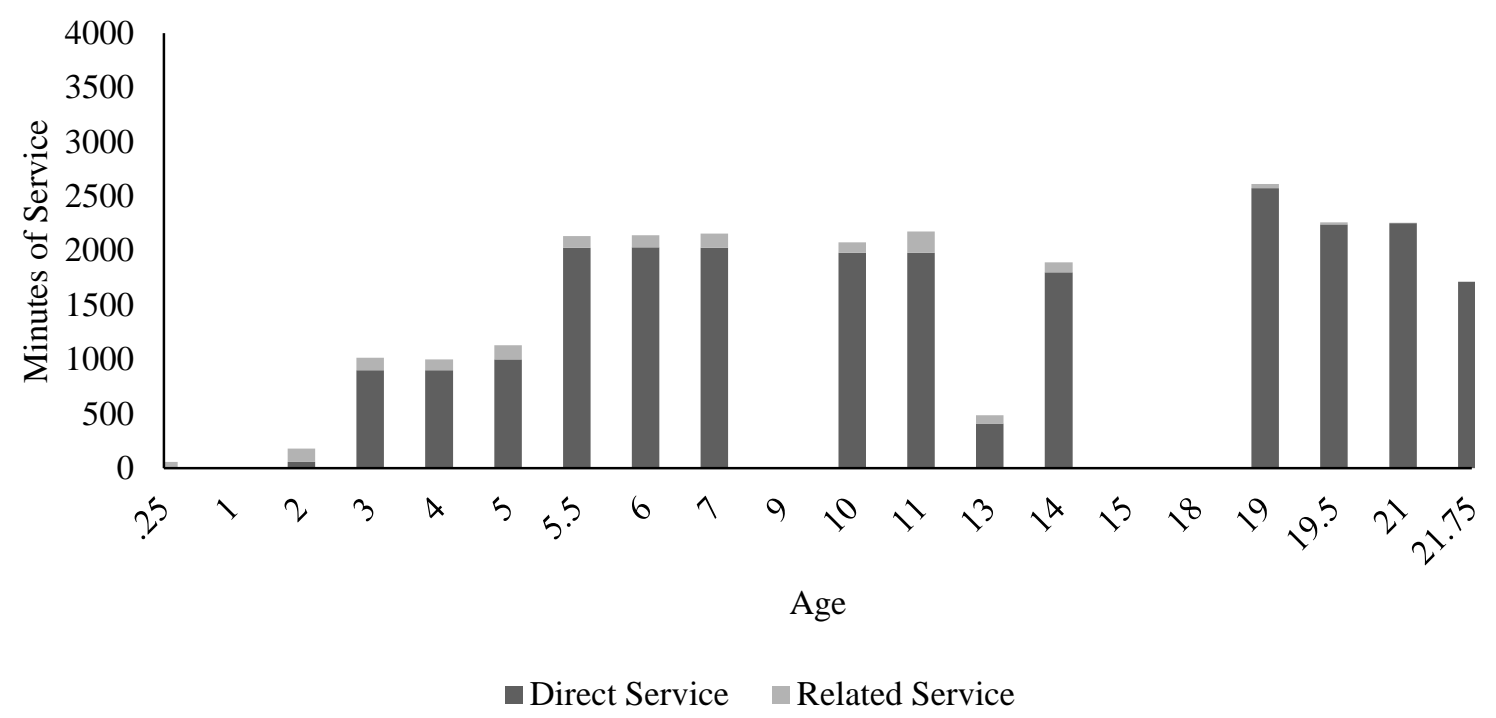

\section{Table 15}

Intensity of Related Service Provision in Minutes for Ian

\begin{tabular}{|c|c|c|c|c|c|c|c|c|c|c|c|}
\hline IEP \# & Age & ACS & Aud & DT & O\&M & OT & PT & SLP & SP & SW & IA \\
\hline 1 & .25 & & & 1 & & & 45 & 11.25 & & 1 & \\
\hline 2 & 1 & & & 1 & & & 1 & 1 & & & \\
\hline 3 & 2 & & 1 & & & & 60 & 60 & & & \\
\hline 4 & 3 & & 1 & & & & 72 & 42 & & & \\
\hline 5 & 4 & & & & & & 60 & 40 & & & \\
\hline 6 & 5 & & & & & 60 & 30 & 40 & & & \\
\hline 7 & 5 & & & & & 40 & 30 & 40 & & & \\
\hline 8 & 6 & & & & & 40 & 30 & 40 & & & \\
\hline 9 & 7 & & & & & 20 & 30 & 80 & & & \\
\hline 10 & 9 & & & & & 1 & 1 & 1 & 1 & & \\
\hline 11 & 10 & 1 & & & & 20 & 30 & 45 & & & 300 \\
\hline 12 & 11 & 1 & & & & 20 & 30 & 45 & & & 300 \\
\hline 13 & 13 & & & & & 1 & 30 & 45 & & & 370 \\
\hline 14 & 14 & & & & & 1 & 30 & 60 & & & 120 \\
\hline 15 & 15 & & & & & & & & & & \\
\hline 16 & 18 & & & & 1 & & & 1 & & & 1 \\
\hline 17 & 19 & & & & 1 & & & 40 & & & 367 \\
\hline 18 & 19 & & & & & & & 20 & & & \\
\hline 19 & 22 & & & & 1 & & & 1 & & & \\
\hline 20 & 21 & & & & 2 & & & 1 & & & \\
\hline
\end{tabular}


Other Learners. While no definitive conclusions could be ascertained from the data gathered for the other learners, one interesting yet disconcerting trend was discovered. As with Terry and Ian, wide variability in service provision from year to year was observed across all participants in both number of services as well as intensity of services (see Figures 19, 20, 21, and 22 and Tables 16, 17, 18 19, 20, 21, 22, and 23).

Table 16

Intensity of Direct Service Provision in Minutes for Steven

\begin{tabular}{ccc}
\hline IEP \# & Age & SET \\
\hline 1 & 5 & 1800 \\
2 & 5.5 & 1800 \\
3 & 6 & 936 \\
\hline
\end{tabular}

Table 17

Intensity of Related Service Provision in Minutes for Steven

\begin{tabular}{cccccc}
\hline IEP \# & Age & APE & CA & OT & SLP \\
\hline 1 & 5 & 30 & 1 & 1 & 1 \\
2 & 5.5 & & 1 & 5 & 60 \\
3 & 6 & & & & 60 \\
\hline
\end{tabular}

Figure 19. Longitudinal Direct and Related Service Intensity for Steven

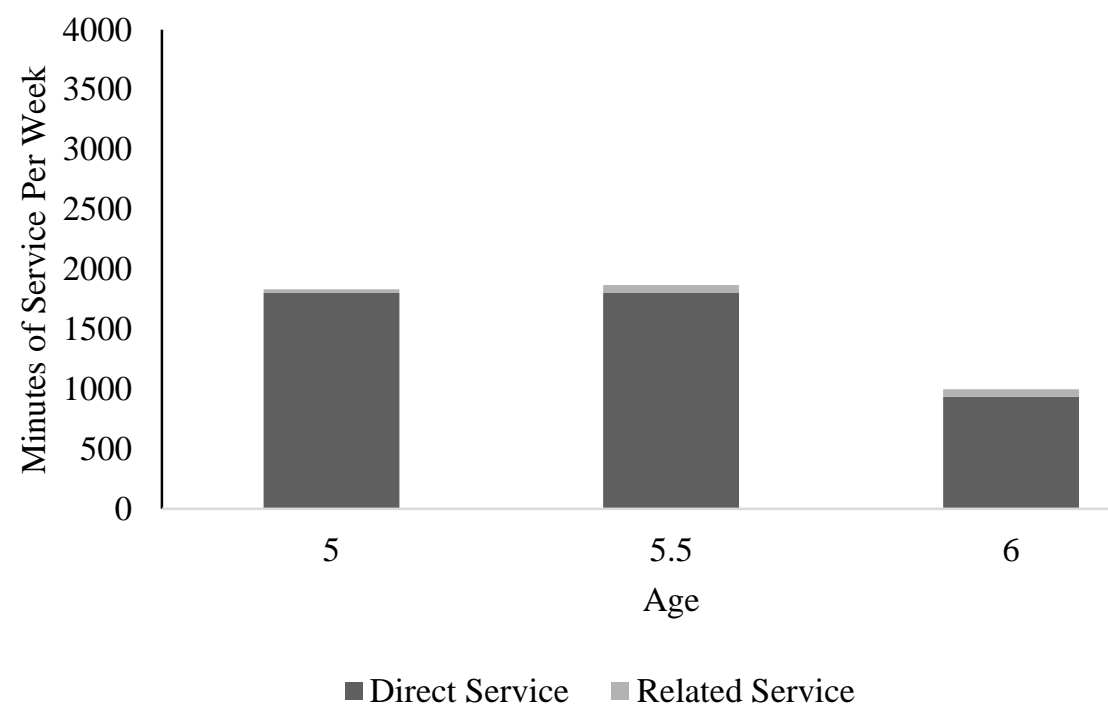




\section{Table 18}

Intensity of Direct Service Provision in Minutes for Anna

\begin{tabular}{cccccc}
\hline IEP \# & Age & SET & Interp & TOD & TVI \\
\hline 1 & 14.5 & 1855 & 1855 & 1 & \\
2 & 17 & 1855 & 1855 & 1 & 1 \\
3 & 17.5 & 1660 & 0 & 525 & 1 \\
4 & 18 & 1575 & 0 & & 1 \\
\hline
\end{tabular}

\section{Table 19}

Intensity of Related Service Provision in Minutes for Anna

\begin{tabular}{ccccccc}
\hline IEP \# & Age & APE & O\&M & OT & SHS & SLP \\
\hline 1 & 14.5 & & & & 1 & 1 \\
2 & 17 & & & 1 & & 1 \\
3 & 17.5 & 50 & 1 & & 1 & 1 \\
4 & 18 & & 1 & & 2 & 1 \\
\hline
\end{tabular}

Figure 20. Longitudinal Direct and Related Service Intensity for Anna

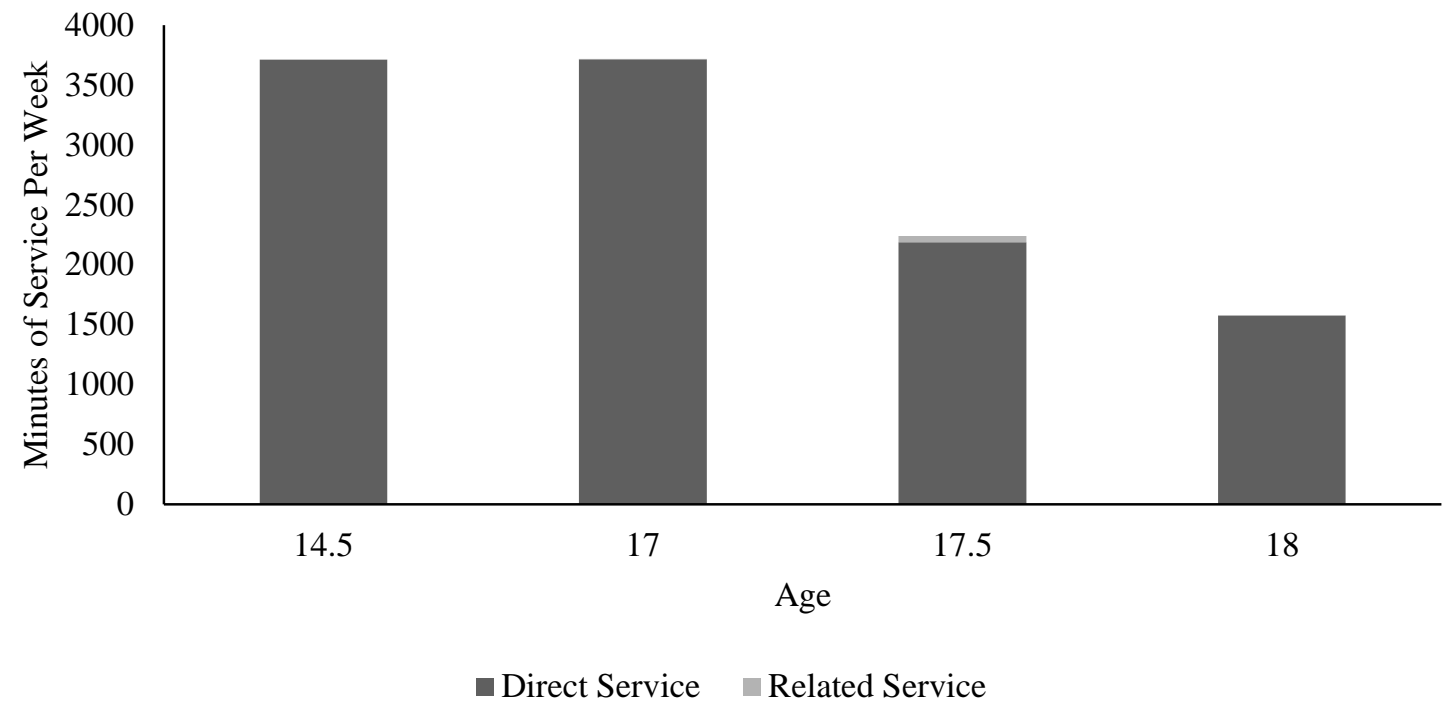


Table 20

Intensity of Direct Service Provision in Minutes for Lacy

\begin{tabular}{ccccc}
\hline IEP \# & Age & SET & Career & TVI \\
\hline 1 & 15 & 2751 & 480 & 15 \\
2 & 15 & 2811 & 480 & 15 \\
3 & 15.5 & 2811 & 480 & 15 \\
4 & 15.75 & 3180 & 480 & 15 \\
5 & 16 & 3180 & 480 & 15 \\
6 & 17 & 1629 & 480 & 15 \\
\hline
\end{tabular}

\section{Table 21}

Intensity of Related Service Provision in Minutes for Lacy

\begin{tabular}{cccccccccc}
\hline IEP \# & Age & Aud & IA & O\&M & SLP & SW & SET & Career & TVI \\
\hline 1 & 15 & 1.19 & 1 & 120 & 30 & 15 & 2751 & 480 & 15 \\
2 & 15 & 1.9 & 1 & 120 & 30 & 15 & 2811 & 480 & 15 \\
3 & 15.5 & 1.9 & 1 & 120 & 30 & 15 & 2811 & 480 & 15 \\
4 & 15.75 & 1.9 & 1 & 90 & 30 & 4 & 3180 & 480 & 15 \\
5 & 16 & 1.9 & 1 & 90 & 30 & 4 & 3180 & 480 & 15 \\
6 & 17 & 1.9 & 1 & 75 & 30 & 4 & 1629 & 480 & 15 \\
\hline
\end{tabular}

Figure 21. Longitudinal Direct and Related Service Intensity for Lacy

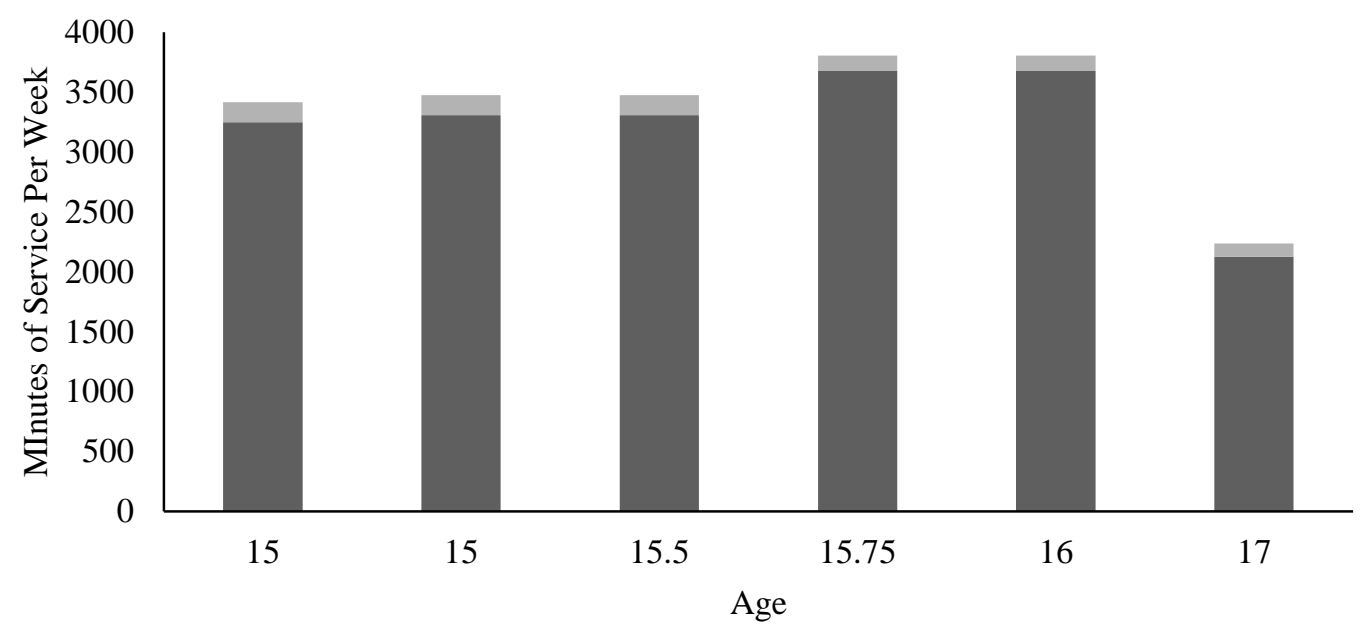

- Direct Services $\square$ Related Services 
Table 22

Intensity of Direct Service Provision in Minutes for Jack

\begin{tabular}{cccccc}
\hline IEP \# & Age & SET & Interp & TOD & TVI \\
\hline 1 & 2.75 & 600 & & & \\
2 & 3 & 120 & & & 15 \\
3 & 5 & 520 & 520 & 80 & \\
4 & 5.5 & 520 & 700 & 80 & \\
5 & 6 & 1800 & 1650 & 225 & \\
6 & 9.5 & 1575 & 1575 & & \\
7 & 11 & 1525 & 1575 & & \\
\hline
\end{tabular}

Table 23

Intensity of Related Service Provision in Minutes for Jack

\begin{tabular}{cccccccccccc}
\hline IEP \# & Age & ACS & Aud & Nurs & Nut & O\&M & OT & PT & SHS & SLP & APE \\
\hline 1 & 2.75 & & & & & & 34 & & & 60 & \\
2 & 3 & & & 10 & & & 15 & 11.25 & 1.9 & & \\
3 & 5 & 1 & 5 & 10 & 7.5 & 60 & 40 & & & 60 & \\
4 & 5.5 & & 5 & 7.5 & & 60 & 40 & 2.5 & & 60 & \\
5 & 6 & & 4 & 7.5 & & 60 & 5 & & & & 600 \\
6 & 9.5 & & 4 & 2 & & 30 & 15 & & 25 & 60 & 60 \\
7 & 11 & & 4 & 2 & & 60 & 15 & & 25 & 60 & 60 \\
\hline
\end{tabular}

Figure 22. Longitudinal Direct and Related Service Intensity for Jack

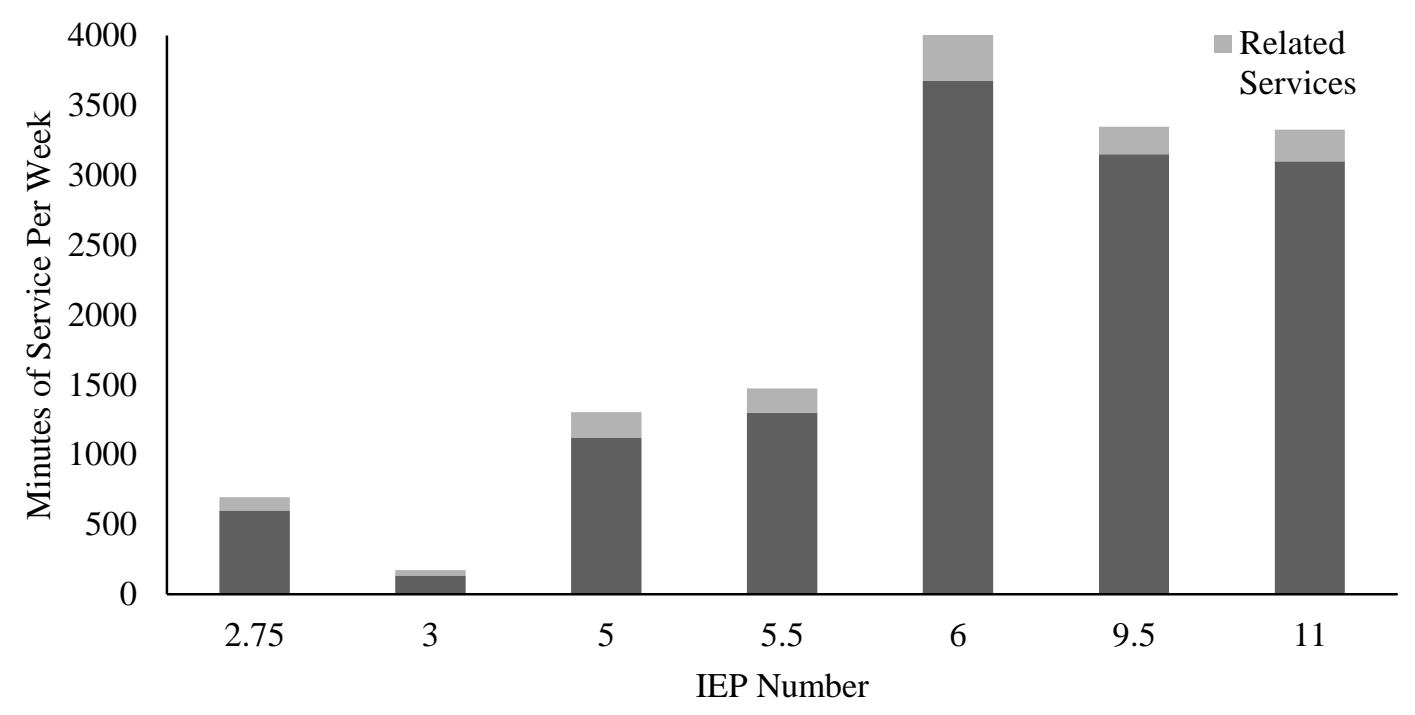




\section{Research Question 4}

What is the trajectory of communication growth over time as measured by the Communication Matrix $(C M)$ for students with both deafness and visual impairment?

To measure communication growth of learners who were DB, I used the documents provided (IEPs, MFEs, evaluations, etc.) to glean information about the student's communication skills to create profiles using the $C M$. A profile was created for every IEP provided. Once a profile was created, an overall score for each of the scoring categories (not used, emerging, mastered, and surpassed) was calculated by dividing the number of boxes scored in each category by the overall number of boxes on the profile (e.g., if there were 56 boxes that were labeled "not used," the score would be $\frac{56}{80}=70 \%$ ). Originally, I planned to use LGM to analyze and illustrate the communication growth as measured by the $C M$ for each participant, however, due to a lack of participants and widely variable data, LGM could not be employed. Instead, descriptive statistics were conducted using SPSS. Two groups of learners were extracted and, using their scores on the $C M$, analyzed for means $(M)$ and standard deviations ( $S D$; see Table 24). In both groups (6-year-olds, $n=3$; 15 -to-18-year-olds, $n=3$ ), the SD are very large indicating large amounts of variations across the categories. Finally, the wide spread in data scores is a result of low sample size.

\section{Table 24}

Means and Standard Deviations of Scores on the CM, Groups

\begin{tabular}{ccccc}
\hline & \multicolumn{2}{c}{ 6-year-olds } & \multicolumn{2}{c}{ 15-18-year-olds } \\
\cline { 2 - 5 } Categories on $C M$ & $M$ & $S D$ & $M$ & $S D$ \\
\hline Not Used & 78.86 & 16.912 & 71.63 & 13.156 \\
Emerging & 8.27 & 14.603 & 11.04 & 9.04 \\
Mastered & 12.91 & 5.74 & 13.7 & 9.687 \\
Surpassed & 2.18 & 3.972 & 5.59 & 4.116 \\
\hline
\end{tabular}


Since there was one participant who had data that fell within both extracted groups, the scores on the $C M$ were analyzed for this learner and analyzed for $M$ and $S D$ (see Table 25). Similar results were obtained from the groups and there was much variation across the categories for Terry.

\section{Table 25}

Means and Standard Deviations of Scores on the CM, Terry

\begin{tabular}{ccccc}
\hline & \multicolumn{2}{c}{6 years old } & \multicolumn{2}{c}{$15-18$ years old } \\
\cline { 2 - 5 } Categories on $C M$ & $M$ & $S D$ & $M$ & $S D$ \\
\hline Not Used & 88 & 6.37 & 74.76 & 14.403 \\
Emerging & 0.38 & 1.061 & 6.71 & 7.679 \\
Mastered & 11.13 & 4.97 & 14.65 & 4.821 \\
Surpassed & 0.5 & 1.414 & 3.24 & 3.327 \\
\hline
\end{tabular}

\section{Longitudinal Communication Growth}

Two participants provided true longitudinal data, thus affording the opportunity to examine the learner's communication growth over time. When using the $C M$, communication growth progresses from "not used" to "emerging" and so on. As the number of "not used" skills decrease, an increase should occur in those skills in the remaining three categories and the "not used" category should decrease steadily while the other categories rise. Additionally, the category of "emerging" should rise and then fall to be replaced by the next category, "mastered." The desire is to see a child progress to at least "mastery" level of communication skills because, as a learner's communication is improving, their mastery of the skills will increase. As each communication skill is mastered, fewer skills should fall into the "not used" category. Finally, another important consideration is that, for typically-developing children, these communication skills develop and are mastered and/or surpassed by 24 months of age (Rowland, 2012). In the case of the two learners discussed in this study, the growth trajectories were from 17 (Terry) and 20 (Ian) IEPs (spanning 16 and 21 years). 
Terry. Over 16 years of receiving EI services and education services in a public school setting, the communication skills of Terry as measured by the $C M$ showed minimal growth (see Figure 23). As can be seen in the figure, Terry achieved mastery of only $30 \%$ of the communication skills on the $C M$. Although his trajectory shows growth (skills mastered/surpassed improved from 5\% to 30\%), this growth occurred over sixteen years.

Figure 23. Terry Communication Growth Over Time

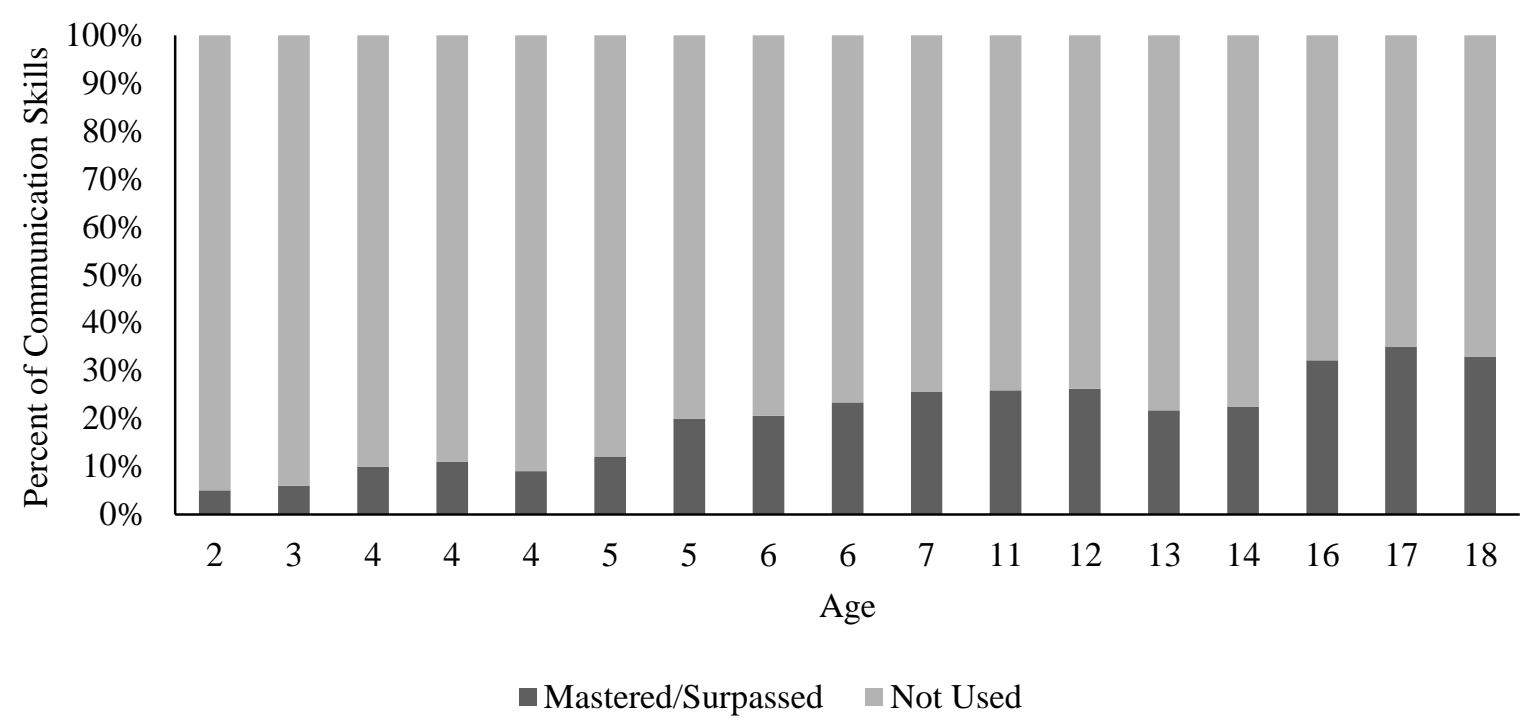

Ian. The information obtained for Ian provided data beginning at three months of age and spanned 21 years. This learner experienced a higher rate of communication growth (see Figure 24) than Terry, however, the rate of growth is much smaller than a typically-developing child. Important to note is that Ian's communication skills show a flat trajectory of growth from IEP numbers 12 to 20 (ages 11-21.75). This indicates that there was no communication skill growth indicated in those nine IEPs. 
Figure 24. Ian Communication Growth Over Time

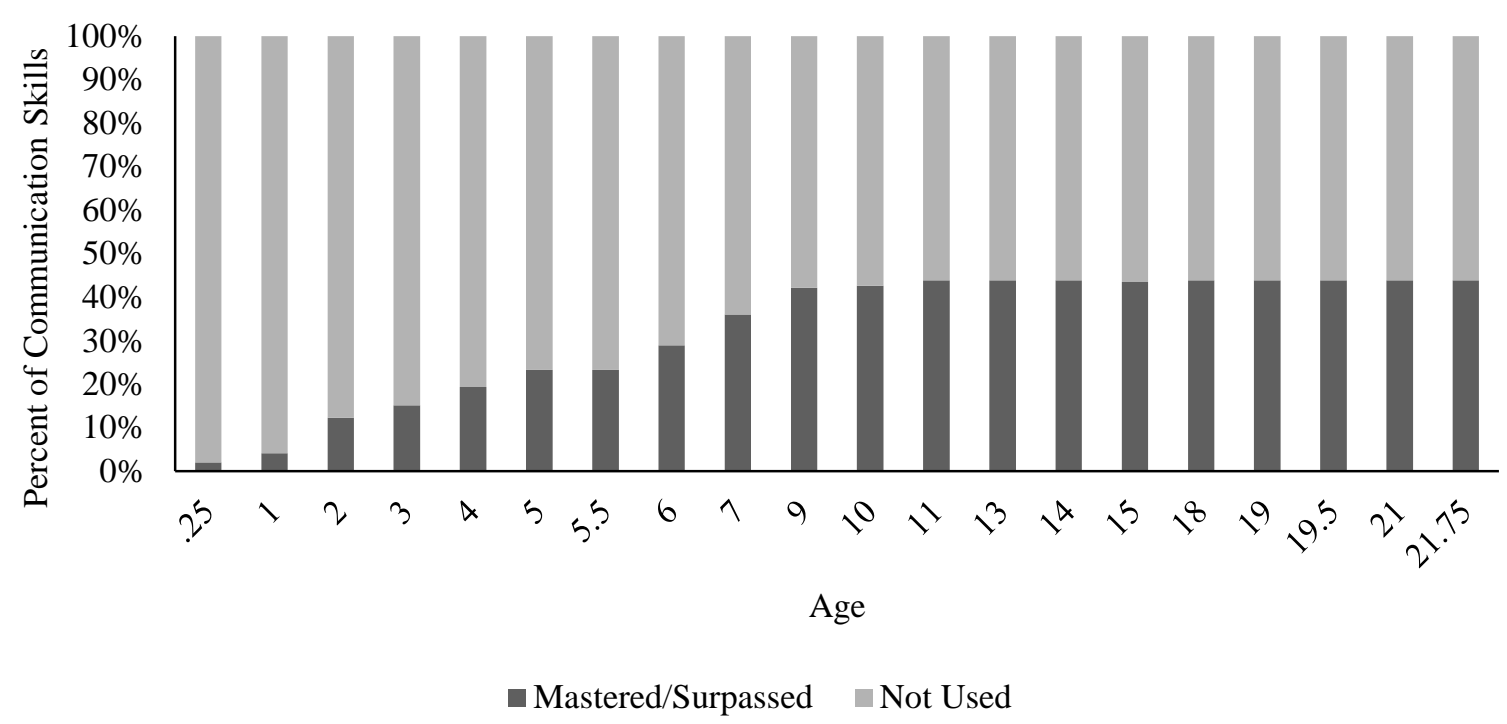

\section{Chapter Summary}

Results from the examination of longitudinal education data was summarized in this chapter. Although questions one, two, and three could not be answered statistically with the data obtained, some preliminary findings about service provision (number, duration, intensity) were presented using descriptive statistics for two groups of learners who were DB: six-year-olds and 15-to-18-year-olds. Service provision for both groups of learners indicated wide variability both intra- and inter-individually with the highest intensity of services being provided by an SET. Case studies were presented for the two learners whose data was a true representation of longitudinal information. Neither individual received services specific to deafblindness. Moreover, while Terry received minimal service provision from both a TOD and TVI for a limited period of time, Ian did not receive combined services.

Only two participants provided true longitudinal data that could be used to answer research question four ("What is the trajectory of communication growth over time as measured by the $C M$ for students with both deafness and visual impairment?"). Although LGM could not 
be used, descriptive statistics were used to extract the $M$ and $S D$ of growth of two groups of learners, 6-year-olds and 15-to-18-year-olds. Furthermore, findings for Terry and Ian indicated that there was minimal communication growth. Graphs depicting the longitudinal communication growth as measured by the $C M$ were presented for Terry and Ian. A summary of these findings will be presented in Chapter V. 


\section{CHAPTER V: SUMMARY AND RECOMMENDATIONS}

This chapter includes a discussion which focuses on several key findings from the current study, implications for educational programming, and recommendations for future research.

The No Child Left Behind Act (NCLB; Sec. 1001, 2001) mandated that schools were required to "ensure that all children have a fair, equal, and significant opportunity to obtain a high quality education" (NCLB, 2001, p. 15). Additionally, students with disabilities who are eligible for special education and related services are given the right to a free and appropriate education (FAPE) in the least restrictive environment (LRE; U.S. Sec. 1412[a][1] \& [a][5]). Both legislative mandates were created to hold school districts responsible for ensuring the educational growth of learners, provide access to and ensure progress in the general education curriculum. However, for learners who have sensory disabilities or multiple disabilities, there is an outcry for improved learner growth (Reichert \& Raimondo, 2017) and appropriate service provision. For learners to receive educational services that best meet their unique learning needs, primary disability labels and, at times, secondary disability labels are assigned; however, often learners are assigned disability labels that did not sufficiently describe their unique learning needs. Furthermore, the concern about appropriate service provision has been a concern in the field of sensory impairment, creating an outcry for a law that will hold states accountable, the Cogswell-Macy Act. This act is the most wide-reaching legislation for learners who have sensory disabilities and seeks to expand the resources available to these students as well as ensure that they receive an education that provides everything they need to succeed ("Take action: The Alice Cogswell," 2017).

The primary purpose of the study was to investigate the differences in the type, duration, and intensity of educational services provided to learners who were deafblind (DB) and to track 
the longitudinal communication growth of these students using the Communication Matrix (CM). To gather the longitudinal data, parents and teachers were contacted. Recruitment for the study was conducted by sending a recruitment blast through professional organizations listservs and social media groups as well as sending emails to administrators, asking them to forward the email to teachers of the deaf (TODs), teachers of the visually impaired (TVIs), and any other teachers known to work with students who were DB. Results from this study provides further evidence of the heterogeneity and the diverse needs of this population of learners.

\section{Summary of Findings and Discussion}

\section{Research Questions One, Two, and Three}

Are there differences in the number of services provided to students who are DB?

Are there differences in the type of services provided to students who are DB?

Are there differences in the intensity of services provided to students who are DB?

Summary of Findings. Due to low numbers of participants, wide variability in data, and the lack of true longitudinal data obtained, questions one, two, and three could not be conclusively answered. Instead, descriptive statistics were conducted to examine the educational services provided to students who were DB with two case studies being further investigated. These are discussed below.

Discussion. With the chosen system of data collection, there was great variability of data obtained. Where one participant would provide one set of documents per year, other participants had multiple IEPs in one year. For example, Terry submitted three IEPs from one school year and none from another year. Given the wide variability and lack of longitudinal data as well as low numbers of participants, only preliminary results can be determined and only for two groups of individuals: 6-year-olds and 15-to-18-year-olds. Furthermore, only two sets of data were true 
examples of longitudinal files, spanning 17 to 20 years of education, which allowed for further examination.

Both groups of learners (6-year-olds and 15-to-18-year-olds) received the highest intensity of service from special education teachers (SETs). Although training programs for SETs often include some introductory information about deafblindness, it is rare that these educators receive training in teaching methodologies specific to learners who are DB as it is the most heterogeneous and lowest incidence disability. To determine the most appropriate services and approaches for each individual learner who is DB and for them to access their educational world, a team of well-trained individuals must work together with the child and family (Luckner et al., 2016). Information gleaned from the education files provided for both groups of learners indicated that they received little, if any, service provision from professionals trained in hearing impairment (HI), visual impairment (VI), and/or deafblindness even though these learners had hearing and vision loss. The variability of services (including the lack of vision and hearing services) over time indicates a need for some type of framework to guide professionals as they make determinations about appropriate educational programming and services for individuals who have disabilities, primarily those who have such unique needs, like deafblindness. The need for a decision-making framework for this population of learners is further enhanced by the dearth of professionals who are appropriately trained to work with these students.

With the low numbers of trained professionals in the field of deafblindness, many school districts lack the employees needed to provide these services, therefore, in these cases, the district should contact the state DB project (SDBP) for advice about technical assistance/support (Ferrell et al., 2014). Moreover, while literature has recommended that a teacher of the DB (TDB) be on any educational team that provides service to a learner who is DB (Ferrell et al., 
2014), none of the education files indicated the presence of a TDB on the team. With the widespread lack of trained personnel, it is possible that these school districts were unfamiliar with the services available through their SDBP staff who are trained in deafblindness to provide guidance, aid in assessment, and deliver professional development, among other things. No indication of SDBP involvement was found in any of the files for 6-year-olds or 15-to-18-yearolds.

When examining the IEPs for the learners in the 15-to-18-year-old group, only one student was provided with career (also referred to as transition) services. In IDEA (2004), the need to provide "effective transition services to promote successful post-school employment and/or education" (Section 1400(c)(14)) is described. The law further goes on to mandate that these services be addressed starting when the child is 14 years of age. That most these students did not receive career/transition services is shocking.

Also disconcerting was the wide variability from year to year of services provided across all participants. While there is the possibility that learners can develop various skills associated with different service provision and thus require less intensity, there are some skills that will not be developed to the point that no services are needed (i.e., hearing and vision loss). Therefore, it would be expected that a child with both hearing and vision loss would require individualized supports for communication as well as the services of an educational audiologist, TOD, TVI, and possibly a paraprofessional, interpreter/intervener, and/or a certified orientation and mobility specialist (COMS; Luckner, Slike, \& Johnson, 2012; Parker, McGinnity, \& Bruce, 2012; Riggio, 2009). Without knowledgeable professionals who have training in sensory impairment, the development of skills in those areas addressed by these professionals (e.g., listening, visual tracking, functional use of vision and/or hearing, O\&M skills, etc.) will regress (the loss of 
learned skills) or, worse, become extinct. If schools provide extended school year (ESY) to students based on their need for continuity of services and to prevent regression, then the same services should be provided from year to year for the same reason.

When examining educational service delivery intensity, one would expect to see direct service minutes (i.e., SET, TOD, interpreter, etc.) to have a different range of intensity than those of related service providers (i.e., adaptive physical education, APE; speech language pathologist, SLP, etc.). While most of the data supported this assumption, it was surprising to find that, in some cases, related services were assigned provision intensity comparable to direct service categories. For instance, Jack was provided 600 minutes of APE services one year and Fiona's related service of braillist/reader (BR) included 300 minutes at one time.

Without more data, it is unclear whether the number, intensity, and duration of educational service provision has any effect on the communication growth of a learner who is DB. There exist many different variables which could result in slow communication growth, however, this study was unable to identify what variables created these results. Overall, there was a lack of any examples of a learner with high outcomes or high intensity of educational services. When examining the communication growth of Terry and Ian, a clear change was observed when both learners reached adolescence. Terry's growth exhibited a dip and then leveling off while Ian's growth showed a flat trajectory. This indicates that both students were acquiring communication skills at a young age, something that is typical, however, when they reached adolescence, the growth slowed or stopped altogether. Additionally, from ages 10 through 19.5, the minutes per week provided by the SET were decreased while those of the IA were increased. This was when Ian's flat trajectory began, continuing until the end of his educational programming. 


\section{Research Question Four}

What is the trajectory of communication growth over time as measured by the $C M$ for students with both deafness and visual impairment?

Summary of Findings. Longitudinal growth modeling (LGM) was the methodology that was planned to be used to inspect the communication growth of participants over time. This method was not able to be used, therefore, descriptive statistics were used to extract the mean and standard deviation (SD) of two groups of learners (6-year-olds and 15-18-year-olds). Results indicated great variation across all categories with SD of 3.972 to 16.912 for 6-year-olds and 4.116 to 13.156 for 15 -18-year-olds.

Additionally, the differences in communication growth as measured by the $C M$ was addressed by creating a visual representation of the $C M$ scores over time. Results indicate that, while some communication growth was displayed by Terry and Ian, the growth was minimal and, compared to a typically-developing child, was extremely delayed.

Discussion. Communication is vital to learning and socialization and begins to develop in utero, providing typically developing babies approximately 20 weeks of listening experience before being born (Cole \& Flexer, 2011). When a child is born with a hearing loss (HL), they have missed those vital weeks of sound input. Additionally, hearing occurs in the brain so when an individual has a HL, the sound does not reach the brain. Important to understand is the way the brain is available and able to grow and develop (neuroplasticity; Kilgard, Vasquez, Engineer, \& Panda, 2007), most available during the first $3 \frac{1}{2} 2$ years of life and is programmed to develop specific skills during precise timeframes. For instance, to create the connections necessary in the brain to understand speech, a child needs 20,000 hours of listening in the first 5 years of their life (Cole \& Flexer, 2011). When those periods of time have passed without the skills being learned 
(or without the necessary 20,000 hours of listening in the example), the brain must be retrained and its neurons reorganized before it can learn the skill. Furthermore, Cole and Flexer (2011) state that the window of time for learning language is lost after age 8 . When auditory development is delayed, communication skills are delayed. Since hearing is the most effective way to facilitate communication, it is important that children who have a HL receive appropriate services as soon as possible to obtain the best benefit from the child's neuroplasticity (Cole \& Flexer, 2011). Finally, since the foundation for education and learning is created when a child is approximately six years old, there is a great need for highly specialized services for learners who have a dual sensory loss from professionals who are trained to address the needs of early learners with vision and/or hearing loss through early intervention (Anthony, 2014; Chen \& Haney, 1995; Ching, 2015; Jackson, Ammerman, \& Trautwein, 2015; Martin-Prudent, Lartz, Borders, \& Meehan, 2016; Nelson \& Bruce, 2016).

To examine the communication growth of learners in two different groups (6-year-olds and 15-to-18-year-olds) the mean and SD were calculated. The mean is the average value of the data whereas the SD reflects the degree to which the observed values of the variable vary around the mean. The mean for each category on the $C M$ (not used, emerging, mastered, and surpassed) were virtually the same for both groups. For instance, in the category of "mastered," the mean for 6-year-olds was 12.91 whereas the mean for the 15-to-18-year-olds was 13.7. This means that the average score (mean) for the older group was only 0.79 higher. These results seem to indicate that there was very little communication growth between the ages of six and 15-to-18years-old, however, only one learner was included in both groups (Terry). For this learner, multiple IEPs were submitted for the age of six as well as for the ages of 15 to 18 . This allowed for an examination of the means and SD of this learner at both ages. While comparing the means 
and SD of Terry shows more variation, the most change was seen in the categories of emerging and surpassed where the means increased from 0.38 to 6.71 (emerging) and from 0.5 to 3.24 (surpassed). The other two categories saw much smaller mean variation (not used $=88$ to 74.76 ; mastered $=11.13$ to 14.65$)$. While the expectation that there would be most growth in the middle (emerging and mastered), but not at the extremes (not used and surpassed), overall, this indicates that there was communication growth from age six to ages 15-to-18 for Terry.

Another important finding that emerged was that Ian showed a flat trajectory of growth of communication skills from IEP 12 through 20 (ages 11 through 21.75). With such scant growth in communicative skills, it would seem that an educational program would endeavor to increase services that would target communication, however, Ian's IEPs indicate that services were reduced or eliminated. During this time, he received basically the same number/type of educational services, however, TVI, PT, OT, and IA services were removed while SLP services were reduced. With an education program that lacks support that would help meet Ian's unique learning needs, it is not surprising that his communication growth stagnated.

One of the most significant findings across all learners in this study was that none of the students were meeting and mastering basic communication skills that a typically developing child would master by 24 months of age. This indicates that all the learners in this study were very language delayed even when growth was observed. The reason for this could not be ascertained, but one could conjecture that inconsistency in service delivery, intensity of services, and/or the duration of services contributed to the continued delay.

\section{Additional Findings}

In this comprehensive review of learner's individualized education plans (IEPs), multiple errors were noted. For instance, one student received 600 minutes of adapted physical education 
(APE) minutes while another student was assigned consult services from an individual aide (IA). Additionally, one learner's IEP, in the "Functional Level of Performance" section, showed no change in wording for five years. Also curious was the assignment of 15 minutes of service per week provision by a TVI to a learner who was in secondary education. There was no indication of whether this service was provided in conjunction with another service provider or what the TVI services would be addressing. This presents a concern about the quality of IEPs that are being written for learners who are DB. An IEP is a legal document that should be written with a high level of quality. It seems that the IEPs provided were without checks and balances and need to be reviewed.

Although not a research question, the issue of primary and secondary disability labels for educational programming emerged during this study. While this is not a new conundrum, the examination of the learners' education files illuminated it further. Federal law indicates that a primary disability is one that includes one or more of the following factors related to the disability: requires the most monetary investment and the most complex adaptations; causes the largest disparity in learning from typical development; or has the most considerable effect on academic achievement (Erin, 2007). When conducting case studies on Terry and Ian, two different problems associated with disability label emerged: change of label from year to year and inadequate label assignment. Terry's data showed many changes in disability label over the years (MD, OHI, and $\mathrm{DB}$ ) while Ian retained the label of $\mathrm{OHI}$ with no changes. While one would expect the primary label of deafblindness would be the label chosen most often, that was not the case with Terry. In 16 years of education, deafblindness was the primary label only four times (ages 13 through 18). Since both learners meet the criteria established by the Individuals with Disabilities Education Act (IDEA; comorbid vision and hearing loss regardless of severity), 
their primary disability label should have been deafblindness. Furthermore, oftentimes students are assigned secondary disability labels to more accurately describe the conditions which impact their learning. Terry only received a secondary disability label of DB on his last IEP (primary label was MD) and Ian was never assigned a secondary disability label. Although a free and appropriate public education that meets the unique communication and learning needs of every child is not to be based upon disability label, the proper identification is imperative for appropriate service provision to be determined (Bruce \& Borders, 2015). For this reason, it is alarming that both learners would not be appropriately identified as well as have so many changes in primary disability label.

These children had complex learning needs that required a team of skilled service providers who could craft an educational program that would meet both the children's unique learning needs and those of the family. Knowing that individuals who are DB often require an education program that includes a different group of service provision (in both type and intensity) than those of children who are only D/HH or only LVB (Knoors \& Vervloed, 2003), it is troubling that their primary disability labels generally did not include DB. There is a dearth of research that addresses primary disability label for children who are DB, however, Borders and colleagues (2015) found that students with MD (including deafblindness) received the least amount of services and that the primary disability label seemed to determine both the amount and type of educational services provided.

Both Terry and Ian were assigned the primary disability label of OHI at one time or another. As defined by IDEA, OHI is an umbrella term used to describe a range of conditions. In the official definition, IDEA says that OHI should be assigned to a learner: 
having limited strength, vitality, or alertness, including a heightened alertness to environmental stimuli, that results in limited alertness with respect to the educational environment, that - (a) is due to chronic or acute health problems such as asthma, attention deficit disorder or attention deficit hyperactivity disorder, diabetes, epilepsy, a heart condition, hemophilia, lead poisoning, leukemia, nephritis [a kidney disorder], rheumatic fever, sickle cell anemia, and Tourette syndrome; and (b) adversely affects a child's educational performance $[\$ 300.8(c)(9)]$

Though many learners who are DB meet the criteria for the label of OHI, such a label does not adequately describe the uniqueness of these learners.

Moreover, the primary disability label used most often on Terry's education plans was MD. As defined by IDEA, MD means:

concomitant impairments (such as mental retardation-blindness or mental retardationorthopedic impairment), the combination of which causes such severe educational needs that they cannot be accommodated in special education programs solely for one of the impairments. Multiple disabilities does not include deaf-blindness [\$300.8(c)(8)]

For this reason, the label of MD should not, according to IDEA, be used for students who are DB.

Although Terry's data indicated many changes in primary and secondary disability label, Ian only had one primary disability label, OHI. While having one primary label is preferable to changing labels from year to year, the fact remains that having a label that did not accurately describe the child's unique learning needs may have contributed to the variability in service provision. Similar to Terry, Ian did not receive any educational services that were specific to deafblindness. In fact, Ian never received services from a TOD, intervener or interpreter, 
educational audiologist, and only received minimal services from a TVI (ages 10, 11, and 14 for 40 minutes per week and age 19 for 10 minutes per week), and consult services from an O\&M, all educational services that are suggested for individuals who experience deafblindness, hearing loss and/or visual impairment.

\section{Implications for Educational Programming}

This study is important to the field of deafblindness because no one has conducted investigations into the educational services provided (number, type, and intensity) of learners who are DB. Information has been disseminated that describes different educational services that could be provided to individuals who are $\mathrm{DB}$, however, none have delved into this issue to determine how service provision is delivered for this population over time. Although no conclusive determinations could be made from the data obtained, preliminary findings indicate that service provision is highly variable in type and intensity both intra- and interindividually and that none of the participants received services from a TDB or an intervener, services that are considered beneficial to learners who are DB (Blaha et al., 2009; Parker \& Nelson, 2016).

Furthermore, an alarming number of participants either did not receive services from either a TOD or a TVI even though they all had vision loss and HI. Education personnel should consider all service providers who are essential to improving student outcomes based upon the learner's needs which, in the case of a learner who is DB, would include TDB, SDBP staff or other professionals trained in deafblindness; interveners; TODs; TVIs; and orientation and mobility specialists (O\&M). Moreover, if a child has a hearing loss, they should have, at minimum, consultation minutes with an educational audiologist (Borders et al., 2015).

Another issue that arose was the quality of IEPs for this population of learners. Since much of educational service provision was provided by SETs (over 65\%) and these are the 
professionals who are likely responsible for drafting each student's IEP, professional development opportunities should be provided regarding the unique learning needs of these students. Information about how to write applicable educational goals, working with specialized education professionals (i.e., TVI, TOD, TDB, and intervener), and ways to incorporate teaching methodologies into the learner's educational programming should also be included.

This study is also significant because it examined the longitudinal communication growth of learners who are DB, something that no other research has investigated in such a way. Although research has been conducted that focused on communication techniques and interventions for learners who are DB (Bashinski, 2011; Borders et al., 2015; Bruce, 2005; Hartmann, 2012; MacFarland, 1995; Miller, Swanson, Steele, Thelin, \& Thelin, 2011; Pittroff, 2011; Rowland, 2011; Rowland \& Schweigert, 2000; Vervloed, van Dijk, Knoors, \& van Dijk, 2006), none have measured the actual growth of communication skills of this population of learners over their educational careers. This study was a preliminary attempt to do that and provides insight into one way in which teachers and researchers could measure longitudinal communication growth of these learners.

Knowing that communication is the area that is most impacted for learners who are DB, it is important that education personnel understand that the needs of this population of learners necessitates breaking communication down to the most minute steps. As detailed previously, Rowland and Schweigert (2000) developed a sequence of communication development that addresses these unique needs: (1) preintentional behavior; (2) intentional behavior; (3) presymbolic, nonconventional communication; (4) pre-symbolic, conventional communication; (5) concrete tangible symbols; (6) use of single, abstract symbols; and (7) combinations of 2-3 abstract symbols. The $C M$ uses information provided to create a profile of communication skills 
that classifies and ranks those skills according to this sequence, providing vital information about where the child is in the developmental communication sequence. Creating a profile every year could aid professionals in determining educational plans, interventions, and provide the supports which will best meet the child's communication needs. Furthermore, by creating an annual $C M$ profile, professionals could track a child's communication growth over time as illustrated in this study.

\section{Limitations}

This study was conducted based solely upon a survey of parents and/or teachers of individuals who were DB and archival paper documentation (IEPs, multi-factored evaluations, MFE, assessment data, etc.). These documents were used to determine service provision and create $C M$ profiles. In some cases, pages were missing from the documents which may have provided more information (i.e., service provision minutes). Additionally, creating $C M$ profiles from these types of documents without the benefit of observation or speaking with individuals who know the learner well is not the same and very likely greatly underestimates or overestimates the communication skills of the learner. Some files provided much information regarding the communication skills of the student while others included scant details. Moreover, the small number of participants $(n=7)$ coupled with the highly variable number of documents submitted limited the ability to answer the research questions with more than descriptive analyses and proved to be inconclusive. More than half of the participants provided a limited number of years of information and only two participants included more than five years of data. While participants were from various parts of the United States (Midwest and Southwest), they were obtained through a convenience sample rather than by random selection. Had more participants responded and provided true longitudinal data (multiple consecutive years), the 
research questions may have been conclusively answered and limited the ability to generalize the findings to the population of learners who are DB.

Furthermore, while use of the $C M$ provided valuable quantitative data, this tool was developed to be used by individuals who are very familiar with the learner about whom they are completing the $C M$ in conjunction with observational data. For this study, the researcher used only information provided through the cumulative education files (i.e., IEPs, MFEs, assessment data, and, when available, teacher notes). When answering the $C M$ questions, the researcher only answered in the affirmative if the data clearly stated that the student performed the skill. For instance, if there was no mention of the learner using a smile to communicate, the researcher answered, "not used" to the question, "Does your child do certain things that attract your attention to him, even though he isn't purposefully trying to get your attention [by using a smile]?" This is a limitation as it is very likely that the learner's skills were underestimated.

\section{Recommendations for Future Research}

There is an overall need for research the field of deafblindness, primarily in the areas of evidence-based practices (EBPs), service provision, assessment, and in accurately measuring communication growth of learners in this population of students. Since this investigation did not achieve conclusive results, it might be important to replicate this study when enough data is obtained to answer the research questions regarding service provision and a true measure of longitudinal communication growth can be conducted. Another consideration would be to use national/state databases that have been de-identified as well as recruit from adult services to obtain longitudinal data. Furthermore, if the intensity and type of services could be controlled, a research could look for a functional relationship between service provision and learner outcomes. 
As mentioned previously, there is little research in the area of deafblindness that meets the rigorous criteria to be called EBPs (Ferrell et al., 2014). Replication studies should be conducted to build the evidence base of intervention studies. As the evidence base is built, these studies and their results should be shared not only with the research community, but also with practitioners and teacher preparation programs. As practices meet the criteria to be labeled EBPs, researchers could provide professional development workshops and suggestions for use to practitioners and institutions of higher education. These studies could also be used to provide rationale for the training and use of largely neglected services like intervener services. Further, as research is completed, it is important to share the findings with practitioners. Historically in the field of special education, dissemination of research findings has been presented in the same ways (e.g., journal articles and conference presentations), failing to meaningfully reach and promote changes among practitioners (Cook, Cook, \& Landrum, 2013; Winton, 2006). This results in a research to practice gap that must be bridged through planned, systematic efforts if the instructional choices of practitioners as well as student outcomes are to be positively impacted (Cook et al., 2013).

Although it was not an objective of the current study, the conundrum of educational disability label emerged when reviewing the data. It would be fascinating to see the results of a study that investigated the primary disability labels of students who are DB and the process by which those labels were chosen. In addition, research could be conducted that investigates the impact that primary disability label has on service provision for this population as one study's results indicated that service provision was closely linked to primary disability label (Borders et al., 2015). 
Since study did not identify whether the learners were included in their state's annual DB child count, research could examine the number of learners who meet the criteria for DB and cross reference that with the number of students reported to the SDBP for their yearly child find data. Not only would this type of investigation give information about the number of learners unidentified, it would also provide insight into the number of school districts that are familiar with their SDBPs. Part of this research could include surveying SETs and administrators to ascertain their knowledge of deafblindness; service provision, assessment practices, and available services for their students who are DB, including familiarity with their SDBP.

Finally, research could be conducted to develop a framework that might be used by educational teams when drafting IEPs and making decisions about educational programming for students with sensory disabilities, primarily those who are DB. The creation of such a framework could provide guidance to professionals when faced with students who have complex learning needs, aiding in the selection of appropriate educational services to be provided as well as the number of minutes of provision for each service and how to match educational goals with the appropriate service provider. Theoretically, a framework that helps teams determine the most appropriate services (including intensity) could improve the learning outcomes of this population of learners, which is the goal of education.

\section{Chapter Summary}

This study was an initial endeavor to examine the educational services received as well as the communication growth of learners who were DB. Educators have long struggled to identify a way to accurately measure the skills (both academic and communicative) of this population of students. The purpose of this investigation was to explore the differences in the number, type, 
and intensity of educational service provision and to measure the longitudinal communication growth of students who were DB using the $C M$.

Although the conclusions drawn from this study are preliminary and non-conclusive, they indicate that educational services that include professionals trained in deafblindness (TDB, SDBP staff), HI (TOD) and/or VI (TVI) are not consistently being provided to learners who are DB. The results also indicate that service provision is highly variable both intra- and interindividually which could hinder learner outcomes. Finally, using the $C M$ to create communication profiles for two learners allowed for the creation of a visual representation of longitudinal communication growth which indicated minimal and dramatically-delayed growth as compared to typically developing learners.

Recommendations were made to replicate this study, conduct replication studies to build the evidence base for the field of deafblindness, and to investigate the primary disability label (process by which it is chosen and the impact on service provision). It is imperative to provide appropriate educational supports to increase learner outcomes. Foundational to increased learner outcomes for this population of students is communication. As communication grows, bridges to educational growth are created and, as is the goal of all educators, the outcomes of learners who are DB are likely to increase as well. 


\section{REFERENCES}

Aitken, S. (1995). Educational assessment of deafblind learners. In D. Etheridge (Ed.), The education of dual sensory impaired children: Recognising and developing ability (pp. 114). London: David Fulton Publishers.

Alsop, L., Killoran, J., Robinson, C., Durkel, J., \& Prouty, S. (2004). Recommendations on the training of interveners for students who are deafblind. Retrieved from http://www.perkinselearning.org/sites/elearning.perkinsdev1.org/files/desg_appendix_c.p df

American Physical Therapy Association (2016). Role of a physical therapist. Retrieved from http://www.apta.org/PTCareers/RoleofaPT/

Anthony, T. L. (2014). Family support and early intervention services for the youngest children with visual impairments. Journal of Visual Impairment \& Blindness, 108(6), 514-519.

Armstrong, T. W., Surya, S., Elliott, T. R., Brossart, D. F., \& Burdine, J. N. (2011). Depression and health-related quality of life among persons with sensory disabilities in a health professional shortage area. Rehabilitation Psychology, 61, 240-250.

doi:10.1037/rep0000083

ASHA (2016). Speech-language pathologists: About speech-language pathology. Retrieved from http://www.asha.org/Students/Speech-Language-Pathologists/

Assessment (n.d.). In Deafblindness educational service guidelines. Retrieved from http://www.perkinselearning.org/sites/elearning.perkinsdev1.org/files/desg_ch3_assessm ent.pdf

Baer, J., \& Schmitz, M. F. (2000). Latent growth curve modeling with a cohort sequential design. Social Work Research, 24, 243-247. doi:10.1093/swr/24.4.243 
Basic skills infused skills assessment. Retrieved from http://www.tsbvi.edu/handouts/oct06/infused-skills-assessment.pdf

Bashinski, S. M. (2011). Communication programming for learners with CHARGE syndrome: Augmenting comprehension and expression. Perspectives on Augmentative \& Alternative Communication, 24, 86-93.

Belanich, J. (1995). Increasing independence and freedom with high tech aids and devices. American Rehabilitation, 21, 15-18.

Bennett, F., Hughes, A., \& Hughes, H. (1979). In brief: Assessment techniques for deaf-blind children. Exceptional Children, 45, 287-289.

Berlin, K. S., Parra, G. R., \& Williams, N. A. (2014). An introduction to latent variable mixed modeling (part 2): Longitudinal latent class growth analysis and growth mixture models. Journal of Pediatric Psychology, 39, 188-203. doi:10.1093/jpepsy/jst085

Best, C. (1983). The 'new' deafblind? Results of a national survey of deaf-blind children in ESN(S) and hospital schools. British Journal of Visual Impairment, 1(2), 11-13. doi:10.1177/026461968300100205

Best, T. (2003). New concepts in deafblindness. Proceedings of the 13th DbI World Conference on Deafblindness. Brandtford, Ontario: Canadian Deafblind and Rubella Association.

Blaha, R. (2001). Calendars for students with multiple impairments including deafblindness. Texas School for the Blind and Visually Impaired.

Blaha, R. (2002). Using calendar systems with children with deafblindness. In I. Alsop (Ed.), Understanding deafblindness: Issues, perspectives, and strategies, (Vol 1, pp. 467-481). Logan: Utah State University, SKI-HI Institute. 
Blaha, R., \& Carlson, B. (2007). Assessment of deafblind access to manual language systems $(A D A M L S)$ [Measurement instrument]. Retrieved from http://www.dblink.org/pdf/adamls.pdf

Blaha, R., Cooper, H., Irby, P., Montgomery, C., \& Parker, A. (2009). Teachers of students with deafblindness: Professionalizing the field. DVI Quarterly, 54(3). Retrieved from http://documents.nationaldb.org/products/dviqblaha.pdf

Borders, C. M., Meinzen-Derr, J., Wiley, S., Bauer, A., \& Embury, D. C. (2015). Students who are deaf with additional disabilities: Educational label impact language services? Deafness \& Education International, 17(4), 204-218.

doi:10.1179/1557069X15Y.0000000006

Bourquin, E., \& Sauerburger, D. (2005). Teaching deaf-blind people to communicate and interact with the public: Critical issues for travelers who are deaf-blind. RE:view, 37, 109-116.

Bracken, M., \& Rohrer, N. (2013). Using an adapted form of the Picture Exchange Communication System to increase independent requesting in deafblind adults with learning disabilities. Research in Developmental Disabilities, 35, 269-277.

Brady, N. C., \& Bashinski, S. M. (2008). Increasing communication in children with concurrent vision and hearing loss. Research and Practice for Persons with Severe Disabilities: The Journal of TASH, 33, 59-70. doi:10.2511/rpsd.33.1-2.59

Brody, J. (2003). Occupational therapy for young children with visual impairments and additional disabilities. Retrieved from http://www.projectsalute.net/Learned/Learnedhtml/OccupationalTherapy.html 
Brown, D., \& Bates, E. (2005). A personal view of changes in deaf-blind population, philosophy, and needs. Deaf-Blind Perspectives, 12(3), 1-5.

Bruce, S. M. (2002). Impact of a communication intervention model on teachers' practice with children who are congenitally deaf-blind. Journal of Visual Impairment \& Blindness, 96, 154-168.

Bruce, S. M. (2005). The impact of congenital deafblindness on the struggle to symbolism. International Journal of Disability, Development, and Education, 52, 233-251.

Bruce, S. M. (2007). Using action plans to support communication programming for children who are deafblind. RE:view, 39(2), 71-83. doi:10.3200/revu.39.2.71-84

Bruce, S. M., \& Borders, C. (2015). Communication and language in learners who are deaf and hard of hearing with disabilities: Theories, research, and practice. American Annals of the Deaf, 160(4), 368-384. doi:10.1353/aad.2015.0035

Bruce, S. \& Conlon, K. (2005). Colby's Daily Journal: A School-Home Effort to Promote Communication Development. TEACHING Exceptional Children Plus, 2(1) Article 3. Retrieved from http://files.eric.ed.gov/fulltext/EJ966531.pdf

Bruce, S., Randall, A., \& Birge, B. (2008). Colby’s growth to language and literacy: The achievements of a child who is congenitally deafblind. TEACHING Exceptional Children Plus, 5(2) Article 6. Retrieved from http://files.eric.ed.gov/fulltext/EJ967739.pdf

Bruce, S. M., Trief, E., \& Cascella, P. W. (2011). Teachers' and speech-language pathologists' perceptions about a tangible symbols intervention: Efficacy, generalization, and recommendations. Augmentative and Alternative Communication, 27, 172-182. doi:10.3109/07434618.2011.610354 
Cascella, P. W., Trief, E., \& Bruce, S. M. (2012). Comparing parent and teacher ratings of communication among children with severe disabilities and visual impairment/blindness. Communication Disorders Quarterly, 33, 249-251. doi:10.1177/1525740112448249

Certified orientation and mobility specialist (COMS) (2016). Retrieved from https://www.acvrep.org/certifications/coms

CHARGE syndrome. (2016, April 26). Retrieved from https://ghr.nlm.nih.gov/condition/chargesyndrome

Chen, D., Alsop, L., \& Minor, L. (2000). Research to practice: PLAI curriculum modules and case study. Deaf-Blind Perspectives, 7(3), 5-8.

Chen, D., Downing, J., \& Rodriguez-Gil, G. (2001). Tactile learning strategies for children who are deaf-blind: Concerns and considerations from Project Salute. Deaf-Blind Perspectives, 8(2), 1-6. Retrieved from http://www.projectsalute.net/Learned/Learnedhtml/TactileLearningStrategies.html

Chen, D., \& Haney, M. (1995). An early intervention model for infants who are deaf-blind. Journal of Visual Impairment \& Blindness, 89(3), 213.

Chen, D., Stillman, R., Mar, H., \& Rowland, C. (2009). Recommended practices for assessing communication and learning skills in young children who are deafblind [PowerPoint slides]. Retrieved from http://www.ohsu.edu/oidd/d21/com_pro/db_assess_ab.cfm

Ching, T. C. (2015). Is early intervention effective in improving spoken language outcomes of children with congenital hearing loss? American Journal of Audiology, 24(3), 345-348. doi:10.1044/2015_AJA-15-0007

Cloninger, C. J., \& Giangreco, M. F. (1995). Including students with deaf-blindness in general education classes. Journal of Visual Impairment \& Blindness, 89, 262-266. 
CMU online certificate to train deafblind interveners (2016, April 27). Retrieved from https://www.cmich.edu/news/article/Pages/deafblindintervener.aspx

Cochlear Implants (2016). Retrieved from https://www.nidcd.nih.gov/health/cochlear-implants

Cole, E. B., \& Flexer, C. (2011). Neurological foundations of listening and talking. In Children with hearing loss: Developing listening and talking (pp. 1-16). San Diego, CA: Plural Publishing Inc.

Collins, M. T. (1995). History of deaf-blind education. Journal of Visual Impairment \& Blindness, 89, 210-212.

Congenital rubella (2015, April 21). Retrieved from https://medlineplus.gov/ency/article/001658.htm

Connor, C. M., Craig, H. K., Raudenbush, S. W., Heavner, K., \& Zwolan, T. A. (2006). The age at which young deaf children receive cochlear implants and their vocabulary and speechproduction growth: Is there an added value for early implantation? Ear \& Hearing, 27, 628-644. doi:0196/0202/06/2706-0628/0

Cook, B. B., Cook, L., \& Landrum, T. J. (2013). Moving research into practice: Can we make dissemination stick? Exceptional Children, 79(2), 163-180. doi:10.1177/001440291307900203

Crook, C., Miles, B., \& Riggio, M. (1999a). Developing early communication and language. In B. Miles \& M. Riggio (Eds.), Remarkable conversations: A guide to developing meaningful communication with children and young adults who are deafblind (pp. 146179). Watertown, MA: Perkins School for the Blind. 
Crook, C., Miles, B., \& Riggio, M. (1999b). Selection of communication modes. In B. Miles \& M. Riggio (Eds.), Remarkable conversations: A guide to developing meaningful communication with children and young adults who are deafblind (p. 126-145). Watertown, MA: Perkins School for the Blind.

Curran, P. J., Obeidat, K., \& Losardo, D. (2010). Twelve frequently asked questions about growth curve modeling. Journal of Cognition and Development, 11, 121-136. doi:10.1080/15248371003699969

Curriculum Associates (2016). BRIGANCE IED III-Early Childhood Edition. Retrieved from http://www.curriculumassociates.com/products/detail.aspx?title=BrigECIED3\#additional_nav

Dammeyer, J. (2009). Congenitally deafblind children and cochlear implants: Effects on communication. Journal of Deaf Studies \& Deaf Education, 14, 278-288. doi:10.1093/deafed/enn042

Dammeyer, J. (2010). Prevalence and aetiology of congenitally deafblind people in Denmark. International Journal of Audiology, 49(2), 76-82. doi:10.3109/14992020903311388

Dammeyer, J. (2011). Mental and behavioral disorders among people with congenital deafblindness. Research in Developmental Disabilities, 32, 571-575. doi:10.1016/j.ridd.2010.12.019

Dammeyer, J. (2012). Identification of congenital deafblindness. British Journal of Visual Impairment, 30, 101-107. doi:10.1177/0264619612443882

Dammeyer, J. (2014). Symptoms of autism among children with congenital deafblindness. Journal of Autism and Developmental Disorders, 44, 1095-1102. doi:10.1007/s10803013-1967-8 
Davis, R., French, L. S., Felix, M., Tymeson, G., Kelly, L., Lytle, R., \& Webbert, L. (n.d.). Preparing qualified and effective adapted physical educators to improve outcomes for students with disabilities. Retrieved from http://personnelcenter.org/documents/nasdse\%20ape\%20webinar\%20\%20final\%20slides_logo.pdf

de Courson, C. (1907). Helen Keller's French sister. Catholic World, 86, 57-67. Retrieved from https://books.google.com/books?id=1b7doJHH4jcC\&pg=PA63\&lpg=PA63\&dq=Marie+ Heurtin+education\&source=bl\&ots=Ojty4UXBem\&sig=re9D9wCeuoZE47t3FhWklFoU DVM\&hl=en\&sa=X\&ved=0ahUKEwjBsf2Ds5fNAhUMPIIKHTduBQg4ChDoAQgjMA $\mathrm{E} \# \mathrm{v}=$ onepage $\& \mathrm{q}=$ Marie $\% 20$ Heurtin $\% 20$ education $\& \mathrm{f}=$ false

Diebold, M. H., Curtis, W. S., \& DuBose, R. F. (1978). Developmental scales versus observational measures for deaf-blind children. Exceptional Children, 44, 275-278.

Dignan, K. C. (n.d.). Chapter 11: Expanded core curriculum. Retrieved from http://www.tsbvi.edu/program-and-admin-resources-items/4373-tb-ecc

Down Syndrome (2016). Retrieved 10/19/2016 from https://ghr.nlm.nih.gov/condition/downsyndrome

Durand, V. M., \& Kishi, G. (1987). Reducing severe behavior problems among persons with dual sensory impairments: An evaluation of a technical assistance model. Research and Practice for Persons with Severe Disabilities, 12, 2-10. doi:10.1177/154079698701200102

Durkel, J. (2010). Formal versus informal hearing tests: What is functional hearing? SEE/HEAR Newsletter. Retrieved from https://www.tsbvi.edu/seehear/summer05/functional.htm Education of the Handicapped Act of 1975, Pub. L. No. 94-142, 20 U.S.C. §1401 (1975). 
Ellis, M. E. (2013). Goldenhar syndrome. Retrieved from http://www.healthline.com/health/goldenhar-syndrome\#Symptoms2

Emerson, J., \& Bishop, J. (2012). Videophone technology and students with deaf-blindness: A method for increasing access and communication. Journal of Visual Impairment \& Blindness, 106, 622-633.

Enerstvedt, R. T. (1996). Legacy of the past: Those who are gone but have not left. Dronninglund, Denmark: Forlaget Nord-Press.

Engleman, M. D., Griffin, H. C., Griffin, L. W., \& Maddox, J. I. (1999). A teacher's guide to communicating with students with deaf-blindness. Teaching Exceptional Children, 31(5), 64-70. doi:10.1177/004005999903100510

Engleman, M. D., Griffin, H. C., \& Wheeler, L. (1998). Deaf-Blindness and communication: Practical knowledge and strategies. Journal of Visual Impairment \& Blindness, 92(11), 783-98.

Erber, N. (1982). Auditory Training. Washington, DC: Alexander Graham Bell Association for the Deaf.

Erin, J. N. (2007). Identifying the primary disability: Are we speaking the same language? Journal of Visual Impairment \& Blindness, 101(10), 582-585.

Evenhuis, H. M. (1996). Dutch consensus on diagnosis and treatment of hearing impairment in children and adults with intellectual disability. The Consensus Committee. Journal of Intellectual Disability Research, 40(5), 451-456. doi:10.1046/j.1365-2788.1996.788788.x

Everson, J. M. (1995). Supporting young adults who are deaf-blind in their communities: A transition planning guide for service providers, families, and friends. Baltimore, MD: Paul H Brookes Pub Co. 
Eyre, J. T. (2002). Holistic assessment. In S. Aitken, M. Buultjens, C. Clark, J. T. Eyre, \& L. Pease (Eds.), Teaching children who are deafblind: Contact communication and learning (pp. 119-140). London, England: David Fulton.

Ferrell, K. A., Bruce, S., \& Luckner, J. L. (2014). Evidence-based practices for students with sensory impairments (Document No. IC-4). Retrieved from University of Florida, Collaboration for Effective Educator, Development, Accountability, and Reform Center Retrieved from http://ceedar.education.ufl.edu/tools/innovation-configurations/

Fewell, R. R. (1991). Trends in the assessment of infants and toddlers with disabilities. Exceptional Children, 58, 166-173. doi:10.1177/001440299105800208

Finn, D. M., \& Fewell, R. R. (1994). The use of play assessment to examine the development of communication skills in children who are deaf-blind. Journal of Visual Impairment \& Blindness, 88, 349.

Gast, D. L., \& Ledford, J. R. (2014). Applied research in education and behavioral sciences. In D. L. Gast \& J. R. Ledford (Eds.), Single case research methodology: Applications in special education and behavioral sciences (pp. 1-18). New York, NY: Routledge.

Giangreco, M. F., \& Doyle, M. B. (2002). Students with disabilities and paraprofessional supports: Benefits, balance, and band-aids. Focus on Exceptional Children, 34, 1-12.

Goodall, D., \& Everson, J. M. (1995). Communication instruction and support strategies for young adults who are deaf-blind. In J. M. Everson (Ed.), Supporting young adults who are deaf-blind in their communities: A transition planning guide for service providers, families, and friends (pp. 203-226). Baltimore, MD: Paul H. Brookes. 
Grilli, L., \& Varriale, R. (2014). Specifying measurement error correlations in latent growth curve models with multiple indicators. Methodology, 10, 117-125. doi:10.1027/1614$2241 / \mathrm{a} 000082$

Hagood, L. (2006). Basic Skills Infused skills assessment. Retrieved from http://www.tsbvi.edu/handouts/oct06/infused-skills-assessment.pdf

Harris, J., et al., (2003). HomeTalk: A family assessment of children who are deafblind. Monmouth, OR: DB-LINK.

Hartmann, E. S. (2012). A socio-cognitive approach to how children with deafblindness understand symbols. International Journal of Disability, Development, and Education, 59, 131-144. doi:10.1080/1034912x.2012.676373

Hartshorne, T. (2011). Understanding behavior in CHARGE syndrome. In U. Horsch \& A. Scheele (Eds.), Compendium on CHARGE syndrome (pp. 189-200). Heidelberg, Germany: MedianVerlag von Killisch-Horn GmbH.

Hartshorne, T. S., \& Cypher, A. D. (2004). Challenging Behavior in CHARGE Syndrome. Mental Health Aspects of Developmental Disabilities, 7, 41-52.

Hartshorne, T. S., Hefner, M. A., \& Davenport, S. L. H. (2000). Behavior in CHARGE syndrome: Introduction to the special topic. American Journal of Medical Genetics, Part A(133A), 228-231. doi:10.1002/ajmg.a.30541

Hartshorne, T. S., Nicholas, J., Grialou, T. L., \& Russ, J. M. (2007). Executive function in CHARGE syndrome. Child Neuropsychology, 13, 333-344.

doi:10.1080/09297040600850944 
Hayes, H., Geers, A. E., Treiman, R., \& Moog, J. S. (2009). Receptive vocabulary development in deaf children with cochlear implants: Achievement in an intensive auditory-oral educational setting. Ear \& Hearing, 30, 128-135. doi:10.1097/aud.0b013e3181926524

Head Start (2014). Early childhood health and wellness. Retrieved from https://eclkc.ohs.acf.hhs.gov/hslc/tta-system/health/link-between/five-domains.html

Heller, K. W. S., Ware, S., Allgood, M. H., \& Castelle, M. (1994). Use of dual communication boards with students who are deaf-blind. Journal of Visual Impairment \& Blindness, 88, $368-376$.

Hersh, M. (2013). Deafblind people, communication, independence, and isolation. Journal of Deaf Studies and Deaf Education, 18, 446-463. doi:10.1093/deafed/ent022

Hodges, L. (2002). Effective teaching and learning. In S. Aitken, M. Buultjens, C. Clark, J. T. Eyre, \& L. Pease (Eds.), Teaching children who are deafblind: Contact communication and learning (pp. 167-199). London, England: David Fulton.

Hofmann, A. O. (2016). What parents need to know about school-based occupational therapy. Retrieved from http://www.aota.org/about-occupationaltherapy/professionals/cy/articles/school-consumer.aspx

Holte, L., Prickett, J. G., Van Dyke, D. C., Olson, R. J., Lubrica, P., Knutson, J. F., Brennan, S. (2006). Inquiry into the adequacy of services to meet the developmental needs of Western Australia's children. Deaf-Blind Perspectives, 7(3), 1-5.

Horner, R. H., Carr, E. G., Halle, J., McGee, G., Odom, S., \& Wolery, M. (2005). The use of single-subject research to identify evidence-based practice in special education. Council for Exceptional Children, 71(2), 165-179. doi:10.1177/001440290507100203 
Horvath, L. S., Kampfer-Bohach, S., \& Kearns, J. F. (2005). The use of accommodations among students with deafblindness in large-scale assessment systems. Journal of Disability Policy Studies, 16, 177-187. doi:10.1177/10442073050160030501

Huebner, K. M., \& Prickett, J. G. (1996). A self-study and in-service training program for individuals who work with people who are deaf-blind. RE:view, 27(4), 159-173.

Huebner, K. M., Kirchner, C., \& Prickett, J. G. (1995). Meeting personnel training needs: The Deaf-Blind Self-Study Curriculum Project. Journal of Visual Impairment \& Blindness, 89, 235-243.

Hull, W., \& Hull, L. (2006). Personal perspectives: Services for individuals who are deaf-blind must be lifelong. Deafblind Perspectives, 13(3), 6-7.

IBM Corp. (2012). IBM SPSS statistics for Windows, version 21.0. Armonk, NY: IBM Corp.

ISBE (2014). Illinois alternate assessment participation guide. Retrieved from http://www.isbe.net/assessment/pdfs/2014/iaa/IAA_Partic_Gdlines.pdf

Individuals With Disabilities Education Improvement Act, 20 U.S.C. $§ 1400$ (2004). Retrieved from http://idea.ed.gov/download/statute.html

Individuals With Disabilities Education Improvement Act, 20 U.S.C. $\$ 300.8$ (2004). Retrieved from https://sites.ed.gov/idea/regs/b/a/300.8

Individuals With Disabilities Education Improvement Act Amendments of 2004, Pub. L. No., 20 U.S.C. $§ 1400$. Retrieved from http://idea.ed.gov/download/statute.html

Jackson, R. W., Ammerman, S. B., \& Trautwein, B. A. (2015). Deafness and diversity: Early intervention. American Annals of the Deaf, 160(4), 356-367. doi:10.1353/aad.2015.0034 
Jackson, C. W., \& Schatschneider, C. (2014). Rate of language growth in children with hearing loss in an auditory-verbal early intervention program. American Annals of the Deaf, 158, 539-554. doi:10.1353/aad.2014.0006

Janssen, M. J., Riksen-Walraven, J. M., \& Van Dijk, J. P. (2002). Enhancing the quality of interaction between deafblind children and their educators. Journal of Developmental and Physical Disabilities, 14, 87-109. doi:10.1023/a:1013583312920

Janssen, M. J., Riksen-Walraven, J. M., \& van Dijk, J. P. M. (2003a). Contact: Effects of an intervention program to foster harmonious interactions between deaf-blind children and their educators. Journal of Visual Impairment \& Blindness, 97, 215-229.

Janssen, M. J., Riksen-Walraven, J. M., \& van Dijk, J. P. (2003b). Toward a diagnostic intervention model for fostering harmonious interactions between deaf-blind children and their educators. Journal of Visual Impairment \& Blindness, 97, 197-214.

Janssen, M. J., Riksen-Walraven, J. M., \& van Dijk, J. P. (2004). Enhancing the interactive competence of deafblind children: Do intervention effects endure? Journal of Developmental and Physical Disabilities, 16, 73-94.

doi:10.1023/b:jodd.0000010040.54094.0f

Janssen, M., Riksen-Walraven, J. M., \& van Dijk, J. (2006). Applying the diagnostic intervention model for fostering harmonious interactions between deaf-blind children and their educators: A case study. Journal of Visual Impairment \& Blindness, 100(2), 91-105.

Janssen, M. J., Riksen-Walraven, J. M., van Dijk, J. P. M., Huisman, M., \& Ruijssenaars, W. A. J. J. M. (2011). Fostering harmonious interactions in a boy with congenital deafblindness: A single-case study. Journal of Visual Impairment \& Blindness, 105, 177-183. 
Janssen, M. J., Riksen-Walraven, J. M., van Dijk, J. P. M., Ruijssenaars, W. A. J. J. M., \& Vlaskamp, C. (2007). Team interaction coaching with educators of adolescents who are deaf-blind: Applying a diagnostic intervention model. Journal of Visual Impairment \& Blindness, 101, 677-689.

Joffee, E. (1995). Approaches to teaching orientation and mobility. In K. M. Huebner, J. G.

Prickett, T. R. Welch, \& E. Joffee (Eds.), Hand in hand: Essentials of communication and orientation and mobility for your students who are deaf-blind (pp. 575-611). New York, NY: AFB Press.

Joffee, E., \& Rikhye, C. H. (1991). Orientation and mobility for students with severe visual and multiple impairments: A new perspective. Journal of Visual Impairment \& Blindness, 85, $137-142$.

Johnson-Martin, N. M. (1991). The Carolina curriculum for infants and toddlers with special needs. Baltimore, MD: Paul H. Brookes Publishing Co.

Jones, C. J. (2002). Evaluation and educational programming of students with deafblindness and severe disabilities (2nd ed.). Springfield, IL: Charles C. Thomas.

Ke, Z., \& Wang, L. (2015). Detecting individual difference in change: Methods and comparisons. A Multidisciplinary Journal, 22, 382-400.

doi:10.1080/10705511.2014.936096

Kilgard, M. P., Vasquez, J. L., Engineer, N. D., \& Pandya, P. K. (2007). Experience dependent plasticity alters cortical synchronization. Hearing Research, 229, 171-179. doi:10.1016/j.heares.2007.01.005 
Knoors, H., \& Vervloed, M. P. (2003). Educational programming for deaf children with multiple disabilities: Accommodating special needs. Oxford handbook of deaf studies, language, and education, 82-94.

Koenig, A. J., \& Holbrook, M. C. (1995). Learning media assessment of students with visual impairments: A resource guide for teachers (2nd ed.). Austin, TX: Texas School for the Blind and Visually Impaired.

Kontak, D. (2012). School social worker's role. Retrieved from http://www.sswaa.org/?page=721

Lagati, S. (1995). 'Deaf-blind' or 'deafblind'? International perspectives on terminology. Journal of Visual Impairment \& Blindness, 89, 306.

Legal Information Institute (n.d.). 29 U.S. Code § 1905-Definitions. Retrieved from https://www.law.cornell.edu/uscode/text/29/1905

Lancioni, G. E. (1980). Teaching independent toileting to profoundly retarded deaf-blind children. Behavior Therapy, 11, 234-244. doi:10.1016/s0005-7894(80)80023-2

Lancioni, G. E., Bellini, D., \& Oliva, D. (1993a). A robot to provide multihandicapped blind persons with physical guidance and activity choices. Journal of Developmental and Physical Disabilities, 5, 337-348. doi:10.1007/bf01046390

Lancioni, G. E., Bellini, D., \& Oliva, D. (1993b). Brief report: Building choice opportunities within a robot-assisted occupational program: A case study. Behavioral Residential Treatment, 8, 219-226. doi:10.1002/bin.2360080305

Lancioni, G. E., Bellini, D., Oliva, D., Guzzini, F., \& Pirani, P. (1989). A robot for guiding multihandicapped blind persons to carry out familiar daily activities. Journal of the Multihandicapped Person, 2, 271-282. doi:10.1007/bf01098169 
Lancioni, G. E., Mantini, M., Cognini, I., \& Pirani, P. (1988). Facilitating ambulation and activity in persons with profound multiple disabilities through a visual orientation system. Behavioral Interventions, 13, 123-133. doi:10.1002/(sici)1099078x(199805)13:2\%3C123::aid-bin11\%3E3.0.co;2-t

Lancioni, G. E., Oliva, D., \& Bartolini, T. (1990). A blind woman who is mentally retarded promoting and sharing the occupational engagement of a dependent deaf-blind adolescent. Behavioral Interventions, 5, 149-157. doi:10.1002/bin.2360050303

Lancioni, G. E., Oliva, D., Formica, M. M., \& Rossetti, A. (1988). Applicability of a computeraided program to increase the occupational engagement of low-functioning blind persons. Journal of the Multihandicapped Person, 1, 271-280. doi:10.1007/bf01098803

Larsen, F. A., \& Damen, S. (2014). Definitions of deafblindness and congenital deafblindness. Research in Developmental Disabilities, 35, 2568-2576. doi:10.1016/j.ridd.2014.05.029

Lewis, S., \& Russo, R. (1998). Educational assessment for students who have visual impairments with other disabilities. In S. Z. Saks \& R. K. Silberman (Eds.), Educating students who have visual impairments with other disabilities (pp. 39-71). Baltimore, MD: Paul H. Brookes Publishing Company.

Literacy (2016). Retrieved from http://www.dictionary.com/browse/literacy Lolli, D., Sauerburger, D., \& Bourquin, E. A. (2010). Teaching orientation and mobility to students with vision and hearing loss. In W. R. Wiener, R. L. Welsh, \& B. B. Blasch (Eds.), Foundations of orientation and mobility: Vol. II. Instructional strategies and practical applications (pp. 537-563). New York, NY: AFB Press. 
Loumiet, R., \& Levack, N. (1993). Independent living: A curriculum with adaptations for students with visual impairment. Austin, TX: Texas School for the Blind.

Luckner, J. L., Bruce, S. M., \& Ferrell, K. A. (2016). A summary of the communication and literacy evidence-based practices for students who are deaf or hard of hearing, visually impaired, and deafblind. Communication Disorders Quarterly, 37, 225-241. doi:10.1177/1525740115597507

Luckner, J. L., Slike, S. B., \& Johnson, H. (2012). Helping students who are deaf or hard of hearing succeed. Teaching Exceptional Children, 44(4), 58-67. doi:10.1177/004005991204400406

Luft, P., Rumrill, P., Snyder, J. L., \& Hennessey, M. (2001). Transition strategies for youths with sensory impairments: Educational, vocational and independent living considerations. Work, 17, 125-134.

Luiselli, J. K. (1988a). Behavioral feeding intervention with deaf-blind, multihandicapped children. Child \& Family Behavior Therapy, 10, 49-62. doi: dx.doi.org/10.1300/j019v10n04_06

Luiselli, J. K. (1988b). Improvement of feeding skills in multihandicapped children through paced-prompting interventions. Journal of the Multihandicapped Person, 1, 17-30. doi: $10.1007 / \mathrm{bf} 01110553$

Luiselli, J. K. (1993). Training self-feeding skills in children who are deaf and blind. Behavior Modification, 17, 457-473. doi:10.1177/01454455930174003

MacFarland, S. Z. C. (1995). Teaching strategies of the van Dijk curricular approach. Journal of Visual Impairment \& Blindness, 89, 222-228. 
Malloy, P., McGinnity, B., Kenley, J., Vellia, P., \& Voelker, S. (2009). Transition. Perspectives, 4.

Mar, H., \& Sall, N. (1999). Dimensions of communication. An instrument to assess the communication skills and behaviors of individuals with disabilities. New York: St. Luke's-Roosevelt Hospital Center.

Marks, S. B., \& Feeley, D. (1995). Transition in action: Michigan's Martin, N. (2006). Test of Visual Perceptual Skills, (TVPS-3). Florida: PAR.

Martin-Prudent, A., Lartz, M., Borders, C., \& Meehan, T. (2016). Early intervention practices for children with hearing loss. Communication Disorders Quarterly, 38(1), 13-23. doi:10.1177/1525740115597861

McGinnity, B. (2008). CHARGE Syndrome: Technical assistance (TA) for children with combined hearing and vision loss (deafblindness). Retrieved from http://www.chargesyndrome.org/professional\%20packet/8\%20technical\%20assistance.pd f

McKelvey, J. L., Sisson, L. A., Van Hasselt, V. B., \& Hersen, M. (1992). An approach to teaching self-dressing to a child with dual sensory impairment. Teaching Exceptional Children, 25, 12-15.

McKenzie, A. R. (2007). The use of learning media assessments with students who are deafblind. Journal of Visual Impairment \& Blindness, 101, 587-600.

McKenzie, A. R. (2009). Practice report: Unique considerations for assessing the learning media of students who are deaf-blind. Journal of Visual Impairment \& Blindness, 103, 241-245.

McKenzie, A. R., \& Davidson, R. (2007). The emergent literacy of preschool students who are deaf-blind: A case study. Journal of Visual Impairment \& Blindness, 101, 720-725. 
McLetchie, B. A. B. (1993). Personnel preparation: Presentation. In J. W. Reiman and P. A. Johnson (Eds.), Proceedings of the National Symposium on Children and Youth Who Are Deaf-Blind (pp. 145-158). Monmouth, OR: Teaching Research Publications.

McLetchie, B. A. B. (1995). Teacher preparation. In N. G. Haring \& L. T. Romer (Eds.), Welcoming students who are deafblind into typical classrooms: Facilitating school participation learning, and friendships (pp. 89-104). Baltimore, MD: Paul H. Brookes.

McLetchie, B. A. B., \& Riggio, M. (1997). Competencies for teachers of learners who are deafblind. Watertown, MA: Perkins School for the Blind.

Michael, M. G., \& Paul, P. V. (1991). Early intervention for infants with deaf-blindness. Exceptional Children, 57, 200-210.

Miles, B. (2005). Literacy for persons who are deaf-blind. Retrieved from https://nationaldb.org/library/page/1935

Miles, B. (2008, October 1). Overview on deaf-blindness. Retrieved from https://nationaldb.org/library/page/1934

Miller, K. B., \& Peck, F. R. (1995). Outreach low vision services to children with deaf-blindness. Journal of Visual Impairment \& Blindness, 89, 267-271.

Miller, E. K., Swanson, L. A., Steele, N. K., Thelin, S. J., \& Thelin, J. W. (2011). Forms and functions in communication. In T. S. Hartshorne, M. A. Hefner, S. L. H. Davenport, \& J. W. Thelin (Eds.), CHARGE syndrome (pp. 295-313). San Diego, CA: Plural.

Mirenda, P. (1997). Supporting individuals with challenging behavior through functional communication training and AAC: Research review. Augmentative and Alternative Communication, 13, 207-225. doi:10.1080/07434619712331278048 
Moebius syndrome (2016, June 28). Retrieved from https://ghr.nlm.nih.gov/condition/moebiussyndrome

Montgomery, C. (2015). Teacher of students with deafblindness pilot part 1. TX Sense Abilities, Fall/Winter. Retrieved from http://www.tsbvi.edu/fall-winter-2015/4568-teacher-ofstudents-with-deafblindness-pilot-part-1

Morgan, E. C. (1989). The INSITE Model: A Model of Home Intervention for Infant, Toddler, and Preschool Aged Multihandicapped Sensory Impaired Children. Retrieved from http://www.skihi.org/INSITE.html

NASP (2015). Who are school psychologists. Retrieved from https://www.nasponline.org/aboutschool-psychologists

National Center on Deafblindness (2012a). Current intervener training programs and activities [Data set]. Retrieved from http://documents.nationaldb.org/products/current\%20training\%20programs.pdf

National Early Childhood Technical Assistance Center (NECTAC) (2016). Retrieved from http://fpg.unc.edu/projects/national-early-childhood-technical-assistance-center-nectac

National Organization for Rare Disorders (2015). Stickler syndrome. Retrieved from https://rarediseases.org/rare-diseases/stickler-syndrome/

NCEO (2016). Alternate assessments for students with disabilities. Retrieved from https://nceo.info/Resources/publications/TopicAreas/AlternateAssessments/altAssessTop ic.htm

Nelson, B. (2005). Creating positive outcomes for deafblind youth and young adults: A personal futures planning transition model. Re:view, 36, 173-181. doi:10.3200/revu.36.4.173-180 
Nelson, C., \& Bruce, S. M. (2016). Critical issues in the lives of children and youth who are deafblind. American Annals of the Deaf, 161(4), 406-411.

Nelson, C., Janssen, M., Oster, T., \& Jayaraman, G. (2010). Reliability of the van Dijk assessment for children with deaf-blindness. AER Journal, 3, 71-80.

Nelson, C., van Dijk, J., McDonnell, A. P., \& Thompson, K. (2002). A framework for understanding young children with severe multiple disabilities: The van Dijk approach to assessment. Research and Practice for Persons with Severe Disabilities, 27, 97-111. doi:10.2511/rpsd.27.2.97

Nelson, C., van Dijk, J., Oster, T., \& McDonnell, A. P. (2009). Child-guided strategies: The van Dijk approach to assessment for understanding children and youth with sensory impairments and multiple disabilities. Louisville, KY: American Printing House for the Blind.

No Child Left Behind Act of 2001, Pub. L. No. 107-110 § 6301, 115 Stat. 1425 (2006).

Oculo-Auriculo-Vertebral Spectrum (2016). Retrieved from https://rarediseases.org/rarediseases/oculo-auriculo-vertebral-spectrum/

Olson, K., Miles, B., \& Riggio, M. (1999). Environments that encourage communication. In B. Miles \& M. Riggio (Eds.), Remarkable conversations: A guide to developing meaningful communication with children and young adults who are deafblind (pp. 76-93).

Watertown, MA: Perkins School for the Blind.

Parker, A. (2009a). Measuring an Adapted Form of Picture Exchange Communication Systems (PECS) for Young Children with Visual Impairments and Developmental Disabilities. Unpublished doctoral dissertation, Texas Tech University, Lubbock, Texas. 
Parker, A. T. (2009b). Orientation and mobility with persons who are deaf-blind: An initial examination of single-subject design research. Journal of Visual Impairment \& Blindness, 103, 372-377.

Parker, A. T., \& Nelson, C. (2016). Toward a comprehensive system of personnel development in deafblind education). American Annals of the Deaf, 161(4), 486-501.

Parker, A. T., \& Pogrund, R. L. (2009). A review of research on the literacy of students with visual impairments and additional disabilities. Journal of Visual Impairment \& Blindness, $103,635-648$.

Parker, A. T., McGinnity, B. L., \& Bruce, S. M. (2012). Educational programming for students who are deafblind: A position paper of the Division on Visual Impairments. Retrieved from http://community.cec.sped.org/dvi/resourcesportal/positionpapers.

Pease, L. (2002). Creating a communicating environment. In S. Aitken, M. Buultjens, C. Clark, J. T. Eyre, \& L. Pease (Eds.), Teaching children who are deafblind: Contact communication and learning (pp. 350-382). London, England: David Fulton.

Penrod, W. M., Haley, C. D., \& Matheson, L. P. (2005). A model for improving science teaching for students with visual impairments. Re:View, 37(2), 53-60. doi:10.3200/revu.37.2.53-58

Piaget, J. (1964). Part I: Cognitive development in children: Piaget development and learning. Journal of Research in Science Teaching, 2(3), 176-186.

Pittroff, H. (2011). Development of communication in children with CHARGE syndrome. In U. Horsch \& A. Scheele (Eds.), Compendium on CHARGE syndrome (pp. 213-236).

Prickett, J. G., \& Welch, T. R. (1998). Educating students who are deafblind. In S. Z. Sacks \& R. K. Silberman (Eds.), Educating students who have visual impairments with other disabilities (pp. 139-159). Baltimore, MD: Paul H. Brookes. 
Probst, K. M., \& Borders, C. (2016). Comorbid deafblindness and autism spectrum disorder: Characteristics, differential diagnosis and possible interventions. Review Journal of Autism and Developmental Disorders. doi:10.1007/s40489-016-0100-2

Public Welfare Department of Human Health and Human Services, 45 U.S.C. $§ 46$ (2009). Retrieved from https://www.hhs.gov/ohrp/regulations-and-policy/regulations/45-cfr46/index.html

Pugh, G. S. \& Erin, J. (Eds.) (1999). Blind and visually impaired students: Education service guidelines. Watertown, MA: Perkins School for the Blind.

Rachal, P. (1995). Interagency approaches to transition services for young adults who are deafblind. In J. M. Everson (Ed.), Supporting young adults who are deaf-blind in their communities: A transition planning guide for service providers, families, and friends (pp. 301-324). Baltimore, MD: Paul H. Brookes.

Rachal, P., Steveley, J., Goehl, K., \& Robertson, K. (2002). Capturing change: Measuring the impact of an interagency team approach. Deaf-Blind Perspectives, 10(2), 5-9. Retrieved from http://documents.nationaldb.org/dbp/pdf/dec02.pdf

Reed, C. M. (1996). The implications of the Tadoma method of speechreading for spoken language processing. In Spoken Language, 1996. ICSLP 96. Proceedings, Fourth International Conference on, 3, (pp. 1489-1492). doi:10.1109/9cslp.1996.607898

Reed, C. M., Rabinowitz, W. M., Durlach, N. I., Braida, L. D., Conway-Fithian, S., \& Schultz, M. C. (1985). Research on the Tadoma method of speech communication. The Journal of the Acoustical society of America, 77, 247-257. doi:10.1121/1.392266

Rehabilitation Act of 1973, 29 U.S. Code $§ 1905$ (1992). 
Reichert, M., \& Raimondo, B. (2017). H.R. 1120, the Alice Cogswell and Anne Sullivan Macy Act: Advocating for the Cogswell-Macy Act. Retrieved from http://www.afb.org/info/programs-and-services/public-policy-center/civilrights/advocacy-resources/house-talking-points-en/12345

Riggio, M. (2009). Deafblindness: Educational service guidelines - a product of our strengthening field. Deaf-Blind Perspectives, 16(2), 1-3. Retrieved from http://documents.nationaldb.org/dbp/apr2009.htm

Riggio, M., \& McLetchie, B. (Eds.). (2008). Deafblindness: Educational service guidelines. Watertown, MA: Perkins School for the Blind.

Rödbroe, I., \& Souriau, J. (1999). Communication. In J. M. McInnes (Ed.), A guide to planning and support for individuals who are deafblind (pp. 119-149). Toronto, Ontario, Canada: University of Toronto Press Incorporated.

Rodriguez-Gil, G. (2009). The roles and responsibilities of team members for a student who is deaf-blind. reSources, 14(3), 1-6.

Rönnberg, J., \& Borg, E. (2001). A review and evaluation of research on the deaf-blind from perceptual, communicative, social and rehabilitative perspectives. Scandinavian Audiology, 30(2), 67-77. doi:10.1080/010503901300112176

Rowland, C. (Ed.). (2009). Assessing communication and learning in young children who are deafblind or who have multiple disabilities. Design to Learn Projects, Oregon Health and Science University.

Rowland, C. (1990). Communication in the classroom for children with dual sensory impairments: Studies of teacher and child behavior. Augmentative and Alternative Communication, 6, 262-274. doi:10.1080/07434619012331275554 
Rowland, C. (2009). Assessing communication and learning in young children who are deafblind or who have multiple disabilities. Retrieved from https://www.designtolearn.com/uploaded/pdf/DeafBlindAssessmentGuide.pdf

Rowland, C. (2011). Using the communication matrix to assess expressive skills in early communicators. Communication Disorders Quarterly, 32, 190-201. doi: $10.1177 / 1525740110394651$

Rowland, C. (2012). Communication matrix: Description, research basis and data. Retrieved from https://communicationmatrix.org/Uploads/Pdfs/CommunicationMatrixDataandResearchB asis.pdf

Rowland, C. (2017). How to use. Retrieved from https://www.communicationmatrix.org/Matrix/Pages/UsingTheMatrix

Rowland, C., \& Schweigert, P. (1989). Tangible symbols: Symbolic communication for individuals with multisensory impairments. Augmentative and Alternative Communication, 5, 226-234. doi:10.1080/07434618912331275276

Rowland, C., \& Schweigert, P. (2000). Tangible symbols, tangible outcomes. Augmentative and Alternative Communication, 16, 61-76. doi: 10.1080/07434610012331278914

Sacks, S. Z. (1998). Educating students who have visual impairments with other disabilities: An overview. In S. Z. Saks \& R. K. Silberman (Eds.), Educating students who have visual impairments with other disabilities. Baltimore, MD: Paul H. Brookes Publishing Company.

Sauerburger, D., \& Jones, S. (1997). Corner to corner: How can deaf-blind travelers solicit aid effectively? RE:view, 29, 34-44. 
Schweigert, P., \& Rowland, C. (1992). Early communication and microtechnology: Instructional sequence and case studies of children with severe disabilities. Augmentative and Alternative Communication, 8, 273-286. doi: 10.1080/07434619212331276313

Schalock, M. D. (2012). The 2014 National Child Count of Children and Youth who are DeafBlind. Monmouth, OR: National Center on Deaf-Blindness, The Research Institute, Western Oregon University.

Schalock, M. D. (2015). The 2014 National Child Count of Children and Youth who are DeafBlind. Monmouth, OR: National Center on Deaf-Blindness, The Research Institute, Western Oregon University.

Sigafoos, J., Didden, R., Schlosser, R., Green, V. A., O’Reilly, M. F., \& Lancioni, G. E. (2008). A review of intervention studies on teaching AAC to individuals who are deaf and blind. Journal of Developmental and Physical Disabilities, 20, 71-99. doi:10.1007/s10882-007$9081-5$

Silberman, R. K., \& Brown, F. (1998). Educating students who have visual impairments with other disabilities. S. Z. Saks \& R. K. Silberman (Eds.). Baltimore, MD: Paul H. Brookes Publishing Company.

Silberman, R., Bruce, S., \& Nelson, C. (2004). Children with sensory impairments. In F. Orelove, D. Sobsey, \& R. Silberman (Eds.), Educating children with multiple disabilities: A collaborative approach (4th ed., pp. 425-528). Baltimore, MD: Paul H. Brookes.

Sisson, L. A., Van Hasselt, V. B., \& Hersen, M. (1987). Psychological approaches with deafblind persons: Strategies and issues in research and treatment. Clinical Psychology Review, 7, 303-328. doi:10.1016/0272-7358(87)90038-9 
Sisson, L. A., Van Hasselt, V. B., \& Hersen, M. (1993). Behavioral interventions to reduce maladaptive responding in youth with dual sensory impairment: An analysis of direct and concurrent effects. Behavior Modification, 17, 164-188.

doi:10.1177/01454455930172005

SKI-HI Institute: About Us (2016). Retrieved from http://www.skihi.org/AboutUS.html

Sparrow, S. S., Cicchetti, D. V., \& Balla, D. A. (2005). Vineland Adaptive Behavior Scales, Second Edition. Livonia, MN: Pearson

Spradlin, J. (1985). Auditory evaluation. In B. Bullis (Ed.), Communication development in young children with deaf-blindness: Literature review I (pp. 49-61). Monmouth, OR: Teaching Research Publications.

Stickler Syndrome (2016). Retrieved from https://rarediseases.org/rare-diseases/sticklersyndrome/

Stillman, R. D. (1973). Measuring Progress in Deaf-Blind Children: Use of the" Azusa Scale". Retrieved from http://files.eric.ed.gov/fulltext/ED084729.pdf

Stillman, R. (1975). Assessment of Deaf-Blind Children: The Callier-Azusa Scale. Reston, VA: Council for Exceptional Children.

Stillman, R., \& Mar, H. (2009). Assessment deafblind children: Validation of evidence-based assessment strategies to promote achievement in children who are deafblind. Retrieved from http://www.ohsu.edu/xd/research/centers-institutes/institute-on-development-anddisability/design-to-learn/completed-projects/upload/Deafblind-AssessmentSummary.pdf

Support Service Providers for People who are Deaf-Blind (2012). Retrieved from http://www.aadb.org/information/ssp/ssp.html 
Swanson, L. A. (2011). Communication: The speech and language perspective. In T. S. Hartshorne, M. A. Hefner, S. L. H. Davenport, \& J. W. Thelin (Eds.), CHARGE syndrome (pp. 253-274). San Diego, CA: Plural.

Take action: The Alice Cogswell Anne Sullivan Macy Act. (2017). Retrieved from http://www.afb.org/info/get-connected/take-action/12

Taylor, R. L. (1997). Assessment of exceptional students: Educational and psychological procedures. Needham Heights, MA: Allyn and Bacon.

Taylor, K. (2007). The participation of children with multi-sensory impairment in personcentered planning. British Journal of Special Education, 34, 204-211. doi:10.1111/j.1467-8578.2007.00480.x

Taylor, K., \& Preece, D. (2010). Using aspects of the TEACCH structured teaching approach with students with multiple disabilities and visual impairment: Reflections on practice. British Journal of Visual Impairment, 28, 244-259. doi:10.1177/0264619610374682

Teele, D., \& Teele, J. (1984). Detection of middle ear effusion by acoustic reflectometry. Pediatrics, 104, 832-838. doi:10.1016/s0022-3476(84)80476-x

Teller, D. (1979). The forced-choice preferential looking procedure: A psychophysical technique for use with human infants. Infants Behavior Development, 2, 135. doi:10.1016/s01636383(79)80016-8

Teller, D., McDonald, M., Preston, K., Sebris, S., \& Dobson, V. (1986). Assessment of visual acuity in infants and children: The acuity card procedure. Developmental Medicine and Child Neurology, 28, 779-789. doi:10.1111/j.1469-8749.1986.tb03932.x

The Education for the Handicapped Act (EHA) of 1986, Pub. L. No. 99-457. 
Thirty-Five Years of Progress in Educating Children With Disabilities Through IDEA (2010). Retrieved from http://www2.ed.gov/about/offices/list/osers/idea35/history/index_pg10.html

Trief, E. (2007). The use of tangible cues for children with multiple disabilities and visual impairment. Journal of Visual Impairment \& Blindness, 101, 613-619.

Trief, E. (2013). STACS: Standardized tactual augmentative communication system. Louisville: American Printing House for the Blind.

Trief, E., Bruce, S. M., Cascella, P. W. (2010). The selection of tangible symbols by educators of students with multiple disabilities and visual impairment. Journal of Visual Impairment \& Blindness, 104, 499-503.

Trief, E., Bruce, S. M., Cascella, P. W., \& Ivy, S. (2009). The development of a universal tangible symbol system. Journal of Visual Impairment \& Blindness, 103, 425-430.

Trief, E., Cascella, P. W., \& Bruce, S. M. (2013). A field study of a standardized tangible symbol system for learners who are visually impaired and have multiple disabilities. Journal of Visual Impairment \& Blindness, 107, 180-191.

U.S. Code - Title 20: Education $§ 1412$ State Eligibility (n.d.). Retrieved from https://www.law.cornell.edu/uscode/text/20/1412

U.S. Department of Education (2015). Regulations: Part 300/A/300.8/c/2. Retrieved from http://idea.ed.gov/explore/view/p/\%2Croot\%2Cregs\%2C300\%2CA\%2C300\%252E8\%2C $\mathrm{c} \% 2 \mathrm{C} 2 \% 2 \mathrm{C}$

Usher Syndrome (2016). Retrieved from https://ghr.nlm.nih.gov/condition/usher-syndrome van Dijk, J. (1965, July). Motor development in the education of deaf-blind children. In Proceedings of the conference on the deafblind, Denmark (pp. 41-47). 
van Dijk, J. \& Nelson, C. (1997). History and change in the education of children who are deafblind since the rubella epidemic of the 1960s: Influence of methods developed in the Netherlands. Deaf-Blind Perspectives, 5(2), 1-5. Retrieved from http://documents.nationaldb.org/dbp/pdf/dec97.pdf\#page=1

Vervloed, M. P. J., van Dijk, R. J. M., Knoors, H., \& van Dijk, J. P. M. (2006). Interaction between the teacher and the congenitally deafblind child. American Annals of the Deaf, 151, 336-344. doi:10.1353/aad.2006.0040

Waardenburg Syndrome (2016). Retrieved from https://ghr.nlm.nih.gov/condition/waardenburgsyndrome

Watkins, S., Clark, T., Strong, C., \& Barringer, D. (1994). Effectiveness of an intervener model of services for young deaf-blind children. American Annals of the Deaf, 139, 404-409. doi:10.1353/aad.2012.0306

What is the vineland test? (n.d.) Retrieved from http://www.comeover.to/FAS/VinelandTest.htm

Wheeler, L., \& Griffin, H. C. (1997). A movement-based approach to language development in children who are deaf-blind. American Annals of the Deaf, 142, 387-390. doi:10.1353/aad.2012.0300

Winton, P. (2006). The evidence-based practice movement and its effect on knowledge utilization. In V. Buysse \& P. Wesley (Eds.), Evidence-based practice in the early childhood field (pp. 71-1 15). Washington, DC: Zero to Three.

Witkow, C. (2016, January 11). What are touch signals? Message posted to the Professionals Serving Deaf-Blind Consumers listserv, archived at https://nationaldb.org/library/page/2588 
Wolff Heller, K., Allgood, M. H., Ware, S., Arnold, S. E., \& Castelle, M. D. (1996). Initiating requests during community based vocational training by students with mental retardation and sensory impairments. Research in Developmental Disabilities, 17, 173-184. doi:10.1016/0891-4222(95)00040-2

Wolff Heller, K., Allgood, M. H., Ware, S., \& Castelle, M. D. (1996). Use of dual communication boards at vocational sites by students who are deaf-blind. RE:view, 27, $180-190$.

Wolf-Schein, E. G. (1993). Assessing the "untestable” client: ADLO. Developmental Disabilities Bulletin, 21, 53-70.

Wolf-Schein, E. G., \& Schein, J. D. (1998). The case for nonintrusive assessment of children who are deafblind. Retrieved from http://files.eric.ed.gov/fulltext/ED442208.pdf

Yarnall, G. D., \& Dodgion-Ensor, B. (1980). Identifying effective reinforcers for a multiply handicapped student. Education of the Visually Handicapped, 12, 11-20. 
APPENDIX A: SPECTRUM OF DEAFBLINDNESS

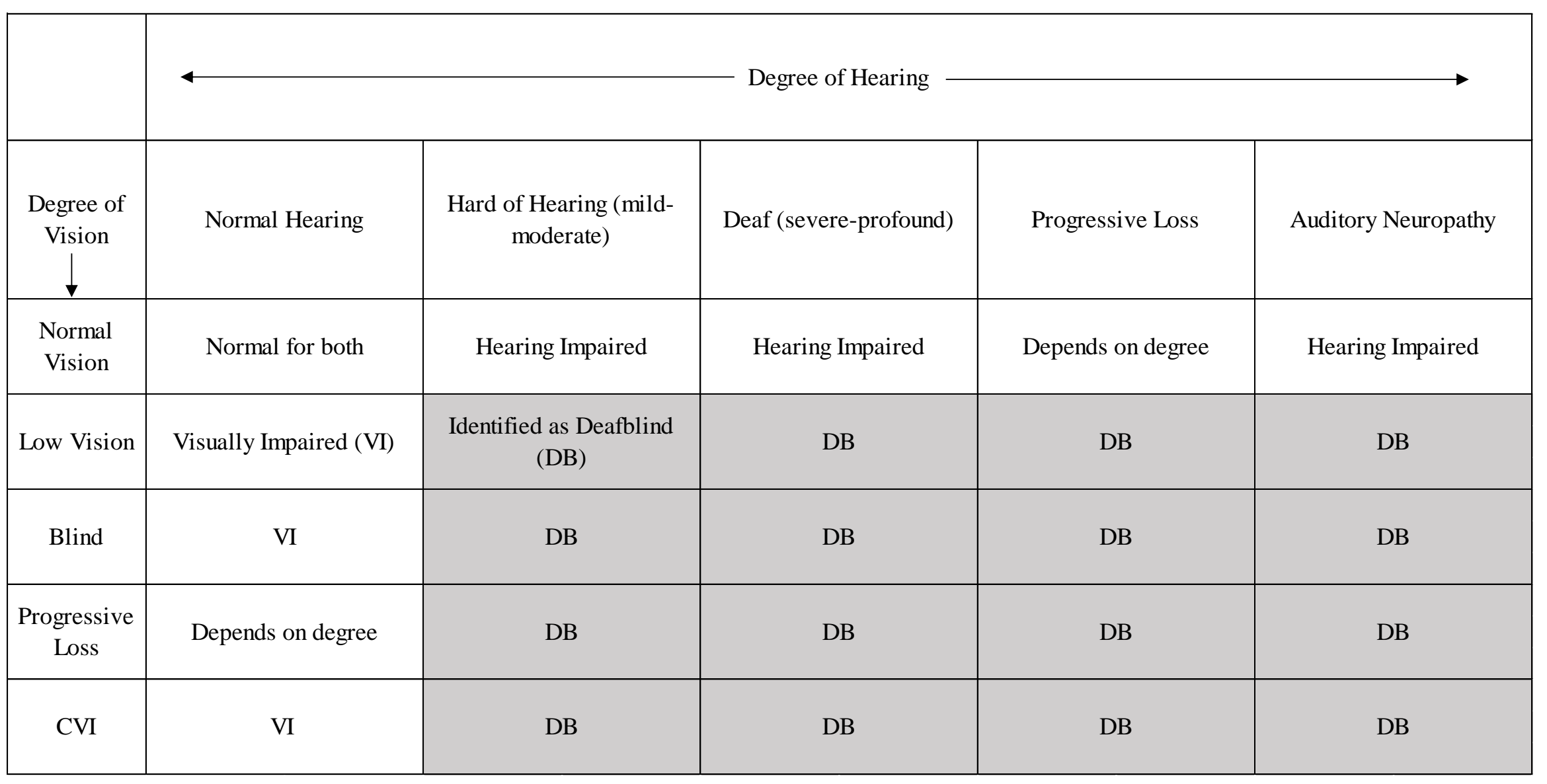

(M. Clyne, personal communication, March 30, 2017) 


\section{APPENDIX B: DESCRIPTIONS OF HEARING LOSS}

Degree of Hearing Loss

\begin{tabular}{ll}
\hline \multicolumn{1}{c}{ Label } & \multicolumn{1}{c}{ Range } \\
\hline Mild & 25 to 40 \\
Moderate & 41 to 55 \\
Moderate-Severe & $56-70$ \\
Severe & $71-90$ \\
Profound & $91+$
\end{tabular}

Configuration of Hearing Loss

\begin{tabular}{lc} 
Label & Description \\
\hline Flat & Thresholds within $10 \mathrm{~dB}$ across all frequencies
\end{tabular}

Sloping

Increasing

Decreasing

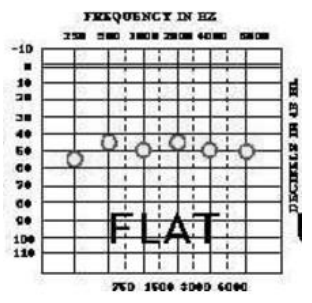

Low frequency thresholds are at least $20 \mathrm{~dB}$ poorer than high frequency thresholds

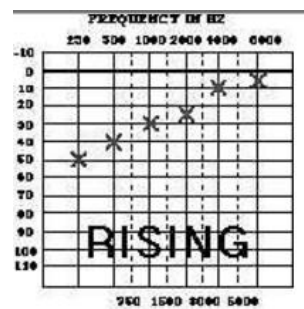

High frequency thresholds are at least $20 \mathrm{~dB}$ poorer than low frequency thresholds 
Cookie

Mid frequency thresholds are at least $20 \mathrm{~dB}$ poorer than both high and low frequency thresholds

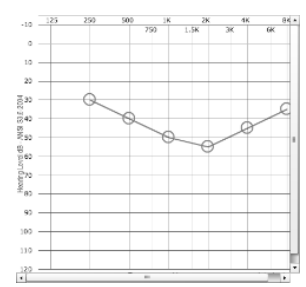

Type of Hearing Loss

Name Description

Sensorineural Hearing loss resulting from inner ear or auditory nerve dysfunction

Conductive Hearing loss resulting from a dysfunction of the middle ear mechanism so that sound is not conducted from the middle to inner ear

Mixed Hearing loss with both sensorineural and conductive dysfunction 


\section{APPENDIX C: COMMUNICATION MATRIX CODING EXPLANATIONS}

$\underline{\text { Emerging behaviors }}$ are used inconsistently or only when prompted or encouraged. They are used only in one or two contexts or with only one person. For example, greeting others is considered emerging if the individual only greets her father, and only after he greets her first.

Mastered behaviors are used independently most of the time, when the opportunity arises. They are used in a number of different contexts, and with different people. For example, greeting others is considered mastered if the individual greets family, friends, and unfamiliar people without being prompted to. TASL 1 and above scores.

Please check ONE of the four statements below that best describes the communication skills of your child.

A. My child doesn't seem to have real control over his body yet. The only way I know that he wants something is because he fusses or whines when he's unhappy or uncomfortable, and he smiles, makes noises or calms down when he's happy and comfortable. Does this statement describe your child?

Not Used: IEP notes that the student does NOT or rarely intentionally reaches for desired objects/people; does not consistently use intentional communication (intentional vocalizations, reaching, signs, move toward item/person, eye contact). IEP may have goals to begin these skills.

Emerging: IEP notes that: student does NOT consistently intentionally reach for desired objects or people; does not consistently use intentional communication (intentional vocalizations, reaching, signs, move toward item/person, eye contact). IEP may have goals to increase intentional reaching. Goals may include criteria to increase to $50 \%$ or more or $2 / 5$.

Mastered: IEP notes that student DOES intentionally reach for desired objects/people; DOES use intentional communication (intentional vocalizations, reaching, signs, moving toward item/person, eye contact). Goals may include criteria to increase from 80 to 90 , or $100 \%$ or from $4 / 5$ to $5 / 5$ (90 or $100 \%$ )

B. My child has control over her own behaviors, but she doesn't use them to try to communicate to me. She doesn't come to me to let me know what she wants, but it's easy for me to figure out, because she tries to do things for herself. She knows what she wants, and her behavior shows me what she wants. If she runs out of something to eat, she will just try to get more, rather than trying to get me to give her more. Does this statement describe your child?

Not Used: IEP notes that the student does NOT or rarely attempts to use intentional 
behavior to obtain wants/needs (i.e., reaching, attempting to obtain items themselves).

Emerging: IEP notes that student sometimes, at times, or occasionally attempts to use intentional behavior to obtain wants/needs (i.e., reaching, attempting to obtain items themselves). Goals may include criteria to increase to $70 \%$ or more or $3 / 5$ or more.

Mastered: IEP notes that student attempts to use intentional behavior to obtain wants/needs (i.e., reaching, attempting to obtain items themselves). IEP may have goals to increase intentional behavior. Goals may include criteria to increase from $80 \%$ to 90 , or $100 \%$ or from $4 / 5$ to $5 / 5$ (90 or $100 \%$ )

C. My child clearly tries to communicate his needs to me through gestures, sounds or language. He knows how to get me to do something for him. He uses some of the kinds of behaviors below to communicate:

- Gestures such as pointing, shaking his head, tugging at my arm or looking back and forth between me and what he wants

- Sounds such as squealing to show you he wants something or fussing when he doesn't want something

- Language or symbolic forms of communication such as speech, written words, Braille, picture symbols, 3-dimensional symbols or sign language

Not Used: IEP notes that student does not use any type of intentional communicative acts (Gestures such as pointing, shaking his head, tugging at my arm or looking back and forth between me and what he wants; Sounds such as squealing to show you he wants something or fussing when he doesn't want something; Language or symbolic forms of communication such as speech, written words, Braille, picture symbols, 3 dimensional symbols or sign language). Goals may focus on beginning to try using these skills.

Emerging: IEP notes that student sometimes, at times, is beginning to, or occasionally attempts to use any type of intentional communicative acts (gestures such as pointing, shaking his head, tugging at someone's arm or looking back and forth between an individual and what he wants; sounds such as squealing to show he wants something to fussing when he doesn't want something; language or symbolic forms of communication such as speech, written words, Braille, picture symbols, 3 dimensional symbols or sign language). Goals may include criteria to increase to $70 \%$ or more or $3 / 5$ or more.

Mastered: IEP notes that student uses intentional communicative acts such as: Gestures such as pointing, shaking his head, tugging at my arm or looking back and forth between me and what he wants; Sounds such as squealing to show you he wants something or fussing when he doesn't want something; Language or symbolic forms of communication such as speech, written words, Braille, picture symbols, 3- 
dimensional symbols or sign language. IEP may have goals to increase intentional communication. Goals may include criteria to increase from $80 \%$ to 90 , or $100 \%$ or from $4 / 5$ to $5 / 5$ (90 or $100 \%)$

\section{SECTION A}

*At this stage, the student doesn't seem to have control over her own behaviors, but seems mostly to react to sensations. Her reactions show you how she feels.

A1. Expresses Discomfort. Can you tell when your child is uncomfortable (in pain, wet, hungry, startled)? If so, what does your child do to make you think s/he's uncomfortable?

Not Used: IEP indicates that the student does not indicate discomfort and may include goals to begin this skill. Goals may focus on beginning to try using these skills.

Emerging: IEP may state that the student is beginning to attempt to increase ability to communicate discomfort or may have goals to increase ability to communicate discomfort. Goals may include criteria to increase to $50 \%$ or more or $2 / 5$ or more.

Mastered: IEP may state that the student indicates discomfort and have goals to increase ability to communicate discomfort. Goals may include criteria to increase from $80 \%$ to 90 , or $100 \%$ or from $4 / 5$ to $5 / 5$ (90 or $100 \%$ )

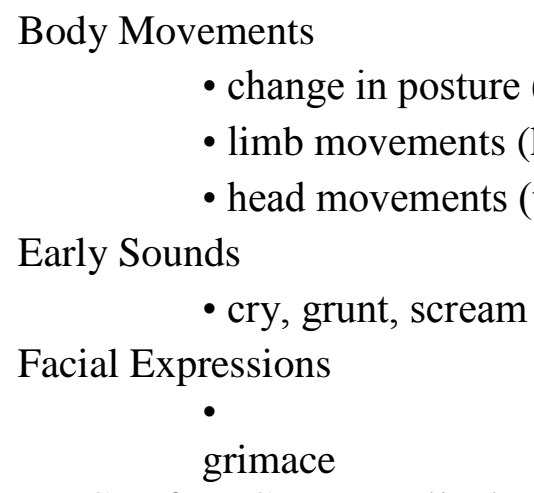

A2. Expresses Comfort. Can you tell when your child is contented, comfortable or pleasantly excited? If so, what does your child to make you think s/he's comfortable?

Not Used: IEP indicates that the student does not indicate comfort and may include goals to begin this skill. Goals may focus on beginning to try using these skills.

Emerging: IEP may state that the student is beginning to attempt to increase ability to communicate comfort or may have goals to increase ability to communicate comfort. Goals may include criteria to increase to $50 \%$ or more or $2 / 5$ or more.

Mastered: IEP may state that the student indicates comfort and have goals to increase ability to communicate comfort. Goals may include criteria to increase from $80 \%$ to 90 , or $100 \%$ or from $4 / 5$ to $5 / 5$ (90 or $100 \%$ ) 


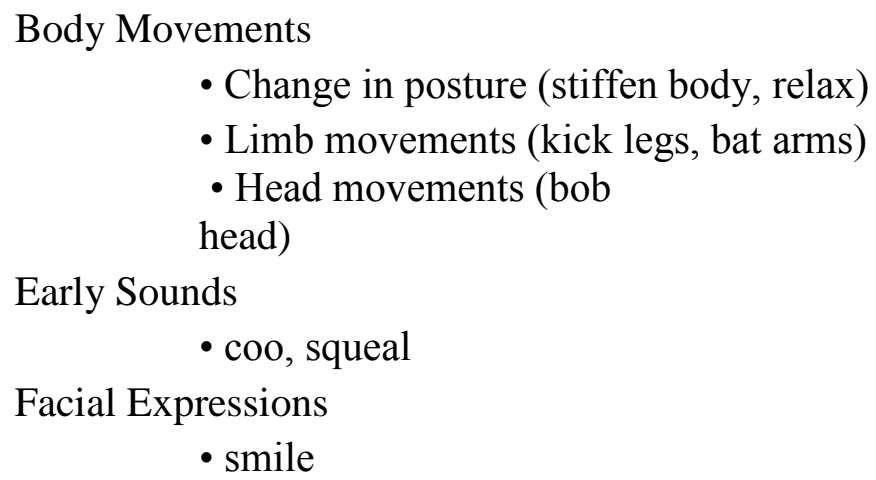

A3. Expresses Interest in Other People. Can you tell that your child is interested in other people? If so, what does your child do to make you think she's interested in you or other people?

Not Used: IEP indicates that the student does not show interest in others and may include goals to begin this skill. Goals may focus on beginning to try using these skills.

Emerging: IEP may state that the student is beginning to show interest in others or may have goals to increase this skill. Goals may include criteria to increase to $50 \%$ or more or $2 / 5$ or more.

Mastered: IEP may state that the student shows interest in others and have goals to increase this ability. Goals may include criteria to increase from $80 \%$ to 90 , or $100 \%$ or from $4 / 5$ to $5 / 5$ (90 or $100 \%$ )

Body Movements

- change in posture (stiffen body, relax)

- limb movements (kick legs, bat arms)

Early Sounds

- coo, fuss

Facial Expressions

- smile

Does your child also have a few behaviors that appear to be under his control (that are intentional?). Not Used: Student does not use intentional behaviors (under his control). IEP may indicate that the student is beginning to use intentional movement (words like: beginning to, starting, may sometimes, at times, inconsistently, etc.). Goals may include criteria to increase to $50 \%$ or more or $2 / 5$ or more.

Emerging: IEP may state that the student is beginning to show interest in others or may have goals to increase this skill. Goals may include criteria to increase to $50 \%$ or more or $2 / 5$ or more.

Mastered: Student uses intentional behaviors. This would consist of: reaching, grabbing, kicking, rolling over (toward desired item), turning head toward desired item, moving hand/finger to point to desired item. Goals may include criteria to increase from 80 to 90 , or $100 \%$ or from 4/5 to 5/5 (90 or $100 \%)$ 


\section{SECTION B}

*At this stage, the student is able to do things on purpose (intentionally), but he doesn't yet realize that he can communicate things to you using his behaviors. For instance, he may cry and roll over to get his bottle when he wants more to drink, but he doesn't seem to whine to get YOU to get him his bottle.

B1. Protests. Can you tell that your child doesn't want some specific thing, such as a certain food or a toy or a game you're playing, like tickling? If so, what does your child do to make you think $\mathrm{s} /$ he doesn't like something?

Not Used: IEP indicates that the student does not communicate that s/he doesn't want a specific item and may include goals to begin this skill. Goals may focus on beginning to try using these skills.

Emerging: IEP may state that the student is beginning to communicate that s/he doesn't want a specific item or may have goals to increase this skill. Goals may include criteria to increase to $50 \%$ or more or $2 / 5$ or more.

Mastered: IEP may state that the student communicates that s/he wants a specific item and have goals to increase this ability. Goals may include criteria to increase from $80 \%$ to 90 , or $100 \%$ or from $4 / 5$ to $5 / 5$ (90 or $100 \%$ )

Body Movements

- head movements (turn head away, pull back head)

- arm movements (bat arms, push or throw away)

- leg movements (stamp, kick)

- moves away from person or object

Early Sounds

- whine, fuss, scream

Facial Expressions

- frown, grimace

B2. Continues an Action. Can you sometimes tell that your child would like to continue an action or activity that you have just stopped doing with her (such as bouncing, pattycake, playing a musical toy)? If so, what does your child do to make you think s/he would like to continue an activity?

Not Used: IEP indicates that the student does not communicate that s/he would like to continue an action/activity and may include goals to begin this skill. Goals may focus on beginning to try using these skills. 
Emerging: IEP may state that the student is beginning to communicate that s/he would like to continue an action/activity and/or may have goals to increase this skill. Goals may include criteria to increase to $50 \%$ or more or $2 / 5$ or more.

Mastered: IEP may state that the student communicates that s/he would like to continue an action/activity and/or have goals to increase this ability. Goals may include criteria to increase from $80 \%$ to 90 , or $100 \%$ or from $4 / 5$ to $5 / 5$ (90 or $100 \%$ )

Body Movements

- head movement (moves forward, bobs head)

- arm movement (bats arms)

- leg movement (kicks)

Early Sounds

- coo, squeal, fuss

Facial Expressions

- smile

Visual

- looks at person

B3. Obtains More of Something. Can you sometimes tell that your child wants more of something specific (such as food or a toy)? If so, what does your child do to make you think s/he wants more of something?

Not Used: IEP indicates that the student does not communicate that s/he would like more of something specific and may include goals to begin this skill. Goals may focus on beginning to try using these skills.

Emerging: IEP may state that the student is beginning to communicate that s/he would like more of something specific and/or may have goals to increase this skill. Goals may include criteria to increase to $50 \%$ or more or $2 / 5$ or more.

Mastered: IEP may state that the student communicates that s/he would like more of something specific and/or have goals to increase this ability. Goals may include criteria to increase from $80 \%$ to 90 , or $100 \%$ or from $4 / 5$ to $5 / 5$ (90 or $100 \%$ )

Body Movements

- approaches desired object

- head movement (moves head forward, bobs head)

- arm movement (bats arms)

- leg movement (kicks)

- takes desired item

Early Sounds

- coo, squeal, fuss

Facial Expressions

- smile

Visual 
- looks at desired item

B4. Attracts Attention. Does your child do certain things that attract your attention to him, even though he isn't purposefully trying to get your attention? If so, what behaviors does your child produce that attract your attention?

Not Used: IEP indicates that the student does not do certain things that attract others' attention to him/her even though s/he isn't purposefully trying to get others' attention and may include goals to begin this skill. Goals may focus on beginning to try using these skills.

Emerging: IEP may state that the student is beginning to do certain things that attract others' attention to him/her even though s/he isn't purposefully trying to get others' attention and/or may have goals to increase this skill. Goals may include criteria to increase to $50 \%$ or more or $2 / 5$ or more.

Mastered: IEP may state that the student does certain things that attract others' attention to him/her even though s/he isn't purposefully trying to get others' attention specific and/or have goals to increase this ability. Goals may include criteria to increase from $80 \%$ to 90 , or $100 \%$ or from $4 / 5$ to $5 / 5$ (90 or $100 \%$ )

\section{Body Movements}

- approaches person

- head movement (moves head forward, bobs head)

- arm movement (bats arms)

- leg movement (kicks)

Early Sounds

- coo, squeal, fuss

Facial Expressions

- smile

Visual

\section{SECTION C}

- looks at person

*At this stage, the student knows that if he does certain things, you will react in certain ways, and he uses his behaviors to communicate very intentionally. There are many different ways that a child may communicate intentionally. Some involve symbols (speech, sign language, picture symbols, 3-dimensional symbols); others involve specific gestures or body movements; some involve early sounds that aren't yet speech. Some children with severe physical impairments may use electronic devices to communicate. Whatever the behavior the child uses to communicate, what's important here is that he uses those behaviors on purpose, obviously trying to communicate something specific to you. Remember that some children may access symbols through a communication device. 
Does your child also have a few behaviors that she clearly uses with the purpose of communicating something to you?

Not Used: IEP indicates that the student does not do have behaviors that are clearly used with the purpose of communicating to others and may include goals to begin this skill. Goals may focus on beginning to try using these skills.

Emerging: IEP may state that the student is beginning to use behaviors that are clearly used with the purpose of communicating to others and/or may have goals to increase this skill. Goals may include criteria to increase to $50 \%$ or more or $2 / 5$ or more.

Mastered: IEP may state that the student uses behaviors that are clearly used with the purpose of communicating to others and/or have goals to increase this ability. Goals may include criteria to increase from $80 \%$ to 90 , or $100 \%$ or from $4 / 5$ to $5 / 5$ (90 or $100 \%$ )

C1. Refuses or Rejects Something. Does your child intentionally show you that he or she doesn't want a certain thing or a certain activity? If so, what does your child do to refuse or reject something?

Not Used: IEP indicates that the student does not intentionally show that s/he doesn't want a certain thing or activity and may include goals to begin this skill. Goals may focus on beginning to try using these skills.

Emerging: IEP may state that the student is beginning to intentionally show that s/he doesn't want a certain thing/activity and/or may have goals to increase this skill. Goals may include criteria to increase to $50 \%$ or more or $2 / 5$ or more.

Mastered: IEP may state that the student intentionally shows that s/he doesn't want a certain thing/activity and/or have goals to increase this ability. Goals may include criteria to increase from $80 \%$ to 90 , or $100 \%$ or from $4 / 5$ to $5 / 5$ (90 or $100 \%$ )

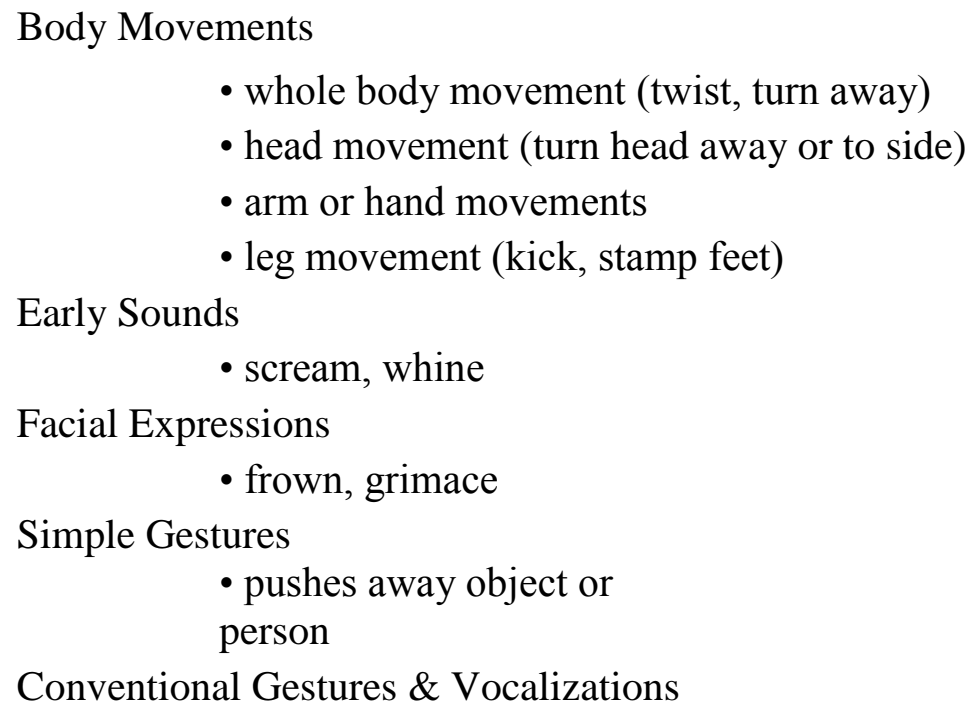


- gives unwanted item to you

- shakes head "no"

- specific vocalizations ("nuh uh")

- specific vocalizations via AAC (i.e.,

"no")

Concrete Symbols

- rejects photo or drawing of unwanted item

- rejects object symbol representing unwanted item

Abstract Symbols

- spoken word ("no", "finished")

- manual sign ("no", "stop")

- written word ("no", "finished")

• brailled word ("no", "stop")

- abstract three-dimensional symbol (for "no", "stop")

- abstract two-dimensional symbol (for "no", "stop")

Language

- Combines two or more symbols ("stop it", "all done", "no go out")

C2. Requests More of an Action. Does your child intentionally show you that s/he wants more of an action (such as playing peek-a-boo or making a musical toy go) that you have just stopped doing? If so, what does your child do to show you that s/he wants more of an action?

Not Used: IEP indicates that the student does not intentionally show that s/he wants more of an activity that has just been stopped and may include goals to begin this skill. Goals may focus on beginning to try using these skills.

Emerging: IEP may state that the student is beginning to intentionally show that s/he wants more of an activity that has just been stopped and/or may have goals to increase this skill. Goals may include criteria to increase to $50 \%$ or more or $2 / 5$ or more.

Mastered: IEP may state that the student intentionally shows that $\mathrm{s} / \mathrm{he}$ wants more of an activity that has just been stopped and/or have goals to increase this ability. Goals may include criteria to increase from $80 \%$ to 90 , or $100 \%$ or from $4 / 5$ to $5 / 5$ (90 or $100 \%)$

Body Movements

- whole body movement (lunge)

- arm/hand movement (bats arms)

- leg movement (kicks)

Early Sounds

- coo, squeal, laugh

Facial Expressions

- smile

Visual 
- looks at you

- turns eyes to individual

- turns head to individual

Simple Gestures

- takes your hand

- touches you

- reaches towards or taps you

Conventional Gestures \& Vocalizations

- beckons you to come

- holds hands up or out to you (for "up")

- nods head

Concrete Symbols

- indicates photo or drawing of desired action

- indicates object symbol representing desired action

- pantomimes desired action

Abstract Symbols

- spoken word ("more", "tickle")

• manual sign ("more", "swing")

- written word ("more", "tickle")

- brailled word ("more", "rock")

- abstract 3-dimensional symbol ("more", "tickle")

- abstract 2-dimensional symbol ("more", "eat")

Language

- combines two or more words or symbols ("more tickle", "do it again")

C3. Requests a New Action. Does your child intentionally indicate that s/he wants you to perform a new action (one that you have not just been engaged in)? If so, how does your child request (or command) a new action?

Not Used: IEP indicates that the student does not intentionally indicate that s/he wants you to perform a new action and may include goals to begin this skill. Goals may focus on beginning to try using these skills.

Emerging: IEP may state that the student is beginning to intentionally indicate that $\mathrm{s} /$ he wants you to perform a new action and/or may have goals to increase this skill. Goals may include criteria to increase to $50 \%$ or more or $2 / 5$ or more.

Mastered: IEP may state that the student intentionally indicates that s/he wants you to perform a new action and/or have goals to increase this ability. Goals may include criteria to increase from $80 \%$ to 90 , or $100 \%$ or from $4 / 5$ to $5 / 5$ (90 or $100 \%$ )

Body Movements

- whole body movement (bounce up and down, as in desired 
new action)

- arm/hand movements (move arms as in desired new action)

- leg movements (move legs as in desired new action)

\section{Facial Expressions}

- smile

Visual

- looks at you

Simple Gestures

- takes your hand

Conventional Gestures \& Vocalizations

- beckons you to come

• holds hands up or out to you (for "up")

Concrete Symbols

- indicates photo or drawing of desired action

- indicates object symbol representing desired action

- pantomimes desired action

- mimics sound that goes with desired action-such as a tune

Abstract Symbols

- spoken word ("tickle")

- manual sign ("eat")

- written word ("tickle")

• brailled word ("swing")

- abstract 3-dimensional symbol ("rock")

- abstract 2-dimensional symbol

("tickle")

Language

- combines two or more symbols ("tickle me", "I want swing")

C4. Requests More of an Object. Does your child intentionally show you that s/he wants more of something (such as a toy or some food), after already having some of it? If so, how does your child request more of an object?

Not Used: IEP indicates that the student does not intentionally show you that s/he wants more of something and may include goals to begin this skill. Goals may focus on beginning to try using these skills.

Emerging: IEP may state that the student is beginning to intentionally show you that s/he wants more of something and/or may have goals to increase this skill. Goals may include criteria to increase to $50 \%$ or more or $2 / 5$ or more.

Mastered: IEP may state that the student intentionally show you that s/he wants more of something and/or have goals to increase this ability. Goals may include criteria to increase from $80 \%$ to 90 , or $100 \%$ or from $4 / 5$ to $5 / 5$ (90 or $100 \%$ )

Body Movements 
- whole body movements (lunge toward object)

- move head towards desired item

- arm/hand movements

- leg movements

- finger movements

Early Sounds

- fuss, squeal

Visual

- looks at desired object

- turns eyes toward desired object

Facial Expressions

- smile

Simple Gestures

- guides your hand to or pulls you over to desired item

- touches desired object (without taking it)

- reaches towards or taps object

Conventional Gestures \& Vocalizations

- looks back and forth between you and desired item

- points at desired item

Concrete Symbols

- indicates photo or drawing of desired item

- indicates object symbol representing desired item

- pantomimes desired item

- mimics sound of desired

item

Abstract Symbols

- spoken word ("more", "ball")

- manual sign ("more", "doll")

• written word ("more", "juice")

• brailled word ("more", "ball")

- abstract 3-dimensional symbol ("more", "ball")

- abstract 2-dimensional symbol ("more", "cracker")

Language

- combines two or more symbols ("more juice", "want more bubbles")

C5. Makes Choices. Does your child intentionally make a choice between two or more items that you offer at the same time? (Make sure that your child is aware of all the choices presented and doesn't just indicate the first item he notices) If so, how does your child make choices?

Not Used: IEP indicates that the student does not intentionally make a choice between 
two or more items that you offer at the same time and may include goals to begin this skill. Goals may focus on beginning to try using these skills.

Emerging: IEP may state that the student is beginning to intentionally make a choice between two or more items that you offer at the same time and/or may have goals to increase this skill. Goals may include criteria to increase to $50 \%$ or more or $2 / 5$ or more.

Mastered: IEP may state that the student intentionally make a choice between two or more items that you offer at the same time and/or have goals to increase this ability. Goals may include criteria to increase from $80 \%$ to 90 , or $100 \%$ or from $4 / 5$ to $5 / 5$ (90 or $100 \%$ )

Body Movements

- whole body movement (lunge toward object)

- move head towards desired item

Visual

- looks at object

Simple Gestures

- guides your hand to desired item

- reaches towards, touches or taps desired item (without taking it)

Conventional Gestures \& Vocalizations

- looks back and forth between you and desired item

- points to desired item

Concrete Symbols

- indicates photo or drawing of desired item

- indicates object symbol representing desired item

- pantomimes desired item

- mimics sound of desired

item

Abstract Symbols

- spoken word ("that" or name of item)

- manual sign ("that" or name of item)

- written word (name of item)

- brailled word (name of item)

- abstract 3-dimensional symbol (name of item)

- abstract 2-dimensional symbol (name of item)

Language

- combines two or more symbols ("that one", "I want train")

C6. Requests a New Object. Does your child intentionally show you that s/he wants a new object (such as a toy or some food) that is within his sight, hearing or touch, but that you have not offered? If so, how does your child request new objects? 
Not Used: IEP indicates that the student does not intentionally show you that s/he wants a new object (such as a toy or some food) that is within his sight, hearing or touch, but that you have not offered and may include goals to begin this skill. Goals may focus on beginning to try using these skills.

Emerging: IEP may state that the student is beginning to intentionally show you that s/he wants a new object (such as a toy or some food) that is within his sight, hearing or touch, but that you have not offered and/or may have goals to increase this skill. Goals may include criteria to increase to $50 \%$ or more or $2 / 5$ or more.

Mastered: IEP may state that the student intentionally show you that s/he wants a new object (such as a toy or some food) that is within his sight, hearing or touch, but that you have not offered and/or have goals to increase this ability. Goals may include criteria to increase from $80 \%$ to 90 , or $100 \%$ or from $4 / 5$ to $5 / 5$ (90 or $100 \%$ )

Body Movements

- whole body movements (lunge toward object)

- move head towards desired item

- move eyes towards desired item

Visual

- looks at object

Simple Gestures

- guides your hand to or pulls you over to desired item

- touches desired object (without taking it)

- reaches towards or taps object

Conventional Gestures \& Vocalizations

- looks back and forth between you and desired item

- points at desired object

Concrete Symbols

- indicates photo or drawing of desired item

- indicates object symbol representing desired item

- pantomimes desired item

- mimics sound of desired item

Abstract Symbols

- spoken word ("car")

- manual sign ("doll")

- written word ("ball")

- brailled word ("cracker")

- abstract 3-dimensional symbol ("car")

- abstract 2-dimensional symbol ("juice")

Language

- combines two or more symbols ("want car", "I want ball") C7. Requests Objects that are Absent. Does your child intentionally request things (toys, food, people) that are not present in the immediate environment (things that are 
out of sight, hearing, touch, in another room, etc.)? If so, how does your child request absent objects?

Not Used: IEP indicates that the student does not intentionally request things (toys, food, people) that are not present in the immediate environment (things that are out of sight, hearing, touch, in another room, etc.) and may include goals to begin this skill. Goals may focus on beginning to try using these skills.

Emerging: IEP may state that the student is beginning to intentionally request things (toys, food, people) that are not present in the immediate environment (things that are out of sight, hearing, touch, in another room, etc.) and/or may have goals to increase this skill. Goals may include criteria to increase to $50 \%$ or more or $2 / 5$ or more.

Mastered: IEP may state that the student intentionally requests things (toys, food, people) that are not present in the immediate environment (things that are out of sight, hearing, touch, in another room, etc.) and/or have goals to increase this ability. Goals may include criteria to increase from $80 \%$ to 90 , or $100 \%$ or from $4 / 5$ to $5 / 5$ (90 or $100 \%)$

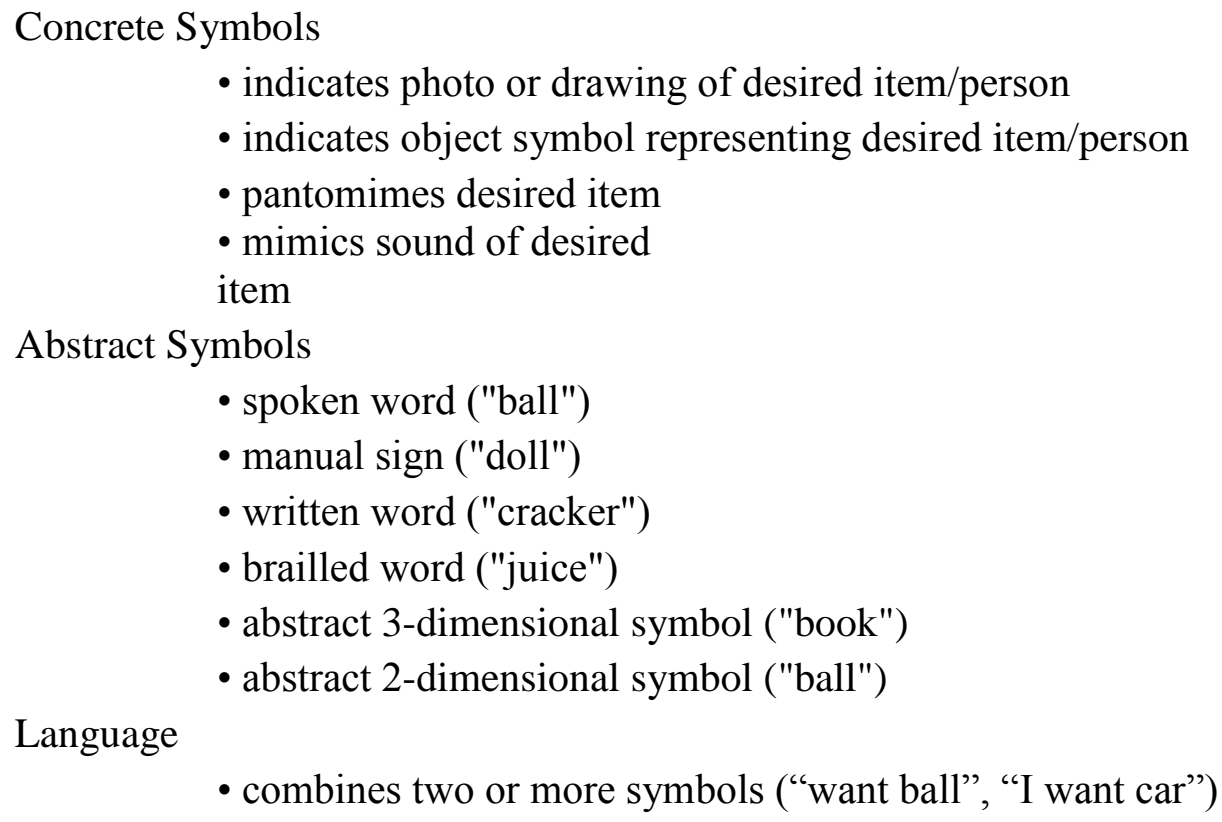

C8. Requests Attention. Does your child intentionally try to attract your attention? If so, how does your child request your attention?

Not Used: IEP indicates that the student does not intentionally try to attract others' attention and may include goals to begin this skill. Goals may focus on beginning to try using these skills.

Emerging: IEP may state that the student is beginning to intentionally try to attract others' attention and/or may have goals to increase this skill. Goals may include criteria to increase to $50 \%$ or more or $2 / 5$ or more.

Mastered: IEP may state that the student intentionally tries to attract others' attention and/or have goals to increase this ability. Goals may include criteria to increase from $80 \%$ to 90 , or $100 \%$ or from $4 / 5$ to $5 / 5$ (90 or $100 \%$ ) 


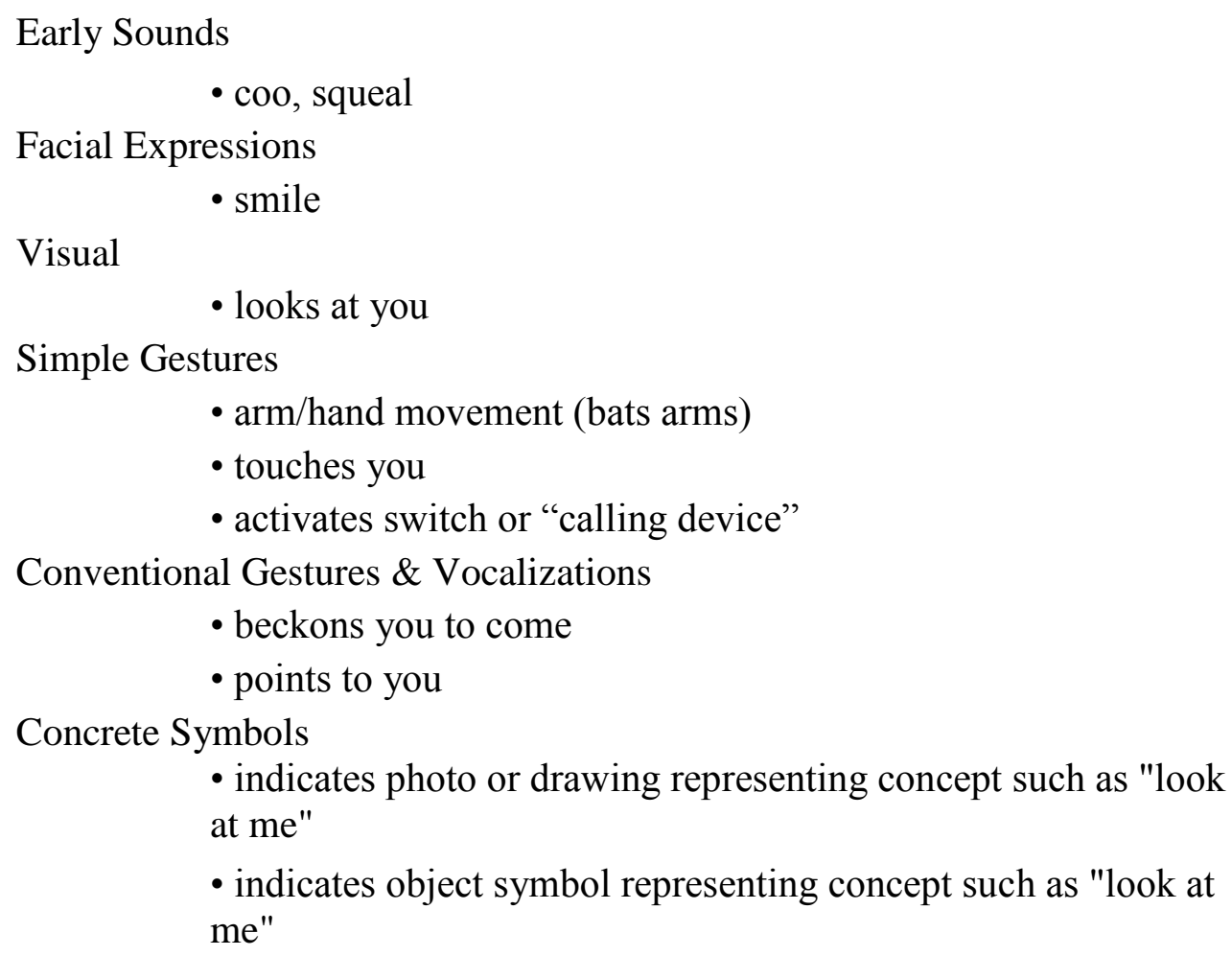

Not Used: IEP indicates that the student does not intentionally demonstrate affection toward his/her parents or others and may include goals to begin this skill. Goals may focus on beginning to try using these skills.

Emerging: IEP may state that the student is beginning to intentionally demonstrate affection toward his/her parents or others and/or may have goals to increase this skill. Goals may include criteria to increase to $50 \%$ or more or $2 / 5$ or more.

Mastered: IEP may state that the student intentionally demonstrates affection toward his/her parents or others and/or have goals to increase this ability. Goals may include criteria to increase from $80 \%$ to 90 , or $100 \%$ or from $4 / 5$ to $5 / 5$ (90 or $100 \%$ )

Early Sounds

- coo, squeal 


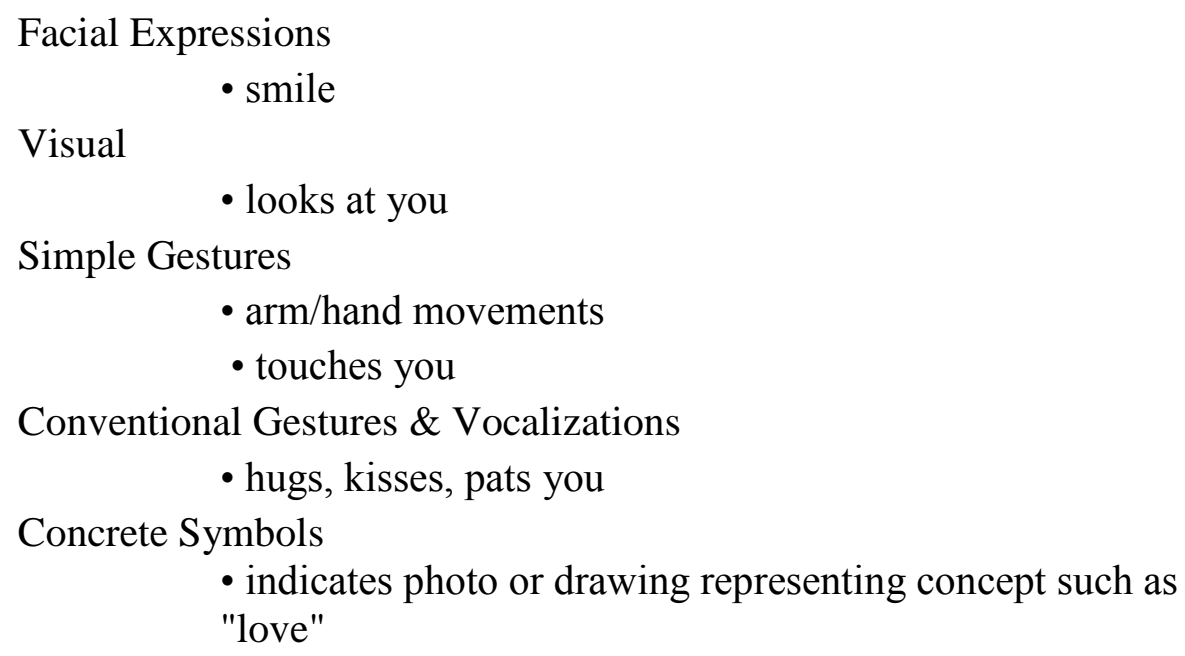

Abstract Symbols

- spoken word ("love")

- manual sign ("hug")

- written word ("love")

- brailled word ("love")

- abstract 3-dimensional symbol ("hug")

- abstract 2-dimensional symbol ("love")

Language

• combines two or more symbols ("love you", "I like mama")

C10. Greets People. Does your child intentionally indicate hello or goodbye when someone arrives or leaves? If so, how does your child greet you or other people?

Not Used: IEP indicates that the student does not intentionally indicate hello or goodbye when someone arrives/leaves and may include goals to begin this skill. Goals may focus on beginning to try using these skills.

Emerging: IEP may state that the student is beginning to intentionally indicate hello or goodbye when someone arrives/leaves and/or may have goals to increase this skill. Goals may include criteria to increase to $50 \%$ or more or $2 / 5$ or more.

Mastered: IEP may state that the student intentionally indicates hello or goodbye when someone arrives/leaves and/or have goals to increase this ability. Goals may include criteria to increase from $80 \%$ to 90 , or $100 \%$ or from $4 / 5$ to $5 / 5$ (90 or $100 \%$ )

Conventional Gestures \& Vocalizations

- Waves "hi" or "bye"

Concrete Symbols

- Indicates photo or drawing representing greeting ("hello", "goodbye")

Abstract Symbols

• spoken word ("hi", "bye")

• manual sign ("hi", "bye") 


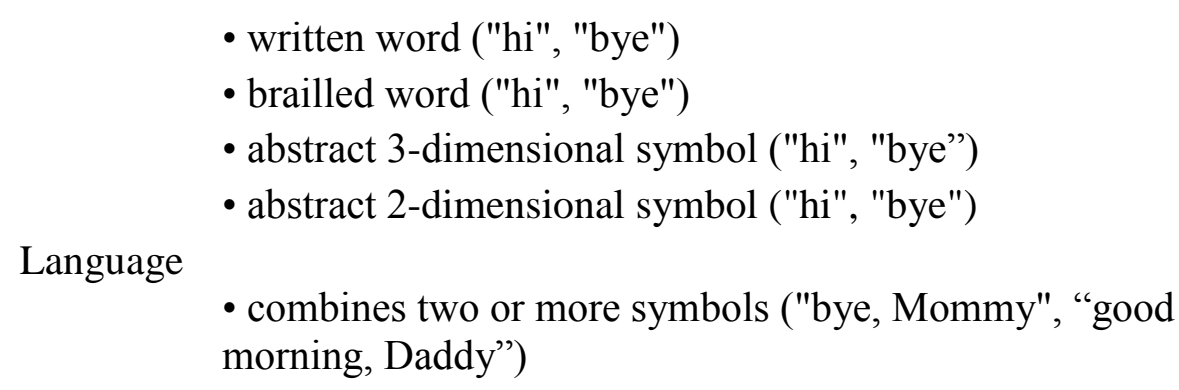

C11. Offers or Shares Things. Does your child intentionally offer things or share things with you, not expecting anything in return? If so, how does your child offer or share something with you?

Not Used: IEP indicates that the student does not intentionally offer things or share things with others, not expecting anything in return and may include goals to begin this skill. Goals may focus on beginning to try using these skills.

Emerging: IEP may state that the student is beginning to intentionally offer things or share things with others, not expecting anything in return and/or may have goals to increase this skill. Goals may include criteria to increase to $50 \%$ or more or $2 / 5$ or more.

Mastered: IEP may state that the student intentionally offers things or share things with others, not expecting anything in return and/or have goals to increase this ability. Goals may include criteria to increase from $80 \%$ to 90 , or $100 \%$ or from $4 / 5$ to $5 / 5$ (90 or $100 \%)$

Conventional Gestures \& Vocalizations

- gives or shows something to you

- specific vocalizations (questioning sound as if for "want this?")

Concrete Symbols

- indicates photo or drawing representing concept such as "yours"

- indicates object symbol representing concept such as "yours" Abstract Symbols

• spoken word ("yours")

- manual sign ( "yours")

• written word ("yours")

• brailled word ("yours")

- abstract 3-dimensional symbol ("yours")

- abstract 2-dimensional symbol

("yours")

Language

• combines two or more symbols ("for you", "cookie for you") 
C12. Directs Your Attention to Something. Does your child intentionally direct your attention to something that s/he is interested in (as if saying "look at that")? If so, how does your child direct your attention to something?

Not Used: IEP indicates that the student does not intentionally direct your attention to something that s/he is interested in (as if saying "look at that") and may include goals to begin this skill. Goals may focus on beginning to try using these skills.

Emerging: IEP may state that the student is beginning to intentionally direct your attention to something that s/he is interested in (as if saying "look at that") and/or may have goals to increase this skill. Goals may include criteria to increase to $50 \%$ or more or $2 / 5$ or more.

Mastered: IEP may state that the student intentionally directs your attention to something that s/he is interested in (as if saying "look at that") and/or have goals to increase this ability. Goals may include criteria to increase from $80 \%$ to 90 , or $100 \%$ or from $4 / 5$ to $5 / 5$ (90 or $100 \%$ )

Conventional Gestures \& Vocalizations

- points to something

- looks back and forth between you and object, person or place

Concrete Symbols

- indicates photo or drawing representing concept such as "look at that"

- indicates object symbol representing concept such as "look at that"

Abstract Symbols

• spoken word ("look", "there")

• manual sign ("look", "there")

• written word ("look", "there")

• brailled word ("look", "there")

• abstract 3-dimensional symbol ("look", "there")

• abstract 2-dimensional symbol ("look", "there")

Language

- combines two or more symbols ("over there", "look at that")

C13. Uses Polite Social Forms. Does your child sometimes intentionally use polite forms of social interaction such as asking you for permission before doing something, indicating "please", "thank you" or "excuse me"? If so, how what polite social forms does your child use?

Not Used: IEP indicates that the student does not intentionally use polite forms of social interaction such as asking you for permission before doing something, indicating "please", "thank you" or "excuse me" and may include goals to begin this skill. Goals may focus on beginning to try using these skills. 
Emerging: IEP may state that the student is beginning to use polite forms of social interaction such as asking you for permission before doing something, indicating "please", "thank you" or "excuse me" and/or may have goals to increase this skill. Goals may include criteria to increase to $50 \%$ or more or $2 / 5$ or more.

Mastered: IEP may state that the student intentionally uses polite forms of social interaction such as asking you for permission before doing something, indicating "please", "thank you" or "excuse me" and/or have goals to increase this ability. Goals may include criteria to increase from $80 \%$ to 90 , or $100 \%$ or from $4 / 5$ to $5 / 5$ (90 or $100 \%)$

$$
\begin{aligned}
& \text { Conventional Gestures \& Vocalizations } \\
& \text { • points to something (as if asking “can I have it?") } \\
& \text { • specific vocalizations (questioning sound for "may I?") } \\
& \text { Concrete Symbols } \\
& \text { • indicates photo or drawing representing concept such as } \\
& \text { "please", "thank you" } \\
& \text { • indicates object symbol representing concept such as "please", } \\
& \text { "thank you" }
\end{aligned}
$$

Abstract Symbols

- spoken word ("please")

- manual sign ("thanks")

- written word ("please")

- brailled word ("sorry")

- abstract 3-dimensional symbol ("please")

- abstract 2-dimensional symbol ("thanks")

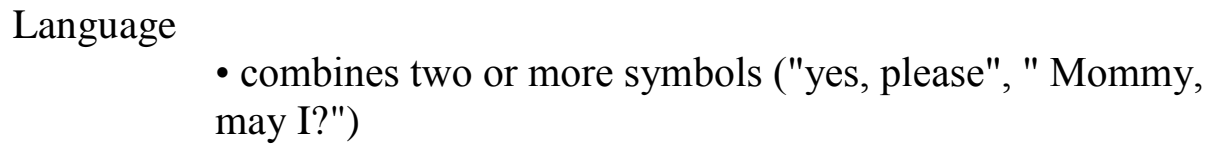
may I?")

C14. Answers "Yes" and "No" Questions. Does your child intentionally indicate "yes" or "no" or "I don't know" in answer to a question? If so, how does your child answer "yes" or "no" questions?

Not Used: IEP indicates that the student does not intentionally indicate "yes" or "no" or "I don't know" in answer to a question and may include goals to begin this skill. Goals may focus on beginning to try using these skills.

Emerging: IEP may state that the student is beginning to indicate "yes" or "no" or "I don't know" in answer to a question and/or may have goals to increase this skill. Goals may include criteria to increase to $50 \%$ or more or $2 / 5$ or more.

Mastered: IEP may state that the student intentionally indicates "yes" or "no" or "I don't know" in answer to a question and/or have goals to increase this ability. Goals may include criteria to increase from $80 \%$ to 90 , or $100 \%$ or from $4 / 5$ to $5 / 5$ (90 or 


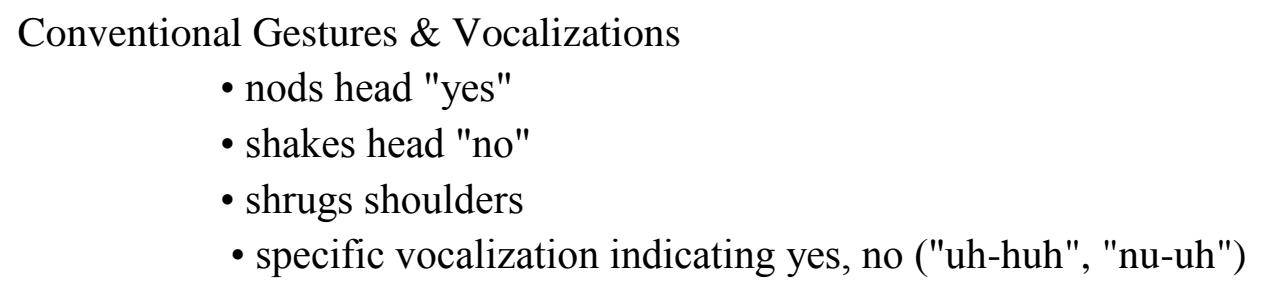

Concrete Symbols

- indicates photo/drawing representing "yes" or "no"

Abstract Symbols

• spoken word ("yes", "no")

• manual sign ("yes", "no")

• written word ("yes", "no")

• brailled word ("yes", "no")

• abstract 3-dimensional symbol ("yes", "no")

• abstract 2-dimensional symbol ("yes", "no")

Language

- combines two or more symbols ("no way", "I don't know")

C15. Asks Questions. Does your child ask you questions (not necessarily using words), clearly wanting an answer from you? If so, how does your child ask questions?

Not Used: IEP indicates that the student does not intentionally asks questions of others (not necessarily using words), clearly wanting an answer and may include goals to begin this skill. Goals may focus on beginning to try using these skills.

Emerging: IEP may state that the student is beginning to ask questions of others (not necessarily using words), clearly wanting an answer and/or may have goals to increase this skill. Goals may include criteria to increase to $50 \%$ or more or $2 / 5$ or more.

Mastered: IEP may state that the student intentionally asks questions of others (not necessarily using words), clearly wanting an answer and/or have goals to increase this ability. Goals may include criteria to increase from $80 \%$ to 90 , or $100 \%$ or from $4 / 5$ to $5 / 5(90$ or $100 \%)$

Conventional Gestures \& Vocalizations

- holds up hands, shrugs shoulders, as if questioning

- specific vocalizations, as if questioning

- looks back and forth between you and object or place

Concrete Symbols

• indicates photo or drawing representing a question ("who?",

"what?", "where?", "when?", "why?")

• indicates object symbol representing a question ("who?",

"what?", "where?", "when?", "why?")

Abstract Symbols 
• spoken word (“who?”, “what?”, ”where?”, “when?”, “why?”)

• manual sign (“who?”, “what?”, ”where?”, “when?”, “why?”)

• written word (“who?”, “what?”, “"”where?”, “when?”, why?")

• brailled word (“who?", “what?”, "where?”, “when?", “why?")

• abstract 3-dimensional symbol ("who?", "what?", "where?",

"when?", "why?")

- abstract 2-dimensional symbol (“who?”, “what?", ”where?”,

"when?", "why?")

\section{Language}

• combines two or more symbols ("why not?", "where you go?")

C16. Names Things or People. Does your child name or label objects, people or actions, either spontaneously or in response to a question from you (such as "what's that?")? If so, how does your child name something?

Not Used: IEP indicates that the student does not name/label objects, people, or actions either spontaneously or in response to a question from another and may include goals to begin this skill. Goals may focus on beginning to try using these skills.

Emerging: IEP may state that the student is beginning to name/label objects, people, or actions either spontaneously or in response to a question from another and/or may have goals to increase this skill. Goals may include criteria to increase to $50 \%$ or more or $2 / 5$ or more.

Mastered: IEP may state that the student names/labels objects, people, or actions either spontaneously or in response to a question from another and/or have goals to increase this ability. Goals may include criteria to increase from $80 \%$ to 90 , or $100 \%$ or from $4 / 5$ to $5 / 5$ (90 or $100 \%)$

Concrete Symbols

- indicates photo/drawing of object/person/place/activity

- indicates object symbol representing

object/person/place/activity

- pantomimes action or object

- mimics sound of object

Abstract Symbols

- spoken word (name of item)

- manual sign (name of item)

- written word (name of item)

- brailled word (name of

item)

- abstract 3-dimensional symbol (name of item)

- abstract 2-dimensional symbol (name of item)

Language 
- combines two or more symbols ("that car", "this your car") C17. Makes Comments. Does your child spontaneously (without being asked) provide information to you about things in the form of comments ("that's pretty", "hot", etc.). If so, how does your child make a comment?

Not Used: IEP indicates that the student does not spontaneously (without being asked) provide information to you about things in the form of comments ("that's pretty", "hot", etc.) and may include goals to begin this skill. Goals may focus on beginning to try using these skills.

Emerging: IEP may state that the student is beginning to spontaneously (without being asked) provide information to you about things in the form of comments ("that's pretty", "hot", etc.) and/or may have goals to increase this skill. Goals may include criteria to increase to $50 \%$ or more or $2 / 5$ or more.

Mastered: IEP may state that the student spontaneously (without being asked) provides information to you about things in the form of comments ("that's pretty", "hot", etc.) and/or have goals to increase this ability. Goals may include criteria to increase from $80 \%$ to 90 , or $100 \%$ or from $4 / 5$ to $5 / 5$ (90 or $100 \%$ )

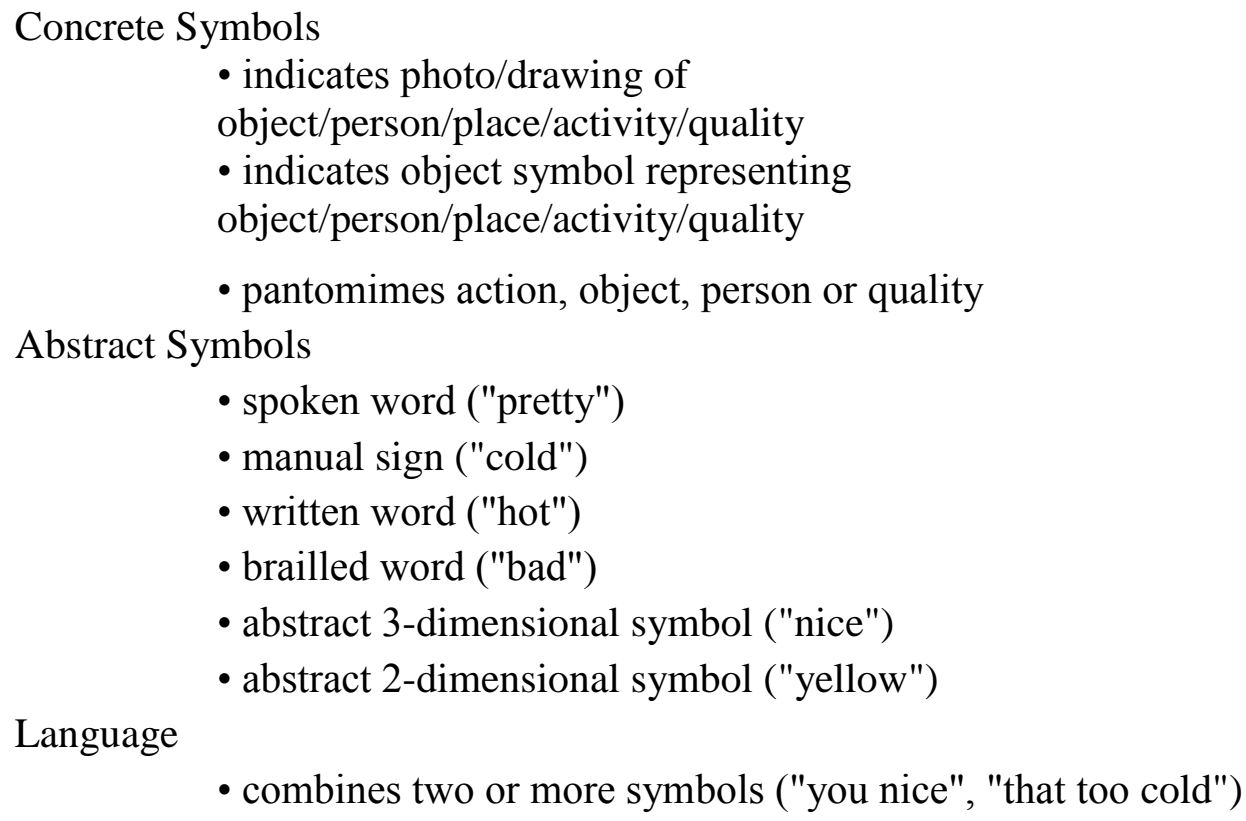

Adapted from Rowland, C. (1990, 1996, 2004, 2011). Communication Matrix. Retrieved February 8, 2017 from www.communicationmatrix.org 


\section{APPENDIX D: PRACTICE CODING TEST}

Using the IEP for "Kendra Vanevenhoeven"

a. Answer the questions (attached) related to the IFSP/IEP Data Sheet

b. Go to www.communicationmatrix.org and complete a Matrix

\section{IFSP/IEP Data Questions}

1. What is Kendra's primary disability label?

\begin{tabular}{|l|l|}
\hline 1 & DB \\
\hline 2 & Deafness \\
\hline 3 & Hearing Impairment \\
\hline 4 & VI \\
\hline 5 & MD \\
\hline 6 & OHI \\
\hline 7 & ID \\
\hline 8 & ASD \\
\hline 9 & Orthopedic Impairments (OI) \\
\hline 10 & DD \\
\hline 11 & SLD \\
\hline 12 & LD \\
\hline 13 & EBD \\
\hline 14 & TBI \\
\hline 15 & Other \\
\hline 16 & Multiple Primary Labels \\
\hline 17 & Unknown/Missing Data \\
\hline
\end{tabular}

2. What is Kendra's hearing loss?
a. Binaural
b. Unilateral
c. Unknown

3. What is Kendra's degree of hearing loss?
a. Mild
b. Moderate
c. Moderate-Severe
d. Severe
e. Profound

4. What is the configuration type of Kendra's hearing loss? 

a. flat
b. increasing slope
c. decreasing slope
d. cookie bite
e. other
f. none

5. What is Kendra's visual acuity?
a. less than $20 / 70$
b. $20 / 71-20 / 200$
c. $20 / 201$ and above
d. Other
e. Unknown
f. None

6. Is Cortical/Cerebral Visual Impairment diagnosed or suspected?
a. diagnosed
b. suspected
c. unknown

7. Does Kendra have an official diagnosis of ASD?
a. Yes
b. No

8. What is the severity level of social communication?
a. Level 3
b. Level 2
c. Level 1

9. What is the severity level of restricted, repetitive behaviors?
a. Level 3
b. Level 2
c. Level 1

10. What communication strategy is used with Kendra?
a. ASL
b. Tactile Sign Language
c. Objects
d. PECS
e. Spoken Language
f. Cued Speech
g. Haptics
h. Back-to-Back Channeling
i. High Tech Devices (AAC, etc.)
j. Low Tech Devices (Dual Communication Boards)
k. Sim Com
1. Signed English
m. Total Communication
n. Other 
11. What is Kendra's educational setting?

\begin{tabular}{|l|l|}
\hline 1 & $\begin{array}{l}\text { Special Ed 20\% or less of day } \\
\text { outside of regular education } \\
\text { classroom }\end{array}$ \\
\hline 2 & $\begin{array}{l}\text { Special Ed } 21 \% \text { to } 60 \% \text { of day } \\
\text { outside of regulate education } \\
\text { classroom }\end{array}$ \\
\hline 3 & $\begin{array}{l}\text { Special Ed over } 60 \% \text { outside of } \\
\text { regular education classroom }\end{array}$ \\
\hline 4 & $\begin{array}{l}\text { Special Ed 100\% in separate public } \\
\text { school building }\end{array}$ \\
\hline 5 & $\begin{array}{l}\text { Residential school operated by } \\
\text { public school district }\end{array}$ \\
\hline 6 & $\begin{array}{l}\text { Philip J. Rock Center and School } \\
\text { (Fund Code H) }\end{array}$ \\
\hline 7 & $\begin{array}{l}\text { Full time Special Ed classes in a } \\
\text { country or municipal detention } \\
\text { center or jail }\end{array}$ \\
\hline 8 & $\begin{array}{l}\text { Private day school program or out of } \\
\text { state public day school program }\end{array}$ \\
\hline 9 & Private residential facility, in state \\
\hline 10 & Private residential facility, out of state \\
\hline 11 & Homebound instruction program \\
\hline 12 & Hospital instruction program \\
\hline 13 & School for the Deaf \\
\hline 14 & School for the Visually Impaired \\
\hline 15 & School for the Deafblind \\
\hline
\end{tabular}

\begin{tabular}{|c|l|}
\hline 16 & Center for Rehab and ED \\
\hline 17 & Department of Human SErvices \\
\hline 18 & $\begin{array}{l}\text { Full time educational program } \\
\text { designed for children without } \\
\text { disabilities }\end{array}$ \\
\hline 19 & $\begin{array}{l}\text { Full time Special Ed Services } \\
\text { provided in educational program } \\
\text { designed with disabilities housed in } \\
\text { community based settings }\end{array}$ \\
\hline 20 & $\begin{array}{l}\text { Part time Special Ed provided at } \\
\text { home or in programs designed for } \\
\text { children with disabilities or without } \\
\text { disabilities }\end{array}$ \\
\hline 21 & Clinic based program \\
\hline 22 & None noted \\
\hline
\end{tabular}

12. What related services and how many minutes per week?
a. Adapted PE
b. Aide, Individual
c. Aide, Classroom
d. Audiology
e. Braillist/Reader
f. Counseling Services
g. Consultant Services
h. Adapted Drivers Education
i. Interpreter Services
j. Intervener Services
k. Assistive Device
1. Music Therapy
m. Occupational Therapy 
n. Outdoor Education

o. Orientation \& Mobility

p. Other Related Services

q. Parent Counseling

r. Psychological Services

s. Physical Therapy

t. Psychiatric Services

u. Recreation

v. School Health Services

w. Speech/Language Service

x. Social Work

y. Special Transportation

z. Career \& Technical Education

aa. Transition/STEP

bb. Behavioral Intervention Plan

cc. Competitive Employment

dd. Travel Time

ee. Acquisition of Daily Skills

ff. Supported Employment

gg. Supports for Transition to Post Sec Ed

hh. Interagency Linkages

ii. Transitional Services

jj. Rehabilitation Counseling

kk. Art Therapy

11. Special Educator

mm. Teacher of the Deaf

$\mathrm{nn}$. Teacher of the Visually Impaired

oo. Teacher of the Deafblind

pp. General Education Teacher 